\title{
DINÂMICA DE POPULAÇÕES E COMUNIDADES DE BORBOLETAS E AVES AO LONGO DO TEMPO
}

Population and community dynamics of butterflies and birds over time

\author{
Carlos Candia-Gallardo
}

Tese apresentada ao Instituto de Biociências da Universidade de São Paulo como parte dos requisitos para obtenção do título de Doutor em Ciências, na área "Ecologia".

Orientador: Prof. Dr. Paulo Inácio Prado

Co-orientação: Dr. Gustavo Accacio 

Autorizo a reprodução e divulgação total ou parcial deste trabalho, por qualquer meio convencional ou eletrônico, para fins de estudo e pesquisa, desde que citada a fonte. 
Para Marianita, Renata,

Raquel, Juan e Tekinha 
What do we do when we measure time? (...) More generally, we search for order among clock readings and, when found, we express them in laws of nature. 


\section{AGRADECIMENTOS}

Gostaria de agradecer às pessoas e instituições que colaboraram para que essa empreitada fosse possível. Duas pessoas foram fundamentais. A primeira é meu orientador, Paulo Inácio (vulgo PI), que comprou a idéia de me orientar em uma tese para investigar padrões temporais de diversidade ainda em 2009, durante meu mestrado. PI me guiou habilmente pelos caminhos que decidi trilhar, me ajudando a sair vivo e mais forte da "nuvem", sempre dando apoio incondicional. Ensinou-me muito mais do que ciência. Pela sua generosidade, benevolência, compreensão e, principalmente pelo brilho nos olhos a cada novo resultado que obtivemos, agradeço-te PI do fundo do coração, você é fera demais da conta. A outra pessoa fundamental para a realização dessa tese foi minha companheira Renata. Desenvolver um doutorado em um centro de excelência e manter uma família na cidade mais cara do país sem ter origens abastadas é tarefa extremamente estressante. Boa parte dessa carga caiu sobre os ombros de Renata, a qual assumiu grandes responsabilidades devido às minhas ausências. Por "segurar a bronca" durante os altos e baixos, por cuidar tão bem da nossa filha permitindo que eu pudesse me dedicar à pesquisa, te agradeço do fundo do coração. Esta tese também é tua. Finalizada essa etapa espero retribuir todo teu amor na mesma moeda e fazer jus a tua parceria.

Meu co-orientador Gustavo Accacio gentilmente compartilhou seus conhecimentos sobre biologia de borboletas e ecologia geral. Melina Leite e Karlla Barbosa fizeram comigo (e as vezes sem mim) a maior parte do estudo de marcação e recaptura de borboletas. Esta tese não seria possível sem vossa dedicação e bom humor. Melina também compartilhou suas habilidades analíticas e críticas, sempre disposta a ouvir e opinar sobre as idéias a respeito da tese. Agradeço aos amigos que também me ajudaram com a marcação-recaptura de borboletas em algumas ocasiões: Marco Podzius, Guilherme Cavicchioli, Leonardo Wedekin, Natalia Targhetta, Thiago Vernaschi, Samuel Betkowski, Camila Hohlenwerger, Denis Mello, Chloé Kipnis, Fernando "Napa" Wehby, Rodrigo Dios, Vinicius Tonetti, Rodolpho Rodrigues, Andrés Calonge, Aline Vieira e Isabel Bluhm. Agradeço também à Marina Rillo, pioneira no estudo da dinâmica das borboletas Ithomiini do campus da USP, por se prontificar a me passar todo seu conhecimento quando eu decidi estudar esses fascinantes bichinhos.

Gostaria de agradecer a Renata Pardini e a Paulo de Marco (UFG) por terem aceitado integrar meu Comitê de Acompanhamento de Doutorado. Suas contribuições e puxadas de orelha elevaram a qualidade da tese. Não obstante, as falhas e limitações que podem ter sobrevivido ao prazo final dessa empreitada são de inteira responsabilidade minha. Glauco Machado, Paulo "Miúdo" Guimarães e Rodrigo Cogni gentilmente aceitaram participar do meu exame de qualificação e avaliaram formalmente e com sagacidade o capítulo 2. Glauco, muito obrigado por suas detalhadas anotações no capitulo 2 . Agradeço também aos demais pesquisadores que contribuíram direta ou indiretamente para esta tese ou para minha formação, através de disciplinas, conversas ou compartilhamento de informações: Leonardo Wedekin, Adriana Martini, Alexandre Adalardo de Oliveira, Suzana Ursi, Márcio Zikán Cardoso, Renato Lima, Marcelo Duarte, Danilo Muniz, Ayana Martins, Daniel Lahr, Leandro Tambosi, Luciano Lima e André Freitas. Profa. Gisele Oda me recebeu de braços abertos no mundo da cronobiologia, sua disciplina foi fenomenal. Agradeço-lhe enormemente pelo entusiasmo e por ter nos colocando em contato com o Prof. Loren Buck da Universidade do Norte do Arizona. Prof. Buck fez breves e valiosas contribuições ao capítulo 1 e 
também mostrou grande entusiasmo em relação aos nossos achados. Renato Coutinho e Renato Andrade construíram o modelo de mimetismo anexo ao capítulo 2 com expertise e dedicação admiráveis. Agradeço a Luís Fabio Silveira pela disponibilização dos dados do monitoramento de avifauna de Jirau (RO) e Fabio Schunck pela disponibilização de dados inéditos do seu estudo de avifauna no Parque Estadual da Serra do Mar, Núcleo Curucutu. Estes dados compartilhados foram vitais para a existência do capítulo 3. A equipe de ornitofuleiros composta por André de Luca, Bruno Rennó, Thiago Vernaschi, Marcelo Barreiros, Vitor Piacentini e Felipe Arantes, além dos ornitólogos Fabio Schunck e Marconi Cerqueira, realizaram as amostragens de avifauna através de contagem por pontos em Jirau. Muito obrigado amigos, encarar avifauna amazônica no ouvido - em dois interflúvios - não é pra qualquer um e vocês são o melhor time de ornitólogos que alguém poderia desejar.

Agradeço a todos os colegas do meta-laboratório LAGE e laboratórios adjacentes pela companhia nessa jornada pela pesquisa científica, em especial Rodolpho Rodrigues, Leonardo Wedekin, Bruno Travassos, Renato Lima, Marcelo Awade, Sara Mortara, Danilo Mori, Larissa Boesing, Paula Prist, Solimary, Lucas Nascimento, Lucas Medeiros, Melina Melito, Renan, Kiss, Tom, Billy, Kate Maia, Marilia Gaiarsa, Paulinha Lemos, Andrés Rojas, Ana Paula Assis e João Menezes. As competentes e sempre simpáticas Vera e Shirlene da secretaria do Departamento de Ecologia forneceram todo o apoio nos assuntos acadêmicos. Agradeço aos amigos do Observatório de Aves do Instituto Butantan - Erika, Luciano, Ju, Priscila, Rodolpho Silva, Bruno, Karlla, Denis, Albert, Amanda, Giu, Alcides e Mari pela abertura, confiança e parceria. Agradeço à Universidade de São Paulo, ao Instituto de Biociências/USP e ao Programa de Pós-graduação em Ecologia pela infra-estrutura e apoio institucional; à CAPES pela bolsa de doutorado concedida e à FAPESP pelo auxílio à pesquisa. Fico em débito com o povo brasileiro que custeou minha formação acadêmica em uma instituição de excelência, em caráter público e gratuito. Por outro lado, não posso me furtar de registrar aqui um repúdio veemente ao desmonte que essas instituições, o estado brasileiro e os direitos dos cidadãos vêm sofrendo por parte de um governo federal ilegítimo e um governo estadual comprometido apenas com interesses financeiros. $O$ presente e futuro das pessoas não é mercadoria.

Pelo carinho agradeço aos meus pais, meu irmão e toda a família e agregados, especialmente meu maior amor do mundo, Marianita minha filhota linda e inteligente, companheirona do papai. E por último, mas não menos importante, agradeço aos meus queridos e fiéis amigos, pois sem vocês nada disso faria sentido: Bogão, Noni, Palomanos, Gabs, Dani Soltys, Roque, Nando, Samuca, Gibson, D2, Manô, Tetê Thomé, Paulinho Zaini, Zé Mario, Cris Carettoni, Dudu Malta, Dé \& Catá, Saci, Rafiki, Berton, Xaliba, Vasco, Zé \& Amandita, Andrés, Martinha, Liss, Robertinha, Gando \& Paçoca, Giraz, Fefe, Gus, Barbosinha, Marjorie, Van, Dani, Omar, Aninha Giorgi, Pati Lopes, Comodoro Panga, Napa, Lari Romandini, Beto, Sheila, Fabinho, Tatá, Rodrigo Magrelo, Seu Roque \& Dona Lurdes, Giu, Schunck, Leo \& Janu, George \& Karen, Brutus, Vitinho Vale, Jow Nodari, Milena Passaia, FefES, Cléston Parruco, Nelsão, Kika \& Tank, Fernando Lambe, Marcão Kawall, Pitú, Paulinha Pedrosa, Kabessa, André Bottini, Flavio Aoer, Lama, Marco Silva e toda a ornitofuleragem, sua imagem e semelhança, pois eu tenho certeza, eles também cantaram um dia. 


\section{Índice}

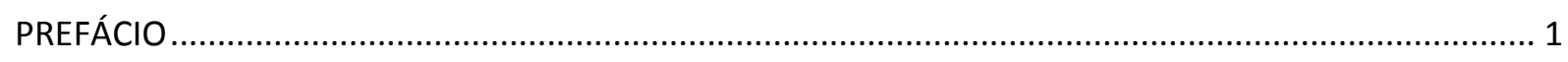

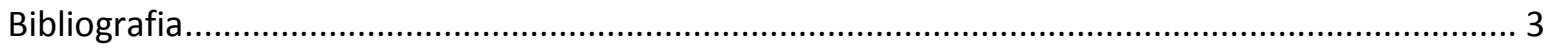

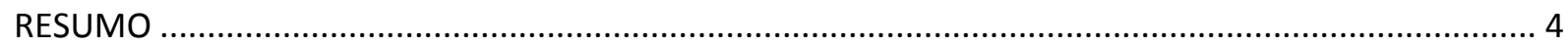

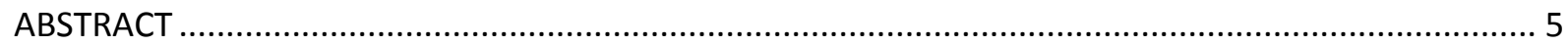

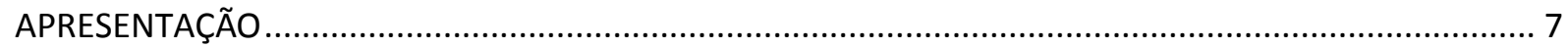

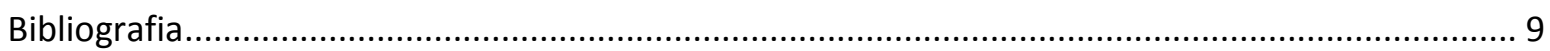

CAPÍTULO 1 - CICLOS ANUAIS DE BORBOLETAS ITHOMIINI (NYMPHALIDAE, DANAINAE) DURANTE

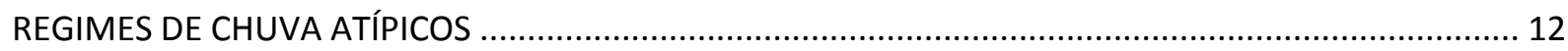

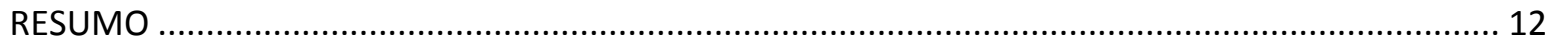

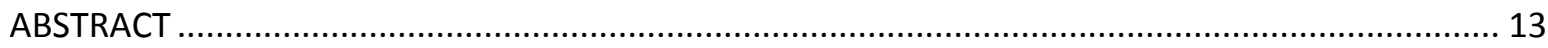

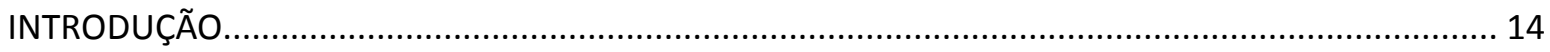

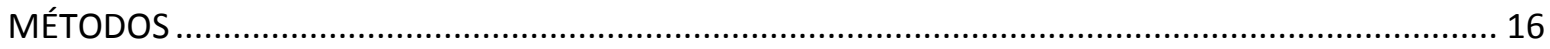

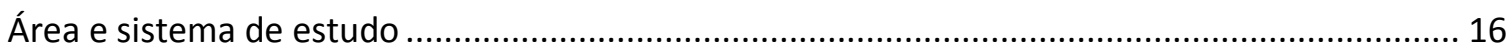

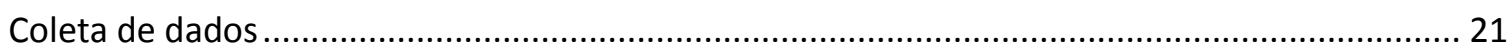

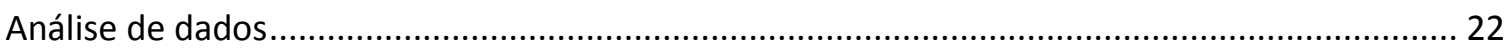

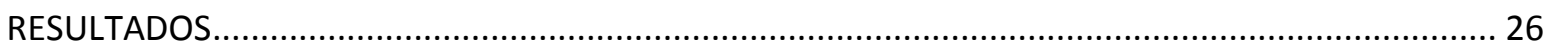

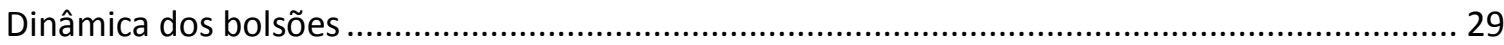

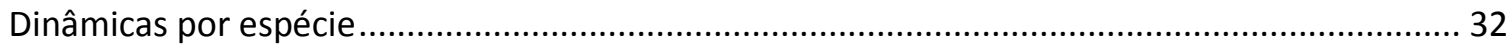

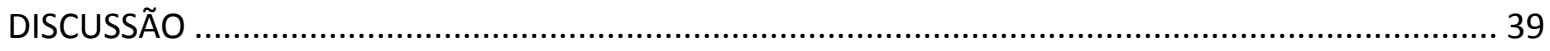

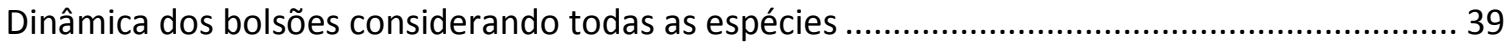

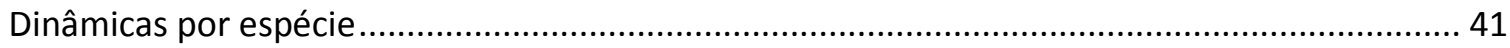

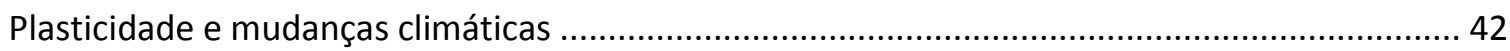

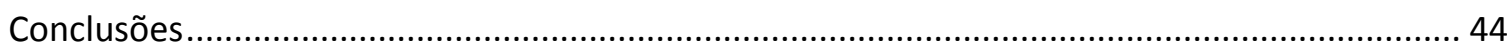

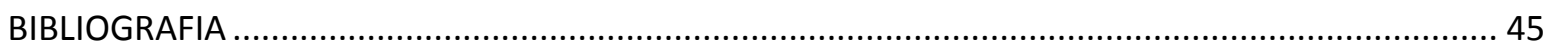

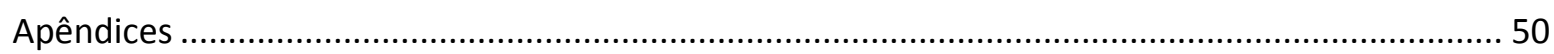

CAPÍTULO 2 - DINÂMICA POPULACIONAL COMPARADA DE BORBOLETAS MIMÉTICAS ....................... 52

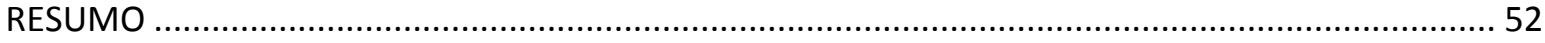

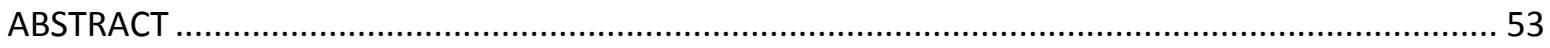

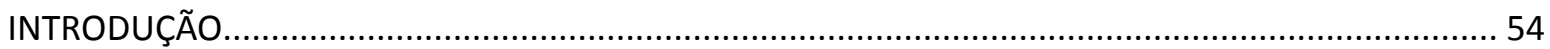

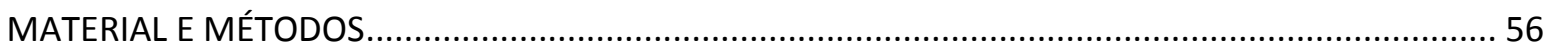




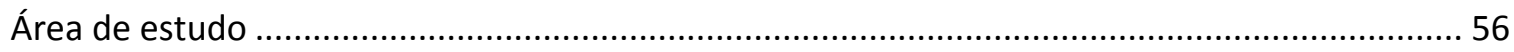

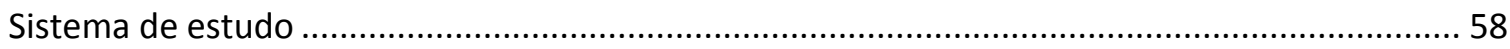

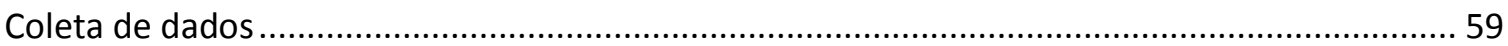

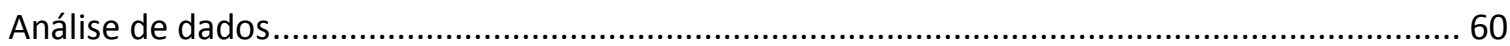

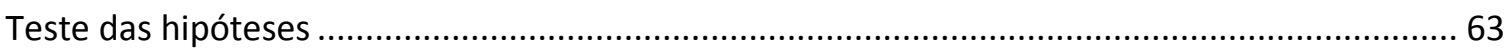

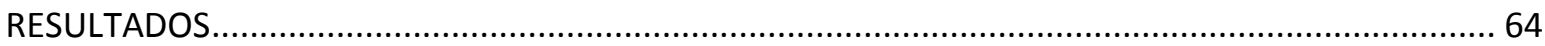

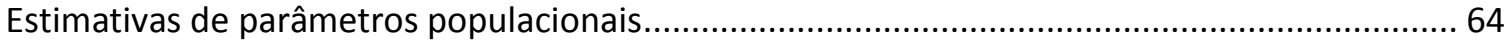

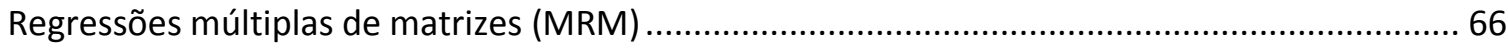

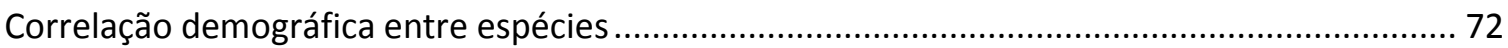

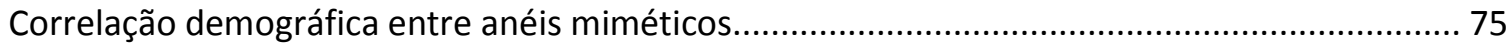

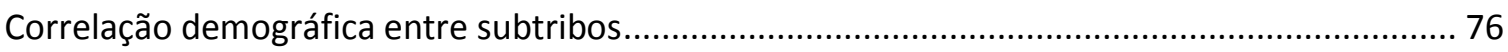

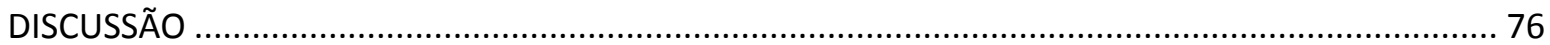

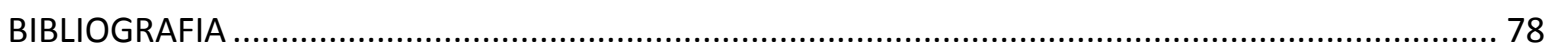

Capítulo 3 - MUDANÇAS TEMPORAIS NA COMPOSIÇÃO DE ASSEMBLEIAS DE AVES E BORBOLETAS TROPICAIS E SUBTROPICAIS SÃO CONDIZENTES COM EQUIVALÊNCIA DEMOGRÁFICA ENTRE

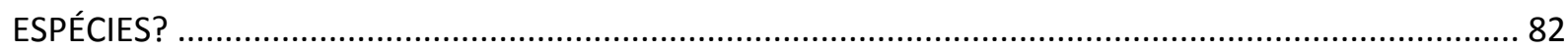

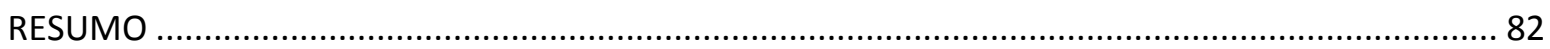

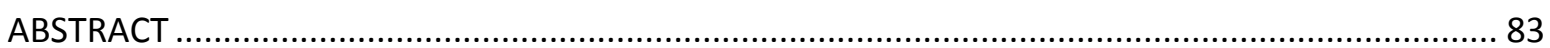

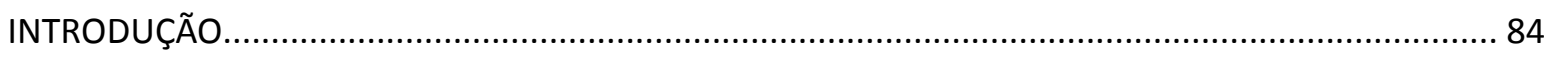

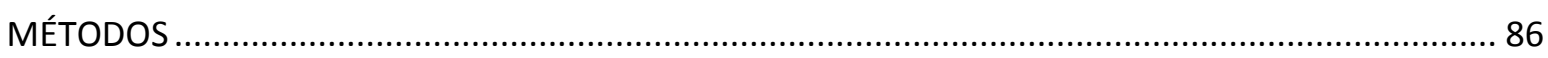

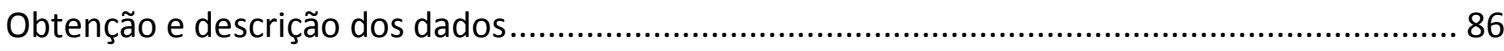

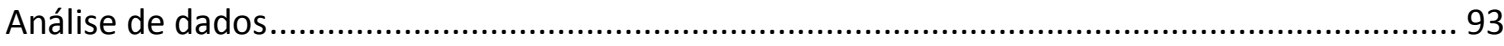

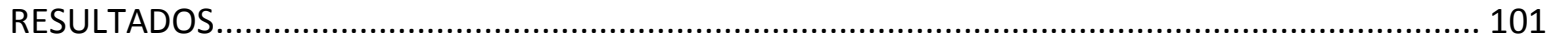

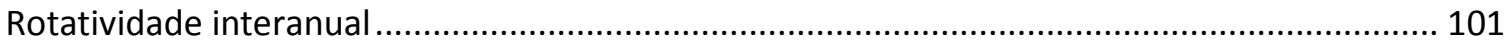

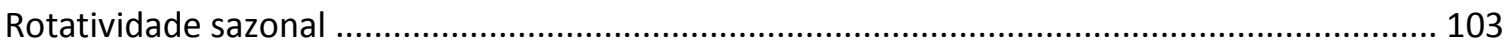

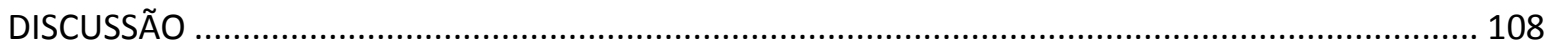

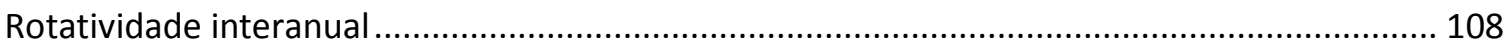

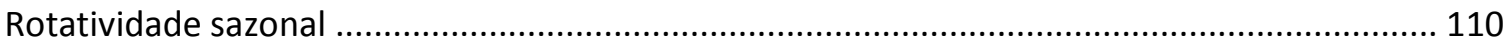

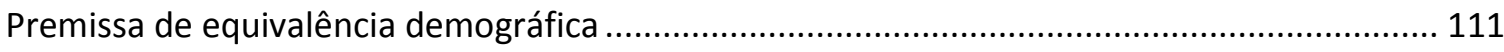

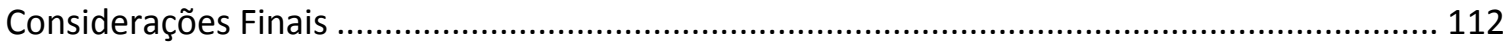

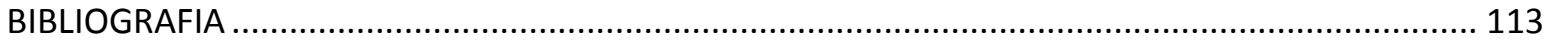

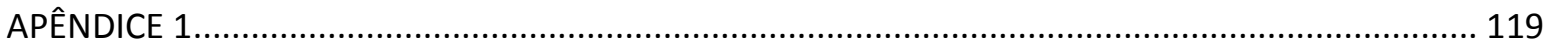

Estimativas De Abundância Baseadas Em Marcação-Recaptura ............................................... 119 


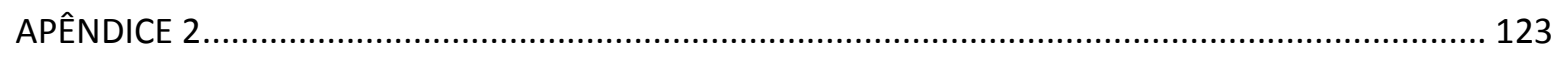

APÊNDICE 3

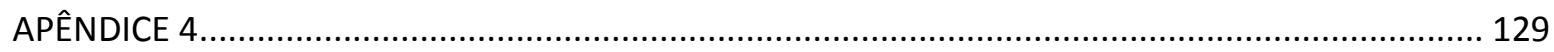

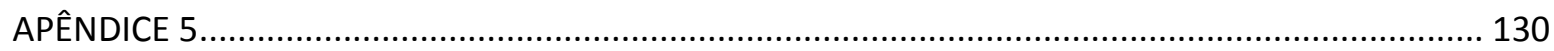

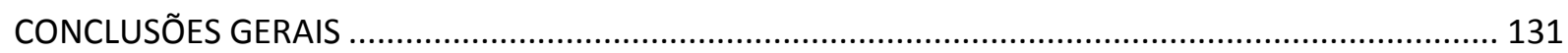

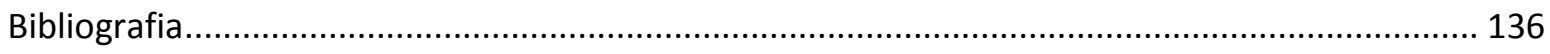

ANEXO

Anexo I - Modelo para avaliar sincronização de dinâmica populacional entre pares de miméticos Müllerianos. 


\section{PREFÁCIO}

A pesquisa cientifica é uma grande jornada, na qual você deve saber de onde parte mas muitas vezes ao longo do percurso não sabe aonde vai chegar. E isso é maravilhoso. Neste prefácio me proponho a explicar a motivação inicial desta tese e as alterações que ocorreram ao longo da jornada. $O$ texto científico dá a entender que o processo de investigação é linear, e raramente abre espaço para as nuances, dificuldades e reviravoltas que invariavelmente ocorrem em qualquer pesquisa. Acredito que expor a não-linearidade inerente à pesquisa científica é benéfico por desmistificar e humanizar essa que é, junto com as artes e a filosofia, a mais nobre das atividades de nossa espécie. Por isso, peço licença para deixar registrado neste espaço aspectos da jornada que não caberiam em um texto acadêmico convencional.

Nesta tese eu me propus a investigar a dinâmica de populações e comunidades biológicas ao longo do tempo. A grande motivação para a escolha do tema foi a percepção de que a maioria dos estudos sobre biodiversidade, especialmente a neotropical, se baseava em amostragens de curto prazo, deixando em aberto uma importante questão: quanto os padrões e conclusões encontrados se alterariam com mais tempo de observação? Ao longo desta jornada de quatro anos essa pergunta se desdobrou, se expandiu e nos levou - fascinantemente - a lugares que não imaginávamos. Minha intenção era realizar uma tese baseada apenas em dados já coletados, visto que minha dissertação de mestrado (Candia-Gallardo 2011) requereu intenso esforço de campo, o qual eu não desejava repetir no doutorado por razões familiares. No entanto, como estudos de campo são uma forte base da minha formação, essa decisão não me deixava totalmente à vontade. Sabendo disso, meu orientador Paulo Inácio propôs que eu retomasse um estudo de marcação-recaptura de borboletas da tribo Ithomiini (Nymphalidae, Danainae) no próprio Campus da USP, o qual havia sido iniciado por Marina Rillo durante sua graduação. A facilidade logística da proposta e o número de gerações que poderíamos acompanhar eram sedutores, porém emplacar uma tese com base em um táxon que eu não tinha nenhuma familiaridade me deixou receoso. Ao longo da minha carreira eu havia me consolidado como um ornitólogo, e uma das características que eu apreciava (e aprecio) era aliar questões ecológicas com um conhecimento profundo sobre os organismos estudados.

Após uma breve hesitação decidi emplacar o estudo de marcação-recaptura com as tais borboletas Ithomiini. A proposta inicial era realizar amostragens mensais por pelo menos três anos e testar previsões da teoria neutra de Hubbell (2001), particularmente distribuições de abundâncias de espécies. Aos poucos fui me familiarizando com as Ithomiini e descobrindo, pela literatura e pela observação, suas fascinantes histórias de vida. Fui me dando conta de que o sistema era repleto de particularidades - mimetismo, defesas químicas, comportamentos sazonais - que tornavam sua existência mais complexa do que as premissas da teoria neutra podiam modelar. Além do sistema violar premissas básicas do modelo neutro, tal como a soma-zero (i.e., número de indivíduos constante ao longo do tempo), ocorreram ao longo do estudo chuvas e estiagens atípicas, as quais comprometiam a premissa de que a assembleia de ithomiini estava em equilíbrio. Inclusive, no ano de 2014 enfrentamos a maior estiagem que a cidade de São Paulo vivenciou nos últimos 42 anos (Coelho et al. 2016). Ao constatar essas limitações fui tomado por um desânimo que perdurou por alguns meses. Entrei no que foi chamado pelo biólogo de sistemas Uri Alon de "a nuvem", uma 
situação comum entre estudantes de pós-graduação, na qual planos e expectativas iniciais são implacavelmente demolidas pela realidade de experimentos que não dão certo, teorias que não funcionam, enfim - becos sem saída. Há uma palestra "TED" de Uri Alon sobre esse tema disponível na internet, imperdível.

Minha primeira resposta ao "caos da nuvem" foi focar em comparar dinâmicas populacionais das Ithomiini e avaliar se pares de espécies co-miméticas (i.e., que compartilham uma mesma morfologia) tenderiam a ter dinâmica mais correlacionadas do que pares de espécies escolhidos ao acaso. Para tanto fiz um mergulho, não previsto inicialmente, na vasta literatura sobre mimetismo. Desse esforço resultou o Capítulo 2. A segunda e mais empolgante resposta à "nuvem" surgiu casualmente. Pesquisando bibliografias sobre aspectos temporais nos organismos vivos descobri a disciplina da cronobiologia através do livro seminal de Gwinner (1986). O arcabouço teórico da cronobiologia era perfeito para abordar e entender os efeitos do regime de chuvas atípico sobre as borboletas Ithomiini. Essa "descoberta" foi uma das experiências mais empolgantes da minha vida. Do mergulho na cronobiologia e da interação com pesquisadores da disciplina, especialmente com a Prof. Gisele Oda do Departamento de Fisiologia do IB-USP, nasceu o Capítulo 1. Percebi que o estudo de padrões e processos temporais de interesse da Ecologia poderiam se beneficiar enormemente de uma interação com a cronobiologia - processos que ocorrem no nível do indivíduo podem ser grandes forças subjacentes aos padrões observados em níveis de organização superiores (populações e comunidades). Até deixei de me importar com o corriqueiro espanto de conhecidos que, ao saberem da minha pesquisa, diziam: "ué, mas você não trabalha com passarinho?".

Por fim, a experiência que tive como monitor de uma disciplina de graduação ao longo do último semestre de 2016 (Ecologia de Populações e Comunidades Vegetais), e os ensinamentos dos seus três docentes - Adriana Martini, Alexandre Adalardo de Oliveira e meu orientador - me inspiraram a conceber um modelo computacional que simula dinâmicas de populações e comunidades. Esse modelo mantém a principal característica da teoria neutra - a equivalência entre espécies - porém sem evocar as outras premissas que eram violadas pelos nossos dados (e.g., soma-zero). O modelo me permitiu retomar, com algumas alterações, o objetivo inicial do estudo com as borboletas Ithomiini que era avaliar previsões da teoria neutra. Porém, ao invés de testar o modelo neutro eu me propus a testar sua principal premissa - a equivalência entre espécies. Nessa abordagem eu consegui incorporar também outras bases de dados de séries temporais de assembleias de aves. Deste esforço resultou o Capítulo 3.

Tenho consciência de que o produto final que resultou desta jornada de quatro anos apresenta imperfeições e limitações, as quais são de minha inteira responsabilidade. Porém, tenho a pretensão de que esta tese contribua com algum avanço na nossa compreensão sobre a dinâmica temporal de populações e comunidades animais. E que ela possa inspirar outras mentes a validar, questionar e expandir os achados aqui apresentados. 


\section{Bibliografia}

Candia-Gallardo, C. E. 2011. O valor de corredores florestais para a conservação de aves em paisagens fragmentadas. Dissertação de Mestrado, Universidade de São Paulo.

Coelho, C. A. S., D. H. F. Cardoso, \& M. A. F. Firpo. 2016. Precipitation diagnostics of an exceptionally dry event in São Paulo, Brazil. Theoretical and Applied Climatology 125:769-784.

Gwinner, E. 1986. Circannual Rhythms: Endogenous Annual Clocks in the Organization of Seasonal Processes. Springer-Verlag, Berlin.

Hubbell, S. P. 2001. The Unified Neutral Theory of Biodiversity and Biogeography. Monographs in Population Biology. Princeton University Press. 


\section{RESUMO}

As abundâncias e identidades das espécies de qualquer comunidade biológica mudam tanto ao longo do espaço quanto do tempo. Não obstante, aspectos espaciais da biodiversidade têm sido muito mais explorados do que os temporais. Um dos motivos pelos quais padrões temporais têm recebido menos atenção é a escassez de estudos de longo prazo, especialmente na região neotropical, uma das mais biodiversas e ameaçadas do planeta. Estudar a dinâmica de populações e comunidades ao longo do tempo pode revelar processos ecológicos fundamentais, bem como descrever como pressões naturais e humanas afetam a biodiversidade. Entender a dinâmica das populações e comunidades envolve entender as histórias de vida dos organismos, como eles interagem com o ambiente, o papel de interações entre espécies, o papel de processos demográficos estocásticos, dentre outros fatores. Nesta tese investigamos a dinâmica temporal de populações e comunidades de borboletas e aves, e ao longo dos capítulos avaliamos o papel de diferentes processos na regulação dessas dinâmicas. No Capítulo $\mathbf{1}$ investigamos se um comportamento sazonal observado em borboletas Ithomiini (Nymphalidae, Danainae), supostamente adaptativo à seca - os "bolsões de Ithomiini" - seria uma simples resposta reativa à falta de chuvas ou se mecanismos endógenos ("relógios biológicos") estariam envolvidos. No Capítulo 2 realizamos um estudo de dinâmica populacional comparada de borboletas miméticas da tribo Ithomiini. Algumas evidências têm sugerido que além de convergir na morfologia, espécies comiméticas tenderiam a convergir também no comportamento, no uso de microhabitats e possivelmente em suas dinâmicas populacionais. Testamos as hipóteses de que 1) pares de espécies co-miméticas (i.e., com a morfologia convergente) ou 2) pares de espécies mais próximas filogeneticamente teriam suas dinâmicas populacionais mais correlacionadas do que pares de espécies agrupados ao acaso. No Capítulo 3 descrevemos como a composição de espécies de assembleias de aves e borboletas de nove localidades tropicais e subtropicais na América do Sul e do Norte variou ao longo do tempo (anos a décadas), e se diferenças demográficas entre espécies (nicho) seriam importantes para explicar os padrões observados. No Capítulo 1 encontramos evidências de que a agregações seriam um comportamento endógeno sincronizado com o fotoperíodo, com plasticidade limitada para lidar com as alterações no regime de chuvas previstas para a região e para o continente. No Capítulo 2 encontramos que as dinâmicas populacionais de pares de espécies de Ithomiini de um mesmo anel mimético ou mais próximas filogeneticamente não tenderam a ser mais correlacionadas do que pares reunidos ao acaso, e que as espécies, anéis miméticos e subtribos estudadas tiveram suas dinâmicas temporais mais correlacionados do que seria esperado por acaso. Estes resultados e os do Capítulo 1 sugerem que na dinâmica desse sistema as pressões seletivas exercidas por fatores ambientais seriam mais importantes do que interações entre espécies. No Capítulo 3 mostramos que a composição de espécies de assembleias de aves na Amazônia, Cerrado, Mata Atlântica e Flórida se alterou ao longo dos anos, mesmo em assembleias de áreas bem preservadas. Sobreposta a essa rotatividade (turnover) interanual também encontramos rotatividade sazonal, previsível, na composição de espécies de assembleias de aves da Amazônia e da Mata Atlântica e na assembleia de borboletas Ithomiini. Padrões de rotatividade sazonal na composição de espécies podem ser mais comuns em comunidades neotropicais do que se imagina. As estratégias temporais dos organismos neotropicais, as quais parecem ser a base dos padrões sazonais observados nas comunidades, podem ser largamente 
determinadas por ritmos ("relógios") endógenos. Estudos sobre a regulação dos ritmos e estratégias temporais dos organismos, e dos efeitos das mudanças climáticas e do uso do solo sobre eles, são essenciais. Um importante passo nesse sentido é a disseminação de estudos de longo-prazo de populações e comunidades, contínuos, sistemáticos e com resolução para detectar padrões sazonais. Além disso, a interação das perspectivas, bases teóricas e abordagens da biologia molecular, fisiologia, cronobiologia e ecologia pode avançar nosso entendimento sobre os processos que moldam a dinâmica da biodiversidade e sobre as consequências das perturbações humanas sobre os ecossistemas.

Palavras-chave: marcação-recaptura, ritmos biológicos, mudanças climáticas, composição de espécies, mimetismo Mülleriano, teoria neutra, simulações computacionais, estudos de longo-prazo, nicho temporal.

\begin{abstract}
The species abundances and identities of any biological community change both over space and time. Nevertheless, Spatial biodiversity dimensions have been much more exploited than temporal ones. One of the reasons for which temporal patterns have received less attention is a scarcity of long-term studies, especially in the neotropical region, one of the most biodiverse and endangered on the planet. Studying the dynamics of populations and communities over time can reveal key ecological processes as well as describe how natural and human pressures affect biodiversity. Understanding the dynamics of populations and communities involves understanding organisms life histories, how they interact with the environment, the role of interactions among species, the role of stochastic demographic processes, and other factors. In this dissertation we investigated the temporal dynamics of butterflies and birds populations and assemblages, and throughout its chapters we evaluate the role of different processes in the regulation of dynamics. In Chapter 1 we investigated whether a seasonal behavior observed in butterflies Ithomiini (Nymphalidae, Danainae), supposedly adaptive to dissecation - the "Ithomiini pockets " - is a simple reactive response to drought or there is internal time-keeping mechanisms involved. In Chapter 2, we performed a comparative population dynamics study of mimetic butterflies of the Ithomiini tribe. Some evidence has suggested that besides the convergence in morphology, co-mimetic species would tend to converge also in behavior, in the use of microhabitats and possibly in their population dynamics. We hypothesized that (1) pairs of co-mimetic species or (2) pairs of species more phylogenetically related would have their population dynamics more correlated than pairs of species grouped at random. In Chapter $\mathbf{3}$ we described how species composition of bird and butterfly assemblages from nine tropical and subtropical locations in South and North America varied over time (years and decades), and if demographic differences between species (niche) are needed to explain observed patterns. In Chapter 1 we found evidence that Ithomiini pockets are regulated by internal time-keeping mechanisms synchronized to photoperiod, and that mechanism has limited plasticity to cope with rainfall regime changes predicted for the study region and for the continent as a whole. In Chapter 2 we found that the population dynamics of Ithomiini species pairs more phylogenetically related or
\end{abstract}


belonging to the same mimetic ring did not tend to be more correlated than pairs assembled at random, and that the species, mimetic rings and subtribes had their temporal dynamics more correlated than would be expected By chance These results and those of Chapter 1 suggest that this system dynamics is more influenced by selective pressures exerted by environmental factors than by species interactions. In Chapter $\mathbf{3}$ we show that the composition of bird assemblages in the Amazon, Cerrado, Atlantic Rainforest, and Florida has changed over the years, even in assemblies of wellpreserved areas. Superimposed to this interannual turnover we also found seasonal, predictable turnover in species composition of bird assemblages of the Amazon and Atlantic Forest and in the Ithomiini butterflies assembly. Patterns of seasonal turnover in species composition may be more common in neotropical communities than is imagined. The temporal strategies of neotropical organisms, which appear to be the basis of the seasonal patterns observed in communities, can be largely determined by endogenous rhythms ("biological clocks"). Studies on the regulation of organisms' temporal rhythms and strategies, and the effects of climate change and land use on them, are essential. An important step in this direction is the dissemination of continuous, systematic, population and community long-term studies, with sampling resolution to detect seasonal patterns. In addition, the interaction of perspectives, theoretical basis, and approaches of molecular biology, physiology, chronobiology, and ecology can advance our understanding of the processes that shape biodiversity dynamics and the consequences of human disturbances on ecosystems.

Key words: marking-recapture, biological rhythms, climatic changes, species composition, Müllerian mimicry, neutral theory, computational simulations, long-term studies, temporal niche. 


\section{APRESENTAÇÃO}

As abundâncias e identidades das espécies de qualquer comunidade biológica mudam tanto ao longo do espaço quanto do tempo. Essa percepção permeia os fundamentos da disciplina da Ecologia, tendo ajudado a moldar as ideias de Darwin a respeito do conceito de seleção natural, e a embasar conceitos-chave da teoria de biogeografia de ilhas (MacArthur \& Wilson 1967) e de modelos de organização de biodiversidade seminais tais como os propostos por Fisher et al. (1943), Preston (1960) e Hubbell (2001) (Magurran 2011). Não obstante, aspectos espaciais da biodiversidade têm sido muito mais explorados do que os temporais (Adler et al. 2005, Magurran 2007, White et al. 2010). Por exemplo, uma "ecologia espacial" se desenvolveu nos últimos trinta anos aumentando nosso conhecimento sobre os efeitos da perda e fragmentação dos habitas naturais sobre indivíduos, populações e comunidades (Wolkovich et al. 2014). Não obstante, é comum que estudos que avaliam os efeitos de perturbações sobre a biodiversidade minimizem a importância da dimensão temporal, realizando amostragens espacialmente intensas porém temporalmente pontuais. Estudos de curto prazo, dependendo dos seus objetivos e enfoques, podem negligenciar fenômenos e processos perceptíveis apenas ao longo do tempo e gerar conclusões enviesadas (e.g., Grant \& Grant 2014).

Um dos motivos pelos quais padrões temporais têm recebido menos atenção é a escassez de estudos de longo prazo, os quais não costumam ser os mais atrativos para as agências de fomento e não se adequam aos ciclos de financiamento e ao tempo de carreira de um único pesquisador (Magurran \& Dornelas 2010). Felizmente existem algumas iniciativas que vêm coletando séries temporais de dados de populações e comunidades biológicas, tal como o North American Breeding Bird Survey (BBS), National Ecological Observatory Network (NEON), Long Term Ecological Research (LTER), e redes de Parcelas Permanentes em florestas (CTFS-ForestGEO), os quais têm fornecido valiosas informações sobre processos ecológicos fundamentais e efeitos de impactos ambientais. No entanto, a diversidade de ambientes e táxons da região neotropical, uma das mais diversas e ameaçadas do planeta, está longe de ser contemplada por estudos sistemáticos de longo-prazo. Também estamos longe de um entendimento geral - e até mesmo básico - dos padrões e processos relacionados à rica biodiversidade neotropical. Para enfrentar o desafio de conservar a biodiversidade em um planeta onde os impactos humanos estão redesenhando ecossistemas a uma velocidade sem precedentes, nós devemos entender como a biodiversidade responde a mudanças ambientais (Magurran 2016).

Apesar do grande interesse em documentar e entender tendências temporais de populações e comunidades frente a perturbações (e.g., Harrison et al., 2014; Parody et al., 2001; Stouffer et al., 2011), é vital entender como e por que a biodiversidade muda naturalmente ao longo do tempo (Magurran 2008, Magurran \& Dornelas 2010). Em todas as comunidades ocorrem mudanças naturais na abundância e presença das espécies, as quais podem ser chamadas de rotatividade (turnover) basal (Magurran 2011). No entanto, existe uma concepção, geralmente implícita, de que na ausência de perturbações as comunidades seriam entes estáticos (Magurran \& Dornelas 2010), refletida, por exemplo, em estratégias de conservação que concebem espécies tal como um curador de arte vê obras de Van Gogh em um museu (Magurran 2011), i.e., ignorando a natureza dinâmica da biodiversidade. Quantificar rotatividades basais, e entender seus processos subjacentes, pode nos fornecer um entendimento mais profundo do funcionamento dos ecossistemas e de como mudanças ambientais podem alterá-los. Estudos que visem detectar impactos de perturbações humanas devem 
distinguir mudanças decorrentes de perturbações de mudanças que ocorreriam de qualquer forma (Magurran 2008, 2011). Entender os processos que moldam e afetam a estrutura e dinâmica de comunidades e populações, portanto, é um dos grandes desafios da Ecologia, confundindo-se com sua própria definição. Um importante passo para enfrentar esse desafio é a disseminação de estudos de longo-prazo que reportem e quantifiquem sistematicamente diferentes aspectos da biodiversidade (Dornelas et al. 2012). Precisamos ir além de retratar a biodiversidade apenas em "fotografias" estáticas no tempo e encará-la como manifestações de sistemas dinâmicos (Supp \& Ernest 2014). Afinal, padrões espaciais em um dado momento são o resultado de processos dinâmicos atuando sobre intervalos de tempo potencialmente longos (Preston 1960, White et al. 2010). Outros passos importantes para entender e prever a estrutura e dinâmica das populações e comunidades envolvem, dentre outras coisas, entender as histórias de vida dos organismos (Wingfield 2012), como eles interagem com o ambiente (Wingfield et al. 2011), o papel de interações entre espécies (Elias et al. 2009, Gilman et al. 2010) e o papel de processos demográficos estocásticos (Hubbell 2006, Vellend 2010).

Nesta tese eu me propus a investigar a dinâmica de populações e comunidades de borboletas e aves ao longo do tempo. Uma grande dificuldade foi obter dados de médio e longo prazo de populações e comunidades em ambientes tropicais. Graças à colaboração de colegas que compartilharam seus dados inéditos, a plataformas de livre acesso a dados biológicos e ao nosso próprio esforço de coleta, conseguimos reunir um conjunto de dados sobre aves e borboletas passível de análise. No Capítulo 1 investigamos se um comportamento sazonal observado em borboletas Ithomiini (Nymphalidae, Danainae), supostamente adaptativo à seca - os "bolsões de Ithomiini" (Pinheiro et al. 2008) - seria uma simples resposta reativa à falta de chuvas ou se mecanismos endógenos ("relógios biológicos", Denlinger et al. 2001) estariam envolvidos. Para tanto, tiramos proveito de regimes de climáticos atípicos que ocorreram durante as amostragens (chuvas e estiagens fora de época) para separar os efeitos das chuvas dos efeitos do calendário. Este estudo é particularmente relevante para entendermos como os organismos lidam com o dilema entre se antecipar a mudanças sazonais (Tauber et al. 1986) e enfrentar imprevisibilidades climáticas (Wingfield et al. 2011). De fato, o aumento na frequência de eventos climáticos extremos (Marengo et al. 2013) e mudanças nos atuais regimes climáticos (Ordonez et al. 2016) são previsões cada vez mais recorrentes.

No Capítulo 2 fizemos um estudo de dinâmica populacional comparada de borboletas miméticas da tribo Ithomiini. Estudos teóricos e empíricos sugerem que relações mutualísticas entre espécies (e.g., mimetismo Mülleriano) podem ser tão ou mais importantes do que interações competitivas em contextos evolutivos (Müller 1879) e na estruturação de comunidades (Elias et al. 2009). Ao invés de criar divergência (e.g., Grant \& Grant 2014), pressões seletivas poderiam promover convergência morfológica, comportamental e até mesmo demográfica entre espécies (Beccaloni 1997, DeVries et al. 1999, Elias et al. 2008). Nesse capítulo testamos as hipóteses de que 1) pares de espécies comiméticas ou 2) pares de espécies mais próximas filogeneticamente teriam suas dinâmicas populacionais mais correlacionadas do que pares de espécies agrupados ao acaso. Também testamos a hipótese de que 3) a dinâmica temporal de todas as espécies da assembleia seria semelhante, independente de anel mimético ou proximidade filogenética. Estes resultados são relevantes para se avaliar os papéis relativos de interações entre espécies e de fatores ambientais na dinâmica de populações. 
No Capítulo 3 descrevemos como a composição de espécies de assembleias de aves e borboletas de nove localidades tropicais e subtropicais na América do Sul e do Norte variou ao longo do tempo (anos a décadas), e se diferenças demográficas entre espécies ("nicho") seriam importantes para explicar os padrões observados. Para tanto medimos a rotatividade na composição de espécies de cada assembleia nas escalas interanual e sazonal, e a comparamos com rotatividades simuladas por modelos que assumem equivalência demográfica. Este estudo é relevante por fornecer rotatividades basais e protocolo para sua medição, os quais podem ser usados como referência para monitoramentos, bem como para avaliar o papel de diferenças entre espécies na estruturação de assembleias.

\section{Bibliografia}

Adler, P. B., E. P. White, and W. K. Lauenroth. 2005. Evidence for a general species-time-area relationship. Ecology 86:2032-2039.

Beccaloni, G. 1997. Vertical stratification of ithomiine butterfly (Nymphalidae: Ithomiinae) mimicry complexes: the relationship between adult flight height and larval host-plant height. Biological Journal of the Linnean Society 62:313-341.

Denlinger, D. L., J. M. Giebultowicz, and D. S. Saunders. 2001. Insect Timing: Circadian Rhythmicity to Seasonality. Page (D. L. Denlinger, J. M. Giebultowicz, and D. S. Saunders, Eds.). Elsevier, Amsterdam.

DeVries, P. J., R. Lande, and D. Murray. 1999. Associations of comimetic ithomiine butterflies on small spatial and temporal scales in a neotropical rainforest. Biological Journal of the Linnean Society 67:73-85.

Dornelas, M., A. E. Magurran, S. T. Buckland, A. Chao, R. L. Chazdon, R. K. Colwell, T. Curtis, K. J. Gaston, N. J. Gotelli, M. a Kosnik, B. J. McGill, J. L. McCune, H. Morlon, P. J. Mumby, L. Ovreås, A. Studeny, and M. Vellend. 2012. Quantifying temporal change in biodiversity: challenges and opportunities. Proceedings of the Royal Society B - Biological Sciences Biological Sciences 280:2-10.

Elias, M., Z. Gompert, C. Jiggins, and K. R. Willmott. 2008. Mutualistic interactions drive ecological niche convergence in a diverse butterfly community. PLoS Biology 6:2642-9.

Elias, M., Z. Gompert, K. R. Willmott, and C. Jiggins. 2009. Phylogenetic community ecology needs to take positive interactions into account. Communicative \& Integrative Biology 2:1-4.

Fisher, R., A. Corbet, and C. B. Williams. 1943. The relation between the number of species and the number of individuals in a random sample of an animal population. The Journal of Animal Ecology 12:42-58.

Gilman, S. E., M. C. Urban, J. Tewksbury, G. W. Gilchrist, and R. D. Holt. 2010. A framework for community interactions under climate change. Trends in Ecology and Evolution 25:325-331.

Grant, P. R., and R. Grant. 2014. 40 Years of Evolution: Darwin's Finches on Daphne Major Island. Princeton University Press. 
Harrison, P. J., S. T. Buckland, Y. Yuan, D. A. Elston, M. J. Brewer, A. Johnston, and J. W. PearceHiggins. 2014. Assessing trends in biodiversity over space and time using the example of British breeding birds. Journal of Applied Ecology 51:1650-1660.

Hubbell, S. P. 2001. The Unified Neutral Theory of Biodiversity and Biogeography. Page Monographs in Population Biology. Princeton University Press.

Hubbell, S. P. 2006. Neutral theory and the evolution of ecological equivalence. Ecology 87:1387-98.

MacArthur, R. H., and E. O. Wilson. 1967. The theory of island biogeography. Page (R. H. MacArthur, Ed.) Monographs in Population Biology. Princeton University Press.

Magurran, A. E. 2007. Species abundance distributions over time. Ecology Letters 10:347-354.

Magurran, A. E. 2008. Diversity over time. Folia Geobotanica 43:319-327.

Magurran, A. E. 2011. Measuring species diversity in time (and space). Pages 89-94in A. E. Magurran and B. J. McGill, editors.Biological Dversity: Frontiers in Measurement and Assesment. Oxford University Press, USA, New York.

Magurran, A. E. 2016. How ecosystems change. Science 351:448-449.

Magurran, A. E., and M. Dornelas. 2010. Biological diversity in a changing world. Philosophical Transactions of the Royal Society of London. Series B, Biological sciences 365:3593-7.

Marengo, J. A., M. C. Valverde, and G. O. Obregon. 2013. Observed and projected changes in rainfall extremes in the Metropolitan Area of São Paulo. Climate Research 57:61-72.

Müller, F. 1879. Ituna and Thyridia: a remarkable case of mimicry in butterflies. Transactions of the Royal Entomological Society of London 1879:xx-xxix.

Ordonez, A., J. W. Williams, and J. Svenning. 2016. Mapping climatic mechanism likely to favour the emergence of novel communities. Nature Climate Change 6:1104-1111.

Parody, J. M., F. J. Cuthbert, and E. H. Decker. 2001. The effect of 50 years of landscape change on species richness and community composition. Global Ecology and Biogeography 10:305-313.

Pinheiro, C., Í. Medri, and A. Salcedo. 2008. Why do the ithomiines (Lepidoptera, Nymphalidae) aggregate? Notes on a butterfly pocket in central Brazil. Revista Brasileira de Entomologia 52:610-614.

Preston, F. W. 1960. Time and space and the variation of species. Ecology 41:612-627.

Stouffer, P. C., E. I. Johnson, R. O. Bierregaard, and T. E. Lovejoy. 2011. Understory bird communities in Amazonian rainforest fragments: species turnover through 25 years post-isolation in recovering landscapes. PloS One 6:e20543.

Supp, S., and S. K. M. Ernest. 2014. Species-level and community-level responses to disturbance: A cross-community analysis. Ecology 95:1717-1723.

Tauber, M. J., C. A. Tauber, and S. Masaki. 1986. Seasonal adaptations of insects. Oxford University Press.

Vellend, M. 2010. Conceptual synthesis in community ecology. The Quarterly Review of Biology 
85:183-206.

White, E. P., S. K. M. Ernest, P. B. Adler, A. H. Hurlbert, and S. K. Lyons. 2010. Integrating spatial and temporal approaches to understanding species richness. Philosophical Transactions of the Royal Society of London. Series B 365:3633-43.

Wingfield, J. C. 2012. Regulatory mechanisms that underlie phenology, behavior, and coping with environmental perturbations: an alternative look at biodiversity. The Auk 129:1-7.

Wingfield, J. C., J. Patrick Kelley, F. Angelier, O. Chastel, F. Lei, S. E. Lynn, B. Miner, J. E. Davis, D. Li, and G. Wang. 2011. Organism-environment interactions in a changing world: A mechanistic approach. Journal of Ornithology 152:S279-\$288.

Wolkovich, E. M., B. I. Cook, K. K. McLauchlan, and T. J. Davies. 2014. Temporal ecology in the Anthropocene. Ecology Letters 17:1365-1379. 


\title{
CAPÍTULO 1 - CICLOS ANUAIS DE BORBOLETAS ITHOMIINI (NYMPHALIDAE, DANAINAE) DURANTE REGIMES DE CHUVA ATÍPICOS
}

\author{
ADAPTATIVE RESPONSES IN CHANGING ENVIRONMENTS: ANNUAL CYCLES OF BUTTERFLIES DURING \\ ATYPICAL RAINFALL REGIMES
}

\section{RESUMO}

A existência de respostas fisiológicas e comportamentais para lidar com mudanças ambientais cíclicas ou imprevisíveis é fundamental para a sobrevivência dos organismos. Estas respostas podem ocorrer diretamente em função de fatores ambientais críticos (e.g., umidade, temperatura), iniciando e cessando junto com estes fatores. Entretanto, também podem ocorrer em épocas do ano prédeterminadas por ritmos biológicos endógenos sincronizados com sinais ambientais (e.g. fotoperíodo) correlacionados a mudanças ambientais sazonais. Enquanto ritmos endógenos conferem vantagem por permitir antecipação, adaptações não-endógenas conferem plasticidade frente a perturbações imprevisíveis. Neste estudo tiramos proveito do regime de chuvas atípico que vem ocorrendo em São Paulo nos últimos quatro anos para separar a influência de um fator ambiental crítico (umidade) e de um sinal preditor desse fator (mudança do fotoperíodo ao longo do ano) sobre os ciclos anuais de borboletas Ithomiini (Nymphalidae, Danainae). Estas borboletas são notórias por - especificamente durante os meses mais secos do ano - formar densas agregações multiespecíficas de adultos ("bolsões") em áreas reduzidas no interior de florestas úmidas em grande parte do Brasil extra-amazônico. A partir de um estudo de marcação-recaptura de médio prazo testamos as hipóteses de que o comportamento de agregação responde: i) diretamente ao regime de chuvas (i.e., seriam adaptações não-endógenas), ii) ao ciclo anual do fotoperíodo, independentemente da pluviosidade (ritmo endógeno) ou iii) a ambos os fatores. As variáveis que melhor predizeram a formação dos bolsões de borboletas Ithomiini foram o fotoperíodo ou o fotoperíodo em conjunto com a pluviosidade. A pluviosidade sozinha não foi um preditor plausível da dinâmica anual dos bolsões. As agregações tiveram um padrão cíclico, anual, com máximos e mínimos sincronizados com os solstícios de inverno (estação usualmente seca) e de verão (estação usualmente chuvosa), respectivamente. As agregações pareceram responder às chuvas, porém não a estiagens fora de época. Portanto, não encontramos evidências de que os bolsões seriam simples respostas reativas diretas às chuvas (e.g., quiescência), mas sim um comportamento endógeno, sincronizado com o fotoperíodo e modulado pela pluviosidade apenas em parte do ciclo. Por isso, o comportamento de agregação, pelo menos em nível populacional, teria plasticidade limitada para lidar com as alterações no regime de chuvas previstas para a região e para o continente.

Palavras-chave: ritmos biológicos, marcação-recaptura, mudanças climáticas, ciclos de pluviosidade, fotoperíodo. 


\begin{abstract}
Physiological and behavioral responses to cope with cyclical or unpredictable environmental changes are fundamental to organisms survival. These responses can occur directly as a function of critical environmental factors (e.g., humidity, temperature), starting and ceasing along with these factors. However, they may also occur at times of the year predetermined by endogenous biological rhythms, synchronized with environmental cues (e.g. photoperiod) correlated to seasonal environmental changes. While endogenous rhythms confer advantage by allowing anticipation, non-endogenous adaptations confer plasticity in face of unpredictable perturbations. In this study we take advantage of the atypical rainfall regime that has been occurring in São Paulo in the last four years to separate the influence of a critical environmental factor (humidity) and a predictor cue of this factor (photoperiod change over the year) on annual cycles of Ithomiini butterflies (Nymphalidae, Danainae). These butterflies are notorious for - specifically during the driest months of the year forming dense multispecies aggregations of adults ("pockets") in small areas within humid forests in much of Brazil outside the Amazon. Using a medium-term mark-recapture study we test the hypothesis that the aggregation behavior responds: i) directly to rainfall (i.e., would be nonendogenous adaptations), ii) to the annual cycle of the photoperiod, independently of the rainfall (endogenous rhythm) or iii) to both factors. The variables that best predicted Ithomiini pockets formation were photoperiod or photoperiod combined with rainfall. Rainfall alone was not a plausible predictor of annual pocket dynamics. The aggregations had cyclical, annual pattern, with maxima and minima synchronized with winter solstices (usually dry season) and summer (usually rainy season), respectively. Aggregations seemed to respond to unexpected rainfall, but not to unexpected droughts. Therefore, we found no evidence that pockets would be simple direct reactive responses to rainfall (e.g., quiescence), but rather an endogenous behavior, synchronized with photoperiod and modulated by rainfall only in part of the cycle. Therefore, aggregation behavior, at least at the population level, would have limited plasticity to cope with changes in rainfall regime predicted for the region and for the continent.
\end{abstract}

Key words: biological rhythms, marking-recapture, climatic changes, rainfall cycles, 


\section{INTRODUÇÃO}

A capacidade de lidar com variações ambientais é crucial para a sobrevivência e reprodução dos organismos. Dentre as variações ambientais mais notáveis nos ambientes terrestres estão os ciclos anuais de temperatura e precipitação, causados pela inclinação no eixo da Terra e pela sua órbita ao redor do sol (Foster \& Kreitzman 2009). A aptidão de um organismo em ambientes sazonais depende, portanto, de habilidades para explorar as estações favoráveis, evitar ou mitigar as estações desfavoráveis e para mudar de uma estratégia para outra no tempo adequado (Bradshaw \& Holzapfel 2010). Estas habilidades dependem de adaptações fisiológicas e comportamentais, cuja sincronização se expressa nos ritmos biológicos anuais (e.g., estações de reprodução, dormência, migração) observados nos mais diversos taxa (Stevenson et al. 2015), desde as zonas polares até a região intertropical (Wolda 1988, Gwinner \& Dittami 1990, Wikelski et al. 2000, Stevenson et al. 2015). Entender como os ritmos biológicos são regulados é fundamental para entendermos a evolução de processos adaptativos (Tauber et al. 1986, Hau et al. 2004, Wingfield et al. 2011b) e para avaliarmos a plasticidade dos organismos diante de mudanças imprevisíveis no ambiente (Wingfield et al. 2011a, Grevstad \& Coop 2015). Esta questão é especialmente relevante visto que dois processos chave de mudança global - mudanças climáticas e urbanização - podem modificar rapidamente os ciclos ambientais anuais e impor desafios substanciais aos organismos (Helm et al. 2013).

Os organismos podem regular seus ritmos anuais através de diferentes mecanismos (Nelson et al. 1990, Paul et al. 2008, Helm et al. 2013). Os mais simples são respostas reativas diretas a fatores que afetam a sobrevivência (e.g. umidade, temperatura), respostas estas que ocorrem apenas na presença do fator e cessam em sua ausência (Paul et al. 2008, Stevenson et al. 2015). No entanto, a disciplina da cronobiologia vem mostrando que os ritmos biológicos de organismos dos mais variados taxa têm um forte componente endógeno, i.e., possuem contadores de tempo ("relógios") internos que possibilitam antecipação e preparação para lidar com mudanças ambientais cíclicas (Gwinner 1986, Tauber et al. 1986, Denlinger et al. 2001, Helm et al. 2013). Os ritmos endógenos geralmente usam sinais externos tal como o comprimento do dia para se sincronizar aos ciclos ambientais, porém a característica mais marcante destes ritmos é que eles não dependem de fatores externos para ocorrer (Foster \& Kreitman 2009). Há organismos cujos ritmos fisiológicos e comportamentais são tão fortemente endógenos que persistem mesmo sob condições ambientais constantes em laboratório (Bradshaw \& Holzapfel 2007, Paul et al. 2008, Helm et al. 2013).

A ampla ocorrência geográfica e taxonômica de ritmos endógenos indica que a evolução tenderia a favorecer mecanismos que permitem antecipação em detrimento à simples reação (Gwinner 1986, Tauber et al. 1986, Denlinger et al. 2001, Bradshaw \& Holzapfel 2007, Helm et al. 2013). De fato, muitas respostas sazonais vitais requerem tempo para se completar (e.g, deposição de gordura em antecipação ao inverno, espematogênese em antecipação à estação reprodutiva) e ocorreriam fora de época se fossem iniciadas apenas em resposta direta a mudanças em fatores ambientais críticos (Paul et al. 2008, Bradshaw \& Holzapfel 2010, Grevstad \& Coop 2015). Por isso, apesar de ritmos biológicos anuais serem adaptações a ciclos sazonais de fatores ambientais que afetam diretamente a aptidão (daqui em diante fatores últimos), sua sincronização depende de sinais ambientais que não influenciam diretamente a aptidão, mas que podem ser usados para prever mudanças sazonais 
(Tauber et al. 1986, Nelson et al. 2010, Helm et al. 2013). Destes sinais (daqui em diante fatores proximais), o mais usado pelos organismos pela sua confiabilidade em sinalizar momento do ano é o fotoperíodo, i.e., a mudança na duração do dia ao longo do ano (Bradshaw \& Holzapfel 2007, 2010, Nelson et al. 2010, Grevstad \& Coop 2015). Mesmo na região intertropical, onde as variações anuais do fotoperíodo são menores do que nas médias e altas latitudes, os organismos parecem utilizar amplamente este sinal para sincronizar seus ritmos anuais (Hau et al. 1998, Wikelski et al. 2000, Foster \& Kreitzman 2009).

As mudanças no fotoperíodo ao longo do ano sincronizam respostas antecipadas endógenas desencadeando uma cascata, geralmente irreversível, de processos fisiológicos e comportamentais que culminam em eventos como reprodução, dormência ou migração (Bradshaw \& Holzapfel 2007, Forrest \& Miller-Rushing 2010). Por isso, é vital para os organismos que seus ritmos estejam precisamente sincronizados com a variação temporal do ambiente (Grevstad \& Coop 2015) - ou seja, que os fatores proximais que sincronizam seus ritmos sejam bons preditores dos fatores ambientais últimos. Apesar do ciclo anual do fotoperíodo ser um indicador preciso da época do ano em grande parte do planeta, ele não prediz variações nos ciclos ambientais entre anos, como por exemplo um adiantamento ou um atraso na chegada de condições sazonais favoráveis (Foster \& Kreitzman 2009). Por isso, apesar do fotoperíodo ser o principal fator proximal que sincroniza os ritmos endógenos, alguns organismos podem usar, em maior ou menor grau, fatores ambientais complementares (e.g., temperatura, umidade) para ajustes adicionais (Helm et al. 2013), conferindo alguma plasticidade aos ritmos diante de imprevisibilidades ambientais. Porém os mecanismos de adaptação que conferem plasticidade aos ritmos, a velocidade com a qual os organismos conseguem responder a novos regimes climáticos, e os próprios limites da capacidade de adaptação são temas ainda longe de ser totalmente compreendidos (Visser 2008, Helm et al. 2013, Wingfield 2011b), especialmente em ecossistemas tropicais, a região terrestre mais biodiversa do planeta. 0 controle e a plasticidade dos ritmos biológicos variam muito entre espécies, ambientes e com os sinais ambientais que interagem com os ritmos, dificultando prever as respostas dos organismos diante de alterações pontuais ou duradouras nos ciclos ambientais (Helm et al., 2013).

Experimentos em laboratório usando organismos cativos, muitas vezes com altos níveis de endogamia, avançaram nosso conhecimento sobre a regulação dos ritmos endógenos nos níveis celulares e moleculares - porém a integração de experimentos e estudos em populações naturais é chave para entendermos as consequências ecológicas de mudanças ambientais (Gaston et al. 2009, Forrest \& Miller-Rushing 2010, Wingfield 2012). Diante das dificuldades em se realizar experimentos em organismos e populações de vida livre, a ocorrência de eventos climáticos atípicos pode ser uma oportunidade única para avaliar as respostas de populações naturais a mudanças ambientais imprevisíveis. Neste estudo tiramos proveito dos regimes de chuva atípicos que ocorreram no sudeste do Brasil entre 2013-2016 (Silva Dias et al. 2013, Coelho et al. 2016) para entender a regulação e a plasticidade de um comportamento anual, supostamente adaptativo à dessecação, observado em borboletas florestais da tribo Ithomiini (Nymphalidae, Danainae). Avaliamos quanto a pluviosidade (um fator último) e o fotoperíodo (um fator proximal) - variáveis que normalmente tendem a ser fortemente correlacionadas - são bons preditores dos ciclos anuais de agregação destas borboletas em vida livre. Durante a estação seca em boa parte do Brasil extra-amazônico os adultos formam densas agregações multiespecíficas ("bolsões"), com até 30 espécies diferentes, em 
pequenas áreas localizadas nos trechos mais úmidos da mata (Brown 1972, Brown \& Benson 1974, Vasconcellos-Neto 1980, Pinheiro et al. 2008). Visto que os bolsões coincidem com a estação seca, parecem se dispersar ao final da estiagem com as primeiras chuvas e aparentam ocorrer apenas em regiões com uma estação seca bem marcada (Drummond 1976, Vasconcellos-Neto 1980, Freitas 1996), postula-se que os bolsões são uma adaptação para enfrentar estiagens sazonais e que a baixa umidade é um fator crítico para os Ithomiini (Vasconcellos-Neto 1980, Pinheiro et al. 2008).

O desacoplamento entre pluviosidade e fotoperíodo em parte do período do estudo (i.e., ocorrência de estiagens e chuvas fora de época) nos permitiu avaliar se o comportamento de agregação sazonal em bolsões seria condizente com (i) uma resposta reativa direta, reversível, à estiagem (e.g., quiescência - Denlinger et al. 2001, Danks 2006); (ii) uma resposta antecipativa endógena, sincronizada com as mudanças no fotoperíodo que precedem a chegada e o término da estação seca (e.g., diapausa, Tauber et al. 1986); ou (iii) uma resposta endógena sincronizada pelo fotoperíodo e modulada pela pluviosidade. Apesar dos estudos da dinâmica de bolsões de Ithomiini em campo postularem que as agregações são uma resposta direta à baixa pluviosidade (Vasconcellos-Neto 1980, Pinheiro et al. 2008), a maioria dos insetos (e outros organismos) lida com ciclos ambientais sazonais através de respostas endógenas antecipativas sincronizadas pelo fotoperíodo (e.g., diapausa), que podem ser moduladas em maior ou menor grau por fatores ambientais adicionais (Tauber et al. 1986, Denlinger et al. 2001, Danks 2007, Saunders 2011). Assim, a partir de estudo mensal de captura-recaptura multi-espécies - realizado ao longo de três ciclos anuais sob um regime de chuvas atípico - testamos hipóteses sobre a regulação e plasticidade do comportamento de agregação. Para isso usamos modelos lineares para testar quais variáveis ambientais melhor prevêem este comportamento: um fator último (pluviosidade), o qual indicaria uma resposta reativa e plástica; um fator proximal (fotoperíodo), o qual indicaria uma resposta endógena (antecipativa) de baixa plasticidade; ou uma combinação de ambos os fatores, que indicaria uma resposta de plasticidade intermediária, i.e., um ritmo endógeno sincronizado pelo fotoperíodo e modulado pela pluviosidade (Tauber et al. 1986).

\section{MÉTODOS}

\section{Área e sistema de estudo}

Conduzimos o estudo de captura-marcação-recaptura de borboletas Ithomiini (Nymphalidae, Danainae) em duas manchas florestais na Cidade Universitária Armando Sales Oliveira - USP, em São Paulo (760 m de altitude), sudeste do Brasil: o Parque Esporte Para Todos (PEPT) e a Reserva Florestal da USP (RF, Figura 1). O PEPT ( $23^{\circ} 33^{\prime} 32^{\prime \prime} \mathrm{S}, 46^{\circ} 44^{\prime} 12^{\prime \prime} \mathrm{W}$ ) possui aproximadamente 4,5 ha de extensão, um sub-bosque com espécies nativas e um dossel formado por Eucalyptus sp. exóticos de mais de $20 \mathrm{~m}$ de altura. Palmeiras-australianas (Archontophoenix cunninghamiana), também exóticas, são abundantes e ocupam múltiplos estratos verticais (Figura 2). A RF (233' $46^{\prime \prime} \mathrm{S}$, $46^{\circ} 43^{\prime} 42^{\prime \prime} \mathrm{W}$ ) é um remanescente de 10 ha de mata nativa em estágio médio de regeneração (Figura 2), localizado a $900 \mathrm{~m}$ do PEPT. Possui duas nascentes e um lago perene, em cujo entorno há Eucalyptus sp. de mais de $20 \mathrm{~m}$ de altura. Já foram registradas na RF 119 espécies de flora arbórea e arbustiva (Dislich \& Pivello 2002, Sandrini 2006). A palmeira-australiana já chegou a ser a espécie 
local mais abundante (Dislich et al. 2002) até que um programa de manejo iniciado em 2011 removeu uma grande quantidade de indivíduos adultos (Pivello com. pess.).

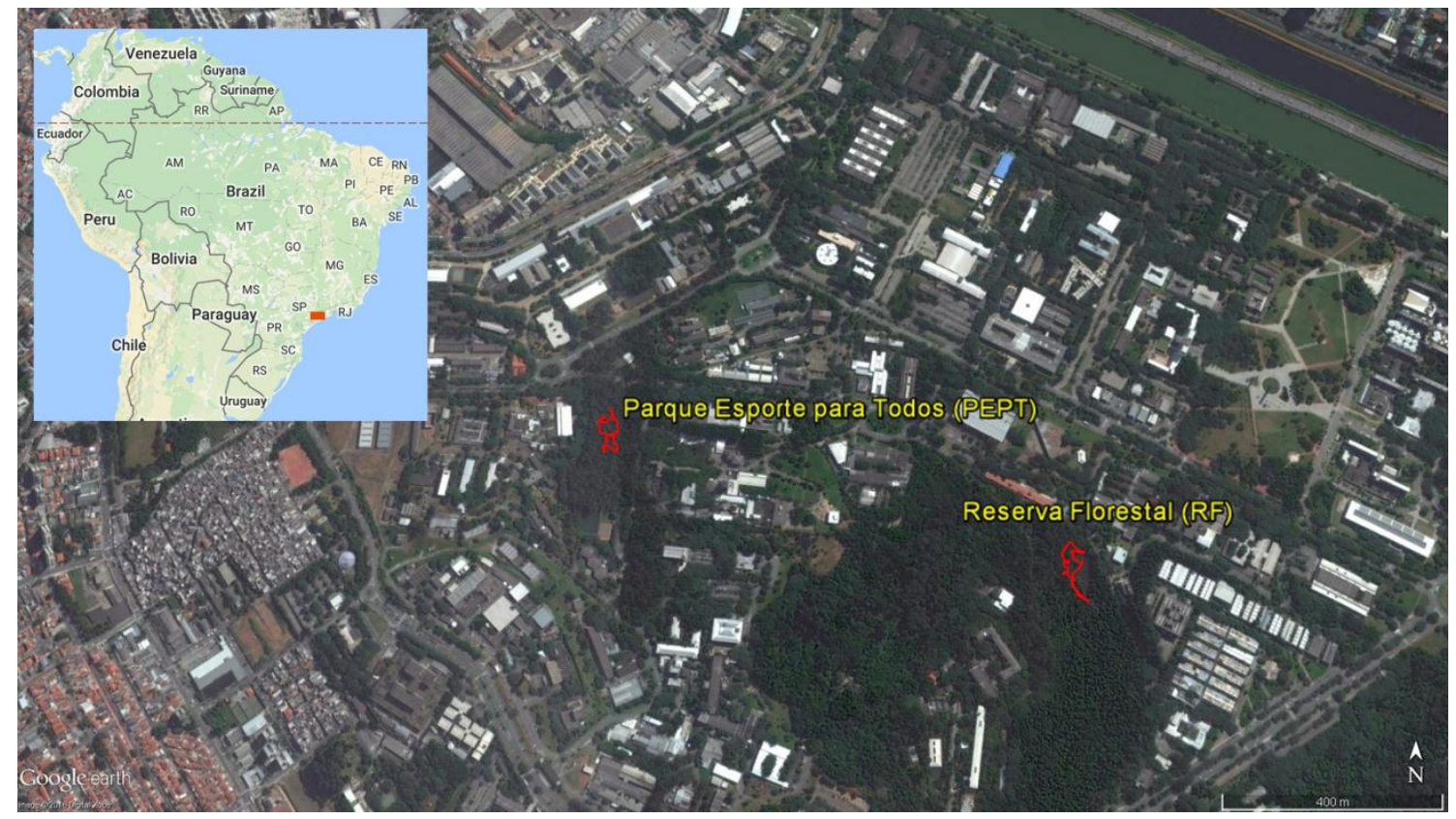

Figura 1. Localização dos dois locais de captura no campus da Universidade de São Paulo, São Paulo, Brasil. As trilhas percorridas estão assinaladas em vermelho. A escala representa $600 \mathrm{~m}$. No mapa do detalhe superior o retângulo vermelho representa a localização da área de estudo na América do Sul (Fonte: Google Earth e Google Maps).

O clima da cidade de São Paulo é temperado úmido com inverno seco e verão quente ( $C$ wa segundo classificação Köppen), com médias anuais históricas (1933-2002) de temperatura e pluviosidade de $18,6^{\circ} \mathrm{C}$ e $1419 \mathrm{~mm}$, respectivamente (IAG 2013). A distribuição histórica das chuvas ao longo do ano se concentra de tal forma que a estação seca (inverno) dura cerca de cinco meses (entre maio e setembro), quando chove, em média, apenas 19\% do total anual (IAG 2013, ver Figura 3). No entanto, durante este estudo (2013-2016) o regime de chuvas foi atípico em algumas estações ( Figura 3), com destaque para a ocorrência de invernos úmidos (2013 e 2015) e de uma estiagem atípica, a mais intensa dos últimos 42 anos, que se estendeu pela primavera/verão 2014-2015 (Coelho et al. 2016). A duração do dia medida em horas-luz (fotoperíodo) - uma variável com um ciclo anual bem marcado e cujos valores mudam muito pouco entre anos $(<0,01$ hora $)$ - varia cerca de 3 horas ao longo do ano na cidade de São Paulo, sendo que o dia mais curto do ano (solstício de inverno) tem cerca de 10,5 horas de duração enquanto que o mais longo (solstício de verão) tem 13,5 horas. Enquanto a pluviosidade mensal histórica (1933-2002) e o fotoperíodo são fortemente correlacionados ao longo do ano (correlação de Spearman, $r=0,73, p=0,009$ ), a correlação entre as médias mensais de pluviosidade e o fotoperíodo ao longo dos três anos do estudo foi inferior ( $r=$ $0,55, p=0,0003$, ver painel inferior da Figura 3). As médias mensais de pluviosidade acumulada e o fotoperíodo não foram correlacionadas no primeiro do estudo (abr/2013-mar/2014, $r=0,28, p=$ $0,36)$ nem no segundo (abr/2014-mar/2015, $r=0,51, p=0,09)$, mas foram correlacionadas no 

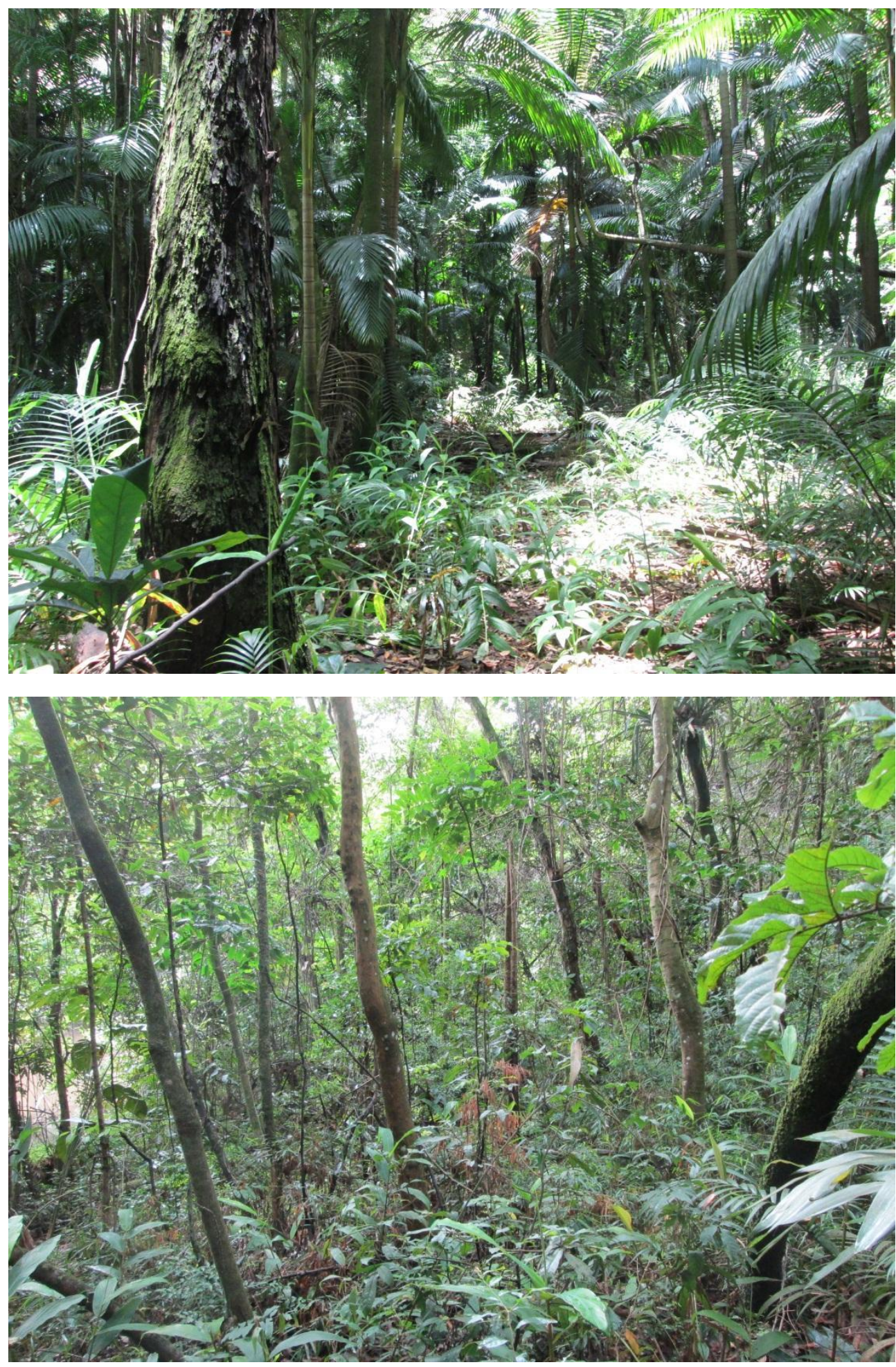

Figura 2. Vista dos locais onde foram realizados os estudos de marcação-recaptura de borboletas Ithomiini (Nymphalidae, Danainae) neste estudo. Acima: Parque Esporte Para Todos (PEPT). Abaixo: Reserva Florestal (RF). Ambos os locais se situam no campus da Universidade de São Paulo, São Paulo, SP. Os locais de captura apresentam maior umidade do que o entorno e abrigam bolsões de Ithomiini durante a estação seca há pelo menos vinte anos (Accacio 1998). 
terceiro ano (abr/2015 a mar/2016; $r=0,63, p=0,03)$, porém sem atingir os valores históricos de correlação (ver painel inferior da Figura 3 ).

Apesar de a área de estudo estar inserida em ambiente urbano, nela persistem assembleias de Ithomiini com riqueza expressiva (26 espécies - Accacio 1998, Accacio dados não-publicados, ver resultados), comparável ou superior a de outros sítios estudados no Brasil fora ou dentro do contexto urbano (e.g., Vasconcellos-Neto 1980, Brown 1992, Freitas 1996, Brown \& Freitas 2000, 2002, Costa 2002, Araújo 2006, Pinheiro et al. 2008, Uehara-Prado \& Freitas 2009, Francini et al. 2011). As borboletas Ithomiini são uma tribo com mais de 300 espécies de distribuição neotropical (Brower et al. 2014), notáveis por suas defesas químicas (Brown 1984a, 1984b), coloração aposemática e pelas relações de mimetismo entre si e com outros grupos de Lepidoptera (Müller 1879, Brown \& Benson 1974, Beccaloni 1997, Mallet \& Joron 1999). Na área de estudo ocorrem espécies de Ithomiini pertencentes a pelo menos quatro anéis miméticos distintos (i.e., a conjuntos de espécies com padrões de coloração das asas muito semelhantes, ver Figura 4), distribuídas em nove clados (subtribos, Accacio 1998, Accacio dados não publicados, ver resultados). Um dos mais notáveis aspectos da história de vida dos Ithomiini, descrito apenas na primeira metade do século $X X$ (Collenette \& Talbot 1928), são os bolsões - densas agregações sazonais com até $10 \mathrm{ind} / \mathrm{m}^{2}$, pertencentes a até 30 espécies, observadas em grande parte da área de ocorrência do grupo (Brown 1972, Brown \& Benson 1974, Vasconcellos-Neto 1980, Pinheiro et al. 2008). Os bolsões se formam no início da estação seca, concentrando-se em pequenas áreas $(<1 \mathrm{ha})$ no interior de florestas, geralmente às margens de cursos d'água ou em locais mais úmidos do que o entorno, e se dispersam no início da estação chuvosa, supostamente coincidindo com as primeiras chuvas (Brown \& Benson 1974, Vasconcellos-Neto 1980, Pinheiro et al. 2008). Apesar de não existirem informações quantitativas sistemáticas, os bolsões parecem ser característicos de regiões onde há uma estação seca, não sendo observados ou ocorrendo em densidades bem menores em regiões onde a pluviosidade é bem distribuída ao longo do ano (Drummond 1976, Vasconcellos-Neto 1980, Freitas 1996).

Os bolsões de Ithomiini na área de estudo ocorrem regularmente nos mesmos locais há pelo menos vinte anos (Accacio 1998). Cada um dos bolsões estudados (PEPT e RF) é composto de várias subagregações próximas entre si, cuja localização pode variar de ano para em ano na ordem de uma ou pouca dezena de metros (Candia-Gallardo, obs. pess.), porém sempre dentro das áreas abrangidas pelas trilhas da Figura 1. Devido aos seus padrões de ocorrência regional (regiões com estiagem sazonal), temporal (coincidência com a estação seca) e local (concentração nas áreas florestais mais úmidas e sombreadas), postula-se que a formação de bolsões seja um comportamento adaptativo a baixa umidade da estação seca (Drummond 1976, Vasconcellos-Neto 1980, Pinheiro et al. 2008). De fato, algumas observações sugerem que a baixa umidade seria um fator crítico para o grupo. Apesar de várias espécies de Ithomiini frequentarem bordas, clareiras e áreas abertas em busca de suas plantas hospedeiras, parceiros e fontes de néctar, os indivíduos parecem selecionar os ambientes mais úmidos e sombreados durante o restante do tempo (Drummond 1976). Além disso, a sobrevivência de ovos e larvas de Ithomiini parece ser muito menor em condições de baixa umidade (Vasconcellos-Neto 1980), sendo que muitas espécies interrompem ou diminuem consideravelmente sua reprodução durante a estação seca (Brown \& Vasconcellos-Neto 1976, Vasconcellos-Neto 1980, Brown \& Freitas 1994). Por isso, consideramos que a sincronia dos bolsões com os ciclos de 
pluviosidade deve ter importante valor adaptativo, e que desajustes nessa sincronia podem ter consequências negativas para as populações de Ithomiini.

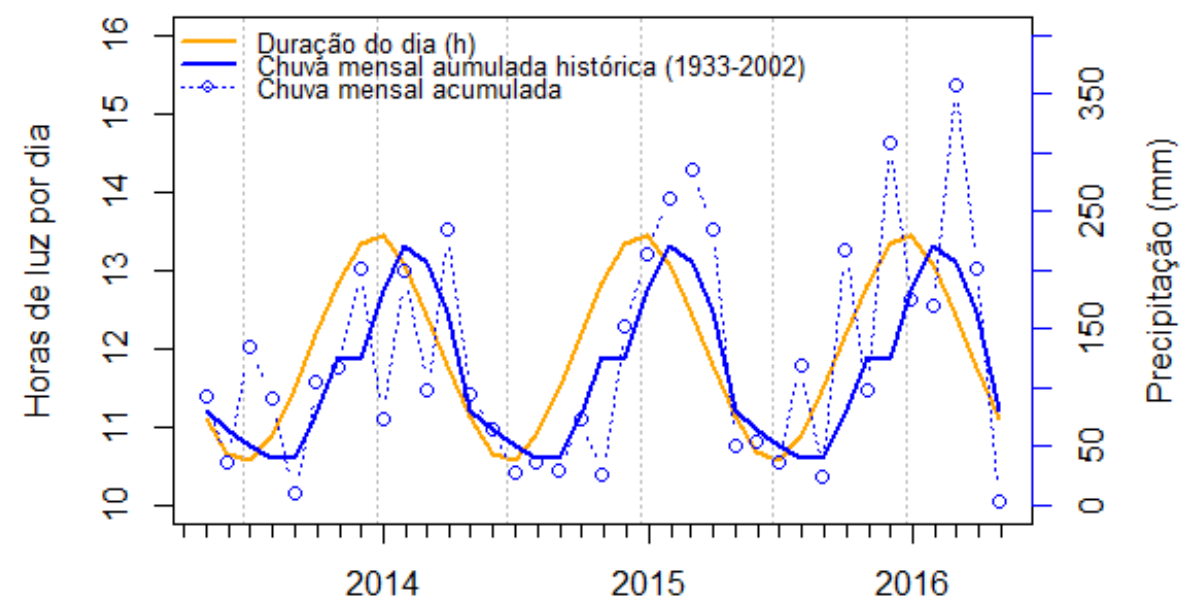

Tempo

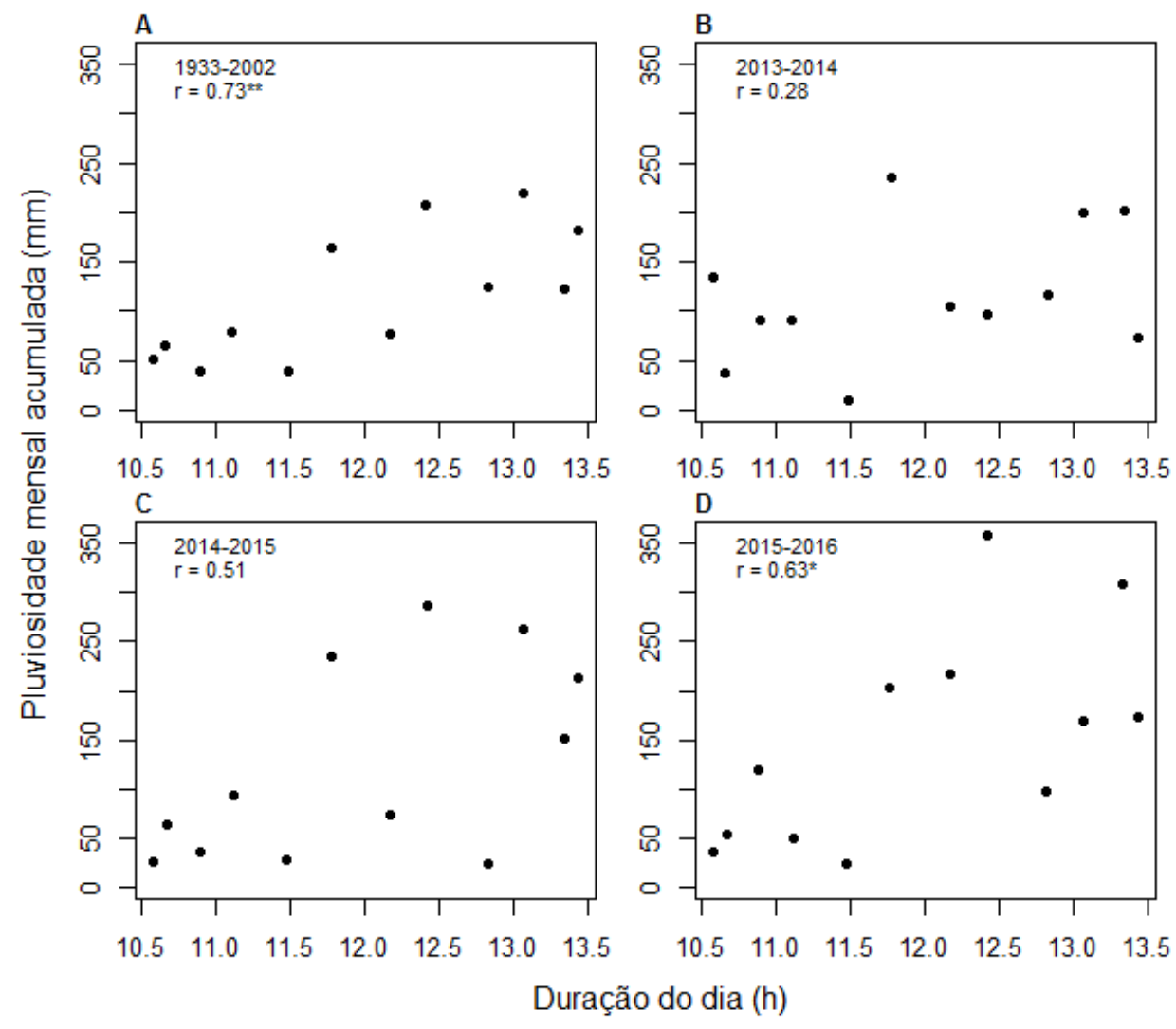

Figura 3. Figura superior: Duração do dia em horas (linha laranja) na cidade de São Paulo ao longo do ano, pluviosidade mensal acumulada histórica (1933 - 2002, linha azul contínua) e pluviosidade acumulada ao longo dos meses de estudo (linha azul pontilhada). Figura inferior: correlação de Spearman entre duração do dia e A chuva acumulada mensal histórica (1933-2002), B - chuva acumulada mensal no primeiro ano do estudo (abr/2013 - mar/2014), C - chuva acumulada mensal no segundo ano (abr/2014 - mar/2015) e D - chuva 
acumulada mensal no terceiro ano do estudo (abr/2015 e mar/2016). Fonte: Estação Meteorológica IAG/USP. * nos valores de correlação indica $0,05<p<0,01 e^{* *}$ indica $0,01<p<0,001$.

\section{Coleta de dados}

Quantificamos a dinâmica temporal das populações de borboletas Ithomiini através de um estudo de captura-marcação-recaptura baseado em captura ativa com redes entomológicas (puçá). O estudo teve 37 meses de duração no PEPT (abril/13 a abril/2016) e 27 meses na RF (fev/14 a abril/16). A fim de obter estimativas populacionais mais precisas, robustas à heterogeneidade nas probabilidades de captura, seguimos o delineamento amostral conhecido como Robusto de Pollock (Pollock 1982, Kendall 2001, Williams et al. 2002). Este delineamento requer amostragem em duas escalas temporais, chamadas ocasiões primárias e secundárias de captura, em que cada ocasião primária é composta de um conjunto de ocasiões secundárias. Assume-se que as populações estão abertas entre ocasiões primárias (i.e., podem ocorrem nascimentos, mortes, imigração e emigração), porém fechadas entre as ocasiões secundárias de uma mesma ocasião primária (Pollock 1982, Williams et al. 2002). Nos primeiros quatro meses de amostragem do PEPT as ocasiões primárias de captura tiveram frequência quinzenal, porém no restante do tempo e na RF as ocasiões primárias tiveram frequência aproximadamente mensal (média do estudo $=26,4$ dias de intervalo, desvio padrão $=$ 12,5). Cada ocasião primária de captura consistiu de quatro (em alguns casos três) ocasiões secundárias (doravante sessões de captura) realizadas ao longo de dois ou três dias consecutivos. As sessões de captura tiveram 30 minutos de duração média (desvio-padrão $=13,6$ ), sendo que os intervalos mínimo e máximo entre sessões de captura de uma mesma ocasião primária foram quatro e 17 horas, respectivamente. As ocasiões primárias do PEPT e da RF ocorreram nos mesmos dias e suas respectivas sessões de captura foram intercaladas, com exceção de dezembro de 2014 quando apenas a RF foi amostrada. Efetuamos as capturas entre as $09 \mathrm{~h} 00$ e $16 \mathrm{~h} 00 \mathrm{em}$ períodos sem chuva ou ventos fortes. No total, realizamos 40 ocasiões primárias de captura distribuídas ao longo de 37 meses no PEPT e 27 ocasiões ao longo de 27 meses na RF.

Conduzimos cada sessão de captura de 30 minutos (i.e., cada ocasião secundária) ao longo de um circuito de aproximadamente $330 \mathrm{~m}$ de extensão no PEPT e de $400 \mathrm{~m}$ na RF, os quais cobriram áreas de aproximadamente 0,1 e 0,23 ha, respectivamente (Figura 1). Estes circuitos abrangeram áreas de ocorrência de agregações (bolsões) de Ithomiini e seu entorno imediato. Nos seis primeiros meses de amostragem no PEPT (abril a setembro de 2013) um único coletor munido de rede entomológica realizou as capturas. Na RF e no restante do estudo no PEPT dois coletores trabalharam simultaneamente. Os coletores caminharam vagarosamente, e em sentidos opostos, ao longo dos circuitos capturando ativamente qualquer Ithomiini detectado até $3 \mathrm{~m}$ do trajeto e até $2,5 \mathrm{~m}$ acima do solo. Usualmente cada coletor completava de duas a três voltas pelos circuitos em cada sessão de captura. A fim de evitar fugas e danos aos espécimes, após o acúmulo de alguns indivíduos na rede entomológica os transferíamos para sacos plásticos transparentes preenchidos com ar. Imediatamente após o término de cada sessão de captura identificamos e marcamos cada espécime individualmente com números sequenciais na face ventral da uma das asas anteriores ou posteriores (dependendo da espécie), com caneta permanente ponta ultrafina da marca "Sharpie" (ver Figura 
4E). Para fins de registro fotografamos espécimes pertencentes a gêneros de identificação mais sutil, tal como Pseudoscada, Episcada e Heterosais. Após a marcação liberamos os espécimes nas imediações dos locais de captura.

Obtivemos os dados de pluviosidade (1933-2016) da Estação Meteorológica IAG/USP (IAG 2013), localizada a $15 \mathrm{~km}$ a sudoeste da área de estudo e também situada em um fragmento florestal urbano (Parque do Estado). Os dados históricos (1933-2002) consistem de médias mensais de precipitação e os dados recentes, i.e., referentes ao período amostral (2013-2016), consistem de valores diários de precipitação. Obtivemos os dados de fotoperíodo diário, i.e., duração do dia ao longo do ano, a partir de estimativas diárias de ângulo solar, obtidas da função sunAngle inclusa no pacote oce (Kelley 2014) do programa R versão 3.2.4 (R Core Team 2016).

\section{Análise de dados}

Para avaliar como o comportamento de agregação é regulado - e sua plasticidade diante de mudanças imprevisíveis no ambiente - testamos quatro hipóteses, representadas por quatro conjuntos de modelos de marcação-recaptura do tipo Robusto (Pollock 1982, Kendall 2001, Williams et al. 2002). As hipóteses, i.e., os conjuntos de modelos, diferem entre si nos fatores (covariáveis) que predizem o comportamento de agregação: pluviosidade (hipótese chuva), fotoperíodo (hipótese fotoperíodo) ou ambas (hipótese mista). Também consideramos a possibilidade da não existência de agregação, i.e., modelos nos quais não ocorre a formação de bolsões sazonais (hipótese constante). Os modelos de uma mesma hipótese diferem entre si na inclusão de covariáveis em parâmetros que não são de interesse direto para testar as hipóteses, mas que podem ser importantes para a obtenção de boas estimativas, tal como os parâmetros que descrevem as probabilidades de captura (ver detalhes adiante). Em termos de plasticidade do comportamento de agregação, a hipótese chuva representaria o cenário de maior plasticidade (resposta reativa direta à pluviosidade), a hipótese fotoperíodo o cenário de menor plasticidade (resposta antecipativa com forte componente endógeno) e a hipótese mista um cenário intermediário (resposta antecipativa endógena modulada pela pluviosidade). Avaliamos as evidências em favor de cada hipótese verificando qual ou quais modelos foram mais plausíveis frente aos dados e qual hipótese ele ou eles apoiaram. Avaliamos também as previsões de cada hipótese a respeito dos padrões de correlações entre o comportamento de agregação e as diferentes covariáveis. Rodamos análises com todas as espécies agrupadas a fim de descrever o fenômeno multiespecífico dos bolsões, e rodamos também análises por espécie (para aquelas que apresentaram número de capturas e recapturas suficiente) a fim de detectar eventuais variações interespecíficas. Por fim, descrevemos o comportamento de agregação através de parâmetros estimados pelo modelo ou conjunto de modelos mais plausíveis frente aos dados. Estes parâmetros são: (i) número de indivíduos (abundância) estimado em cada ocasião primária, o qual representa o tamanho dos bolsões ao longo do tempo; e (ii) a probabilidade de permanência na área de captura entre duas ocasiões primárias subsequentes, a qual representa a tendência dos indivíduos se manterem agregados ao longo do tempo.

O tipo de modelo que utilizamos para descrever os dados (Robusto) utiliza as recapturas entre ocasiões primárias para estimar probabilidade de permanência e as recapturas entre ocasiões 
secundárias (sessões de captura) de uma dada ocasião primária para estimar abundância (Williams et al. 2002). O modelo Robusto fornece estimativas de abundância mais eficientes e menos enviesadas do que outros modelos disponíveis (e.g. Jolly-Seber), robustas à heterogeneidade nas probabilidades de captura (Kendall 2001), pois não têm a premissa de que todos os indivíduos têm a mesma probabilidade de ser capturados (Pollock 1982). Além disso, o modelo robusto é capaz de estimar emigração temporária, i.e., a probabilidade de um indivíduo estar temporariamente indisponível ou não para captura, e de modelar este e seus demais parâmetros em função de covariáveis (Kendall 2001, Cooch \& White 2006). Por estes motivos o modelo Robusto é uma opção conveniente para descrever o fenômeno dos bolsões e para testar as hipóteses que propusemos. Os parâmetros do modelo robusto, de acordo com a parametrização implantada em Cooch \& White (2006), são:

$N$ (abundância) - numero estimado de indivíduos presentes na área de captura em cada ocasião primária. Inclui os indivíduos capturados mais uma estimativa do número de indivíduos presentes porém não capturados, a qual usa como base estimativas de probabilidade de captura (ver abaixo). Utilizamos ? para descrever a intensidade das agregações em cada ocasião primária;

$\gamma^{\prime \prime}$ ("Gamma duas linhas") - probabilidade do indivíduo presente em uma ocasião primária abandonar (emigrar) temporariamente a área de captura e não estar disponível para captura na ocasião primária seguinte. A probabilidade de permanência na área de captura é dada por $1-\gamma^{\prime \prime}$ Utilizamos $1-\gamma^{\prime \prime}$ para descrever a tendência dos indivíduos permanecerem nas agregações ao longo do tempo.

Além destes dois parâmetros que utilizamos para descrever a dinâmica das agregações, o modelo Robusto também estima:

$\gamma^{\prime}$ (“Gamma linha”) - probabilidade do individuo que está fora da área de captura durante uma ocasião primária continue fora na ocasião seguinte. A probabilidade de entrada na área de captura entre duas ocasiões é dada por $1-\gamma^{\prime}$;

Ф (sobrevivência aparente) - probabilidade de um indivíduo sobreviver e não abandonar permanentemente a área de captura no intervalo entre duas instâncias primárias;

$p$ (probabilidade de captura) - probabilidade de um indivíduo ser capturado em uma dada sessão de captura (ocasião secundária);

$c$ (probabilidade de recaptura) - probabilidade de um indivíduo previamente capturado ser capturado novamente em uma dada sessão de captura.

Como temos expectativas de que as maiores variações de abundância $(N)$ nas áreas de captura se devem a movimentos de entrada e saída representados pelos parâmetros de emigração temporária do modelo robusto $\left(\gamma^{\prime}\right.$ e $\left.\gamma^{\prime \prime}\right)$, optamos por incluir as covariáveis nestes parâmetros e deixar as abundâncias variando ao longo do tempo sem associação direta com covariáveis. Assim, montamos conjuntos de modelos onde as probabilidades de entrada $\left(1-\gamma^{\prime}\right)$ e de permanência $\left(1-\gamma^{\prime \prime}\right)$ entre ocasiões primárias de captura covariaram com a pluviosidade (hipótese chuva), com o fotoperíodo (hipótese fotoperíodo), com ambas as covariáveis (hipótese mista) ou foram constantes ao longo do 
tempo (hipótese constante, ver tabela 1). Em alguns modelos associamos covariáveis diferentes às probabilidade de entrada e de permanência; nestes casos consideramos estes modelos como representantes da hipótese mista. Em alguns modelos mantivemos apenas um destes parâmetros constantes, considerando-os representantes da hipótese referente à covariável associada ao outro parâmetro (Tabela 1). O significado biológico das diferentes combinações de covariáveis em modelos de uma mesma hipótese foi considerado e discutido quando houve incerteza na seleção de modelos.

Além de variar nos parâmetros de entrada e permanência, os modelos também variaram quanto a parâmetros não relacionados diretamente às hipóteses de formação dos bolsões, motivo pelo qual uma dada hipótese pôde ser representada por mais de um modelo (Tabela 1). A sobrevivência aparente $(\Phi)$ de cada modelo pôde ser constante ao longo do tempo ou covariar com pluviosidade (tabela 1) pois um estudo no Equador mostrou evidências de mortalidade de Ithomiini após chuvas torrenciais (Drummond 1976). As probabilidades de captura $(p)$ de cada ocasião secundária puderam ser constantes ao longo de todas as sessões de captura ou, como houve variação no esforço amostral, covariar com o esforço (ver tabela 1). Definimos o esforço de cada sessão de captura como sua duração (minutos) multiplicada pelo número de coletores presentes. Consideramos que as probabilidades de recaptura $(c)$ foram iguais às probabilidades de captura $(p=c)$ Cooch \& White 2006), o que reduziu o número de parâmetros dos modelos e facilitou sua convergência numérica. Assumimos, portanto, que a captura e marcação dos indivíduos não afetou a probabilidade de que fossem capturados novamente.

Os valores da covariável pluviosidade corresponderam à média da precipitação diária $(\mathrm{mm})$ que ocorreu entre cada ocasião primária de captura. A covariável fotoperíodo correspondeu a duas medidas relacionadas, usadas sempre em conjunto em um efeito aditivo: a duração do dia (horas-luz) e a aceleração na duração do dia (segundos). São necessárias pelo menos estas duas informações para que os sistemas biológicos possam reconhecer sem ambiguidade a época do ano para antecipar mudanças sazonais (Nelson et al. 1990). A duração e a aceleração do dia corresponderam, respectivamente, a média diária de horas-luz e à aceleração média diária dos intervalos entre cada ocasião primária de captura. Medimos a aceleração na duração do dia calculando a diferença entre as horas-luz de cada dia e as horas-luz do dia anterior, em segundos.

As diferentes combinações de covariáveis que aplicamos a cada parâmetro resultaram em um total de 32 modelos candidatos (Tabela 1). Oito destes modelos representam a hipótese de relação entre as agregações e pluviosidade (hipótese chuva), oito representam a hipótese de relação entre as agregações e fotoperíodo, doze a hipótese de relação das agregações com ambos os fatores (hipótese mista) e quatro representam a hipótese de que as taxas de entrada e saída são constantes (i.e., não agregação, hipótese constante). Para avaliar quais modelos (e hipóteses) foram mais plausíveis frente aos dados comparamos os valores do critério de informação de Akaike (AIC) e métricas relacionadas de cada um dos 32 modelos candidatos (Burnham \& Anderson 2002). Realizamos análises separadas por local de captura (PEPT e RF), sendo que em cada local analisamos todas as espécies em conjunto. Também repetimos as análises para cada espécie que teve dados suficientes. Para sumarizar o apoio que cada hipótese teve dos dados calculamos, para cada análise, o peso de evidência de cada hipótese, representado pela soma dos pesos de Akaike (WAIC) dos 
modelos que representam a respectiva hipótese. Em cada análise a soma dos pesos das quatro hipóteses deve somar 1.

Para descrever a dinâmica temporal dos bolsões e de cada população utilizamos os valores de abundância $(N)$ ao longo das ocasiões primárias e as probabilidades de permanência (1- $\left.\gamma^{\prime \prime}\right)$ entre estas ocasiões, estimativas obtidas do modelo ou do grupo de modelos mais plausíveis frente aos dados. Apesar da probabilidade de entrada (1- $\left.\gamma^{\prime}\right)$ ser um parâmetro de interesse direto na dinâmica de agregação, não utilizamos seus valores para descrever a dinâmica dos bolsões pois suas estimativas, ao contrário das estimativas de permanência, revelaram problemas de convergência (e.g., estimativas com valores extremos, com intervalos de confiança igual a zero ou com amplitude além do intervalo entre 0 e 1 , Cooch \& White 2006). Para levar em conta eventuais incertezas na seleção de modelos sobre os valores estimados dos parâmetros de interesse, utilizamos estimativas ponderadas (averaged) pelo peso de AIC ( $\triangle \mathrm{AIC}$ ) de cada modelo candidato (Burnham \& Anderson 2002). O ajuste e seleção dos modelos de captura-marcação-recaptura foi realizado no programa MARK versão 8.0 (Cooch \& White 2006), usando como interface o pacote RMark versão 2.2.0 (Laake 2016) no programa R versão 3.2.4 (R Core Team 2016).

Tabela 1. Modelos de marcação-recaptura do tipo Robusto de Pollock (Kendall 2001, Williams et al. 2002) utilizados para descrever a dinâmica de formação de bolsões de borboletas Ithomiini neste estudo. São mostrados os parâmetros de cada modelo e entre parênteses as covariáveis que os influenciam. Hipótese designa a hipótese biológica que cada modelo representa, a qual é determinada pelas covariáveis associadas aos parâmetros de entrada $\left(\gamma^{\prime}\right)$ e permanência $\left(\gamma^{\prime \prime}\right)$ nos bolsões.

\begin{tabular}{|c|c|c|}
\hline ID & Modelo & Hipótese \\
\hline 1 & $\Phi\left({ }^{*}\right) \gamma^{\prime \prime}($ rain $) \gamma^{\prime}\left({ }^{*}\right) p\left(^{*}\right)$ & Chuva \\
\hline 2 & $\Phi\left(^{*}\right) \gamma^{\prime \prime}($ rain $) \gamma^{\prime}\left({ }^{*}\right) p($ eff $)$ & Chuva \\
\hline 3 & $\Phi($ rain $) y^{\prime \prime}($ rain $) \gamma^{\prime}\left({ }^{*}\right) p(*)$ & Chuva \\
\hline 4 & $\Phi\left(^{*}\right) \gamma^{\prime \prime}($ rain $) \gamma^{\prime}($ rain $) p\left(^{*}\right)$ & Chuva \\
\hline 5 & $\Phi\left({ }^{*}\right) \gamma^{\prime \prime}($ rain $) \gamma^{\prime}($ rain $) p($ eff $)$ & Chuva \\
\hline 6 & $\Phi($ rain $) \gamma^{\prime \prime}($ rain $) \gamma^{\prime}\left({ }^{*}\right) p($ eff $)$ & Chuva \\
\hline 7 & $\Phi($ rain $) \gamma^{\prime \prime}($ rain $) \gamma^{\prime}($ rain $) p\left(^{*}\right)$ & Chuva \\
\hline 8 & $\Phi($ rain $) \gamma^{\prime \prime}($ rain $) \gamma^{\prime}($ rain $) p($ eff $)$ & Chuva \\
\hline 9 & $\Phi\left({ }^{*}\right) \gamma^{\prime \prime}($ Photo $) \gamma^{\prime}\left({ }^{*}\right) p\left(^{*}\right)$ & Fotoperíodo \\
\hline 10 & $\Phi\left({ }^{*}\right) \gamma^{\prime \prime}($ Photo $) \gamma^{\prime}(*) p($ eff $)$ & Fotoperíodo \\
\hline 11 & $\Phi($ rain $) \gamma^{\prime \prime}($ Photo $) \gamma^{\prime}\left({ }^{*}\right) p(*)$ & Fotoperíodo \\
\hline 12 & $\Phi\left({ }^{*}\right) \gamma^{\prime \prime}($ Photo $) \gamma^{\prime}$ (Photo)p $\left(^{*}\right)$ & Fotoperíodo \\
\hline 13 & $\Phi($ rain $) \gamma^{\prime \prime}($ Photo $) \gamma^{\prime}\left({ }^{*}\right) p($ eff $)$ & Fotoperíodo \\
\hline 14 & $\Phi($ rain $) \gamma^{\prime \prime}($ Photo $) \gamma^{\prime}($ Photo $) p\left(^{*}\right)$ & Fotoperíodo \\
\hline 15 & $\Phi\left({ }^{*}\right) \gamma^{\prime \prime}($ Photo $) \gamma^{\prime}$ (Photo)p(eff) & Fotoperíodo \\
\hline 16 & $\Phi\left(\right.$ rain) $\gamma^{\prime \prime}$ (Photo) $\gamma^{\prime}$ (Photo)p(eff) & Fotoperíodo \\
\hline 17 & $\Phi\left({ }^{*}\right) \gamma^{\prime \prime}($ Photo $) \gamma^{\prime}($ rain $) p\left({ }^{*}\right)$ & Mista \\
\hline 18 & $\Phi\left({ }^{*}\right) \gamma^{\prime \prime}($ rain $) \gamma^{\prime}($ Photo $) p\left(^{*}\right)$ & Mista \\
\hline 19 & $\Phi\left(^{*}\right) \gamma^{\prime \prime}($ Photo $) \gamma^{\prime}($ rain $) p($ eff $)$ & Mista \\
\hline 20 & $\Phi($ rain $) \gamma^{\prime \prime}($ rain $) \gamma^{\prime}($ Photo $) p\left({ }^{*}\right)$ & Mista \\
\hline 21 & $\Phi($ rain $) \gamma^{\prime \prime}($ Photo $) \gamma^{\prime}($ rain $) p\left(^{*}\right)$ & Mista \\
\hline 22 & $\Phi\left(^{*}\right) \gamma^{\prime \prime}($ rain $) \gamma^{\prime}($ Photo)p(eff) & Mista \\
\hline
\end{tabular}




\begin{tabular}{|c|c|c|}
\hline ID & Modelo & Hipótese \\
\hline 23 & $\Phi($ rain $) \gamma^{\prime \prime}($ Photo $) \gamma^{\prime}$ (rain)p(eff) & Mista \\
\hline 24 & $\Phi($ rain $) \gamma^{\prime \prime}($ rain $) \gamma^{\prime}$ (Photo)p(eff) & Mista \\
\hline 25 & $\Phi\left({ }^{*}\right) \gamma^{\prime \prime}($ Photo + rain $) \gamma^{\prime}($ Photo + rain) $)\left(^{*}\right)$ & Mista \\
\hline 26 & $\Phi\left({ }^{*}\right) \gamma^{\prime \prime}\left(\right.$ Photo + rain) $\gamma^{\prime}$ (Photo + rain)p(eff) & Mista \\
\hline 27 & $\Phi($ rain $) v^{\prime \prime}($ Photo + rain $) v^{\prime}($ Photo + rain $) p\left(^{*}\right)$ & Mista \\
\hline 28 & $\Phi($ rain $) \gamma^{\prime \prime}\left(\right.$ Photo + rain) $\gamma^{\prime}($ Photo + rain)p(eff) & Mista \\
\hline 29 & $\Phi\left(^{*}\right) \gamma^{\prime \prime}\left({ }^{*}\right) \gamma^{\prime}\left({ }^{*}\right) p\left(^{*}\right)$ & Constante \\
\hline 30 & $\Phi($ rain $) \gamma^{\prime \prime}(*) \gamma^{\prime}(*) p(*)$ & Constante \\
\hline 31 & $\Phi(*) \gamma^{\prime \prime}\left({ }^{*}\right) \gamma^{\prime}(*) p($ eff $)$ & Constante \\
\hline 32 & $\Phi($ rain $) \gamma^{\prime \prime}\left({ }^{*}\right) \gamma^{\prime}\left({ }^{*}\right) p($ eff $)$ & Constante \\
\hline
\end{tabular}

Parâmetros: $\Phi$ - sobrevivência aparente; $\gamma^{\prime \prime}$ - probabilidade de saída (emigração temporária) da área de captura (probabilidade de permanência é dada por $\left.1-\gamma^{\prime \prime}\right) ; \gamma^{\prime}$ - probabilidade de permanência fora da área de captura (probabilidade de entrada é dada por $1-\gamma^{\prime}$ ); $p$ - probabilidade de captura em cada sessão de captura. O parâmetro (N) não é mostrado pois em todos os modelos ele variou ao longo do tempo sem nenhuma covariável associada. O parâmetro recaptura (c) também não é mostrado pois foi igualado ao parâmetro captura $(p)$ em todos os modelos. Covariáveis entre parênteses são: rain - pluviosidade diária média entre ocasiões primárias de captura; Photo - indica a inclusão de duas variáveis em um efeito aditivo: média diária de horas-luz e aceleração na quantidade de horas luz entre campanhas; eff - esforço amostral em cada sessão de captura (medida como minutos de captura vezes o número de coletores); ${ }^{*}$ - indica que o parâmetro teve um valor constante ao longo do tempo.

\section{RESULTADOS}

No estudo de marcação-recaptura registramos 24 espécies de borboletas Ithomiini divididas em nove subtribos (Tabela 2). No PEPT efetuamos 17.159 capturas de 12.149 indivíduos pertencentes a 23 espécies ao longo de 37 meses (abril/14 a abril/16). Na RF, entre fevereiro/15 e abril/16 realizamos 5.548 capturas de 4.572 indivíduos pertencentes a 24 espécies. Do total de 22.387 capturas efetuadas em ambas as áreas, pouco mais de 1\% (279 capturas) corresponderam a deslocamentos entre o PEPT e a RF (Tabela 2). Oito das 24 espécies registradas (marcadas com asterisco na Tabela 2 e Figura 4) tiveram número de capturas e recapturas suficiente, tanto no PEPT quanto na RF, para que estimativas demográficas pudessem ser calculadas separadamente e as hipóteses sobre a dinâmica de cada espécie pudessem ser testadas. Estas oito espécies representaram aproximadamente $95 \%$ do total de indivíduos e de capturas que obtivemos ao longo do estudo. 
Tabela 2. Espécies de borboletas Ithomiini (Nymphalidae, Danainae) registradas no Parque Esporte para Todos (PEPT, entre abr/2013 e abr/2016) e na Reserva Florestal da Cidade Universitária (RF, entre fev/2014 e abr/2016), São Paulo, SP, ao longo deste estudo. Ind - número de indivíduos capturados; recap - número de recapturas; Total - número total de capturas. Desloc. Número de recapturas entre áreas diferentes. Estão marcadas com asterisco as espécies que tiveram número suficiente de capturas/recapturas para o cálculo separado de estimativas de parâmetros demográficos.

\begin{tabular}{|c|c|c|c|c|c|c|c|}
\hline \multirow{2}{*}{ Subtribo/Espécie } & \multicolumn{3}{|c|}{ PEPT } & \multicolumn{3}{|c|}{ Reserva Florestal } & \multirow{2}{*}{ Deslocamentos } \\
\hline & Ind & recap & Total & Ind & recap & Total & \\
\hline \multicolumn{8}{|l|}{ Melinaeina } \\
\hline Melinaea Iudovica & 1 & & 1 & 1 & & 1 & \\
\hline \multicolumn{8}{|l|}{ Methonina } \\
\hline Methona themisto & 18 & 1 & 19 & 1 & & 1 & \\
\hline \multicolumn{8}{|l|}{ Tithoreina } \\
\hline Aeria olena & 13 & 6 & 19 & 9 & 1 & 10 & \\
\hline \multicolumn{8}{|l|}{ Mechanitina } \\
\hline Mechanitis lysimnia* & 451 & 181 & 632 & 177 & 50 & 227 & 6 \\
\hline Mechanitis polymnia* & 1371 & 457 & 1828 & 358 & 61 & 419 & 57 \\
\hline Thyridia psidii & 1 & & 1 & 2 & & 2 & \\
\hline \multicolumn{8}{|l|}{ Dircennina } \\
\hline Dircenna dero & 123 & 6 & 129 & 79 & 1 & 80 & 2 \\
\hline Pteronymia sylvo & 16 & & 16 & 27 & & 27 & \\
\hline Episcada carcinia & 14 & 1 & 15 & 13 & & 13 & \\
\hline Episcada clausina & 22 & 4 & 26 & 22 & & 22 & \\
\hline Episcada hymenaea & 104 & 14 & 118 & 73 & 2 & 75 & \\
\hline Episcada philoclea & & & & 1 & & 1 & \\
\hline \multicolumn{8}{|l|}{ Ithomiina } \\
\hline Ithomia agnosia* & 3950 & 828 & 4778 & $\begin{array}{c}115 \\
7\end{array}$ & 111 & 1268 & 16 \\
\hline Ithomia drymo & 47 & 7 & 54 & 34 & 1 & 35 & 2 \\
\hline Placidina euryanassa & 8 & & 8 & 14 & & 14 & \\
\hline \multicolumn{8}{|l|}{ Napeogenina } \\
\hline Epityches eupompe* & 511 & 120 & 631 & 168 & 17 & 185 & 4 \\
\hline Hypothyris euclea* & 1107 & 456 & 1563 & 719 & 256 & 975 & 41 \\
\hline Hypothyris ninonia* & 3398 & 2683 & 6081 & 866 & 366 & 1232 & 144 \\
\hline \multicolumn{8}{|l|}{ Oleriina } \\
\hline Oleria aquata & 20 & 2 & 22 & 47 & 6 & 53 & \\
\hline \multicolumn{8}{|l|}{ Godyridina } \\
\hline Hypoleria lavinia* & 397 & 126 & 523 & 348 & 71 & 419 & 7 \\
\hline Heterosais edessa & 28 & 3 & 31 & 5 & & 5 & \\
\hline $\begin{array}{l}\text { Mcclungia cymo } \\
\text { salonina* }^{*}\end{array}$ & 432 & 96 & 528 & 81 & 6 & 87 & \\
\hline Pseudoscada acilla & 56 & 13 & 69 & 24 & 1 & 25 & \\
\hline Pseudoscada erruca & 61 & 6 & 67 & 49 & 3 & 52 & \\
\hline Total & $\begin{array}{c}1214 \\
9\end{array}$ & 5010 & $\begin{array}{c}1715 \\
9\end{array}$ & $\begin{array}{c}427 \\
5\end{array}$ & 953 & 5228 & 279 \\
\hline
\end{tabular}




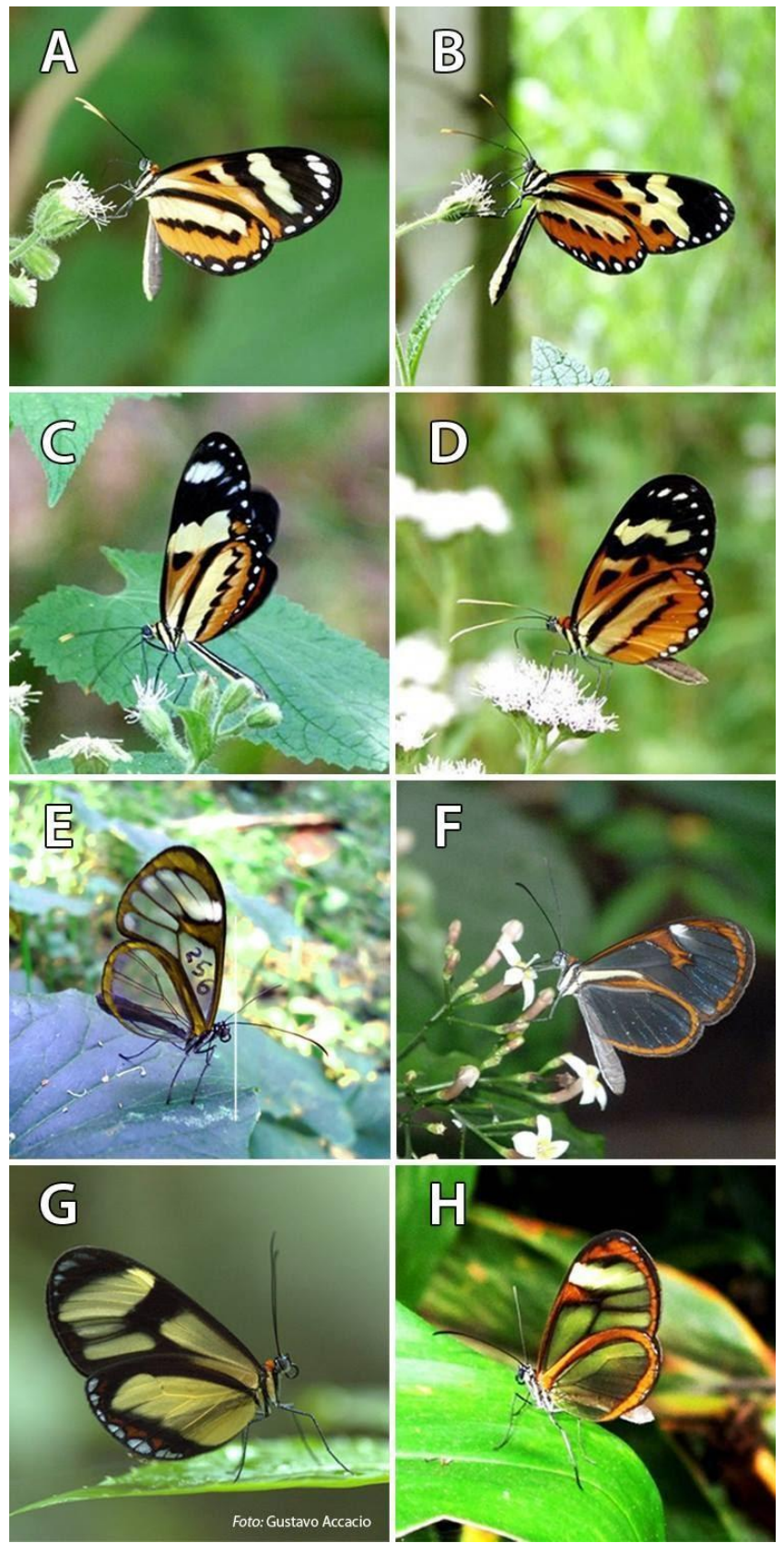

Figura 4. Oito espécies de borboletas da tribo Ithomiini (Nymphalidae, Danainae) que tiveram número de capturas e recapturas suficientes para analisarmos sua dinâmica de formação de bolsões separadamente neste estudo. A - Hypothyris ninonia (código usado nas próximas figuras: Hnino), B - Mechanitis polymnia (Mpoly), C - Mechanitis lysimnia (Mlysi), D - Hypothyris euclea (Heu), E - Hypoleria lavinia (Hlavinia), notar marcação na asa anterior, F - Ithomia agnosia (lagn), G - Epityches eupompe (Eeupompe), H - Mcclungia cymo salonina (Msalonina). Figura preparada por Renata Polydoro. 


\section{Dinâmica dos bolsões}

O modelo mais plausível para descrever a dinâmica dos bolsões (i.e., de todas as espécies agrupadas) apresentou $w A I C=1 \mathrm{em}$ ambas as áreas amostradas, ou seja, não houve incerteza no processo de seleção de modelos (Apêndices 1A e 1B e Tabelas 3 e 4). No PEPT o modelo mais plausível foi o que considerou que as probabilidades de entrada $\left(1-\gamma^{\prime}\right)$ e de permanência $\left(1-\gamma^{\prime \prime}\right)$ covariaram com fotoperíodo e pluviosidade, que a sobrevivência $(\Phi)$ foi constante ao longo do tempo e que as probabilidades de captura $(p)$ covariaram com esforço amostral. Este modelo representa a hipótese mista (modelo 26 da Tabela 1), na qual a dinâmica de agregação dos bolsões seria predita por uma combinação de fotoperíodo e chuva. Na RF o modelo mais plausível foi o que considerou que as probabilidades de permanência e de entrada covariaram apenas com fotoperíodo, que a sobrevivência covariou com a pluviosidade e que as probabilidades de captura foram constantes. Este modelo representa a hipótese fotoperíodo (modelo 14 da Tabela 1), na qual a dinâmica de agregação dos bolsões seria predita apenas por variações na duração do dia.

Tanto no PEPT quanto na RF observamos grandes agregações multiespecíficas de borboletas Ithomiini (bolsões) nos locais de captura durante o outono e inverno (maio a setembro), as quais não foram observadas durante a primavera e verão (Figura 5A). Os picos de abundância máxima e mínima foram cíclicos, aproximadamente sincronizados com os solstícios de inverno (estação seca) e de verão (chuvosa), respectivamente (Figura 5A). Os picos de agregação chegaram a ter abundâncias 200 vezes maiores do que as abundâncias mínimas de verão na RF; no PEPT as agregações chegaram a ter 400 vezes mais indivíduos do que no verão (Figura 5A). Em ambos os locais de amostragem a abundância estimada foi inversamente correlacionada à pluviosidade (PEPT: correlação de Spearman $r=-0,57, p=0,0002$; RF: $r=-0,55, p=0,004$ ) e ao fotoperíodo (PEPT: $r=-0,85, p<0,00001 ; R F: r=-$ $0,85, p<0,00001$ ), sendo a correlação entre abundância e fotoperíodo mais intensa (Figura 6). Ao contrário do padrão encontrado para as abundâncias, o número de espécies observado ao longo das ocasiões primárias não apresentou um padrão cíclico anual (Figura 5C).

A probabilidade de permanência dos indivíduos nas áreas de captura também apresentou um ciclo anual semelhante ao observado para abundância, com os valores de máximo e mínimo ocorrendo ligeiramente depois dos solstícios, tanto no PEPT quanto na RF (Figura 5B). As probabilidades de permanência foram próximas de zero $\left(1-\gamma^{\prime \prime}<0,02\right)$ nos solstícios de verão (estação normalmente chuvosa) e subiram para quase 0,9 nos solstícios de inverno (estação normalmente seca, Figura 5B). A probabilidade de permanência foi inversamente correlacionada à pluviosidade no PEPT (correlação de Spearman $r=-0,46 p=0,003)$ porém não na RF ( $r=-0,34, p=0,08)$, e inversamente correlacionada ao fotoperíodo em ambos os locais (PEPT: $r=-0,94, p<0,00001 ; R F: r=-0,89, p<$ 0,00001, Figura 6). 

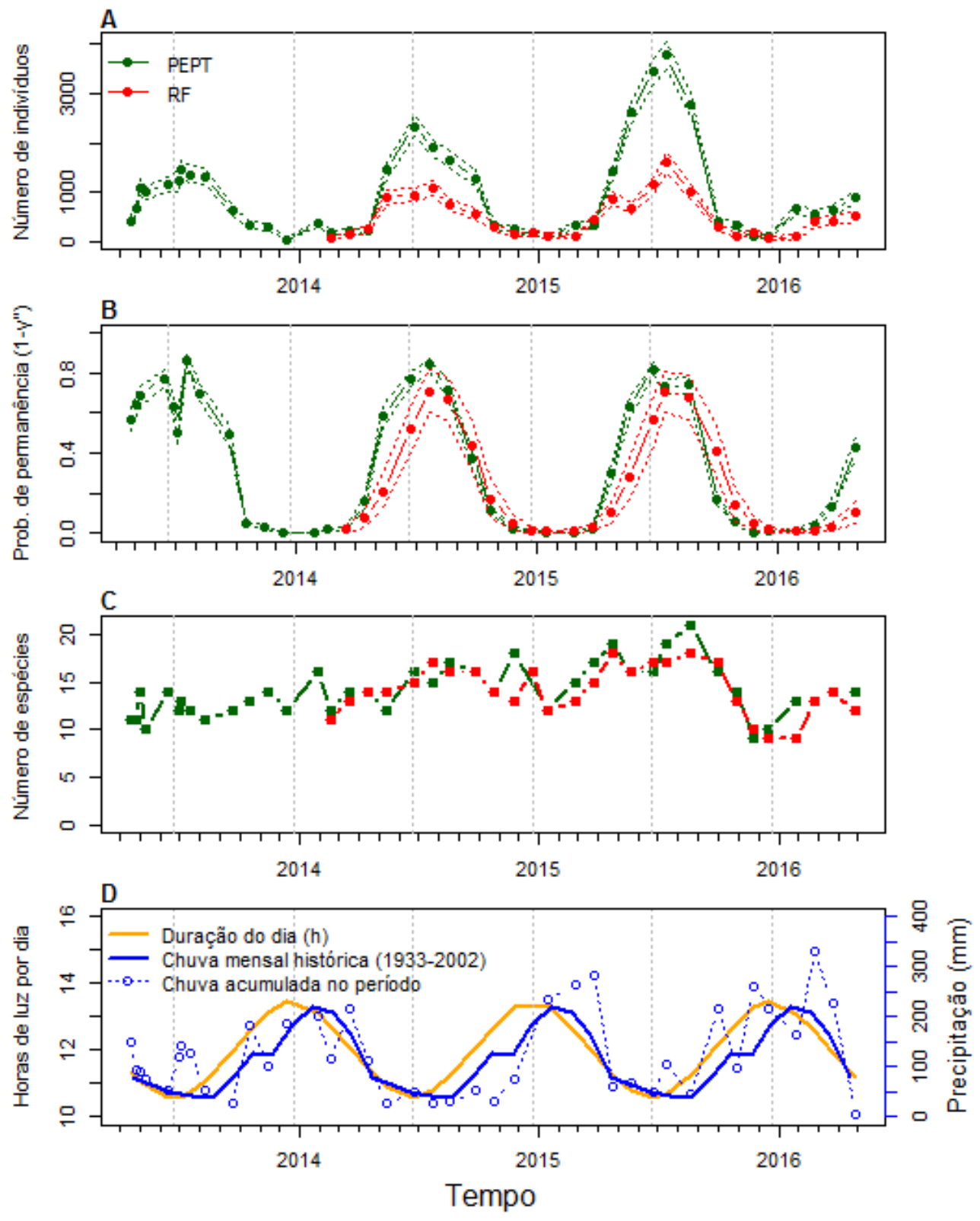

Figura 5. A: Estimativas de abundância da comunidade no PEPT (23 espécies agrupadas) e na RF (24 espécies, Tabela 1) obtidas através de técnicas de marcação-recaptura (modelo robusto). As linhas pontilhadas coloridas representam intervalos de confiança de 95\%. Notar a sincronia dos valores máximos e mínimos com os solstícios de inverno e verão, respectivamente, representados pelas linhas pontilhadas verticais. B: Probabilidades de permanência (parâmetro $1-\gamma^{\prime \prime}$ do modelo robusto) na área de captura ao longo do tempo considerando os dados de todas as espécies agrupadas. No PEPT estas probabilidades covariaram com fotoperíodo e pluviosidade em conjunto e na RF apenas com fotoperíodo. As linhas pontilhadas coloridas representam intervalos de confiança de $95 \%$. C: Número de espécies de borboletas Ithomiini registradas em cada ocasião primária de captura no PEPT (linha verde) e na RF (linha vermelha). D: Séries temporais de duração do dia (fotoperíodo, linha laranja), chuva mensal acumulada média entre 1933-2002 (linha azul contínua) e de pluviosidade acumulada entre campanhas (linha azul pontilhada). Nos quatro painéis as linhas verticais pontilhadas de coloração cinza representam os solstícios de inverno e verão. 

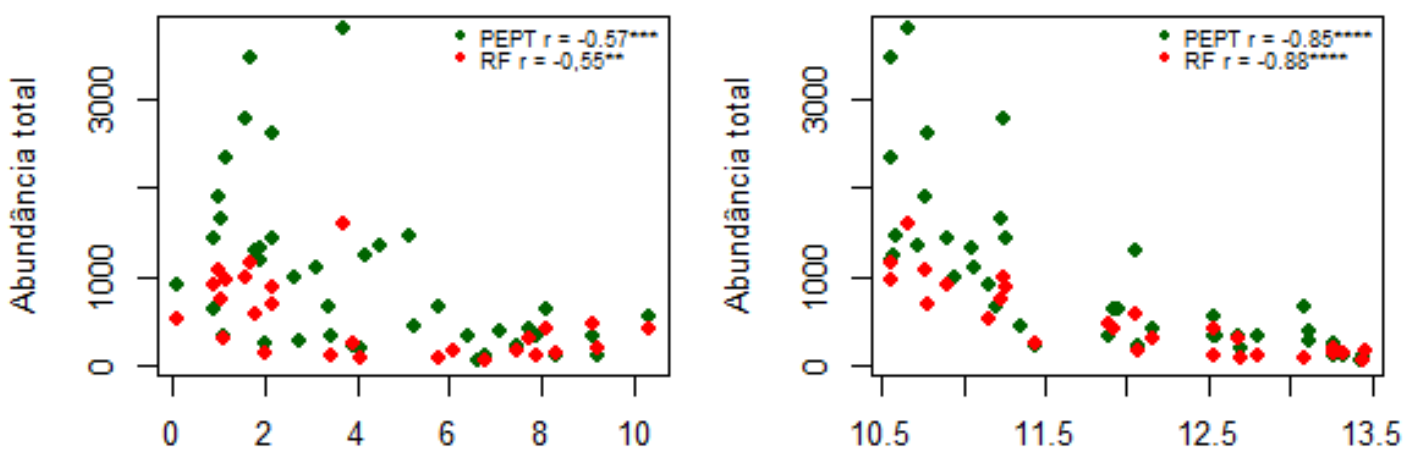

Pluviosidade (mm)
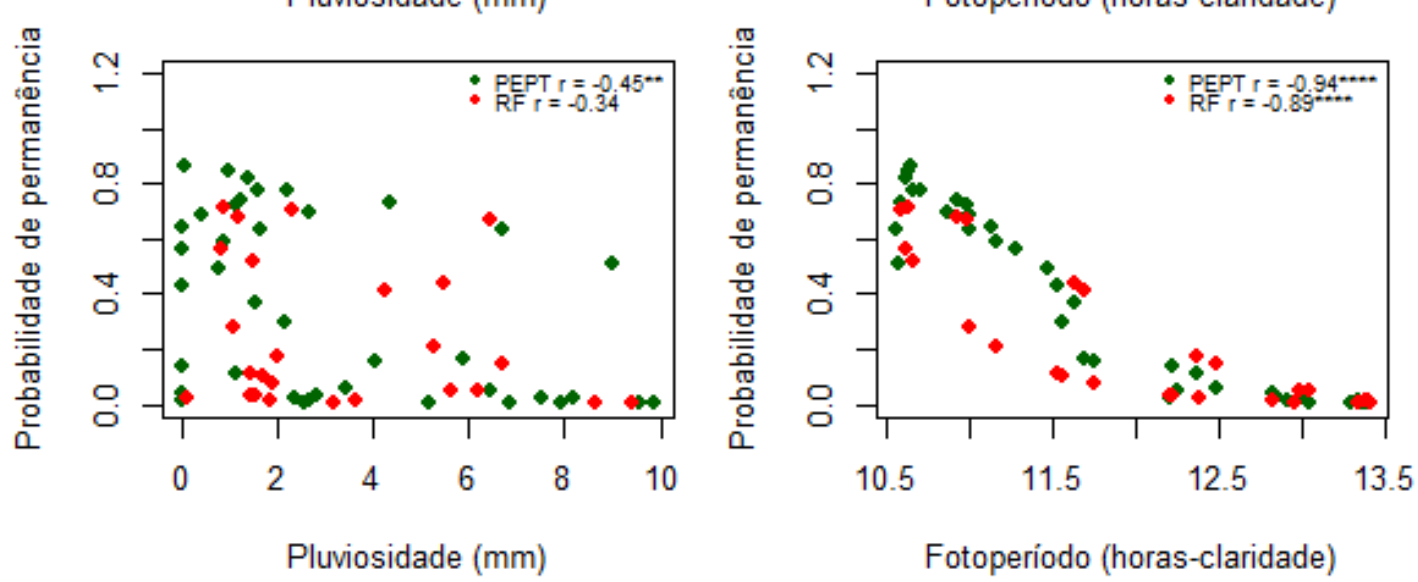

Figura 6. Relação de duas variáveis descritoras da dinâmica temporal dos bolsões de Ithomiini (i) abundância (linha superior) e probabilidade de permanência nos bolsões (linha inferior) com as variáveis ambientais pluviosidade média diária ( $\mathrm{mm}$ - coluna da direita) e fotoperíodo (horas-claridade, coluna da esquerda). PEPT Parque Esporte Para Todos; RF - Reserva Florestal. Em cada painel são apresentados os valores de correlação (Spearman) entre as variáveis. Valores com asterisco indicam que a correlação é significativa: ${ }^{* *} 0,01>p>$ $0,001, * * * 0,001>p>0,0001 ; * * * * p<0,00001$.

Ao contrário das probabilidades de permanência, as probabilidades de entrada de indivíduos nas áreas de captura foram pouco informativas para descrever a dinâmica da comunidade (e das populações, ver adiante). A maioria das estimativas deste parâmetro, tanto no PEPT quanto na RF, teve valor zero ou muito próximo de zero, com intervalos de confiança também estimados em zero ou com valores mínimos negativos. Isto é um indicativo de que este parâmetro não pôde ser estimado no ajuste dos modelos aos dados (Cooch \& White 2006), restringindo o uso das probabilidades de entrada para descrever e fazer inferências sobre dinâmica. 


\section{Dinâmicas por espécie}

As análises separadas das oito espécies que tiveram dados suficientes revelou considerável incerteza na seleção de modelos em ambos os locais de captura, especialmente na RF onde o número de capturas foi 3,3 vezes inferior (Tabelas 3 e 4). Apenas duas espécies, ambas no PEPT, tiveram modelos com $\triangle A I C \geq 0,8$, i.e., tiveram um único modelo com plausibilidade claramente superior aos demais (Tabelas 3 e 4). A incerteza também se manifestou no fato de que os modelos mais plausíveis diferiram entre espécies, e dentro de uma espécie geralmente diferiram entre locais (Tabelas 3 e 4).

Os modelos mais plausíveis (i.e., com valores de $\triangle \mathrm{AIC} \leq 3$ ) para cada uma das oito espécies do PEPT indicaram que as probabilidades de permanência dos indivíduos (1 $\left.-\gamma^{\prime \prime}\right)$ covariaram apenas com fotoperíodo (três espécies), com fotoperíodo e pluviosidade combinados (duas espécies), com fotoperíodo ou com fotoperíodo e pluviosidade combinados (duas espécies), ou com pluviosidade, ou fotoperíodo ou foram constantes (uma espécie, Tabela 3). Na RF os modelos mais plausíveis ( $\triangle \mathrm{AIC}$ $\leq 3$ ) indicaram que as probabilidades de permanência de indivíduos covariaram apenas com fotoperíodo (cinco espécies), com fotoperíodo ou com fotoperíodo e pluviosidade combinados (uma espécie), com pluviosidade ou foram constantes (uma espécie) ou foram constantes ao longo do estudo (uma espécie, Tabela 4). Assim como ocorreu com os modelos com todas as espécies agrupadas, as probabilidades de entrada por espécie tiveram uma grande incerteza de estimativa, tornando limitado o uso deste parâmetro para descrição e inferência. 
Tabela 3. Modelos com algum grau de plausibilidade frente aos dados segundo o Critério de Informação de Akaike $(\triangle \mathrm{AICc} \leq 3)$ para as amostragens realizadas no Parque Esporte Para Todos (PEPT) ao longo deste estudo. São mostrados os modelos elaborados para cada uma das de oito espécies (ver legenda ao final da tabela) que tiveram dados suficientes bem como o modelo agrupando todas as espécies. ID indica o número do modelo de acordo com a Tabela 1. Hipótese indica a hipótese biológica a qual cada modelo representa. Modelo: descrição dos parâmetros e covariáveis de cada modelo de acordo com os códigos da Tabela 1. NP indica o número de parâmetros de cada modelo. wAIC indica o peso de Akaike de cada modelo.

\begin{tabular}{|c|c|c|c|c|c|c|}
\hline Espécie & ID & Hipótese & Modelo & NP & $\triangle \mathrm{AICc}$ & wAIC \\
\hline Todas & 26 & Mista & $\Phi\left({ }^{*}\right) \gamma^{\prime \prime}\left(\right.$ Photo+rain) $\gamma^{\prime}$ (Photo+rain)p(eff) & 51 & 0,00 & 1,00 \\
\hline Hnino & 26 & Mista & $\Phi\left(^{*}\right) \gamma^{\prime \prime}$ (Photo+rain) $\gamma^{\prime}$ (Photo+rain)p(eff) & 51 & 0,00 & 1,00 \\
\hline \multirow[t]{2}{*}{ Mpoly } & 13 & Fotoperíodo & $\Phi($ rain $) \gamma^{\prime \prime}($ Photo $) \gamma^{\prime}\left({ }^{*}\right) p($ eff $)$ & 48 & 0,00 & 0,74 \\
\hline & 23 & Mista & $\Phi($ rain $) \gamma^{\prime \prime}($ Photo $) \gamma^{\prime}($ rain $) p($ eff $)$ & 49 & 2,11 & 0,26 \\
\hline Mlysi & 27 & Mista & $\Phi($ rain $) v^{\prime \prime}\left(\right.$ Photo+rain) $v^{\prime}\left(\right.$ Photo+rain) $p\left(^{*}\right)$ & 51 & 0,00 & 0,89 \\
\hline \multirow[t]{2}{*}{$\mathrm{Heu}$} & 23 & Mista & $\Phi($ rain $) \gamma^{\prime \prime}($ Photo $) \gamma^{\prime}($ rain $) p($ eff $)$ & 49 & 0,00 & 0,56 \\
\hline & 25 & Mista & $\Phi\left({ }^{*}\right) \gamma^{\prime \prime}\left(\right.$ Photo+rain) $\gamma^{\prime}($ Photo+rain $) p\left(^{*}\right)$ & 50 & 0,51 & 0,43 \\
\hline \multirow[t]{2}{*}{ lagn } & 23 & Mista & $\Phi($ rain $) \gamma^{\prime \prime}($ Photo $) \gamma^{\prime}$ (rain)p(eff) & 49 & 0,00 & 0,71 \\
\hline & 16 & Fotoperíodo & $\Phi($ rain $) \gamma^{\prime \prime}($ Photo $) \gamma^{\prime}$ (Photo)p(eff) & 50 & 2,04 & 0,26 \\
\hline \multirow[t]{2}{*}{ Hlavinia } & 21 & Mista & $\Phi($ rain $) \gamma^{\prime \prime}($ Photo $) \gamma^{\prime}($ rain $) p\left(^{*}\right)$ & 48 & 0,00 & 0,72 \\
\hline & 10 & Fotoperíodo & $\Phi\left({ }^{*}\right) \gamma^{\prime \prime}($ Photo $) \gamma^{\prime}\left({ }^{*}\right) p($ eff $)$ & 47 & 2,98 & 0,16 \\
\hline \multirow[t]{5}{*}{ Eeupompe } & 25 & Mista & $\Phi\left({ }^{*}\right) \gamma^{\prime \prime}\left(\right.$ Photo+rain) $v^{\prime}\left(\right.$ Photo+rain) $p\left(^{*}\right)$ & 50 & 0,00 & 0,28 \\
\hline & 26 & Mista & $\Phi\left(^{*}\right) \gamma^{\prime \prime}\left(\right.$ Photo+rain) $\gamma^{\prime}$ (Photo+rain)p(eff) & 51 & 0,15 & 0,26 \\
\hline & 15 & Fotoperíodo & $\Phi\left({ }^{*}\right) \gamma^{\prime \prime}$ (Photo) $\gamma^{\prime}$ (Photo)p(eff) & 49 & 1,29 & 0,15 \\
\hline & 12 & Fotoperíodo & $\Phi\left({ }^{*}\right) \gamma^{\prime \prime}($ Photo $) \gamma^{\prime}($ Photo $) p(*)$ & 48 & 1,69 & 0,12 \\
\hline & 27 & Mista & $\Phi($ rain $) v^{\prime \prime}\left(\right.$ Photo+rain) $v^{\prime}\left(\right.$ Photo+rain) $p\left(^{*}\right)$ & 51 & 2,34 & 0,09 \\
\hline \multirow[t]{6}{*}{ Msalonina } & 22 & Mista & $\Phi\left({ }^{*}\right) \gamma^{\prime \prime}($ rain $) \gamma^{\prime}$ (Photo)p(eff) & 48 & 0,00 & 0,24 \\
\hline & 2 & Constante & $\Phi\left({ }^{*}\right) \gamma^{\prime \prime}\left({ }^{*}\right) \gamma^{\prime}(*) p($ eff $)$ & 45 & 1,88 & 0,10 \\
\hline & 14 & Fotoperíodo & $\Phi($ rain $) \gamma^{\prime \prime}($ Photo $) \gamma^{\prime}($ Photo $) p\left(^{*}\right)$ & 49 & 1,94 & 0,09 \\
\hline & 6 & Constante & $\Phi($ rain $) \gamma^{\prime \prime}\left({ }^{*}\right) \gamma^{\prime}\left({ }^{*}\right) p($ eff $)$ & 46 & 2,01 & 0,09 \\
\hline & 1 & Constante & $\Phi\left(^{*}\right) \nu^{\prime \prime}\left({ }^{*}\right) \gamma^{\prime}(*) p\left(^{*}\right)$ & 44 & 2,30 & 0,08 \\
\hline & 3 & Constante & $\Phi($ rain $) \gamma^{\prime \prime}\left({ }^{*}\right) \gamma^{\prime}\left({ }^{*}\right) p\left(^{*}\right)$ & 45 & 2,60 & 0,07 \\
\hline
\end{tabular}

Espécie*: Todas - todas as espécies agrupadas (23 spp.); Hnino - Hypothyris ninonia; Mpoly - Mechanitis polymnia; Mlysi - Mechanitis lysimnia; Heu - Hypothyris euclea; lagn - Ithomia agnosia; Hlav - Hypoleria lavinia; Eeup - Epityches eupompe; Msal - Mcclungia cymo salonina. Parâmetros: $\Phi$ - sobrevivência aparente; $\gamma^{\prime \prime}$ - probabilidade de saída da área de captura (probabilidade de permanência é dada por $\left.1-\gamma^{\prime \prime}\right) ; \gamma^{\prime}-$ probabilidade de permanência fora da área de captura (probabilidade de entrada é dada por 1 - $\gamma^{\prime}$ ); $p-$ probabilidade de captura em cada sessão de captura. Covariáveis: rain - pluviosidade diária média entre ocasiões primárias de captura; Photo -duas variáveis em um efeito aditivo: média diária de horas-luz e aceleração na quantidade de horas luz entre campanhas; eff - esforço amostral em cada sessão de captura (minutos de captura vezes o número de coletores); * - valor constante ao longo do tempo. 
Tabela 4. Modelos com algum grau de plausibilidade frente aos dados segundo o Critério de Informação de Akaike $(\triangle \mathrm{AICc} \leq 3)$ para as amostragens realizadas Reserva Florestal (RF) ao longo deste estudo. São mostrados os modelos elaborados para cada uma das de oito espécies (ver legenda da Tabela 3) que tiveram dados suficientes, bem como o modelo agrupando todas as espécies (24 spp.). ID indica o número do modelo de acordo com a Tabela 1. Hipótese indica a hipótese biológica a qual cada modelo representa. Modelo: descrição dos parâmetros e covariáveis de cada modelo de acordo com os códigos da Tabela 1. NP indica o número de parâmetros de cada modelo. wAIC indica o peso de Akaike de cada modelo em relação aos modelos concorrentes.

\begin{tabular}{|c|c|c|c|c|c|c|}
\hline Espécie & ID & Hipótese & Modelo & NP & $\triangle \mathrm{AICC}$ & WAIC \\
\hline Todas & 14 & Fotoperíodo & $\Phi($ rain $) \gamma^{\prime \prime}($ Photo $) \gamma^{\prime}($ Photo $\left.) p{ }^{*}\right)$ & 36 & 0,00 & 1,00 \\
\hline \multirow[t]{5}{*}{ Hnino } & 13 & Fotoperíodo & $\Phi($ rain $) \gamma^{\prime \prime}($ Photo $) \gamma^{\prime}\left({ }^{*}\right) p($ eff $)$ & 35 & 0,00 & 0,39 \\
\hline & 11 & Fotoperíodo & $\Phi($ rain $) \gamma^{\prime \prime}($ Photo $) \gamma^{\prime}\left({ }^{*}\right) p\left(^{*}\right)$ & 34 & 1,31 & 0,20 \\
\hline & 23 & Mista & $\Phi($ rain $) \gamma^{\prime \prime}($ Photo $) \gamma^{\prime}$ (rain)p(eff) & 36 & 1,33 & 0,20 \\
\hline & 21 & Mista & $\Phi($ rain $) \gamma^{\prime \prime}($ Photo $) v^{\prime}($ rain $) p\left(^{*}\right)$ & 35 & 2,62 & 0,10 \\
\hline & 16 & Fotoperíodo & $\Phi\left(\right.$ rain) $\gamma^{\prime \prime}$ (Photo) $\gamma^{\prime}$ (Photo)p(eff) & 37 & 2,67 & 0,10 \\
\hline \multirow[t]{6}{*}{ Mpoly } & 17 & Mista & $\Phi\left({ }^{*}\right) \gamma^{\prime \prime}($ Photo $) \gamma^{\prime}($ rain $) p(*)$ & 34 & 0,00 & 0,29 \\
\hline & 9 & Fotoperíodo & $\Phi\left({ }^{*}\right) \gamma^{\prime \prime}($ Photo $) \gamma^{\prime}\left({ }^{*}\right) p(*)$ & 33 & 1,48 & 0,14 \\
\hline & 15 & Fotoperíodo & $\Phi\left({ }^{*}\right) \gamma^{\prime \prime}$ (Photo) $\gamma^{\prime}$ (Photo)p(eff) & 36 & 2,01 & 0,11 \\
\hline & 19 & Mista & $\Phi\left(^{*}\right) \gamma^{\prime \prime}($ Photo $) \gamma^{\prime}($ rain $) p($ eff $)$ & 35 & 2,03 & 0,10 \\
\hline & 10 & Fotoperíodo & $\Phi\left({ }^{*}\right) \gamma^{\prime \prime}($ Photo $) \gamma^{\prime}\left({ }^{*}\right) \mathrm{p}($ eff $)$ & 34 & 2,51 & 0,08 \\
\hline & 11 & Fotoperíodo & $\Phi($ rain $) \gamma^{\prime \prime}($ Photo $) \gamma^{\prime}\left({ }^{*}\right) p\left(^{*}\right)$ & 34 & 2,91 & 0,07 \\
\hline \multirow[t]{3}{*}{ Mlysi } & 10 & Fotoperíodo & $\Phi\left({ }^{*}\right) \gamma^{\prime \prime}($ Photo $) \gamma^{\prime}(*) p($ eff $)$ & 34 & 0,00 & 0,60 \\
\hline & 13 & Fotoperíodo & $\Phi($ rain $) \gamma^{\prime \prime}($ Photo $) \gamma^{\prime}\left({ }^{*}\right) p($ eff $)$ & 35 & 2,77 & 0,15 \\
\hline & 19 & Mista & $\Phi\left(^{*}\right) \gamma^{\prime \prime}($ Photo $) \gamma^{\prime}($ rain)p(eff) & 35 & 2,80 & 0,15 \\
\hline \multirow[t]{2}{*}{ Heu } & 23 & Mista & $\Phi($ rain $) \gamma^{\prime \prime}($ Photo $) \gamma^{\prime}($ rain $) p($ eff $)$ & 36 & 0,00 & 0,61 \\
\hline & 13 & Fotoperíodo & $\Phi($ rain $) \gamma^{\prime \prime}($ Photo $) \gamma^{\prime}\left({ }^{*}\right) p($ eff $)$ & 35 & 2,81 & 0,15 \\
\hline \multirow[t]{4}{*}{ lagn } & 10 & Fotoperíodo & $\Phi\left({ }^{*}\right) \gamma^{\prime \prime}($ Photo $) \gamma^{\prime}\left({ }^{*}\right) p($ eff $)$ & 34 & 0,00 & 0,34 \\
\hline & 28 & Mista & $\Phi($ rain $) \gamma^{\prime \prime}\left(\right.$ Photo+rain) $\gamma^{\prime}$ (Photo+rain)p(eff) & 39 & 0,67 & 0,24 \\
\hline & 26 & Mista & $\Phi\left({ }^{*}\right) \gamma^{\prime \prime}\left(\right.$ Photo+rain) $\gamma^{\prime}$ (Photo+rain)p(eff) & 38 & 1,00 & 0,20 \\
\hline & 13 & Fotoperíodo & $\Phi($ rain $) \gamma^{\prime \prime}($ Photo $) \gamma^{\prime}\left({ }^{*}\right) p($ eff $)$ & 35 & 1,38 & 0,17 \\
\hline \multirow[t]{3}{*}{ Hlavinia } & 11 & Fotoperíodo & $\Phi($ rain $) \gamma^{\prime \prime}($ Photo $) \gamma^{\prime}\left({ }^{*}\right) p\left({ }^{*}\right)$ & 34 & 0,00 & 0,56 \\
\hline & 10 & Fotoperíodo & $\Phi\left({ }^{*}\right) \gamma^{\prime \prime}($ Photo $) \gamma^{\prime}\left({ }^{*}\right) p($ eff $)$ & 34 & 2,02 & 0,20 \\
\hline & 21 & Mista & $\Phi($ rain $) \gamma^{\prime \prime}($ Photo $) \gamma^{\prime}($ rain $) p\left(^{*}\right)$ & 35 & 2,38 & 0,17 \\
\hline \multirow[t]{5}{*}{ Eeupompe } & 1 & Constante & $\Phi\left({ }^{*}\right) \gamma^{\prime \prime}\left({ }^{*}\right) \gamma^{\prime}(*) p(*)$ & 31 & 0,00 & 0,25 \\
\hline & 2 & Chuva & $\Phi\left({ }^{*}\right) \gamma^{\prime \prime}($ rain $) \gamma^{\prime}(*) p($ eff $)$ & 32 & 0,08 & 0,24 \\
\hline & 2 & Constante & $\Phi\left({ }^{*}\right) \gamma^{\prime \prime}\left({ }^{*}\right) \gamma^{\prime}\left({ }^{*}\right) p($ eff $)$ & 32 & 0,08 & 0,24 \\
\hline & 1 & Chuva & $\Phi\left({ }^{*}\right) \gamma^{\prime \prime}($ rain $) \gamma^{\prime}\left({ }^{*}\right) p\left(^{*}\right)$ & 32 & 2,93 & 0,06 \\
\hline & 3 & Constante & $\Phi($ rain $) \gamma^{\prime \prime}(*) \gamma^{\prime}\left({ }^{*}\right) p\left(^{*}\right)$ & 32 & 2,93 & 0,06 \\
\hline Msalonina & 1 & Constante & $\Phi\left({ }^{*}\right) \nu^{\prime \prime}\left({ }^{*}\right) \nu^{\prime}\left({ }^{*}\right) \mathrm{p}\left(^{*}\right)$ & 31 & 0,00 & 0,70 \\
\hline
\end{tabular}

Parâmetros: $\Phi$ - sobrevivência aparente; $\gamma^{\prime \prime}$ - probabilidade de saída da área de captura (probabilidade de permanência é dada por $1-\gamma^{\prime \prime}$ ); $\gamma^{\prime}$ - probabilidade de permanência fora da área de captura (probabilidade de entrada é dada por 1 - $\gamma^{\prime}$ ); $p$ - probabilidade de captura em cada sessão de captura. Covariáveis: rain pluviosidade diária média entre ocasiões primárias de captura; Photo -duas variáveis em um efeito aditivo: média diária de horas-luz e aceleração na quantidade de horas luz entre campanhas; eff - esforço amostral em cada sessão de captura (minutos de captura vezes o número de coletores); * - valor constante ao longo do tempo. 
Apesar da incerteza na seleção de modelos, os dados fornecem evidências de que pelo menos seis das oito espécies têm suas dinâmicas de agregação preditas pelo fotoperíodo ou por uma combinação entre fotoperíodo e pluviosidade. Nestas seis espécies as hipóteses que consideram apenas pluviosidade como preditor das agregações, ou que consideram que as probabilidades de entrada e saída foram constantes (i.e., assumem que não ocorreram agregações sazonais) tiveram peso de evidência igual à zero (Figura 7). Nas outras duas espécies (Epityches eupompe e Mcclungia cymo salonina) estas duas hipóteses, especialmente a constante, foram plausíveis (Figura 7).

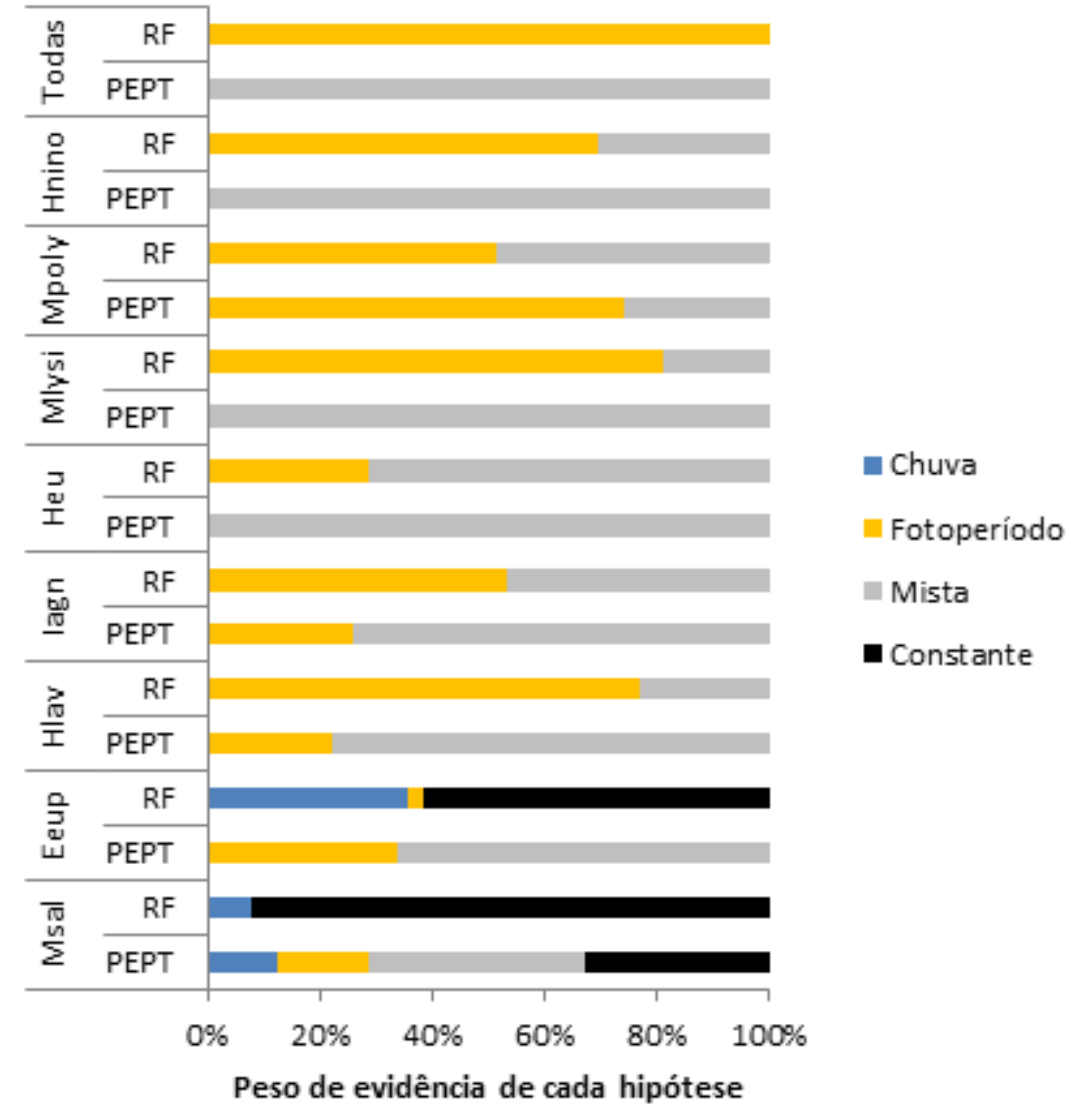

Figura 7 Peso de evidência das quatro hipóteses formuladas para descrever a dinâmica de agregação de borboletas Ithomiini, na quais as probabilidades de entrada e permanência de indivíduos covariam com: i) pluviosidade (hipótese chuva), ii) ciclo anual do fotoperíodo, iii) ambos os fatores (hipótese mista) e iv) a nenhum dos dois fatores (hipótese constante). Os pesos foram obtidos somando-se, para cada espécie em cada local, o peso de AIC ( $\triangle \mathrm{AIC}$ ) dos modelos referentes a cada hipótese (ver Tabelas 3 e 4). PEPT - Parque Esporte Para Todos; RF - Reserva Florestal da Cidade Universitária. Os códigos do nome das espécies no eixo y seguem os da Tabela 3.

As estimativas de abundância de cada espécie tiveram tendências muito semelhantes entre locais, porém os picos de abundância de algumas espécies foram muito maiores no PEPT do que na RF. (Figura 8). O padrão de agregação sazonal evidente na comunidade de Ithomiini (Figura 5A) também foi evidente em seis das oito espécies analisadas separadamente, especialmente nas mais abundantes (Ithomia agnosia e Hypothyris ninonia, Figura 8). Nestas seis espécies os picos de abundância foram aproximadamente sincronizados com os solstícios de inverno. Por outro lado duas 
espécies (Epityches eupompe e Mcclungia cymo salonina), as mesmas que apresentaram um padrão diferente das demais na seleção de modelos (Tabelas 3 e 4 e Figura 7), pareceram não apresentar as agregações sazonais observadas na comunidade e nas demais espécies (ver Eeupompe e Msalonina no painel inferior da Figura 8). Estas duas espécies tiveram picos de abundância aparentemente acíclicos e fora dos períodos de agregação das demais espécies, notadamente nos meses de janeiro e fevereiro, quando as outras espécies tiveram valores mínimos de abundância (Figura 8).
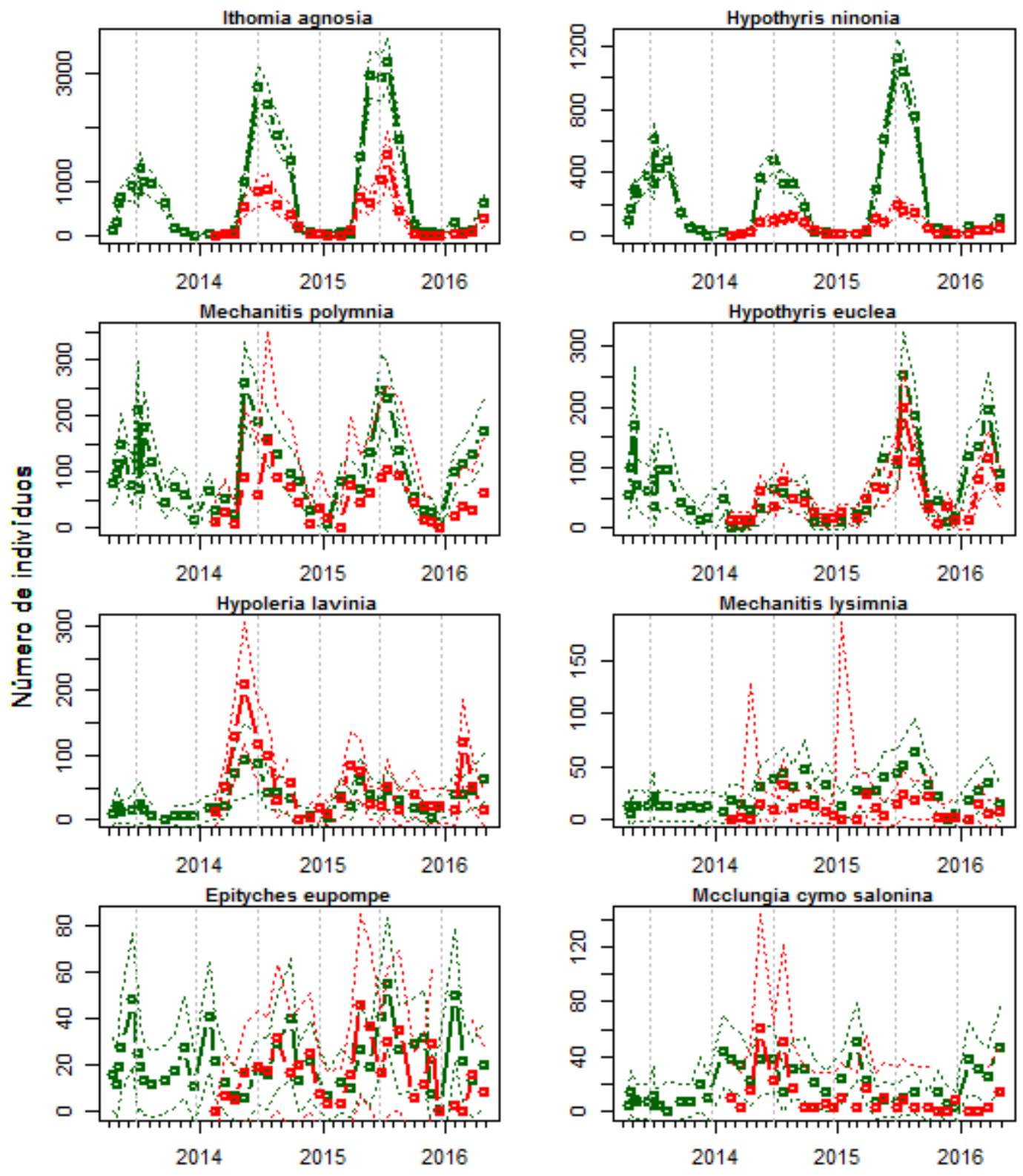

Tempo

Figura 8. Estimativas de abundâncias de oito espécies de Ithomiini obtidas através do modelo Robusto de Pollock no Parque Esporte para Todos (PEPT - linha verde) e na Reserva Florestal da USP (RF - linha vermelha). As linhas pontilhadas coloridas representam intervalos de confiança de $95 \%$. As linhas pontilhadas verticais de cor cinza representam os solstícios de inverno (meio do ano) e de verão (final do ano). 
Assim como observado nos modelos com todas as espécies agrupadas, as probabilidades de permanência por espécie apresentaram ciclos anuais de agregação em pelo menos seis das oito espécies analisadas em separado, com os picos máximo e mínimo ocorrendo quando dos solstícios de inverno e verão, respectivamente (Figura 9). Apesar da forma do ciclo anual das probabilidades de permanência apresentar alguma heterogeneidade entre espécies, e apesar de algumas diferenças entre locais de captura, os resultados fornecem evidências de que os comportamentos de agregação apresentam um padrão anual bem marcado (Figura 9). Exceções foram novamente as duas espécies para as quais os modelos sugerem ausência de sazonalidade na agregação na área estudada, Epityches eupompe e Mcclungia cymo. Epityches eupompe apresentou um padrão típico de agregação anual no PEPT porém uma probabilidade de permanência constante na RF, apesar dos intervalos de confiança terem sido próximos de 1 nesta última (ver Eeupompe na Figura 9). Já $M$. cymo salonina apresentou probabilidade de permanência constante em ambos os locais, sugerindo que esta espécie não forma agregações sazonais como as demais (ver Msalonina na Figura 9). No entanto, na RF os intervalos de confiança tiveram valor zero sugerindo que as estimativas deste parâmetro não convergiram (Figura 9). 


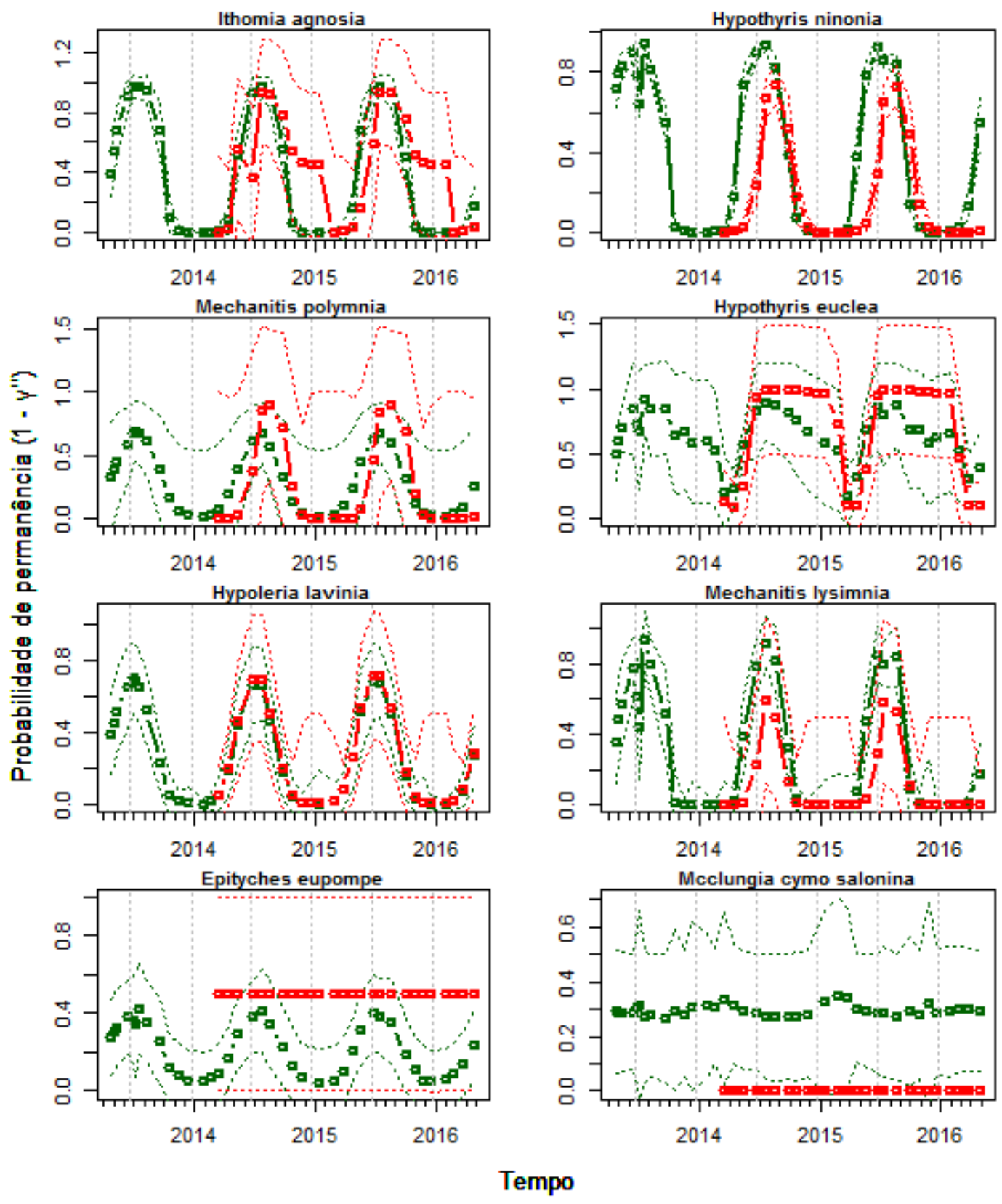

Figura 9. Probabilidades de permanência no local de captura entre ocasiões primárias (1 - $\left.\gamma^{\prime \prime}\right)$ para oito espécies de Ithomiini obtidas através do modelo Robusto de Pollock no Parque Esporte para Todos (PEPT linha verde) e na Reserva Florestal da USP (RF - linha vermelha). As linhas pontilhadas coloridas representam intervalos de confiança de $95 \%$. As linhas pontilhadas verticais de cor cinza representam os solstícios de inverno (meio do ano) e de verão (final do ano). Os códigos para os nomes da cada espécie são os mesmos da tabela 3. 


\section{DISCUSSÃO}

Em nossos modelos, as variáveis que melhor predizem a formação dos bolsões de borboletas Ithomiini são o fotoperíodo ou o fotoperíodo em conjunto com a pluviosidade. A pluviosidade sozinha não foi um preditor plausível da dinâmica anual dos bolsões. As agregações tiveram um padrão anual cíclico, com máximos e mínimos sincronizados com os solstícios de inverno (estação usualmente seca) e de verão (estação usualmente chuvosa), respectivamente. As agregações pareceram responder a chuvas porém não a estiagens fora de época. Portanto, não encontramos evidências de que os bolsões seriam simples respostas reativas diretas às chuvas (e.g., quiescência, Denlinger et al. 2001). Os resultados apoiam a hipótese de que se trata de um comportamento endógeno, sincronizado com o fotoperíodo e modulado pela pluviosidade apenas em parte do ciclo. Por isso, o comportamento de agregação, pelo menos em nível populacional, teria plasticidade limitada para lidar com as mudanças no regime de chuvas previstas para a região e para o continente (Marengo et al. 2013, Ordonez et al. 2016). Embora haja um padrão geral condizente com respostas endógenas, há diferenças interespecíficas nas dinâmicas anuais. Pelo menos seis das oito espécies analisadas separadamente formam bolsões e uma parece não formar. A seguir discutiremos os resultados considerando as espécies agrupadas, depois os resultados por espécie e por fim o potencial das borboletas Ithomiini em lidar com mudanças no ciclo anual de chuvas.

\section{Dinâmica dos bolsões considerando todas as espécies}

A "hipótese chuva", levantada em estudos anteriores de dinâmica de Ithomiini (Vasconcellos-Neto 1980, Pinheiro et al. 2008), postula que o comportamento de agregação em bolsões seria uma resposta reativa, direta e reversível à baixa pluviosidade (e.g., mecanismo do tipo III segundo Paul et al. 2008 ou quiescência segundo Tauber et al. 1986, Denlinger et al. 2001). Uma previsão dessa hipótese é uma relação inversa entre a intensidade das agregações e a pluviosidade ao longo de todo o ano; nossos dados, no entanto, não corroboram essa previsão visto que enquanto em ocasiões com alta pluviosidade sempre observamos baixas concentrações de indivíduos, em períodos com baixa pluviosidade observamos grande variação nas abundâncias, representada pela forma triangular dos dados no gráfico de relação entre estas variáveis (Figura 6). Assim, a pluviosidade não foi um bom preditor do comportamento de agregação dada a grande variação observada nas abundância e nas probabilidades de permanência ao longo do gradiente de chuvas. Portanto, a dinâmica dos bolsões é mais complexa do que uma resposta reativa e reversível à pluviosidade - medidores de tempo endógenos parecem regular o comportamento de agregação. Estes resultados se somam a muitos outros que corroboram a perspectiva do campo da cronobiologia, na qual os organismos tendem a lidar com as variações ambientais cíclicas usando mecanismos endógenos de contagem de tempo (Helm et al. 2013), o que gera respostas mais complexas - e portanto mais difíceis de prever - do que simples reações a mudanças nos fatores críticos (Foster \& Kreitzman 2009).

Os dados forneceram fortes evidências em favor das hipóteses de que a dinâmica de formação e dissolução dos bolsões depende de uma combinação entre fotoperíodo e pluviosidade (hipótese mista, resultados obtidos no PEPT) ou apenas do fotoperíodo (hipótese fotoperíodo, resultados obtidos na RF). Acreditamos, porém, que o apoio fornecido pelos dados da RF à hipótese fotoperíodo pode ser resultado de um efeito amostral, oriundo da menor extensão temporal dos dados deste 
local (ver adiante). Em ambos os locais, tanto a abundância como a probabilidade de permanência nos bolsões tiveram forte correlação negativa com fotoperíodo, porém não tiveram nenhuma correlação ou tiveram uma correlação negativa fraca com a pluviosidade - especialmente probabilidade de permanência (ver Figura 6). Portanto, o fotoperíodo foi um melhor preditor da dinâmica dos bolsões do que a pluviosidade, resultado condizente com a hipótese de que haveria um componente endógeno regulando o comportamento de agregação sazonal. Este resultado não é inusitado visto que é comum que os insetos lidem com variações cíclicas do ambiente através de respostas endógenas sincronizadas com o fotoperíodo (Tauber et al. 1986, Denlinger et al. 2001, Saunders 2011). Por outro lado, o fato de que o modelo mais plausível de cada local representou hipóteses distintas - mista no PEPT e fotoperíodo na RF - poderia adicionar incerteza a respeito do papel das chuvas na modulação do comportamento de agregação. Além do fotoperíodo, os ritmos endógenos podem utilizar fatores ambientais adicionais para se ajustar, porém a importância relativa destes outros fatores varia entre espécies e ambientes (Helm et al. 2013). Dada a pequena distância que separa os dois locais de estudo $(0,9 \mathrm{~km})$, consideramos mais provável que a diferença nas hipóteses selecionadas em cada local seja mais relacionada à diferença na duração do estudo entre locais do que a diferenças ambientais ou entre as populações de cada local.

O primeiro ano do estudo (abr 2013 - mar/2014) foi o que teve maior desacoplamento (ausência de correlação) entre chuvas e fotoperíodo (Figura 2). No entanto, como iniciamos as amostragens do segundo local dez meses depois do início do estudo, registramos este fenômeno apenas no PEPT. Durante a estação seca atipicamente chuvosa de 2013 observamos uma queda momentânea nas probabilidades de permanência, a qual se reverteu após o término destas chuvas fora de época (Figura 3B e 3D). Com exceção deste trecho da série temporal, documentado apenas no PEPT, a probabilidade de permanência foi inversamente relacionada ao fotoperíodo ao longo de todo o estudo em ambos os locais. Assim, especulamos que se tivéssemos amostrado a RF no inverno atipicamente chuvoso de 2013, talvez o modelo mais plausível para este local também fosse o que inclui uma combinação de fotoperíodo e pluviosidade como covariáveis. A redução atípica na probabilidade de permanência em pleno auge do bolsão de 2013 sugere que houve uma resposta reativa (desagregação) a estas chuvas fora de época, porém também poderia ser resultado de mortalidade (Figura 3B). Eventos de mortalidade de Ithomiini na região Amazônica já foram associados a chuvas torrenciais (Drummond 1976), e é possível que chuvas associadas a baixas temperaturas por período prolongados também induzam mortalidade (Accacio com. pess.). Entretanto, visto que as chuvas atípicas do inverno de 2013 não foram torrenciais nem tampouco suas temperaturas foram baixas em relação a média histórica (IAG 2013), consideramos mais plausível que a redução na permanência durante o bolsão de 2013 se deva defato a uma resposta comportamental.

Curiosamente, não observamos respostas reativas semelhantes em outras ocasiões com pluviosidade atípica, tal como durante a severa estiagem que se estendeu pela estação chuvosa (primavera-verão) de 2014 (Coelho et al. 2016). Apesar das observações de que dissolução dos bolsões coincide com as primeiras chuvas do final da estação seca (Vasconcellos-Neto 1980, Pinheiro et al. 2008), em 2014 em ambos os locais os bolsões se dissolveram no mesmo mês do que nos demais anos (setembro), mesmo na ausência de chuvas. E nos meses seguintes, atipicamente secos devido à maior estiagem dos últimos 42 anos, não detectamos qualquer sinal de reagregação (Figura 3). Nossos resultados 
indicam, portanto, que o comportamento de agregação seria regulado ou sincronizado pelo fotoperíodo. Também fornecem evidências de que a pluviosidade poderia modular esse comportamento, porém apenas durante os dias curtos da estação seca, limitando a capacidade de respostas a imprevisibilidades no ciclo de chuvas.

\section{Dinâmicas por espécie}

Em pelo menos seis das oito espécies que analisamos separadamente observamos padrões de agregação e dissolução regulares, com ritmo anual, preditos pelo fotoperíodo. Em algumas destas espécies os padrões de agregação tiveram ligeiras variações entre locais, especialmente nas probabilidades de permanência, porém em cada situação os padrões foram regulares e cíclicos. Nestas seis espécies as hipóteses "mista" ou "fotoperíodo" foram mais plausíveis, sendo que as hipóteses "chuva" ou "constante" tiveram peso de evidência nulo. Para as outras duas espécies (Epityches eupompe e Mcclungia cymo salonina) os resultados não fornecem evidências contundentes para descartar a hipótese de que elas não formam agregações anuais. Na maioria das espécies houve incerteza na seleção da hipótese mais plausível, tanto dentro quanto entre locais. Consideramos que parte dessa incerteza, a qual foi maior do que a observada nos dados com todas as espécies agrupadas, se deva aos menores tamanhos amostrais dos dados das espécies separadas. Consideramos também que, assim como observado para os dados agrupados, as diferenças entre locais reflitam as diferentes extensões temporais dos dados de cada local, e não diferenças ambientais ou entre populações. Apesar da incerteza na seleção entre as hipóteses mista e fotoperíodo, os resultados indicam que o fotoperíodo foi o fator de maior peso para estas seis espécies em ambos os locais, visto que modelos sem esta variável tiveram peso de evidência nulo frente aos dados. Estes resultados são condizentes com a hipótese de que o comportamento de agregação das seis espécies envolve um componente endógeno regulado ou sincronizado pelo fotoperíodo, mas sugerem também um papel modulador, porém limitado, da pluviosidade.

Para as duas espécies que destoaram das demais houve a maior incerteza na seleção de hipóteses, possivelmente pela menor quantidade de dados (capturas e recapturas) obtidos para estas espécies. Mcclungia cymo salonina foi a única das oito espécies para a qual fotoperíodo não foi um bom preditor de dinâmica temporal. Os modelos da hipótese constante tenderam a ser mais plausíveis, corroborando a hipótese de que M. cymo salonina não formaria agregações sazonais (VasconcellosNeto 1980). As espécies que fazem agregações frequentam ambientes de borda e entorno da mata durante a estação chuvosa em busca de suas plantas hospedeiras (Solanaceae) e de parceiros (Vasconcellos-Neto 1980). Durante a estação seca, quando suas plantas hospedeiras não estão disponíveis (Vasconcellos-Neto 1980), formam bolsões nas áreas mais úmidas e sombrias da mata (Pinheiro et al. 2008). Já M. cymo salonina, cuja planta hospedeira (Cestrum sp., Solanaceae) ocorre em ambientes sombreados e é abundante ao longo do ano todo, estaria associada apenas ao ambiente de interior da mata (Vasconcellos-Neto 1980). Por não formar agregações anuais, as variações no número de indivíduos de $M$. cymo salonina que estimamos devem ser mais indicativas de nascimentos e mortes do que de entrada e saída nos locais de captura (Vasconcellos-Neto 1980). Isto explicaria seus picos de abundância no verão (janeiro-fevereiro), estação de baixa concentração de outras espécies nos bolsões, porém de alta atividade reprodutiva (Vasconcellos-Neto 1980). 
Os resultados não foram conclusivos para avaliar a plausibilidade das diferentes hipóteses a respeito da dinâmica anual de Epityches eupompe. Sua dinâmica foi predita por fotoperíodo ou fotoperíodo e chuva no PEPT, porém foi constante ou predita por pluviosidade na RF. Como na RF as estimativas de permanência desta espécie não foram robustas (i.e., intervalos de confiança entre 0 e 1), e no PEPT elas tiveram um padrão anual cíclico, não descartamos a possibilidade que esta espécie forme agregações anuais. Porém, além de apresentar picos de abundância nos períodos de bolsão, $E$. eupompe também apresentou picos no verão-outono, especialmente no PEPT, quando as outras espécies estão dispersas. É possível que estes picos representem ganhos na população por nascimentos seguidos de dispersão, visto que estes picos não foram acompanhados de uma maior probabilidade de permanência. Portanto, também não descartamos a possibilidade de que $E$. eupompe tenha uma história de vida semelhante à de $M$. salonina e não forme agregações anuais. Curiosamente, dentre as espécies analisadas separadamente estas duas são as únicas representantes do anel mimético "philoclea" (Willmott \& Mallet 2004), porém parecem não compartilhar plantas hospedeiras (Drummond \& Brown 1987). Para entendermos a dinâmica populacional de E. eupompe é necessário conhecer a fenologia de suas plantas hospedeiras e saber se ela interrompe ou não sua reprodução nos períodos de estiagem.

\section{Plasticidade e mudanças climáticas}

O quanto os organismo são capazes de se adaptar a alterações nos ciclos ambientais depende de como seus ritmos anuais são regulados (Bradshaw \& Holzapfel 2010) e da natureza e magnitude das alterações. Estudos prévios propuseram que as agregações de Ithomiini seriam respostas reativas diretas à intensidade e ocorrência das chuvas (Vasconcellos-Neto 1980, Pinheiro et al. 2008), o que implica que este comportamento adaptativo à dessecação seria altamente plástico a imprevisibilidades no regime de chuvas. No entanto, a forte relação que encontramos entre as agregações e o fotoperíodo - bem como a resposta limitada ou ausente a chuvas e estiagens fora de época - indicam que as agregações seriam reguladas principalmente por ritmos endógenos sincronizados ao fotoperíodo. Isto implica que o comportamento de agregação teria de moderada a baixa plasticidade diante de alterações no ciclo de chuvas, e que a capacidade de adaptação deste comportamento dependeria do tipo de alteração. Por exemplo, os indivíduos parecem ter alterado seu ímpeto de agregação diante de chuvas durante a estação seca, porém não diante de estiagem durante a estação chuvosa. Mesmo com uma severa estiagem e um atraso de quase três meses na chegada das chuvas (Coelho et al. 2016), os bolsões de Ithomiini se diluíram na primavera de 2014 na mesma época que nos demais anos, e assim permaneceram até o próximo outono.

Essa plasticidade assimétrica, capaz de responder a uma atenuação mas não a um aumento na duração de condições sazonais adversas, seria esperada se um mecanismo endógeno sincronizado com o fotoperíodo alterasse sazonalmente a sensibilidade dos indivíduos à dessecação. Neste modelo de regulação os dias curtos (ou noites longas) com menos de 11,5 horas-luz característicos do outono-inverno (estação seca) sinalizariam um aumento na sensibilidade à dessecação, levando os indivíduos a formar bolsões durante os períodos secos típicos da estação. A ocorrência de chuvas nessa época poderia estimular circulação momentânea de indivíduos fora dos bolsões, porém eles voltariam a se concentrar com o restabelecimento das condições normais de estiagem. $O$ aumento do fotoperíodo na primavera ( $>12$ horas de luz por dia), época que normalmente coincide com a 
chegada das chuvas da estação úmida, sinalizaria a diminuição da sensibilidade à dessecação e marcaria a diluição dos bolsões mesmo na ausência de chuvas. No momento não temos como especular sobre as bases fisiológicas e moleculares deste suposto mecanismo de alteração de sensibilidade à dessecação, visto que os aspectos fisiológicos e metabólicos dos Ithomiini nunca foram estudados. Não obstante, o comportamento dos Ithomiini durante chuvas na estação seca é condizente com uma resposta reativa à pluviosidade - porém esta resposta seria sazonal e desencadeada por um ritmo endógeno sensível ao fotoperíodo. Assim, enquanto a intensidade das agregações parece responder positivamente à severidade da estação seca, o início e principalmente o final da fase de agregação em bolsões são marcados por fotoperíodos críticos (11,5 - 12 horas-luz por dia), fazendo com que a duração dos bolsões seja relativamente rígida. Este modelo de regulação se assemelha a proposição da nossa hipótese "mista" (i.e., sincronização por fotoperíodo e modulação por pluviosidade), no entanto combina respostas reativas (tal como postulado pela hipótese "chuva") com mecanismos endógenos sincronizados pelo fotoperíodo. Além de explicar nossos resultados, este modelo de regulação também poderia explicar por que os Ithomiini aparentemente não formam bolsões em regiões com chuvas bem distribuídas ao longo do ano (Drummond 1976, Freitas 1996, Araújo 2006). Em uma localidade litorânea situada a apenas 60 km a sudoeste da nossa área de estudo (São Vicente) - sujeita ao mesmo regime de fotoperíodo porém com uma estação seca bem menos pronunciada - as assembléias de Ithomiini não formam bolsões (Freitas et al. 1996). Nessa localidade, bem como em toda região litorânea do estado de São Paulo onde os Ithomiini também parecem não se agregar no inverno (A. V. Freitas, com. pess.), a estiagem não seria severa o bastante para induzir as agregações. Seria pertinente avaliar se uma resposta de agregação poderia ser experimentalmente induzida em indivíduos das populações litorâneas.

As rápidas mudanças climáticas globais que vêm sendo documentadas (Ordonez et al., 2016) impõem sérios desafios adaptativos aos ciclos anuais dos organismos (Visser 2008, Helm et al. 2013, Grevstad \& Coop 2015). No leste do Brasil e na região de estudo em particular estão previstas, especialmente a partir da segunda metade do deste século, uma maior incidência de chuvas torrenciais na estação úmida e um aumento na duração da estação seca (Marengo et al. 2013). Estas alterações no regime de chuvas devem impor grandes desafios aos Ithomiini, visto que (i) chuvas torrenciais podem causar mortalidade de adultos (Drummond 1976), (ii) os ovos e larvas parecem ser particularmente sensíveis à dessecação (Vasconcellos-Neto 1980) e (iii) os adultos de populações que formam bolsões parecem ter muito mais potencial para diminuir do que para aumentar o tempo no qual se mantém agregados (ver resultados). Nesse novo cenário de secas prolongadas é provável que ocorram desacoplamentos entre o ritmo dos Ithomiini e os ciclos de pluviosidade, tal como observamos em 2014 quanto os bolsões se dissociaram mesmo em meio a uma estiagem atípica. Nessas situações os adultos, e eventuais ovos e larvas produzidos após a saída dos bolsões, estariam expostos a condições atipicamente secas que podem comprometer sua sobrevivência e capacidade reprodutiva. Além disso, um desacoplamento entre o ritmo dos Ithomiini e a fenologia de suas plantas fontes de néctar e plantas hospedeiras, muitas delas anuais ou bianuais com ciclos dependentes das chuvas (Vasconcellos-Neto 1980), também poderia afetar sua sobrevivência e capacidade reprodutiva (Foster \& Kreitzman 2009). Já foram documentadas reduções no sucesso reprodutivo, na sobrevivência e no tamanho populacional de algumas espécies de aves em virtude do desacoplamento entre seus ritmos biológicos e os ciclos ambientais (Helm et al. 2013), bem como 
extinções de populações de borboletas relacionadas a um aumento na variabilidade dos ciclos de chuvas (McLaughlin et al. 2002). Ao contrário da maioria dos Lepidoptera, nos Ithomiini o adulto é o estágio de vida que enfrenta as condições anuais adversas (estiagem). Isso pode conferir vantagens ao permitir uma rápida exploração de recursos e uma retomada da reprodução logo que a estação favorável inicia. Estas vantagens dependeriam de sincronia entre a dissolução dos bolsões e a chegada das chuvas. No entanto, a capacidade dos Ithomiini adiarem a saída dos bolsões para lidar com um prolongamento da estação seca parece limitada, pelo menos em nível populacional. A variabilidade individual na expressão e plasticidade dos ritmos anuais - ainda desconhecida em Ithomiini - deve ser um dos requisitos chave para adaptação a novos regimes climáticos.

\section{Conclusões}

Os regimes de chuva atípicos que ocorreram durante nosso estudo foram uma oportunidade única para avaliar a plasticidade de um comportamento adaptativo (agregações sazonais) em uma assembleia de borboletas Ithomiini em vida livre, e de testar algumas hipóteses sobre a regulação deste comportamento. Encontramos evidências contundentes de que a dinâmica dos bolsões não é uma simples resposta direta à pluviosidade. As respostas que observamos são condizentes com regulação por ritmo endógeno sincronizado com o fotoperíodo, ritmo este que induziria uma resposta reativa à pluviosidade apenas nos dias curtos da estação seca (inverno). No entanto, o início e principalmente o final da fase de agregação seriam relativamente rígidos por serem marcados por fotoperíodos críticos (11,5 - 12 horas-luz por dia). Esse modelo de regulação implica que o aumento da duração da estação seca previsto para a região de estudo (Marengo et al. 2013) pode resultar em um desacoplamento entre o ritmo anual de Ithomiini e os ciclos de pluviosidade, fazendo com que os adultos abandonem prematuramente os bolsões em plena estiagem. Enquanto estudos em campo podem detectar desacoplamentos e suas eventuais consequências ecológicas, experimentos que manipulem o fotoperíodo e outros fatores - e avaliem respostas comportamentais, fisiológicas e metabólicas - podem testar o modelo de regulação que propomos. De especial interesse seria investigar a natureza e a magnitude de eventuais mudanças fisiológicas e metabólicas ao longo do ciclo anual, quantificando variações intra e interespecíficas e entre populações. O comportamento de agregação em bolsões seria precedido e acompanhado por mudanças fisiológicas características da síndrome de diapausa (Tauber et al. 1986), tal como redução do metabolismo e das estruturas reprodutivas? Como essas eventuais alterações metabólicas reagiriam a chuvas durante a estiagem? Como variam os ritmos de populações que habitam regiões com e sem estiagem sazonal? A integração de experimentos com estudos em campo de longo prazo, abordando múltiplos níveis de organização (moléculas, comportamento, populações, assembleias), é uma via promissora para aprofundar nosso entendimento sobre a evolução e regulação dos ritmos anuais, bem como sobre o as consequências das mudanças climáticas para os organismos e ecossistemas. 


\section{BIBLIOGRAFIA}

Accacio, G. de M. 1998. Borboletas em parques urbanos - estudos na cidade de São Paulo. Dissertação de Mestrado, Universidade de São Paulo.

Araújo, I. 2006. Estrutura e influência da sazonalidade na comunidade de borboletas da subfamília Ithomiinae (Lepidoptera: Nymphalidae) na Estação Científica Ferreira Penna, Melgaço, Pará. Museu Paraense Emílio Goeldi e Universidade Federal do Pará.

Beccaloni, G. 1997. Ecology, natural history and behaviour of the Ithomiinae Butterflies and their mimics in Ecuador (Lepidoptera: Nymphalidae: Ithomiinae). Tropical Lepidoptera 8:130-124.

Bradshaw, W. E., and C. M. Holzapfel. 2007. Evolution of animal photoperiodism. Annual Review of Ecology, Evolution, and Systematics 38:1-25.

Bradshaw, W. E., and C. M. Holzapfel. 2010. Light, time, and the physiology of biotic response to rapid climate change in animals. Annual Review of Physiology 72:147-166.

Brower, A. V. Z., K. R. Willmott, K. L. Silva-Brandão, I. J. Garzón-Orduña, and A. V. L. Freitas. 2014. Phylogenetic relationships of ithomiine butterflies (Lepidoptera: Nymphalidae: Danainae) as implied by combined morphological and molecular data. Systematics and Biodiversity 12:133147.

Brown, K. S. 1972. Maximizing daily butterfly counts. Journal of the Lepidopterists' Society 26:183196.

Brown, K. S. 1984a. Chemical ecology of dehydropyrrolizidine alkaloids in adult Ithomiinae (Lepidoptera: Nymphalidae). Revista Brasileira de Biologia 44:435-460.

Brown, K. S. 1984b. Adult-obtained pyrrolizidine alkaloids defend ithomiine butterflies against a spider predator. Nature 309:707-709.

Brown, K. S. 1992. Borboletas da Serra do Japi: Diversidade, habitats, recursos alimentares e variação temporal. Pages 142-186in L. P. C. Morellato, editor.História Natural da Serra do Japi: ecologia e preservação de uma área florestal no Sudeste do Brasil. Editora Unicamp, Campinas.

Brown, K. S., and W. W. Benson. 1974. Adaptive polymorphism associated with multiple Müllerian mimicry in Heliconius numata (Lepid. Nymph.). Biotropica 6:205-228.

Brown, K. S., and A. V. L. Freitas. 1994. Juvenile stages of Ithomiinae: overview and systematics (Lepidoptera: Nymphalidae). Tropical Lepidoptera 5:9-20.

Brown, K. S., and A. V. L. Freitas. 2000. Diversidade de Lepidoptera em Santa Teresa, Espírito Santo, Brazil. Boletim do Museu de Biologia Mello Leitao: Nova Série 11/12:71-118.

Brown, K. S., and A. V. L. Freitas. 2002. Butterfly communities of urban forest fragments in Campinas, São Paulo, Brazil: structure, instability, environmental correlates, and conservation. Journal of Insect Conservation 6:217-231.

Brown, K. S., and J. Vasconcellos-Neto. 1976. Predation on aposematic ithomiine butterflies by tanagers (Pipraeidea melanonota). Biotropica 8:136-141.

Burnham, K. P., and D. R. Anderson. 2002. Model Selection and Multimodel Inference. second edi. 
Springer, NewYork.

Coelho, C. A. S., D. H. F. Cardoso, and M. A. F. Firpo. 2016. Precipitation diagnostics of an exceptionally dry event in São Paulo, Brazil. Theoretical and Applied Climatology 125:769-784.

Cooch, E. G., and G. White. 2006. Program MARK: a gentle introduction.

Costa, F. A. P. L. 2002. Borboletas Ithomiinae (Lepidoptera, Nymphalidae) da Reserva Biológicas D’Anta (Juiz de Fora, MG). Revista Brasileira de Zoociências 4:143-149.

Danks, H. V. 2006. Key themes in the study of seasonal adaptations in insects II. Life-cycle patterns. Applied Entomology and Zoology 40:1-13.

Danks, H. V. 2007. The elements of seasonal adaptations in insects. The Canadian Entomologist 139:1-44.

Denlinger, D. L., J. M. Giebultowicz, and D. S. Saunders. 2001. Insect Timing: Circadian Rhythmicity to Seasonality. Page (D. L. Denlinger, J. M. Giebultowicz, and D. S. Saunders, Eds.). Elsevier, Amsterdam.

Develey, and P.F., Peres, C.A., 2000. Resource seasonality and the structure of mixed species bird flocks in a coastal Atlantic forest of southeastern Brazil. Journal of Tropical Ecology 16:33-53.

Dislich, R., N. Kisser, and V. R. Pivello. 2002. A invasão de um fragmento florestal em São Paulo (SP) pela palmeira australiana Archontophoenix cunninghamiana H. Wendl. \& Drude. Revista Brasileira de Botânica 25:55-64.

Dislich, R., and V. R. Pivello. 2002. Tree structure and species composition changes in an urban tropical forest fragment (São Paulo, Brazil) during a five-year interval. Boletim de Botânica da Universidade de São Paulo 20:1-11.

Drummond, B. 1976. Comparative ecology and mimetic relationships of ithomiine butterflies in eastern Ecuador. University of Florida.

Drummond, B., Brown, K.S., 1987. Ithomiinae (Lepidoptera: Nymphalidae): summary of known larval food plants. Ann. Missouri Bot. Gard. 74:341-358.

Forrest, J., and A. J. Miller-Rushing. 2010. Toward a synthetic understanding of the role of phenology in ecology and evolution. Philosophical Transactions of the Royal Society B: Biological Sciences 365:3101-3112.

Foster, R.G., Kreitzman, L., 2009. Seasons of life: The biological rhythms that enable living things to thrive and survive. Profile Books, London. 303 pp.

Francini, R., M. Duarte, O. H. H. Mielke, A. Caldas, and A. V. L. Freitas. 2011. Butterflies (Lepidoptera, Papilionoidea and Hesperioidea) of the" Baixada Santista" region, coastal São Paulo, southeastern Brazil. Revista Brasileira de Entomologia 55:55-68.

Freitas, A. V. L. 1996. Population biology of Heterosais edessa (Nymphalidae) and its associated Atlantic forest Ithomiinae community. Journal of the Lepidopterists' Society 50:273-289.

Gaston, K. J., S. L. Chown, P. Calosi, J. Bernardo, D. T. Bilton, A. Clarke, S. Clusella-Trullas, C. K. Ghalambor, M. Konarzewski, L. S. Peck, W. P. Porter, H. O. Pörtner, E. L. Rezende, P. M. Schulte, J. I. Spicer, J. H. Stillman, J. S. Terblanche, and M. van Kleunen. 2009. Macrophysiology: A 
Conceptual Reunification. American Naturalist 174:595-612.

Grevstad, F. S., and L. B. Coop. 2015. The consequences of photoperiodism for organisms in new climates. Ecological Applications 25:1506-1517.

Gwinner, E. 1986. Circannual Rhythms: Endogenous Annual Clocks in the Organization of Seasonal Processes. Springer-Verlag, Berlin.

Gwinner, E., and J. Dittami. 1990. Endogenous reproductive rhythms in a tropical bird. Science (New York, N.Y.) 249:906-8.

Hau, M., M. Wikelski, H. Gwinner, and E. Gwinner. 2004. Timing of reproduction in a Darwin's finch: temporal opportunism under spatial constraints. Oikos 106:489-500.

Hau, M., M. Wikelski, and J. C. Wingfield. 1998. A neotropical forest bird can measure the slight changes in tropical photoperiod. Proceedings of The Royal Society B.

Helm, B., R. Ben-Shlomo, M. J. Sheriff, R. a Hut, R. Foster, B. M. Barnes, and D. Dominoni. 2013. Annual rhythms that underlie phenology: biological time-keeping meets environmental change. Proceedings of the Royal Society B.Biological sciences 280:20130016.

IAG. 2013. Boletim Climatológico Anual da Estação Meteorológica do IAG/USP. São Paulo.

Kelley, D. 2014. oce: Analysis of Oceanographic data.

Kendall, W. 2001. The robust design for capture-recapture studies: analysis using program MARK. Pages 357-360International Wildlife Management Congress.

Laake, J. L. 2016. RMark: An R Interface for Analysis of Capture-Recapture Data with MARK. Alaska Fish. Sci. Cent., NOAA, Natl. Mar. Fish. Serv, Seattle.

Mallet, J., and M. Joron. 1999. Evolution of diversity in warning color and mimicry: Polymorphisms, shifting balance, and speciation. Annual Review of Ecology and Systematics 30:201-233.

Marengo, J. A., M. C. Valverde, and G. O. Obregon. 2013. Observed and projected changes in rainfall extremes in the Metropolitan Area of São Paulo. Climate Research 57:61-72.

McLaughlin, J. F., J. J. Hellmann, C. L. Boggs, and P. R. Ehrlich. 2002. Climate change hastens population extinctions. Proceedings of the National Academy of Sciences of the United States of America 99:6070-6074.

Müller, F. 1879. Ituna and Thyridia: a remarkable case of mimicry in butterflies. Transactions of the Royal Entomological Society of London 1879:xx-xxix.

Nelson, R. J., L. L. Badura, and B. D. Goldman. 1990. Mechanisms of seasonal cycles of behavior. Annual Review of Psychology 41:81-108.

Nelson, R. J., D. L. Denlinger, and D. E. Somers (Eds.). 2010. Photoperiodism: The Biological Calendar. Oxford University Press, Oxford.

Ordonez, A., J. W. Williams, and J. Svenning. 2016. Mapping climatic mechanism likely to favour the emergence of novel communities. Nature Climate Change Letters; 0:1-8.

Paul, M. J., I. Zucker, and W. J. Schwartz. 2008. Tracking the seasons: the internal calendars of 
vertebrates. Philosophical Transactions of the Royal Society B: Biological Sciences:341-361.

Pinheiro, C., Í. Medri, and A. Salcedo. 2008. Why do the ithomiines (Lepidoptera, Nymphalidae) aggregate? Notes on a butterfly pocket in central Brazil. Revista Brasileira de Entomologia 52:610-614.

Pollock, K. H. 1982. A Capture-Recapture Design Robust to Unequal Probability of Capture. Journal of Wildlife Management 46:752-757.

R Core Team. 2016. R: A Language and environment for statistical computing. R Foundation for Statistical Computing, Vienna, Austria.

Sandrini, M. P. 2006. Guia ilustrado da flora arbóreo-arbustiva da reserva da Cidade Universitária "Armando de Salles Oliveira." http://www.ib.usp.br/labtrop/guiamatinha/.

Saunders, D. S. 2011. Unity and diversity in the insect photoperiodic mechanism. Entomological Science 14:235-244.

Silva Dias, M. A. F., J. Dias, L. M. V Carvalho, E. D. Freitas, and P. L. Silva Dias. 2013. Changes in extreme daily rainfall for São Paulo, Brazil. Climatic Change 116:705-722.

Stevenson, T. J., M. E. Visser, W. Arnold, P. Barrett, S. Biello, A. Dawson, D. L. Denlinger, D. Dominoni, F. J. Ebling, S. Elton, N. Evans, H. M. Ferguson, R. G. Foster, M. Hau, D. T. Haydon, D. G. Hazlerigg, P. Heideman, J. G. C. Hopcraft, N. N. Jonsson, N. Kronfeld-Schor, V. Kumar, G. A. Lincoln, R. Macleod, S. A. M. Martin, M. Martinez-Bakker, R. J. Nelson, T. Reed, J. E. Robinson, D. Rock, W. J. Schwartz, I. Steffan-Fewenter, E. Tauber, S. J. Thackeray, C. Umstatter, T. Yoshimura, and B. Helm. 2015. Disrupted seasonal biology impacts health, food security and ecosystems. Proceedings of the Royal Society B: Biological Sciences 282:20151453.

Tauber, M. J., C. A. Tauber, and S. Masaki. 1986. Seasonal adaptations of insects. Oxford University Press.

Uehara-Prado, M., and A. V. L. Freitas. 2009. The effect of rainforest fragmentation on species diversity and mimicry ring composition of ithomiine butterflies. Insect Conservation and Diversity 2:23-28.

Vasconcellos-Neto, J. 1980. Dinamica de populações de Ithomiinae (Lep., Nymphalidae) em Sumaré SP. Dissertação de Mestrado, Universidade Estadual de Campinas.

Visser, M. E. M. E. 2008. Keeping up with a warming world: assessing the rate of adaptation to climate change. Proceedings of the Royal Society B: Biological Sciences 275:649-659.

Wikelski, M., M. Hau, and J. C. Wingfield. 2000. Seasonality of reproduction in a neotropical rain forest bird. Ecology 81:2458-2472.

Williams, B. K., J. D. Nichols, and M. J. Conroy. 2002. Analysis and Management of Animal Populations. B. K. Williams, J. D. Nichols, and M. J. Conroy (Eds.). Academic Press, San Diego.

Willmott, K.R., Mallet, J.L.B., 2004. Correlations between adult mimicry and larval host plants in ithomiine butterflies. Proceedings of the Royal Society B: Biological Sciences 271:S266-S269.

Wingfield, J. C. 2012. Regulatory mechanisms that underlie phenology, behavior, and coping with environmental perturbations: an alternative look at biodiversity. The Auk 129:1-7. 
Wingfield, J. C., J. P. Kelley, and F. Angelier. 2011a. What are extreme environmental conditions and how do organisms cope with them? Current Zoology 57:363-374.

Wingfield, J. C., J. Patrick Kelley, F. Angelier, O. Chastel, F. Lei, S. E. Lynn, B. Miner, J. E. Davis, D. Li, and G. Wang. 2011b. Organism-environment interactions in a changing world: A mechanistic approach. Journal of Ornithology 152.

Wolda, H. 1988. Insect Seasonality: Why? Annual Review of Ecology and Systematics 19:1-18. 


\section{Apêndices}

Apêndice 1A. Valores de AIC e métricas relacionadas para os modelos de marcação-recaptura com todas as espécies agrupadas capturadas no Parque Esporte para Todos da Universidade de São Paulo.

\begin{tabular}{|c|c|c|c|c|c|c|}
\hline Hipótese & ID & model & npar & AICc & DeltaAICc & WAIC \\
\hline Mista & 26 & $\begin{array}{l}\text { S( 1)Gamma"( light + lightdiff + rain)Gamma'( light + lightdiff + } \\
\text { rain)p( effort)c()fO( session) }\end{array}$ & 51 & $-91443,5$ & 0 & 1 \\
\hline Fotoperíodo & 10 & $\mathrm{~S}(\sim 1) G a m m a "(\sim$ light + lightdiff)Gamma'( 1)p( effort)c()fO( session) & 47 & $-91307,5$ & 136,0207 & 0 \\
\hline Mista & 19 & $\begin{array}{l}\text { S( 1)Gamma"( }(\sim \text { light }+ \\
\text { lightdiff)Gamma'( } \sim \text { rain)p( effort)c()fO( } \text { session) }\end{array}$ & 48 & $-91305,5$ & 138,0319 & 0 \\
\hline Mista & 27 & $\begin{array}{l}\mathrm{S}(\sim \text { rain)Gamma"( }) \text { light + lightdiff + rain)Gamma'( } \text { light + lightdiff + } \\
\text { rain)p( } \sim 1) \mathrm{c}() \mathrm{fO}(\sim \text { session })\end{array}$ & 51 & $-91279,3$ & 164,147 & 0 \\
\hline Mista & 25 & $\begin{array}{l}\mathrm{S}(\sim 1) \text { Gamma"( } \sim \text { light + lightdiff + rain)Gamma'( } \text { light + lightdiff + } \\
\text { rain)p( } \sim 1) c() f 0(\sim \text { session })\end{array}$ & 50 & $-91180,7$ & 262,8201 & 0 \\
\hline Fotoperíodo & 9 & $\mathrm{~S}(\sim 1) G a m m a "(\sim$ light + lightdiff)Gamma'( 1)p( 1)c()f0( session) & 46 & $-91029,6$ & 413,9257 & 0 \\
\hline Mista & 17 & $\mathrm{~S}(\sim 1) G a m m a "(\sim$ light + lightdiff)Gamma'( rain)p( 1)c()fO( session) & 47 & $-91027,6$ & 415,9367 & 0 \\
\hline Fotoperíodo & 12 & $\begin{array}{l}\text { S( 1)Gamma"( light + lightdiff)Gamma'( light + } \\
\text { lightdiff)p( } \sim 1) c() f 0(\sim \text { session) }\end{array}$ & 48 & $-91025,5$ & 417,9479 & 0 \\
\hline Mista & 28 & $\begin{array}{l}\mathrm{S}(\sim \text { rain }) \text { Gamma" }(\sim \text { light + lightdiff + rain)Gamma'( light + lightdiff + } \\
\text { rain)p( } \text { effort)c()fO( } \text { session })\end{array}$ & 52 & $-90995,2$ & 448,3082 & 0 \\
\hline Fotoperíodo & 13 & $\begin{array}{l}\text { S( } \text { rain)Gamma"( } \text { light }+ \\
\text { lightdiff)Gamma'( } 1) p(\sim \text { effort)c()fO( session) }\end{array}$ & 48 & -90766 & 677,4429 & 0 \\
\hline Mista & 23 & $\begin{array}{l}\text { S( } \sim \text { rain)Gamma"( }(\text { light }+ \\
\text { lightdiff)Gamma'( } \sim \text { rain)p( }(\sim \text { effort }) c() f 0(\sim \text { session })\end{array}$ & 49 & -90762 & 681,5044 & 0 \\
\hline Chuva & 8 & $\mathrm{~S}(\sim$ rain)Gamma"( rain)Gamma'( rain)p( effort)c()fO( session) & 48 & $-90688,6$ & 754,8949 & 0 \\
\hline Chuva & 6 & $\mathrm{~S}\left(\sim\right.$ rain)Gamma"( ${ }^{\prime}$ rain)Gamma'( 1)p( effort)c()fO( session) & 47 & $-90683,7$ & 759,7677 & 0 \\
\hline Mista & 24 & $\begin{array}{l}\text { S( } \text { rain)Gamma"( }(\sim \text { rain }) \text { Gamma'( } \text { light + } \\
\text { lightdiff)p( }(\sim \text { effort }) c() f 0(\sim \text { session })\end{array}$ & 49 & $-90652,5$ & 790,9754 & 0 \\
\hline Mista & 20 & 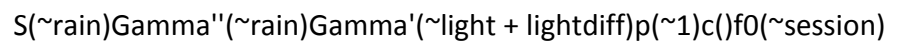 & 48 & $-90543,8$ & 899,7229 & 0 \\
\hline Fotoperíodo & 14 & $\begin{array}{l}\text { S( } \sim \text { rain)Gamma"( }(\sim \text { light + lightdiff)Gamma'( light + } \\
\text { lightdiff }) p(\sim 1) c() f O(\sim \text { session })\end{array}$ & 49 & $-90506,9$ & 936,5664 & 0 \\
\hline Mista & 21 & $\mathrm{~S}(\sim$ rain)Gamma" $(\sim$ light + lightdiff)Gamma'( rain)p( 1)c()fO( session) & 48 & $-90441,4$ & 1002,104 & 0 \\
\hline Fotoperíodo & 16 & $\begin{array}{l}\text { S( } \sim \text { rain)Gamma"( } \sim \text { light + lightdiff)Gamma'( light + } \\
\text { lightdiff)p( } \sim \text { effort)c()fO( } \sim \text { session })\end{array}$ & 50 & $-90302,3$ & 1141,22 & 0 \\
\hline Constante & 30 & $\mathrm{~S}(\sim$ rain)Gamma"( 1$)$ Gamma'( 1)p( 1)c()f0( session) & 45 & $-90231,2$ & 1212,292 & 0 \\
\hline Fotoperíodo & 15 & $\begin{array}{l}\text { S( 1)Gamma"( light + lightdiff)Gamma'( light + } \\
\text { lightdiff)p( }(\sim \text { effort }) c() f 0(\sim \text { session) }\end{array}$ & 49 & $-90220,5$ & 1223,004 & 0 \\
\hline Mista & 22 & $\begin{array}{l}\text { S( 1)Gamma"( } \sim \text { rain)Gamma'( light + } \\
\text { lightdiff)p( } \text { ( effort)c()fO( session) }\end{array}$ & 48 & $-89520,5$ & 1923,036 & 0 \\
\hline Mista & 18 & $\mathrm{~S}(\sim 1)$ Gamma"( rain)Gamma'( light + lightdiff)p( $\sim 1) \mathrm{c}() \mathrm{fO}(\sim$ session $)$ & 47 & $-89396,5$ & 2046,943 & 0 \\
\hline Fotoperíodo & 11 & $\mathrm{~S}(\sim$ rain)Gamma"( light + lightdiff)Gamma'( 1$) p(\sim 1) \mathrm{c}() \mathrm{fO}(\sim$ session $)$ & 47 & $-89333,9$ & 2109,608 & 0 \\
\hline Chuva & 5 & $\mathrm{~S}(\sim 1)$ Gamma"( ${ }^{\prime}$ rain)Gamma'( rain)p( effort)c()fO( $\sim$ session) & 47 & -87986 & 3457,495 & 0 \\
\hline Chuva & 2 & $\mathrm{~S}(\sim 1)$ Gamma"( rain)Gamma'( 1)p( effort)c()f0( session) & 46 & $-87983,1$ & 3460,402 & 0 \\
\hline Constante & 32 & $\mathrm{~S}(\sim$ rain)Gamma"( 1$)$ Gamma'( 1)p( effort)c()f0( session) & 46 & $-87894,1$ & 3549,393 & 0 \\
\hline Chuva & 3 & $\mathrm{~S}(\sim$ rain)Gamma"( rain)Gamma'( 1)p( 1)c()fO( session) & 46 & $-87791,9$ & 3651,567 & 0 \\
\hline Chuva & 7 & $\mathrm{~S}(\sim$ rain)Gamma"( rain)Gamma'( rain)p( 1)c()fO( session) & 47 & $-87789,9$ & 3653,568 & 0 \\
\hline Constante & 31 & $\mathrm{~S}(\sim 1)$ Gamma"( 1)Gamma'( 1)p( effort)c()fo( session) & 45 & $-87542,3$ & 3901,206 & 0 \\
\hline Chuva & 1 & $\mathrm{~S}(\sim 1) G a m m a "(\sim$ rain)Gamma'( 1)p( 1)c()f0( session) & 45 & $-86599,9$ & 4843,543 & 0 \\
\hline Chuva & 4 & S( 1)Gamma"( rain)Gamma'( rain)p( 1$) \mathrm{c}() \mathrm{fO}(\sim$ session $)$ & 46 & $-86479,2$ & 4964,333 & 0 \\
\hline Constante & 29 & $\mathrm{~S}(\sim 1)$ Gamma" $(\sim 1)$ Gamma'( 1)p( 1)c()fO( session) & 44 & $-86184,7$ & 5258,785 & 0 \\
\hline
\end{tabular}


Apêndice 1B. Valores de AIC e métricas relacionadas para os modelos de marcação-recaptura com todas as espécies agrupadas capturadas Reserva Florestal da Universidade de São Paulo.

\begin{tabular}{|c|c|c|c|c|c|c|}
\hline Hipótese & ID & model & npar & AlCc & DeltaAICc & wAIC \\
\hline Fotoperíodo & 14 & $\begin{array}{l}\text { S( } \sim \text { rain)Gamma"( light + lightdiff)Gamma'( light + } \\
\text { lightdiff)p( } \sim 1) c() f 0(\sim \text { session })\end{array}$ & 36 & $-23596,7$ & 0 & 1 \\
\hline Mlsta & 27 & $\begin{array}{l}\mathrm{S}(\sim \text { rain }) \text { Gamma" }(\sim \text { light + lightdiff + rain)Gamma'( light + lightdiff + } \\
\text { rain }) p(\sim 1) c() f 0(\sim \text { session })\end{array}$ & 38 & $-23551,3$ & 45,36491 & 0 \\
\hline Mista & 28 & $\begin{array}{l}\mathrm{S}(\sim \text { rain }) \text { Gamma"( } \sim \text { light + lightdiff + rain)Gamma'( light + lightdiff + } \\
\text { rain)p( } \sim \text { effort }) c() f 0(\sim \text { session })\end{array}$ & 39 & $-23543,1$ & 53,51704 & 0 \\
\hline Fotoperíodo & 16 & $\begin{array}{l}\text { S( rain)Gamma"( light + lightdiff)Gamma'( light + } \\
\text { lightdiff)p( } \sim \text { effort)c()fO( } \sim \text { session })\end{array}$ & 37 & $-23513,8$ & 82,85757 & 0 \\
\hline Fotoperíodo & 10 & S( 1)Gamma"( light + lightdiff)Gamma'( 1)p( effort)c()fo( session) & 34 & $-23512,5$ & 84,14521 & 0 \\
\hline Mista & 19 & $\mathrm{~S}(\sim 1) G a m m a "\left(\sim\right.$ light + lightdiff)Gamma'( ${ }^{\prime}$ rain)p( effort)c()fO( session) & 35 & $-23510,5$ & 86,17221 & 0 \\
\hline Fotoperíodo & 15 & $\begin{array}{l}\text { S( 1)Gamma"( ( light + lightdiff)Gamma'( light + } \\
\text { lightdiff)p( } \text { effort)c()fO( } \text { session) }\end{array}$ & 36 & $-23508,5$ & 88,2 & 0 \\
\hline Mista & 26 & $\begin{array}{l}\text { S( } \sim 1) \text { Gamma"( }(\text { light + lightdiff + rain)Gamma'( light + lightdiff + } \\
\text { rain)p( } \text { effort)c()fO( } \sim \text { session })\end{array}$ & 38 & $-23507,7$ & 88,96791 & 0 \\
\hline Fotoperíodo & 9 & $\mathrm{~S}(\sim 1) G a m m a "(\sim$ light + lightdiff)Gamma'( 1)p( 1)c()fo( session) & 33 & $-23474,3$ & 122,375 & 0 \\
\hline Mista & 17 & $\mathrm{~S}(\sim 1)$ Gamma"( light + lightdiff)Gamma'( ${ }^{\prime}$ rain)p( 1$) c() f 0(\sim$ session $)$ & 34 & $-23472,3$ & 124,4012 & 0 \\
\hline Fotoperíodo & 12 & $\begin{array}{l}\text { S( 1)Gamma"( ( light + lightdiff)Gamma'( light + } \\
\text { lightdiff)p( } \sim 1) c() f 0(\sim \text { session })\end{array}$ & 35 & $-23470,2$ & 126,4282 & 0 \\
\hline Mista & 25 & $\begin{array}{l}\mathrm{S}(\sim 1) \text { Gamma"( } \sim \text { light + lightdiff + rain)Gamma'( light + lightdiff + } \\
\text { rain)p( }(\sim) \mathrm{c}() \mathrm{fO}(\sim \text { session })\end{array}$ & 37 & $-23469,5$ & 127,2106 & 0 \\
\hline Mista & 24 & $\begin{array}{l}\text { S( } \text { rain)Gamma"( } \sim \text { rain)Gamma'( light + } \\
\text { lightdiff)p( } \text { effort)c()fO( } \text { session) }\end{array}$ & 36 & $-23430,5$ & 166,123 & 0 \\
\hline Chuva & 2 & $\mathrm{~S}(\sim 1)$ Gamma"( rain)Gamma'( 1)p( effort)c()fo( session) & 33 & $-23426,9$ & 169,711 & 0 \\
\hline Chuva & 5 & 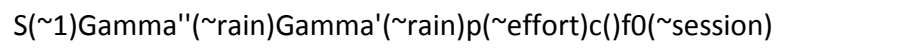 & 34 & $-23424,9$ & 171,7372 & 0 \\
\hline Mista & 22 & S( 1)Gamma"( rain)Gamma'( light + lightdiff)p( effort)c()fO( session) & 35 & $-23422,9$ & 173,7642 & 0 \\
\hline Chuva & 6 & $\mathrm{~S}(\sim$ rain)Gamma"( rain)Gamma'( 1)p( effort)c()fO( session) & 34 & $-23406,6$ & 190,0482 & 0 \\
\hline Chuva & 8 & 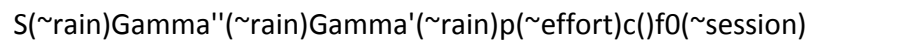 & 35 & $-23404,6$ & 192,0752 & 0 \\
\hline Constante & 32 & $\mathrm{~S}(\sim$ rain)Gamma"( 1)Gamma'( 1)p( effort)c()fO( session) & 33 & $-23402,3$ & 194,401 & 0 \\
\hline Constante & 31 & S( 1)Gamma"( 1)Gamma'( 1)p( effort)c()fO( session) & 32 & $-23395,3$ & 201,3885 & 0 \\
\hline Chuva & 1 & $\mathrm{~S}(\sim 1) G a m m a "(\sim$ rain)Gamma'( 1)p( 1)c()fo( session) & 32 & $-23393,2$ & 203,4615 & 0 \\
\hline Chuva & 4 & $\mathrm{~S}(\sim 1)$ Gamma"( $\sim$ rain)Gamma'( rain)p( 1)c()fO( session) & 33 & $-23391,2$ & 205,487 & 0 \\
\hline Mista & 18 & $\mathrm{~S}(\sim 1)$ Gamma"( rain)Gamma'( light + lightdiff)p( 1)c()f0( session) & 34 & $-23389,2$ & 207,4982 & 0 \\
\hline Chuva & 3 & $S(\sim$ rain)Gamma"( rain)Gamma'( 1)p( 1)c()fo( session) & 33 & $-23373,1$ & 223,519 & 0 \\
\hline Chuva & 7 & 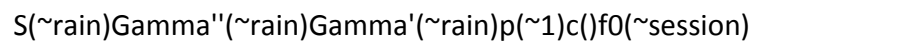 & 34 & $-23371,1$ & 225,5452 & 0 \\
\hline Mista & 20 & 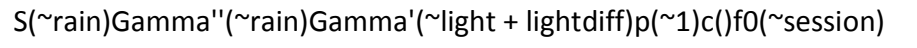 & 35 & $-23369,1$ & 227,5722 & 0 \\
\hline Constante & 29 & $\mathrm{~S}(\sim 1)$ Gamma"'( 1)Gamma'( 1)p( 1)c()fO( session) & 31 & $-23360,5$ & 236,1459 & 0 \\
\hline Fotoperíodo & 11 & $\mathrm{~S}(\sim$ rain)Gamma"( light + lightdiff)Gamma'( 1$) \mathrm{p}(\sim 1) \mathrm{c}() \mathrm{fO}(\sim$ session $)$ & 34 & $-22716,3$ & 880,3642 & 0 \\
\hline Constante & 30 & $\mathrm{~S}(\sim$ rain)Gamma"( 1$)$ Gamma'( 1)p( 1)c()fo( session) & 32 & $-22575,5$ & 1021,129 & 0 \\
\hline Fotoperíodo & 13 & $\mathrm{~S}(\sim$ rain)Gamma"( light + lightdiff)Gamma'( 1)p( effort)c()fO( session) & \multicolumn{2}{|c|}{ não convergiu } & & \\
\hline Mista & 21 & $\mathrm{~S}(\sim$ rain)Gamma"( light + lightdiff)Gamma'( rain)p( 1)c()fO( session) & \multicolumn{2}{|c|}{ não convergiu } & & \\
\hline Mista & 23 & 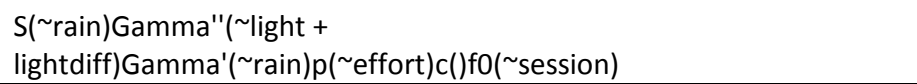 & \multicolumn{2}{|c|}{ não convergiu } & & \\
\hline
\end{tabular}




\title{
CAPÍTULO 2 - DINÂMICA POPULACIONAL COMPARADA DE BORBOLETAS MIMÉTICAS
}

\author{
COMPARATIVE POPULATION DYNAMICS OF MIMETIC BUTTERFLIES
}

\section{RESUMO}

Segundo a teoria do mimetismo Mülleriano, espécies impalatáveis que coexistem convergiriam na aparência por que teriam um benefício mútuo ao compartilhar sinal de alerta em comum. Ter vários indivíduos compartilhando o mesmo sinal de alerta reduziria a mortalidade per capita das espécies co-miméticas devido a um efeito de diluição, e também por que os predadores associaram mais fortemente o sinal à impalatabilidade. Além de convergir na aparência, espécies miméticas também parecem convergir em características comportamentais, tal como no uso de vertical e horizontal do espaço. É possível que comiméticos também tendam a convergir demograficamente, tendo dinâmicas populacionais correlacionadas, mas as evidências empíricas para isso são limitadas e contraditórias. Neste estudo fizemos a primeira comparação quantitativa da dinâmica populacional de borboletas miméticas baseada em estimativas de parâmetros populacionais com detecção imperfeita. A partir de um estudo de captura-marcação-recaptura de borboletas da tribo Ithomiini com 22 meses de duração, testamos as hipóteses de que 1) espécies co-miméticas ou 2) espécies mais próximas filogeneticamente teriam suas dinâmicas populacionais mais correlacionadas do que espécies agrupadas ao acaso. Também testamos a hipótese de que 3) a dinâmica populacional de todas as espécies seria semelhante, independente de anel mimético ou proximidade filogenética. Nossos resultados indicam que os parâmetros demográficos das espécies de um mesmo anel mimético ou mais próximas filogeneticamente não tenderam a ser mais correlacionadas entre si, e que as espécies, anéis miméticos e subtribos estudadas tiveram suas dinâmicas temporais mais correlacionados do que seria esperado por acaso. Requerimentos fisiológicos estreitos conservados no nível da tribo Ithomiini poderiam explicar as dinâmicas populacionais sincronizadas observadas nas espécies estudadas, dinâmica esta que seria resultante da pressão seletiva de fatores climáticos, notadamente a sazonalidade no regime de chuvas. Prevemos que os efeitos de requerimentos fisiológicos sobre a dinâmica populacional devem ser dependentes da distribuição anual das chuvas de uma dada região. Em localidades com chuvas bem distribuídas ao longo do ano, os efeitos do mimetismo poderiam se sobressair aos de requerimentos fisiológicos, promovendo convergência temporal entre espécies co-miméticas. Estudos demográficos de longo prazo, com tamanhos amostrais suficientes para que se obtenham estimativas populacionais, e que comparem regiões com regimes de chuvas contrastantes podem avançar nosso conhecimento sobre os fatores que influem na dinâmica populacional de borboletas Ithomiini.

Palavras-chave: marcação-captura-recaptura, modelos demográficos, regressão múltipla de matrizes, convergência mimética, estimativas de abundância. 


\begin{abstract}
According to Müllerian mimicry theory, coexisting unpalatable species that share a common warning signal would gain mutual benefits. When many individuals share a common warning signal there is a decrease in the per capita mortality rate of co-mimetic species due to a dilution effect and also because predators associate more strongly the warning signal with unpalatability. Besides converge in appearance, co-mimetic species may also converge in behavioral traits such as vertical and horizontal space use. It is possible that co-mimics also converge in their demography, resulting in correlated population dynamics, but empirical evidence is limited and controversial. In this study we compared for the first time the populational dynamics of mimetic butterflies based on estimates of population parameters that account for imperfect detection. Through a 22 month mark-recapture study of mimetic butterflies of the tribe Ithomiini, we tested the following hypothesis: 1) co-mimetic species or 2) phylogenetically closer species have their population dynamics more correlated than groups of species randomly assembled. We also tested the hypothesis that 3) population dynamics of all studied species is similar regardless of mimicry or phylogenetic relationships among them. Our results indicate that the demographic parameters of co-mimetic or phyllogenetically closer species are not more correlated than expected by chance and that species, mimicry rings and subtribes were more correlated than expected by chance. Narrow physiological requirements conserved at tribe level could explain the synchronized population dynamics we found, since dynamics appears to be controlled by rainfall seasonality. We predict that the effects of climate requirements on neotropical butterflies population dynamics would be dependent on the distribution of annual rainfall of a given region. In regions with rainfall well distributed throughout the year, mimicry effects could outweigh physiological requirements and promote temporal correlation among co-mimic species. Our understanding of the factors that affect population dynamics of neotropical butterflies would benefit from long term demographic studies, based on sample sizes large enough to estimate population parameters, and also from studies that compare regions with contrasting seasonality in rainfall.
\end{abstract}

Keywords: capture-mark-recapture, demographic models, matrix multiple regression, convergence, abundance estimates. 


\section{INTRODUÇÃO}

A coexistência de duas ou mais espécies impalatáveis ou venenosas de aparência similar em uma mesma localidade é tradicionalmente explicada pela teoria do mimetismo Mülleriano (revisão em Ruxton et al. 2004). O argumento é que espécies que possuem defesas químicas e que convergem para uma aparência comum dividiriam os custos de condicionar potenciais predadores, sendo então favorecidas pela seleção natural (Müller 1879). O mimetismo Mülleriano, portanto, poderia ser considerado um exemplo de coevolução no qual a convergência para uma aparência (sinal de alerta) comum seria benéfica para todas as espécies miméticas envolvidas (Ruxton et al. 2004). Conjuntos de espécies que compartilham uma mesma morfologia são denominados anéis miméticos.

Previsões teóricas, experimentos e simulações indicam que relações miméticas devem ser fortemente (porém não exclusivamente) dependentes de dois fatores: densidade e grau de semelhança entre as espécies miméticas (Joron \& Mallet 1998, MacDougall \& Dawkins 1998, Mallet 1999, Kapan 2001, Rowland et al. 2007). O benefício que uma espécie adquire ao participar de uma relação mimética Mülleriana é positivamente dependente da densidade total de indivíduos que compartilham do sinal de alerta (Müller 1879, Joron \& Mallet 1998). Quanto maior a densidade de indivíduos de um mesmo anel mimético, menor a mortalidade per capita das populações pertencentes a este anel (Rowland et al. 2007). Paralelamente, quanto mais semelhantes forem os miméticos Müllerianos, mais eficiente seria condicionamento dos predadores (Ruxton et al. 2004). De fato, há evidências de que espécies miméticas, especialmente borboletas neotropicais, convergem não apenas na aparência, mas também em múltiplas características ecológicas e comportamentais, tal como no uso horizontal e vertical do espaço. Frequentemente são mais semelhantes entre si do que com as espécies filogeneticamente mais próximas (Brown Jr. \& Benson 1974, Mallet \& Gilbert 1995, Beccaloni 1997b, Srygley 1999, DeVries et al. 1999, Elias et al. 2008), de modo, é comum que as espécies de um mesmo anel mimético não sejam as espécies mais aparentadas da assembleia.

Foi sugerido que espécies de um mesmo anel mimético devem ter dinâmicas populacionais semelhantes (Vasconcellos-Neto 1980). Segundo essa hipótese, espécies miméticas Müllerianas poderiam convergir não apenas na aparência e na ecologia, mas também na demografia Seria mais seguro estar entre muitos outros que compartilham seu sinal de alerta do que estar só. No entanto, ao contrário das fortes evidências de convergência morfológica e comportamental, evidências a respeito de convergência demográfica entre miméticos Müllerianos são limitadas e contraditórias. Dois estudos (Brown Jr. \& Benson 1974, DeVries et al. 1999) apoiam a hipótese de convergência demográfica entre espécies co-miméticas, visto que encontraram associação temporal entre espécies de um mesmo anel mimético e divergência temporal entre anéis diferentes. Outro estudo, porém, reportou que a dinâmica temporal das espécies de Ithomiini variou de forma semelhante, independente de anel mimético, e de acordo com fatores ambientais (Drummond 1976). Esse último cenário resultaria do fato de que as espécies da tribo, independente do anel mimético ou da subtribo ao qual pertencem, compartilham requerimentos fisiológicos similares (Brown Jr. \& Benson 1974) tal como sensibilidade à alta luminosidade, a altas temperaturas e à dessecação (Drummond 1976, Vasconcellos-Neto 1980, Pinheiro et al. 2008). 
Para abordar essa hipótese de correlação entre dinâmicas populacionais de miméticos Müllerianos Andrade et al. (ver Anexo I ao final da tese) estão desenvolvendo um modelo matemático inspirado no comportamento sazonal de agregação ("bolsões") de borboletas da tribo Ithomiini (ver Capítulo 1), o grupo de borboletas miméticas mais abundante da América do Sul (Beccaloni 1997a), considerado modelo mimético para outros grupos de Lepidoptera (Brown Jr. \& Benson 1974). Tomando como base o modelo de Hadler (1982), o modelo busca entender se duas populações de miméticos Müllerianos sujeitas a um mesmo predador tenderiam a sincronizar suas dinâmicas populacionais em um cenário de deslocamentos sazonais entre uma área reprodutiva e uma área de não reprodução (bolsão). Os resultados mostram que o par de miméticos, o qual inicia com períodos de deslocamento ótimos diferentes, só tende a sincronizar suas dinâmicas populacionais na ocorrência de predação. Porém, taxas moderadas de predação são suficientes para induzir sincronização. Em concordância com as previsões de modelos clássicos de mimetismo Mülleriano (Müller 1879), as populações são capazes de persistir sob taxas mais elevadas de predação quando coexistem do que quando estão sós. Para detalhes sobre a estrutura, parâmetros e resultados do modelo ver Anexo I.

Para testar de maneira mais robusta a hipótese de convergência demográfica entre espécies co-miméticas são necessários dados empíricos mais consistentes do que os disponíveis. Além de resultados contraditórios, os dados disponíveis compartilham pelo menos três das seguintes limitações metodológicas: amostragem temporal restrita ou irregular, uso de técnicas de captura sub ótimas para os grupos estudados, análises baseadas apenas em inspeção visual de gráficos, além de número de capturas insuficientes estimar parâmetros populacionais. Ainda, estes estudos avaliaram as dinâmicas populacionais usando exclusivamente número bruto de capturas, número este que pode não refletir abundância por ser afetado por variações na probabilidade de captura (Williams et al. 2002). Número bruto de capturas nada diz sobre os processos demográficos responsáveis pelas variações temporais na abundância de uma espécie, tal como sobrevivência e recrutamento.

Neste estudo avaliamos a influência da semelhança morfológica e do parentesco filogenético entre espécies sobre a dinâmica populacional de borboletas da tribo Ithomiini. Com base em estimativas populacionais oriundas de um estudo sistemático de captura-marcação-recaptura, testamos três hipóteses. A hipótese de correlação mimética (1) postula que as dinâmicas populacionais de espécies miméticas, ou seja, que apresentam aparência (mas não necessariamente ancestralidade) comum, tendem a convergir. Logo, espécies de um mesmo anel mimético apresentariam dinâmicas populacionais mais correlacionadas entre si do que espécies agrupadas ao acaso. A hipótese de correlação filogenética (2) postula que espécies mais próximas filogeneticamente tendem a conservar suas dinâmicas populacionais. Logo, subgrupos de espécies mais aparentadas - que, no nosso sistema, tendem a não pertencer a um mesmo anel mimético - apresentariam dinâmicas populacionais mais correlacionadas entre si do que subgrupos de espécies reunidas ao acaso. A hipótese de correlação geral (3) postula que devido a restrições fisiológicas conservadas em toda a tribo, a dinâmica temporal de todas as espécies deve ser mais correlacionada entre si do que seria esperado por acaso, independente de anel mimético ou de parentesco filogenético. 


\section{MATERIAL E MÉTODOS}

\section{Área de estudo}

Realizamos o estudo de marcação-captura-recaptura no Parque Esporte Para Todos (PEPT), localizado na cidade de São Paulo (Figura 1). O PEPT, com aproximadamente 4,5 ha, é um dos remanescentes de vegetação nativa da Cidade Universitária da Universidade de São Paulo, com um sub-bosque dominado por espécies nativas e um dossel dominado por Eucalyptus sp. com mais de $20 \mathrm{~m}$ de altura. Sua fisionomia florestal confere ao seu sub-bosque maior sombreamento, umidade e menor temperatura do que o ambiente de construções e pavimento do entorno, favorecendo assim a existência de borboletas Ithomiini (Drummond 1976, Vasconcellos-Neto 1976, Pinheiro et al., 2008). Para mais detalhes sobre a descrição da área ver Capítulo 1. O clima da região é temperado úmido com inverno seco e verão quente (Cwa segundo classificação Köppen), com médias anuais históricas (1933-2013) de temperatura e pluviosidade de $18,6^{\circ} \mathrm{C}$ e $1419 \mathrm{~mm}$, respectivamente (IAG 2013).

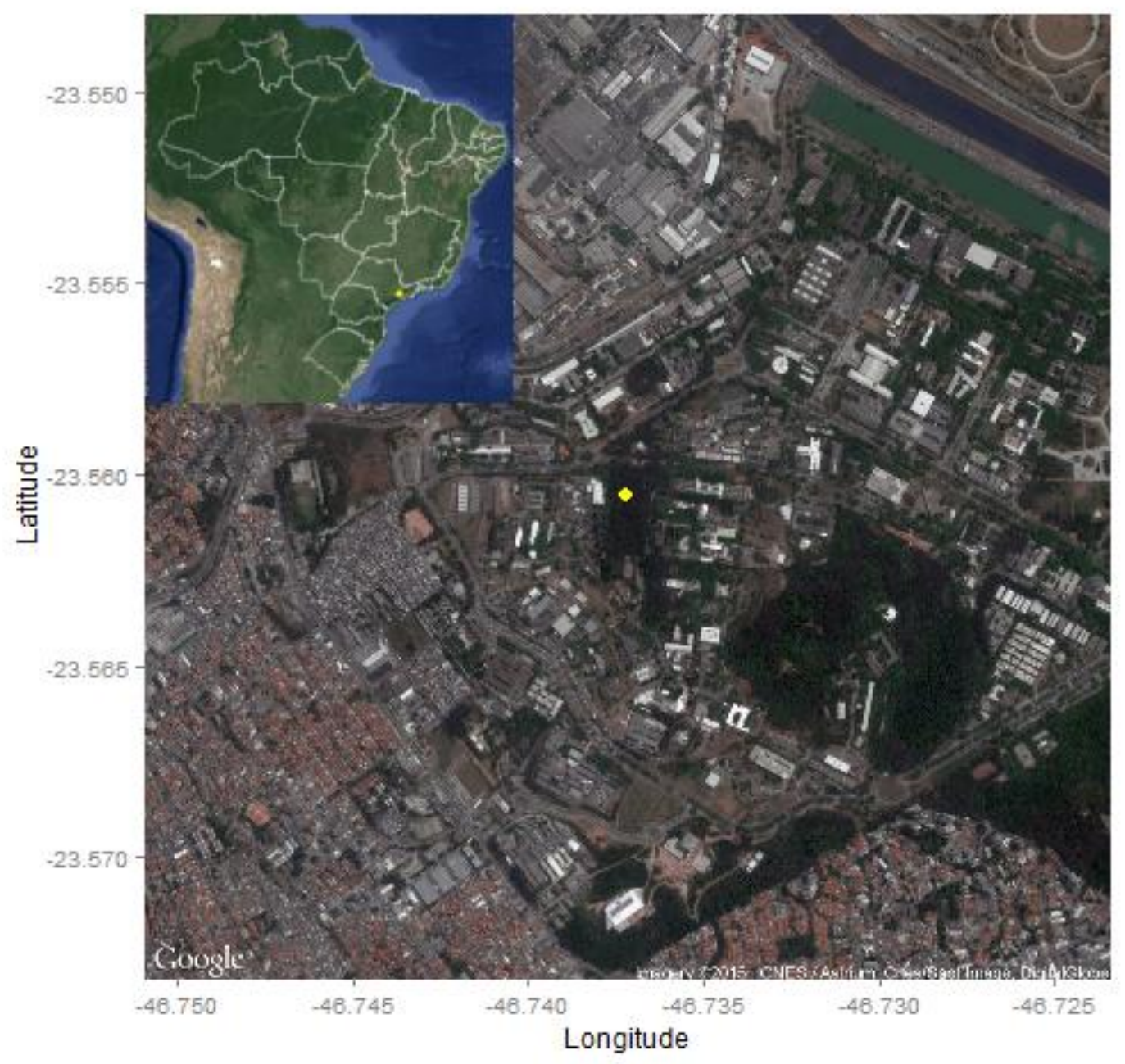

Figura 1. Localização da área de estudo (ponto amarelo) no Brasil e no campus da Universidade de São Paulo. 


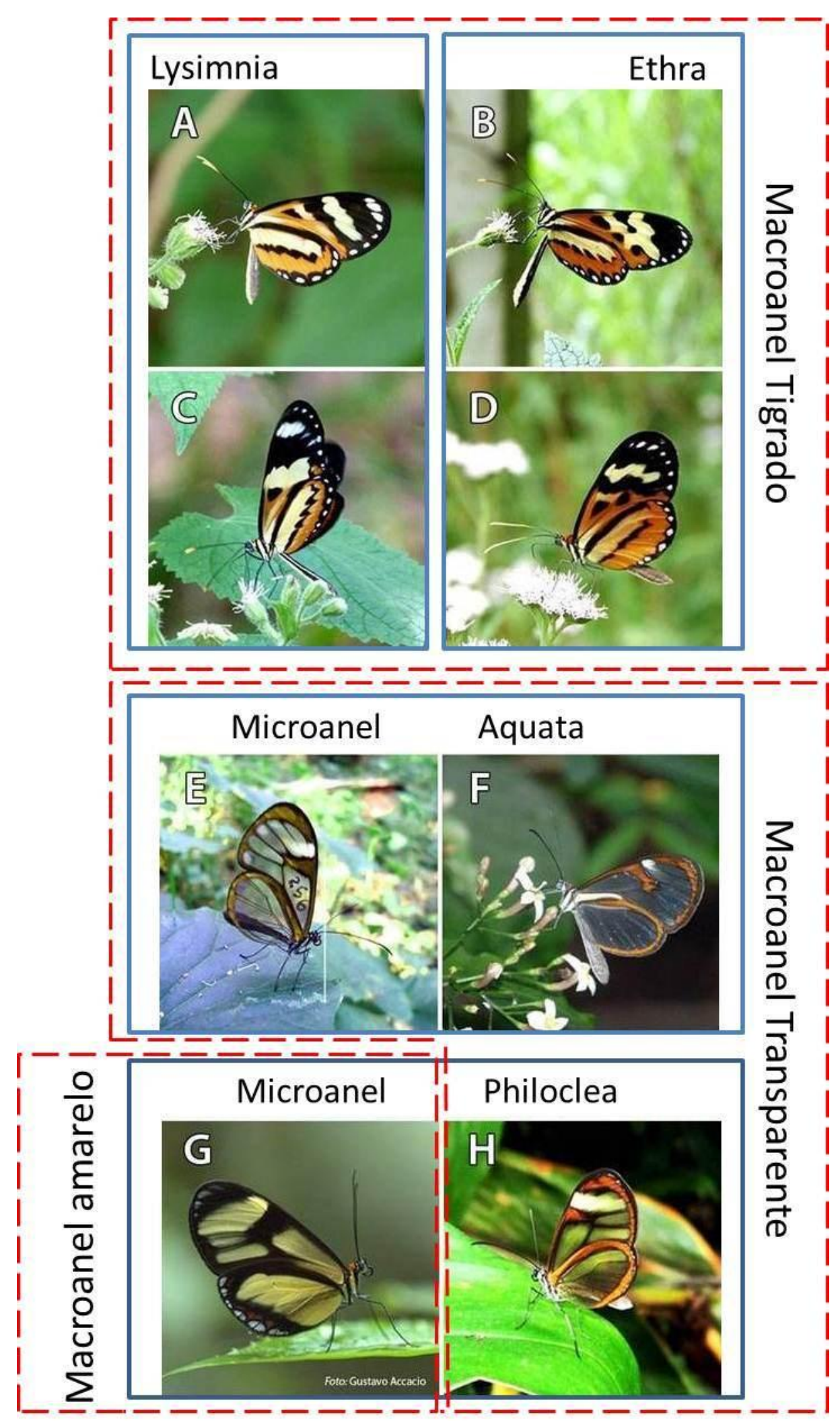

Figura 2. Oito espécies de borboletas Ithomiini (Nymphalidae, Danainae) investigadas neste estudo e seus respectivos macro e micro anéis miméticos. A) Hypothyris ninonia; B) Mechanitis polymnia; C) Mechanitis lysimnia; D) HYpothyris euclea; E) Hypoleria lavinia; F) Ithomia agnosia zikani; G) Epityches eupompe; H) Mcclungia cymo salonina. Microanéis miméticos segundo Willmot \& Mallet (2004). Macroanéis miméticos segundo critérios descritos em Material e Métodos. Para as subtribos de cada espécie ver Tabela 1. 


\section{Sistema de estudo}

As borboletas da tribo Ithomiini (Nymphalidae, Danainae) são o grupo de borboletas miméticas mais diverso e abundante da região neotropical, com cerca de 370 espécies (Wilmott \& Freitas 2006). Os Ithomiini compõe um grupo tipicamente florestal e virtualmente todos seus representantes fazem parte de anéis miméticos, sendo impalatáveis para predadores devido ao acúmulo de compostos químicos (alcalóides pirrozilidínicos) em seus tecidos (Brower et al. 2014). Por dominarem numericamente os anéis miméticos de Lepidoptera na região neotropical (Poole 1970, Brown Jr. \& Benson 1974, Beccaloni 1997a), acredita-se que os Ithomiini sejam os principais modelos de mimetismo entre os lepidópteros neotropicais (Brown Jr. \& Benson 1974, Brown 1988).

É recorrente que espécies de Ithomiini que fazem parte de um mesmo anel mimético não pertençam ao mesmo clado, mais especificamente da mesma subtribo (Brower et al. 2014). A semelhança entre as espécies de um mesmo anel mimético seria, portanto, resultado principalmente de convergência evolutiva. Por este motivo, trata-se de um grupo adequado para testar hipóteses a respeito da importância relativa do morfologia (anel mimético) e das relações de parentesco filogenético sobre a evolução de características morfológicas, comportamentais e demográficas. Ainda, como populações de Ithomiini exibem acentuadas flutuações temporais de abundância (Brown Jr. \& Benson 1974, Drummond 1976, Vasconcellos-Neto 1980, Pinheiro et al. 2008, Capítulo 1), trata-se de um grupo propício para estudos comparativos de dinâmica populacional. Em regiões com chuvas sazonais, os Ithomiini são notórios por se agregarem em pequenas áreas no interior da mata regularmente durante a estação seca, formando os "bolsões de Ithomiini" (Capítulo 1), um comportamento supostamente adaptativo à dessecação (Pinheiro et al., 2008). Em um bolsão de Ithomiini podem estar presentes de uma a cinco dezenas de espécies pertencentes a diferentes subtribos e anéis miméticos (Drummond 1976, Vasconcellos-Neto 1980, Brown Jr. 1992, Beccaloni 1997a, Pinheiro et al. 2008), tornando esta tribo adequada para comparações de parâmetros demográficos entre e dentro de anéis miméticos e clados.

$\mathrm{Na}$ área de estudo e seus arredores, já foram registradas 24 espécies de Ithomiini (Accacio 1998, Capítulo 1). No entanto, analisamos aqui apenas espécies cujo número de capturas foi suficiente para que estimativas de parâmetros populacionais pudessem ser obtidas (Tabela 1). As oito espécies nessas condições pertencem a quatro anéis miméticos (sensu Willmott \& Mallet 2004) e, segundo proposta de Brower et al. (2014), se distribuem entre quatro subtribos (ver Figura 2 e Tabela 1). Como é comum em Ithomiini, praticamente não há dentre as espécies estudadas correspondência entre o clado e o anel mimético ao qual cada espécie pertence (Tabela 1). A classificação e nomenclatura de subtribos e gêneros aqui adotada segue a proposta de Brower et al. (2014). 
Tabela 1. Relação das oito espécies de borboletas da tribo Ithomiini (Nymphalidae, Danainae) analisadas neste estudo e suas relações miméticas.

\begin{tabular}{lcc}
\hline $\begin{array}{l}\text { Subtribo/Espécie } \\
\text { Mechanitina }\end{array}$ & $\begin{array}{c}\text { Microanel } \\
\text { mimético }\end{array}$ & $\begin{array}{c}\text { Macroanel } \\
\text { mimético }^{3}\end{array}$ \\
\hline $\begin{array}{l}\text { Mechanitis lysimnia } \\
\text { Ithomiina }\end{array}$ & LYSIMNIA & $\begin{array}{c}\text { TIGRE } \\
\text { Ithomia agnosia zikani }\end{array}$ \\
$\begin{array}{l}\text { Napeogenina } \\
\text { Epityches eupompe }\end{array}$ & AQUATA & TIGRE \\
$\begin{array}{l}\text { Hypothyris euclea } \\
\text { Hypothyris ninonia daeta }\end{array}$ & TRANSPARENTE \\
$\begin{array}{l}\text { Godyridina } \\
\text { Hypoleria lavinia }\end{array}$ & PHILOCLEA & AMARELO \\
Mcclungia cymo salonina & LYHRA & TIGRE \\
\hline
\end{tabular}

1. Taxonomia segundo Brower et al. (2014).

2. Microanéis miméticos segundo Willmot \& Mallet (2004).

3. Macroanéis miméticos segundo critérios descritos em Material e Métodos.

* Espécie não citada em Willmott \& Mallet (2004) mas que compartilha das características morfológicas do respectivo anel.

\section{Coleta de dados}

A frequência das sessões de captura-marcação-recaptura seguiu o delineamento robusto de Pollock (Williams et al. 2002). As ocasiões primárias tiveram frequência quinzenal a mensal (média $\pm \mathrm{dp}=26,4 \pm 12,5$ dias de intervalo) e cada ocasião primária consistiu de quatro (em alguns casos três) ocasiões secundárias de captura com duração média de 30 minutos de ( $\mathrm{dp}=$ 13,6 min), realizadas ao longo de dois ou três dias consecutivos. O intervalo entre ocasiões secundárias de uma dada ocasião primária variou entre quatro e 17 horas. Realizamos as capturas entre $09 \mathrm{~h}$ e $16 \mathrm{~h}$ em períodos sem chuva. No total, realizamos 25 ocasiões primárias de captura distribuídas ao longo de 22 meses (abr/2013 a jan/2015).

Cada sessão de captura de 30 min foi conduzida por duas pessoas munidas de redes entomológicas. Realizamos as capturas ao longo de um circuito de aproximadamente $350 \mathrm{~m}$, com o formato do número 8 , posicionado no interior do PEPT. O percurso abrangeu uma área onde são formados bolsões de Ithomiini regularmente durante a estação seca (Capítulo 1) e seu entorno imediato. Os coletores caminharam vagarosamente e em sentidos opostos ao longo do circuito capturando ativamente qualquer Ithomiini visível localizado a até $3 \mathrm{~m} \mathrm{da}$ linha do trajeto. Usualmente cada coletor completava de três a quatro voltas pelo circuito em cada sessão de captura. A fim de evitar fugas e danos aos espécimes, os coletores os transferiam para sacos plásticos cheios de ar e lacrados com elásticos de borracha após o acúmulo de alguns indivíduos na rede entomológica. Imediatamente após o término de cada sessão de captura nós identificamos os espécimes e os marcamos individualmente com números sequenciais na face ventral das asas anterior ou posterior (dependendo da espécie), 
usando uma caneta permanente de ponta ultrafina (Figura 2). Após a marcação, soltamos os espécimes nas imediações dos locais de captura.

\section{Análise de dados}

Para testar as hipóteses 1 (correlação mimética) e 2 (correlação filogenética), utilizamos regressões múltiplas de matrizes de distância (MRM - Lichstein 2007). Esta técnica de análise também permitiu testar uma possível interação entre anel mimético e parentesco filogenético sobre as dinâmicas populacionais. Para testar a hipótese 3 (correlação geral), utilizamos testes exatos baseados em aleatorização dos dados (ver adiante).

Com as MRM testamos se matrizes de distância entre estimativas de parâmetros populacionais de cada espécie são correlacionadas com matrizes de distância mimética e/ou filogenética entre espécies. MRM são uma extensão do teste de Mantel parcial que permite a regressão de uma matriz (variável) dependente em função de múltiplas matrizes independentes, cada matriz contendo distâncias, correlações ou similaridades entre todas as combinações par a par de $\mathrm{n}$ objetos (Lichstein 2007) - espécies, no nosso caso. MRM também fornecem testes de significância estatística baseados em permutações, as quais, no nosso caso, avaliaram se eventuais correlações observadas entre espécies co-miméticas (ou entre espécies filogeneticamente mais próximas) são maiores do que entre espécies agrupadas ao acaso. A seguir, descreveremos os procedimentos utilizados para obter as matrizes (variáveis) dependentes e independentes usadas nas MRM. As matrizes usadas nos testes exatos foram as matrizes dependentes usadas nas regressões.

\section{Variáveis dependentes}

A fim de medir a correlação demográfica entre espécies estimamos para cada uma das oito espécies três parâmetros demográficos que representam o tamanho populacional ao longo do tempo e os processos de entrada e saída que afetam esse tamanho. Para tanto usamos o modelo Jolly-Seber com a parametrização POPAN (Schwarz \& Arnason 1996), o qual estima a probabilidade de captura $(p)$ e a utiliza para ajustar as estimativas dos parâmetros demográficos. Trata-se de um modelo de população aberta, isto é, assume a ocorrência de adições (nascimentos e imigrações) e subtrações (mortes e emigração) entre as ocasiões de captura. Nos nossos dados, agrupamos as ocasiões secundárias de cada ocasião primária, resultando em um histórico de capturas com 25 ocasiões (distribuídas ao longo de 22 meses), entre as quais se considerou que as populações estavam abertas para adições e subtrações.

Os três parâmetros populacionais, estimados separadamente para cada espécie, foram, seguindo notação de Cooch \& White (2006): sobrevivência aparente (Phi), definida como a probabilidade de permanência na população entre a ocasião $t$ e a ocasião $t+1$; "nascimentos" aparentes (pent), definido como a probabilidade de entrada na população entre a ocasião $t$ e a ocasião $t+1$; e abundância $(n-h a t)$, que corresponde ao tamanho populacional estimado em cada ocasião de captura. Além desses, o POPAN também estima o tamanho da superpopulação $N$, que corresponde ao número de indivíduos, capturado ou não, que entraram na população ao longo de todo o estudo. Para cada espécie obtivemos as estimativas de cada parâmetro do modelo ou do subconjunto de modelos mais plausíveis dentre um conjunto de 12 modelos candidatos (ver abaixo) selecionados através do critério de seleção de Akaike corrigido para amostras pequenas (AICc - Burnham \& Anderson 2002). Nos 
casos em que houve incerteza na seleção de modelos, as estimativas de parâmetros foram ponderadas pelo peso de $\mathrm{AICC}$ dos modelos que tiveram peso de evidência $>0$ (Burnham \& Anderson 2002).

O conjunto de 12 modelos POPAN candidatos, os quais foram avaliados separadamente para cada espécie, diferiram quanto à possibilidade de variação temporal dos parâmetros e quanto à inclusão ou não de covariáveis (Tabela 2). Montamos modelos em que os parâmetros Phi e pent e $n$-hat puderam ser constantes ao longo do tempo, variar entre cada ocasião ou depender de covariáveis. Visto que a abundância de Ithomiini parece ser fortemente influenciada pela pluviosidade (Drummond 1976, Vasconcellos-Neto 1980, Araújo 2006), montamos modelos em que Phi e pent covariaram com i) chuva acumulada ( $\mathrm{mm}$ ) entre cada ocasião de captura; ii) com chuva mensal histórica (1933-2013); ou iii) com estação do ano chuvosa (outubro a março) ou seca (abril a setembro). Apesar de não termos incluído fotoperíodo, uma variável correlacionada à dinâmica dos Ithomiini (Capítulo 1), o fotoperíodo é fortemente correlacionada à chuva história porém não às chuvas que ocorreram no período (Capítulo 1). Utilizamos dados de pluviosidade coletados em uma estação meteorológica localizada na mancha urbana de São Paulo, a 15 km da área de estudo (IAG 2013, 2015). Para levar em conta esforços de captura desiguais em algumas ocasiões, incluímos modelos em que o parâmetro probabilidade de captura $(p)$ covariou com esforço amostral. Também incluímos modelos onde $p$ foi constante e modelos em que $p$ foi variável entre as ocasiões de captura. Quantificamos o esforço amostral como a somatória dos minutos de captura empreendidos durante as quatro ou três sessões de captura de uma ocasião primária, multiplicado pelo número de coletores presentes em cada sessão. Dado que $n$ - hat é um parâmetro derivado não estimado diretamente pela função de verossimilhança do POPAN (Schwarz \& Arnason 1996), não foi possível associar a ele nenhuma covariável diretamente (ver Tabela 2). Construímos os modelos POPAN no programa R (R Core Team 2013) a partir de funções disponíveis no pacote RMark (Laake 2013) e rodados no programa Mark (Cooch \& White 2006) tendo o programa $\mathrm{R}$ como interface. 
Tabela 2. Doze modelos Jolly-Seber POPAN utilizados para as estimativas de parâmetros demográficos de oito espécies de borboletas da tribo Ithomiini (Nymphalidae, Danainae). São mostrados os parâmetros de cada modelo e entre parênteses suas covariáveis.

\begin{tabular}{llc}
\hline \# & Modelos & $\begin{array}{c}\text { Número de } \\
\text { parâmetros }\end{array}$ \\
\hline 1 & Phi(*) p(*) pent(*) N & 4 \\
2 & Phi(*) p(effort) pent $\left(^{*}\right) \mathrm{N}$ & 5 \\
3 & Phi(rain_hist) $p\left(^{*}\right)$ pent(rain_hist) N & 6 \\
4 & Phi(rain_month) p(*) pent(rain_month) N & 6 \\
5 & Phi(rain_month) p(effort) pent(rain_month) N & 7 \\
6 & Phi(season) p(effort) pent(season) N & 7 \\
7 & Phi(rain_hist) p(effort) pent(rain_hist) N & 7 \\
8 & Phi(rain_month) p(t) pent(rain_month) N & 30 \\
9 & Phi(rain_hist) p(t) pent(rain_hist) N & 30 \\
10 & Phi(t) p(*) pent(t) N & 50 \\
11 & Phi(t) p(effort) pent(t) N & 51 \\
12 & Phi(t) p(t) pent(t) N & 72 \\
\hline
\end{tabular}

Parâmetros: Phi: Sobrevivência aparente; $p$ : probabilidade de captura; pent: nascimentos aparentes; $N$ : tamanho da superpopulacão - tamanho populacional estimado em cada ocasião de captura - é um parâmetro derivado dos demais. Covariáveis entre parênteses: $\mathrm{t}$ = tempo; effort = esforço amostral; rain_hist = chuva média mensal histórica (1933-2013), rain_month = chuva acumulada (mm) entre as ocasiões de captura; * indica que o parâmetro foi mantido constante.

Uma vez obtidas as melhores estimativas de parâmetros populacionais (Phi, pent e $n$ - hat) para cada espécie, construímos três matrizes de correlação temporal (uma para cada parâmetro) entre os valores estimados para cada espécie a cada ocasião primária. Cada matriz contém o valor do coeficiente de correlação de Pearson entre as séries temporais das estimativas de Phi, pent ou $\mathrm{n}$-hat de cada par possível de espécies, compreendendo 28 combinações no total. Estas matrizes de distância demográfica entre cada par de espécies foram as variáveis dependentes das MRM. Como os parâmetros populacionais estimados para cada espécie em cada ocasião ( $n$-hat) ou intervalos entre ocasiões (Phi e pent) variaram quanto a suas incertezas, ponderamos as correlações acima descritas pelos erros padrão associados a cada estimativa. Criamos um vetor de pesos para cada uma das 28 correlações, de comprimento igual ao número de ocasiões, dado por:

$$
P_{x y i}=\frac{1}{S E_{x i} * S E_{y i}}
$$

Onde $P_{x y i}$ representa o peso associado às estimativas dos parâmetros populacionais do par de espécies $x$ e $y$ na ocasião $i, S E_{x i}$ representa o erro padrão da estimativa do parâmetro populacional da espécie $\mathrm{x}$ na ocasião i, e $S E_{y i}$ representa o erro padrão da estimativa do parâmetro populacional da espécie $y$ na ocasião $i$. Calculamos as correlações ponderadas no programa R com a função “wtd.cor” disponível no pacote weights (Pasek 2014). 


\section{Variáveis independentes}

As variáveis independentes que utilizamos nas MRM foram duas matrizes de distância mimética e duas matrizes de distância filogenética entre espécies, bem como uma combinação de matrizes de ambos os tipos. Usamos dois tipos de distâncias mimética e filogenética para levar em conta a existência de critérios alternativos de classificação, e avaliar se os resultados das análises seriam robustos à escolha de um ou outro critério.

Dos dois critérios adotados para definir os anéis miméticos de Ithomiini, um é mais detalhado (microanéis) e o outro mais inclusivo (macroanéis, Figura 2). 0 critério de microanéis se baseou na proposta de Willmott \& Mallet (2004), que agrupou espécies de Ithomiini em anéis miméticos com base em 16 caracteres morfológicos, resultando em uma classificação mais detalhada do que a fornecida por autores prévios. Segundo este critério, as oito espécies aqui analisadas se distribuem em quatro anéis miméticos, um par de espécies em cada anel (Figura 2 e Tabela 1). O critério de macroanéis miméticos foi baseado na percepção dos coletores deste estudo. Agrupamos em um mesmo anel as espécies indistinguíveis em voo e cuja identificação segura só é possível com o espécime em mãos (ou parado e observado de perto). Segundo este critério, as oito espécies se dividem em três anéis miméticos, um anel com quatro espécies, um com três e um com apenas uma espécie (Tab. 1). Ambas as matrizes de distância mimética acima descritas são binárias, tendo o valor zero quando o par de espécies pertence a um mesmo anel mimético ou 1 quando não pertence.

As duas matrizes de distância filogenética que usamos como variáveis independentes nas MRM representaram maneiras distintas de medir a proximidade filogenética entre espécies. Uma delas é binária e considera as espécies que pertencem a uma mesma subtribo (clado) como tendo distância zero entre si e espécies que pertencem a subtribos distintas como tendo distância 1. A outra matriz representa o número de nós (entre 1 e 20) que separa cada par de espécies (Webb et al. 2002) em um cladograma da tribo baseado em uma análise combinada de dados morfológicos e moleculares de representantes de todos (com exceção de quatro) gêneros de Ithomiini (Brower et al. 2014).

\section{Teste das hipóteses}

Para avaliar o apoio fornecido por nossos dados às hipóteses 1 e 2 (correlação mimética e filogenética, respectivamente) montamos oito modelos de MRM nos quais a variável dependente (matriz de correlação entre os valores de Phi, pent ou $n$ - hat estimados para cada espécie) podia ser influenciada por apenas uma das distâncias miméticas, por uma das distâncias filogenéticas ou pela combinação de uma distância mimética e uma filogenética (Tabela 3). Dividimos os oito modelos de regressão de acordo com suas variáveis independentes em três tipos, segundo as hipóteses que representam: "mimetismo", "filogenia" ou "interação". Então avaliamos os tamanhos dos efeitos de cada variável independente em cada modelo, os valores de $R^{2}$ do modelo e o resultado dos testes de permutação (10 mil aleatorizações). As MRM foram executadas no programa R com a função "MRM" do pacote ecodist (Goslee \& Urban 2007). 
Tabela 3. Modelos de regressão múltipla de matrizes (MRM) construídos para avaliar a influência da distância mimética, da distância filogenética ou da interação entre ambas sobre a dinâmica populacional de oito espécies de Ithomiini. A variável dependente de todas as regressões é uma matriz de distância entre os parâmetros populacionais estimados (Phi, pent ou $n-h a t$ ) para cada espécie.

\begin{tabular}{|c|c|c|c|c|}
\hline ID & Hipótese & $\begin{array}{l}\text { Variável (matriz) } \\
\text { dependente }\end{array}$ & $\begin{array}{l}\text { Variáveis (matrizes) } \\
\text { independentes }\end{array}$ & $\begin{array}{l}\text { Tipo de matriz } \\
\text { independente }\end{array}$ \\
\hline 1 & Mimetismo & Phi, pent ou $n-$ hat & microanel & categórica \\
\hline 2 & Mimetismo & Phi, pent ou $n-h a t$ & macroanel & categórica \\
\hline 3 & Filogenia & Phi, pent ou $n-h a t$ & número de nós & contagem \\
\hline 4 & Filogenia & Phi, pent ou $n-h a t$ & clados (subtribos) & categórica \\
\hline 5 & Int & Phi & $\begin{array}{l}\text { microaneis * número } \\
\text { de nós }\end{array}$ & $\begin{array}{l}\text { categórica e } \\
\text { contagem }\end{array}$ \\
\hline 6 & Inte & Phi, pent o & microaneis * clados & categóricas \\
\hline 7 & Interação & Phi, pent ou $n-h a t$ & $\begin{array}{l}\text { macroaneis * número } \\
\text { de nós }\end{array}$ & $\begin{array}{l}\text { categórica e } \\
\text { contagem }\end{array}$ \\
\hline 8 & Interação & Phi, pent ou $n-$ hat & macroaneis $*$ clados & categóricas \\
\hline
\end{tabular}

Phi: Sobrevivência aparente; pent: nascimentos aparentes; $n$ - hat: tamanho populacional estimado.

Para avaliar o apoio fornecido por nossos dados à hipótese 3 (correlação geral entre as espécies da tribo independente de anel mimético ou proximidade filogenética), realizamos testes exatos em seis matrizes de correlação demográfica, divididas em três tipos: i) matrizes de correlação demográfica entre espécies (três matrizes, uma para cada parâmetro - Phi, pent e $n$ - hat); ii) matrizes de correlação entre estimativas de abundância ( $n$ - hat) de cada anel mimético (duas matrizes, uma para cada critério - microanel e macroanel); iii) matriz de correlação entre estimativas de abundância ( $n-h a t$ ) de cada clado (uma matriz). Obtivemos as estimativas de abundância de cada anel mimético ou clado somando as estimativas das espécies pertencentes a cada um desses agrupamentos.

Em cada teste exato (seis no total), calculamos a probabilidade de se obter ao acaso a correlação média observada em uma das seis matrizes de distância demográfica descritas no parágrafo anterior. Para tanto, geramos em cada teste uma distribuição nula de correlações médias baseada em 10 mil aleatorizações dos dados (Gotelli \& Graves 1996). Obtivemos esta distribuição aleatorizando, sem reposição e de forma independente, a ordem temporal das estimativas populacionais de cada espécie, anel mimético ou clado. Então calculamos uma matriz de correlação (Pearson) demográfica entre espécies, anéis miméticos ou clados para cada rodada de aleatorização dos dados e calculamos o valor de correlação médio dessa matriz aleatorizada. Este processo foi repetido 10 mil vezes para cada uma das seis distribuições nulas de correlações médias.

\section{RESULTADOS}

\section{Estimativas de parâmetros populacionais}

Ao longo de 22 meses, marcamos 5481 indivíduos das oito espécies analisadas. A espécie com maior número de capturas foi Ithomia agnosia zikani, com 1992 indivíduos marcados. A 
espécie com menor número foi Hypoleria lavinia, com 210 indivíduos marcados. Os modelos de dinâmica populacional selecionados variaram entre as espécies. Na maioria dos casos, houve incerteza na seleção de modelos de dinâmica populacional visto que todas as espécies, com exceção de uma, tiveram mais de um modelo selecionado como mais plausível (Tabela 4). Para cinco das oito espécies os modelos selecionados tiveram os parâmetros sobrevivência aparente $(P h i)$ e nascimentos aparentes (pent) covariando com alguma medida de pluviosidade (Tabela 4). Os modelos selecionados para as outras três espécies tiveram estes parâmetros variando no tempo.

Tabela 4. Modelos de dinâmica populacional Jolly-Seber POPAN selecionados, dentre os doze modelos da Tab. 3, para cada espécie de Ithomiini. São mostradas as covariáveis, o número de parâmetros (Npar), a diferença entre o valor de AIC do respectivo modelo e do modelo com o menor valor ( $\triangle \mathrm{AICC}$ ), e o peso de Akaike (wAIC) de cada modelo com $\boldsymbol{w A I C}>0,0001$.

\begin{tabular}{llccc}
\hline Espécie & Modelo & Npar & $\Delta$ AICc & wAIC \\
\hline Hypothyris ninonia & Phi(t) p(effort) pent(t) & 51 & 0,00 & 0,6279 \\
& Phi(t) p(t) pent(t) & 72 & 1,05 & 0,3721 \\
Mechanitis lysimnia & Phi(rain_hist) p(t) pent(rain_hist) & 30 & 0,00 & 0,9850 \\
& Phi(rain_month) p(t) pent(rain_month) & 30 & 8,49 & 0,0141 \\
& Phi(rain_month) p(effort) pent(rain_month) & 7 & 14,79 & 0,0006 \\
& Phi(t) p(effort) pent(t) & 51 & 17,36 & 0,0002 \\
Mechanitis polymnia & Phi(t) p(effort) pent(t) & 51 & 0,00 & 0,9832 \\
& Phi(rain_hist) p(t) pent(rain_hist) & 30 & 8,22 & 0,0161 \\
Hypothyris euclea & 50 & 14,46 & 0,0007 \\
& Phi(t) p(*) pent(t) & 30 & 0,00 & 0,9955 \\
Ithomia agnosia & Phi(rain_hist) p(t) pent(rain_hist) & 30 & 10,80 & 0,0045 \\
Hypoleria lavinia & Phi(rain_month) p(t) pent(rain_month) & 51 & 0,00 & 1,0000 \\
& Phi(t) p(effort) pent(t) & 30 & 0,00 & 0,6945 \\
Epityches eupompe & Phi(rain_month) p(t) pent(rain_month) & 30 & 1,64 & 0,3055 \\
& Phi(rain_hist) p(t) pent(rain_hist) & 6 & 0,00 & 0,4523 \\
& Phi(rain_month) p(*) pent(rain_month) & 7 & 0,25 & 0,3991 \\
& Phi(rain_month) p(effort) pent(rain_month) & 30 & 2,47 & 0,1314 \\
& Phi(rain_month) p(t) pent(rain_month) & 30 & 6,64 & 0,0163 \\
& Phi(rain_hist) p(t) pent(rain_hist) & 50 & 13,19 & 0,0006 \\
& Phi(t) p(*) pent(t) & 30 & 0,00 & 0,5530 \\
Mcclungia cymo & Phi(rain_hist) p(t) pent(rain_hist) & 30 & 0,43 & 0,4470 \\
& Phi(rain_month) p(t) pent(rain_month) &
\end{tabular}

Parâmetros: Phi - sobrevivência aparente; $p$ - probabilidade de captura; pent - nascimentos aparentes (sensu Cooch \& White 2006). Covariáveis entre parênteses: $t=$ tempo; effort = esforço amostral; rain_hist = chuva média mensal histórica (1933-2013), rain_month = chuva acumulada $(\mathrm{mm})$ entre as ocasiões de captura; ${ }^{*}$ indica que o parâmetro foi mantido constante. 


\section{Regressões múltiplas de matrizes (MRM)}

Os parâmetros populacionais estimados não tenderam a ser mais correlacionados entre espécies pertencentes a um mesmo anel mimético, tampouco entre espécies mais próximas filogeneticamente. Nenhum dos modelos de MRM apresentou valores de $R^{2}$ superiores a 0,11 para nenhum dos três parâmetros populacionais avaliados, nem valores significativos nos testes de permutação (Tabelas 5 a 7). Os resultados não dependeram do tipo de distância mimética ou filogenética e foram consistentes para os três parâmetros populacionais.

Tabela 5. Estimativas de coeficientes da regressão, valores de $R^{2}$, estatística $F$ e respectivos valores de $p$ dos modelos de regressão múltipla de matrizes (MRM) utilizados para avaliar a influência da distância mimética e da distância filogenética sobre a correlação entre as sobrevivências aparentes (Phi) de oito espécies de Ithomiini ao longo de 22 meses.

\begin{tabular}{|c|c|c|c|c|c|c|c|c|}
\hline \multirow{2}{*}{$\begin{array}{l}\text { Modelo } \\
\text { Phi número de nós }\end{array}$} & \multirow{2}{*}{$\frac{\text { Hipóteses }}{\text { filogenia }}$} & \multicolumn{2}{|c|}{ Coeficientes } & \multirow{2}{*}{$\frac{\mathbf{p}}{0,74}$} & \multirow{2}{*}{$\frac{\mathbf{R}^{2}}{0,02}$} & \multirow{2}{*}{$\frac{\mathbf{p}}{0,53}$} & \multirow{2}{*}{$\frac{\mathbf{F}}{0,44}$} & \multirow{2}{*}{$\frac{\mathbf{p}}{0,53}$} \\
\hline & & Int & 0,47 & & & & & \\
\hline & & nnos & 0,01 & 0,53 & & & & \\
\hline \multirow[t]{2}{*}{ Phi microanel } & mimetismo & Int & 0,60 & 0,47 & 0,00 & 0,87 & 0,04 & 0,87 \\
\hline & & micro & 0,04 & 0,87 & & & & \\
\hline \multirow[t]{2}{*}{ Phi macroanel } & mimetismo & Int & 0,65 & 0,18 & 0,03 & 0,36 & 0,67 & 0,36 \\
\hline & & macro & 0,12 & 0,36 & & & & \\
\hline \multirow[t]{2}{*}{ Phi clados } & filogenia & Int & 0,75 & 0,11 & 0,06 & 0,23 & 1,60 & 0,23 \\
\hline & & clados & 0,22 & 0,23 & & & & \\
\hline \multicolumn{9}{|l|}{ Phi $\sim$ microaneis * número de } \\
\hline \multirow[t]{3}{*}{ nós } & interação & Int & $\begin{array}{r}0,48 \\
-\end{array}$ & 0,64 & 0,02 & 0,82 & 0,22 & 0,82 \\
\hline & & micro & 0,02 & 0,94 & & & & \\
\hline & & nnos & 0,01 & 0,56 & & & & \\
\hline \multirow[t]{3}{*}{ Phi microaneis * clados } & interação & Int & 0,84 & 0,15 & 0,07 & 0,45 & 0,87 & 0,45 \\
\hline & & micro & 0,09 & 0,69 & & & & \\
\hline & & clados & 0,23 & 0,22 & & & & \\
\hline \multirow{4}{*}{$\begin{array}{l}\text { Phi macroaneis * número } \\
\text { de nós }\end{array}$} & & & & & & & & \\
\hline & interação & Int & 0,54 & 0,58 & 0,05 & 0,51 & 0,65 & 0,51 \\
\hline & & macro & 0.14 & 0.32 & & & & \\
\hline & & nnos & 0,01 & 0,45 & & & & \\
\hline \multirow[t]{3}{*}{ Phi macroaneis * clados } & interação & Int & 0,78 & 0,10 & 0,07 & 0,40 & 0,90 & 0,40 \\
\hline & & macro & 0,07 & 0,59 & & & & \\
\hline & & clados & 0,19 & 0,31 & & & & \\
\hline
\end{tabular}

Coeficientes: Int = intercepto; nnos = número de nós. 
Tabela 6. Estimativas de coeficientes da regressão, valores de $R^{2}$, estatística $F$ e seus respectivos valores de $p$ dos modelos de regressão múltipla de matrizes (MRM) utilizados para avaliar a influência da distância mimética e da distância filogenética sobre a correlação entre os nascimentos aparentes (pent) de oito espécies de Ithomiini ao longo de 22 meses em São Paulo.

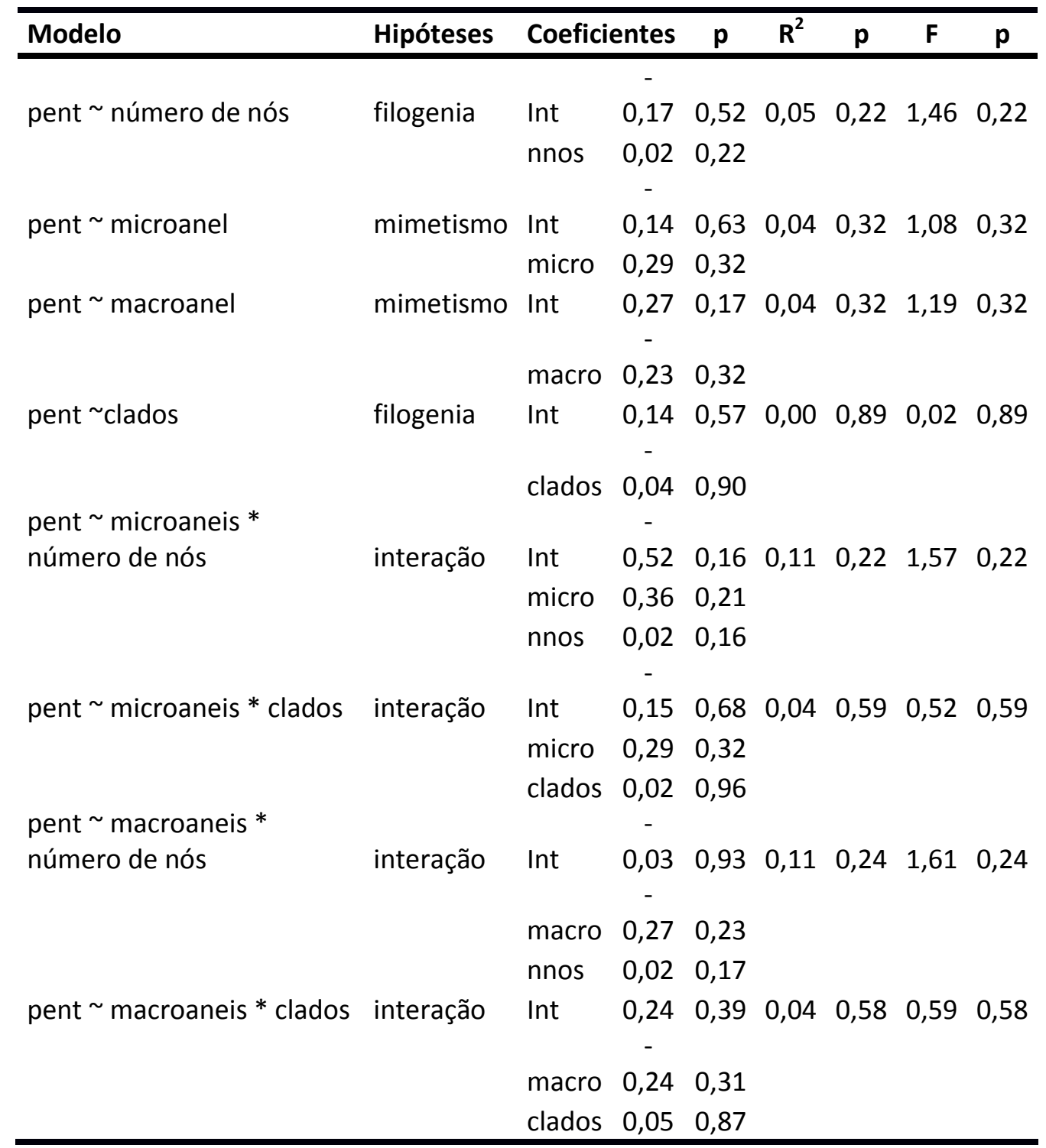

Coeficientes: Int = intercepto; nnos = número de nós. 
Tabela 7. Estimativas de coeficientes da regressão, valores de $R^{2}$, estatística $F$ e seus respectivos valores de $p$ dos modelos de regressão múltipla de matrizes (MRM) utilizados para avaliar a influência da distância mimética e da distância filogenética sobre a correlação entre os tamanhos populacionais ( $n$ - hat) de oito espécies de borboletas Ithomiini ao longo de 22 meses.

\begin{tabular}{|c|c|c|c|c|c|c|c|c|}
\hline \multirow{2}{*}{$\begin{array}{l}\text { Modelo } \\
\text { nhat número de nós }\end{array}$} & \multirow{2}{*}{$\begin{array}{l}\text { Hipóteses } \\
\text { filogenia }\end{array}$} & \multicolumn{2}{|c|}{ coeficientes } & \multirow{2}{*}{$\frac{\text { pval }}{0,69}$} & \multirow{2}{*}{$\frac{\mathbf{R}^{2}}{0,01}$} & \multirow{2}{*}{$\frac{\text { pval }}{0,62}$} & \multirow{2}{*}{$\frac{\mathbf{F}}{0,25}$} & \multirow{2}{*}{$\frac{\text { F.pval }}{0,62}$} \\
\hline & & Int & 0,56 & & & & & \\
\hline & & nnos & 0,00 & 0,62 & & & & \\
\hline \multirow[t]{2}{*}{ nhat $\sim$ microanel } & mimetismo & Int & 0,51 & 0,85 & 0,04 & 0,31 & 1,06 & 0,31 \\
\hline & & micro & 0,11 & 0,31 & & & & \\
\hline \multirow[t]{2}{*}{ nhat $\sim$ macroanel } & mimetismo & Int & 0,63 & 0,31 & 0,01 & 0,63 & 0,24 & 0,63 \\
\hline & & macro & 0,04 & 0,63 & & & & \\
\hline \multirow[t]{2}{*}{ nhat $\sim$ clados } & filogenia & Int & 0,62 & 0,45 & 0,00 & 0,91 & 0,01 & 0,91 \\
\hline & & clados & $\overline{-}, 01$ & & & & & \\
\hline \multirow[t]{3}{*}{ nhat microaneis * número de nós } & interação & Int & 0,43 & 0,89 & 0,06 & 0,49 & 0,75 & 0,49 \\
\hline & & micro & 0,13 & 0,28 & & & & \\
\hline & & nnos & 0,00 & 0,50 & & & & \\
\hline \multirow[t]{3}{*}{ nhat $\sim$ microaneis * clados } & interação & Int & 0,50 & 0,77 & 0,04 & 0,60 & 0,51 & 0,60 \\
\hline & & micro & 0,12 & 0,32 & & & & \\
\hline & & clados & 0,01 & 0,94 & & & & \\
\hline \multirow{4}{*}{$\begin{array}{l}\text { nhat } ~ \text { macroaneis } * \text { número de } \\
\text { nós }\end{array}$} & & & & & & & & \\
\hline & interação & Int & $\begin{array}{c}0,58 \\
-\end{array}$ & 0,60 & 0,02 & 0,75 & 0,28 & 0,75 \\
\hline & & macro & 0,05 & 0,58 & & & & \\
\hline & & nnos & 0,00 & 0,56 & & & & \\
\hline \multirow[t]{3}{*}{ nhat $\sim$ macroaneis $*$ clados } & interação & Int & 0,63 & 0,42 & 0,01 & 0,89 & 0,12 & 0,89 \\
\hline & & macro & 0,04 & 0,63 & & & & \\
\hline & & clados & 0,00 & 0,98 & & & & \\
\hline
\end{tabular}

Coeficientes: Int = intercepto; nnos = número de nós. 

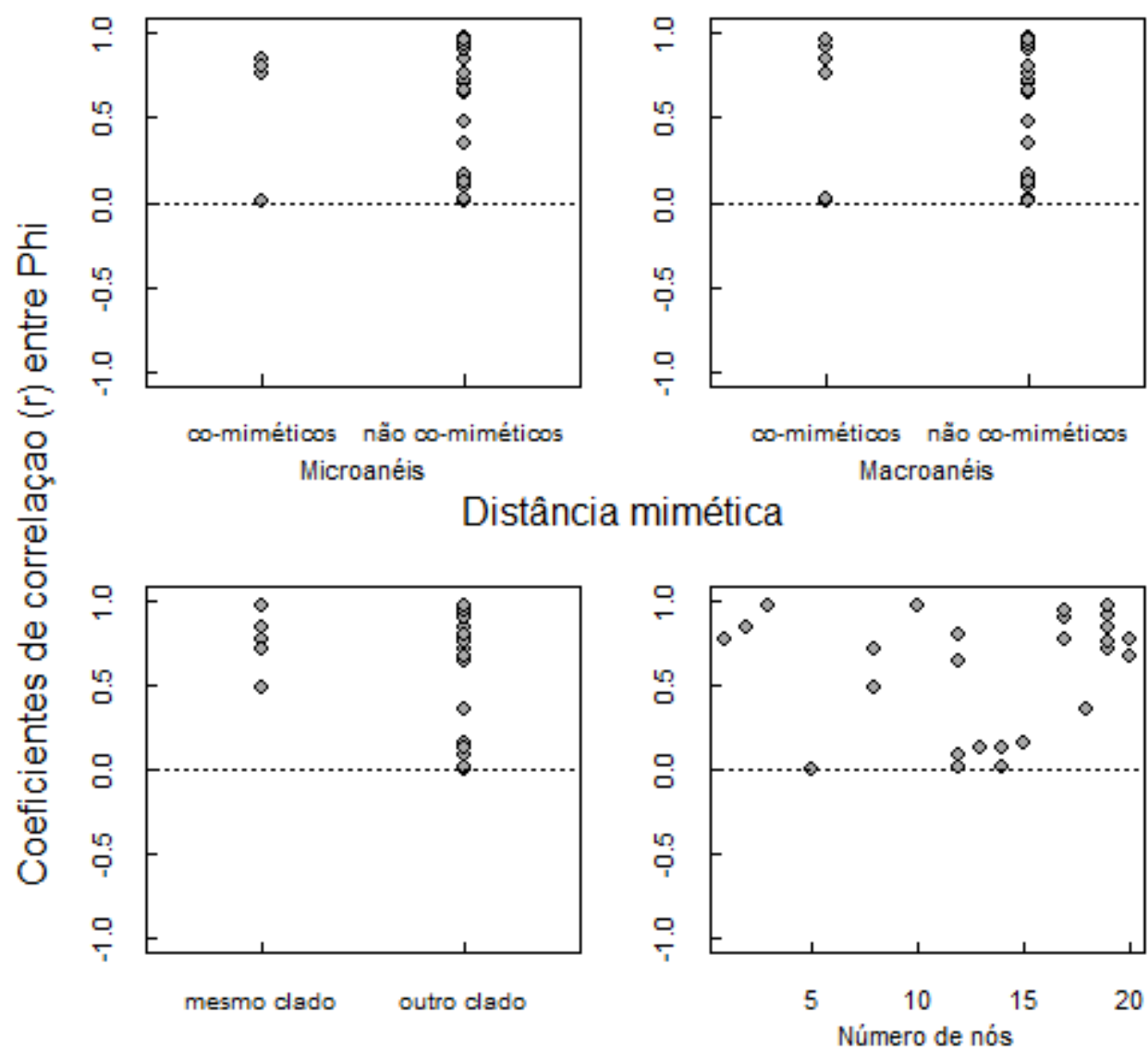

Distância filogenética

Figura 3. Coeficientes de correlação de Pearson entre as estimativas de sobrevivência aparente $(P h i)$ de oito espécies de borboletas Ithomiini obtidas ao longo de 22 meses em São Paulo, Brasil. Na linha superior estão apresentadas as correlações em função da distância mimética (micro e macroanéis) entre espécies e, na linha inferior, em função da distância filogenética (clados e número de nós) entre espécies. 

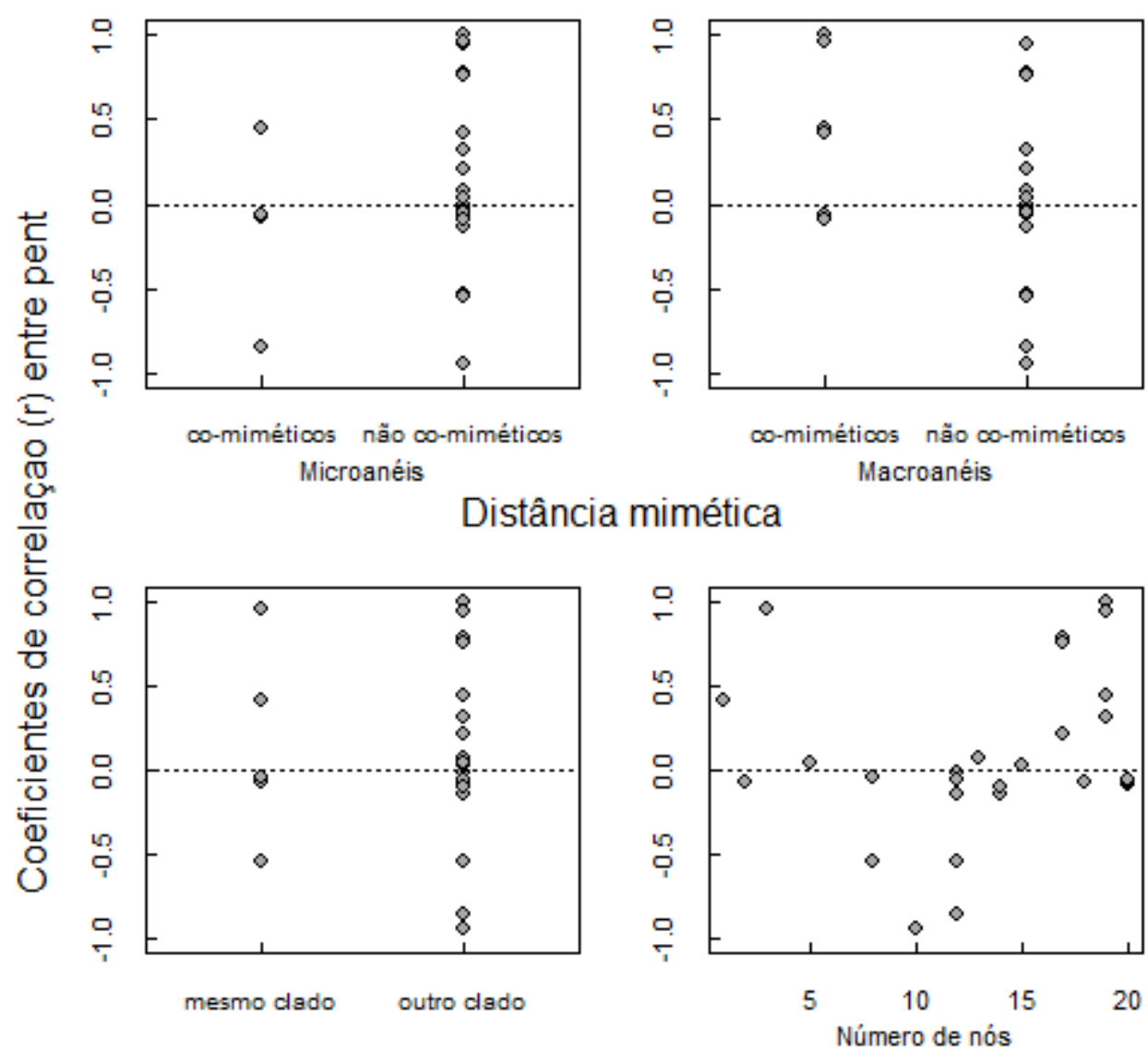

Distância filogenética

Figura 4. Coeficientes de correlação de Pearson entre as estimativas de nascimentos aparentes (pent) de oito espécies de borboletas Ithomiini obtidas ao longo de 22 meses em São Paulo, Brasil. Na linha superior estão apresentadas as correlações em função da distância mimética (micro e macroanéis) e, na linha inferior, em função da distância filogenética (clados e número de nós) entre espécies. 

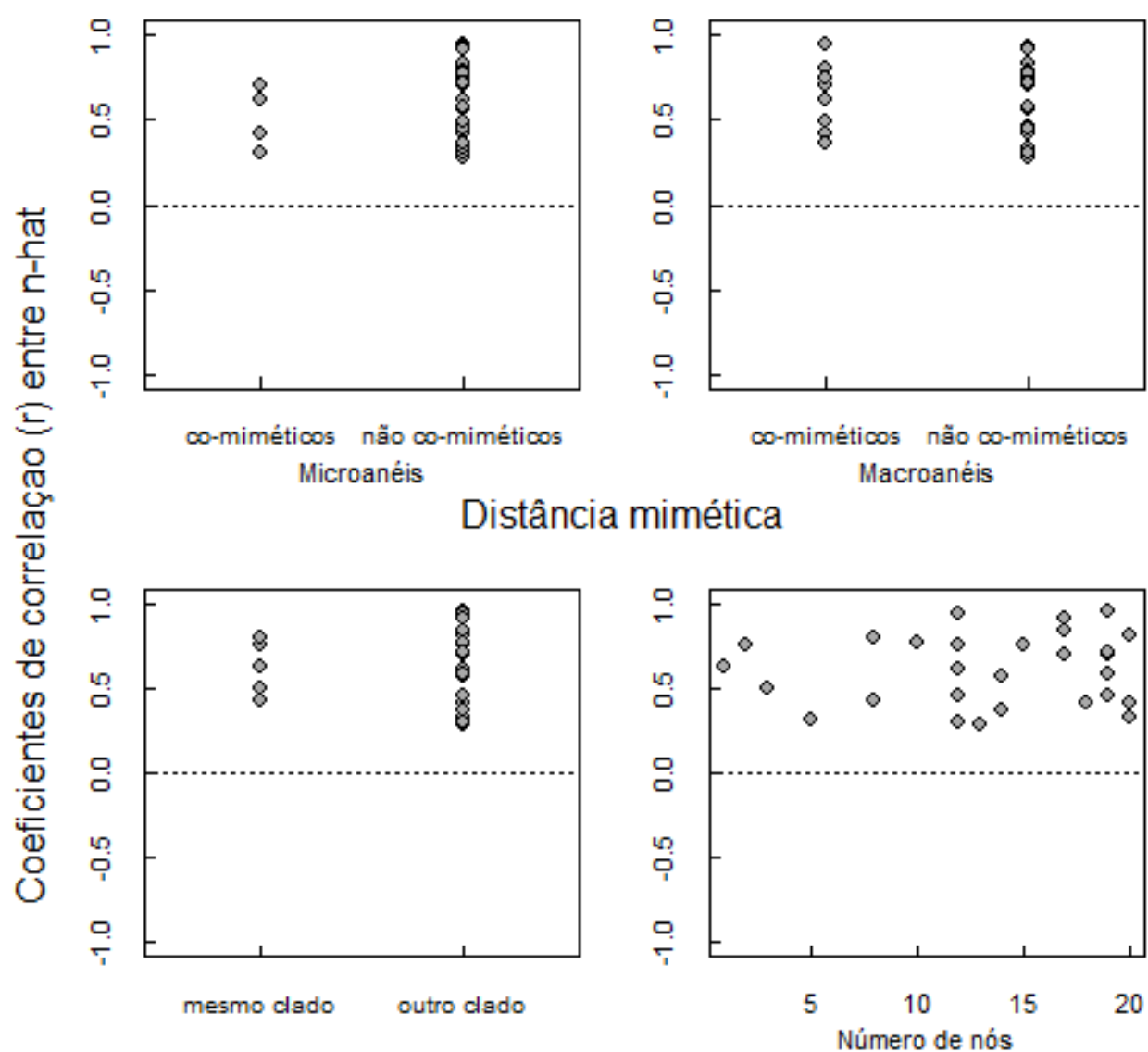

Distância filogenética

Figura 5. Coeficientes de correlação de Pearson entre tamanhos populacionais estimados $(n-h a t)$ de oito espécies de borboletas Ithomiini obtidas ao longo de 22 meses em São Paulo, Brasil. Na linha superior estão apresentadas as correlações em função da distância mimética medida de duas formas: microanéis (sensu Willmott \& Mallet 2004) e macroanéis (ver métodos). Na linha inferior estão apresentadas as correlações em função da distância filogenética (clados e número de nós) entre espécies. 


\section{Correlação demográfica entre espécies}

As oito espécies de Ithomiini tenderam ter suas estimativas de parâmetros populacionais mais correlacionadas entre si do que esperado por acaso, independente de anel mimético ou de distância filogenética (Tabela 8, Figuras 6 a 8). A correlação média entre as estimativas de Phi de todos os pares de espécies foi $r_{P h i}=0,64$, sendo que o valor máximo de correlação média obtido nas simulações foi $r=0,17$. A probabilidade de se obter a correlação média estimada sob a hipótese nula de ausência de correlação foi $p<0,0001$ (Tabela 8). A correlação média observada entre as estimativas de pent foi 0,21 e a probabilidade de se obter este valor sob a hipótese nula foi $p<0,0001$. A correlação média observada entre as estimativas de $n-$ hat foi 0,54 , e a probabilidade de se obter este valor sob a hipótese nula foi $p<0,0001$ (Tabela 8).

\section{Correlaçoes entre sobrevivências aparentes (Phi)}

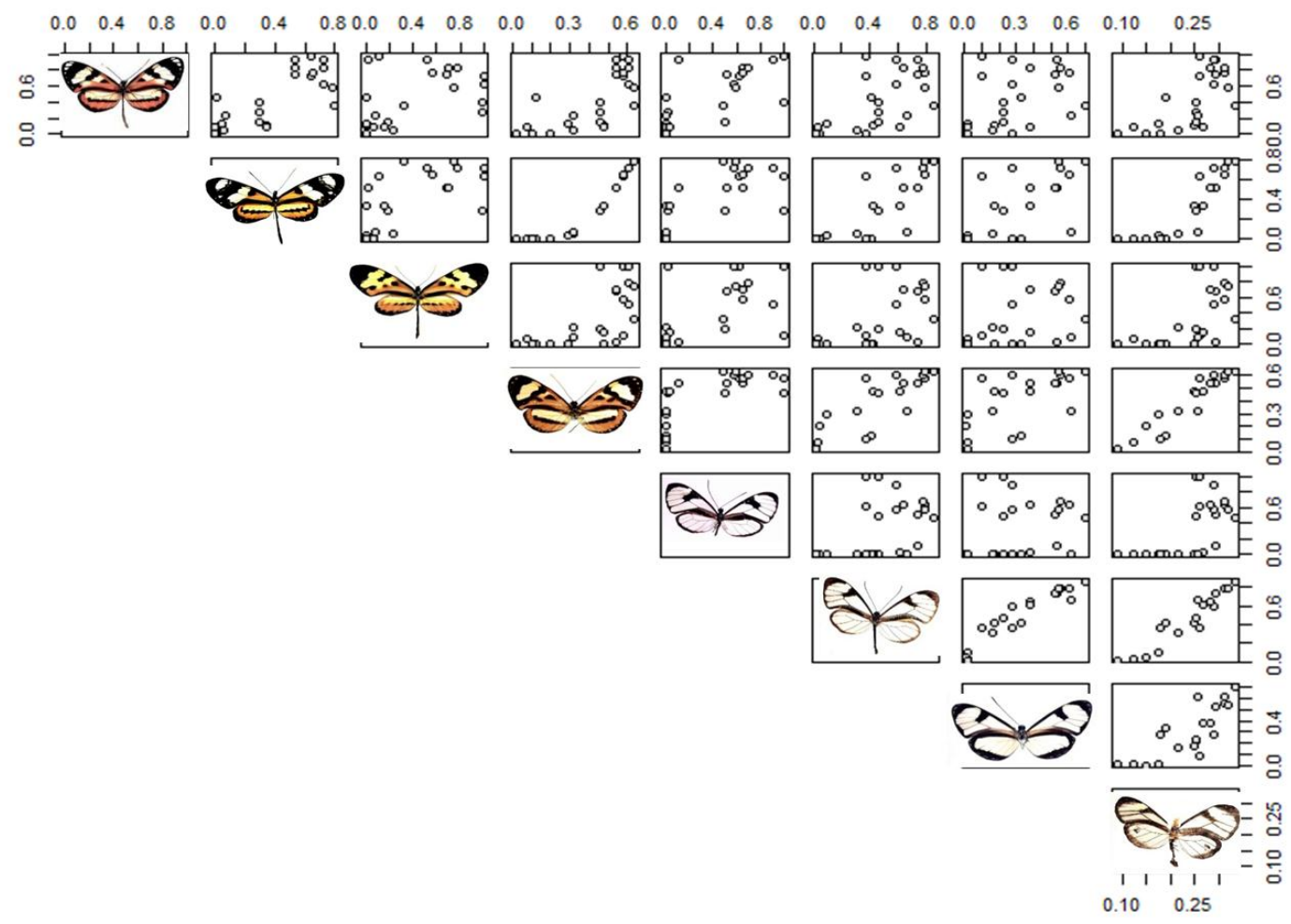

Figura 6. Correlações entre estimativas de sobrevivência aparente $(P h i)$ de oito espécies de borboletas da tribo Ithomiini (Nymphalidae, Dananinae) ao longo de 22 meses. De cima para baixo as espécies são: Hypothyris ninonia, Mechanitis lysimnia, Mechanitis polymnia, Hypothyris euclea, Ithomia agnosia, Hypoleria lavinia, Epityches eupompe e Mcclungia cymo. 


\section{Correlaçoes entre nascimentos aparentes (pent)}

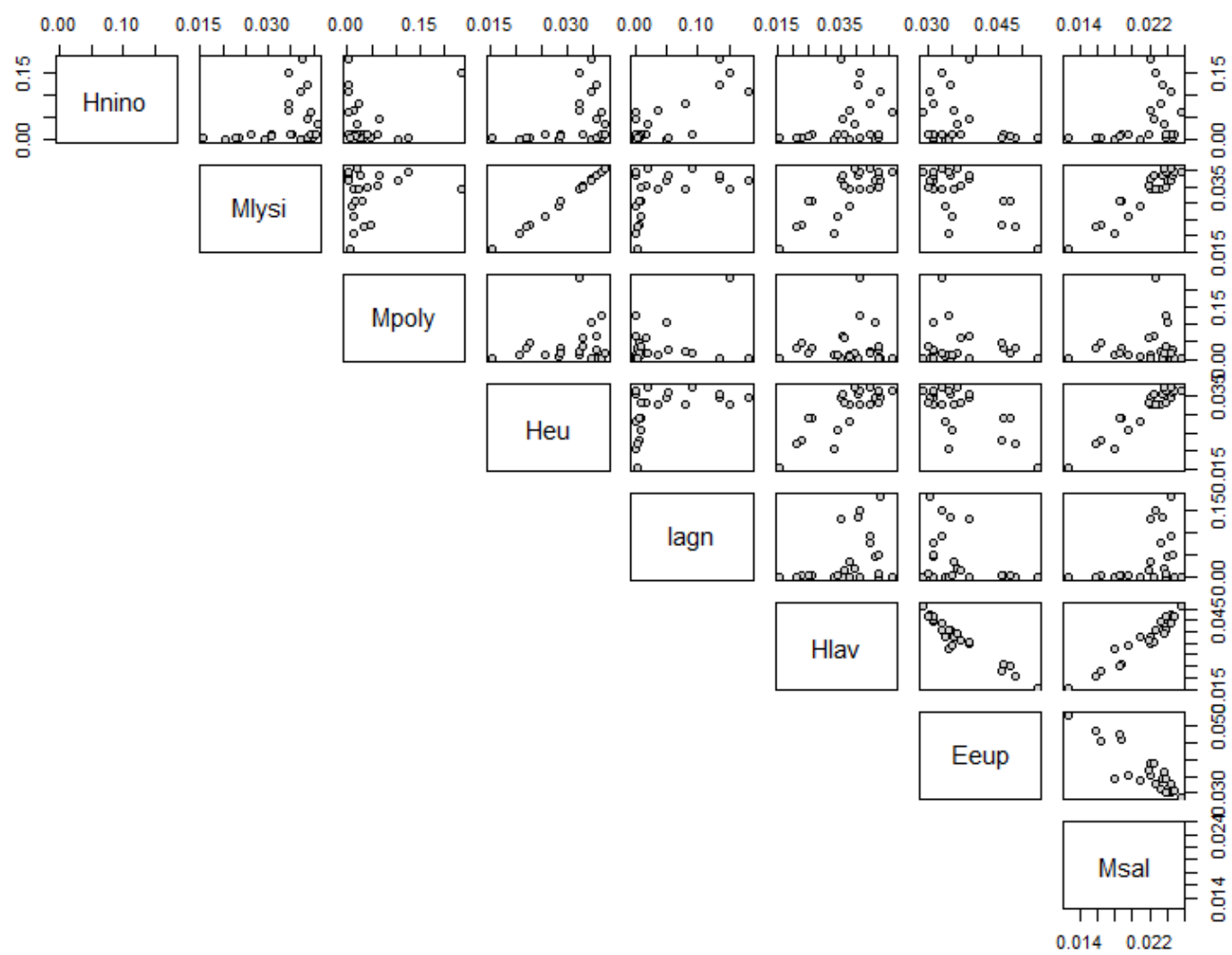

Figura 7. Correlações entre estimativas de nascimentos aparentes (pent) de oito espécies de borboletas da tribo Ithomiini (Nymphalidae, Dananinae) ao longo de 22 meses. De cima para baixo as espécies são: Hypothyris ninonia, Mechanitis lysimnia, Mechanitis polymnia, Hypothyris euclea, Ithomia agnosia, Hypoleria lavinia, Epityches eupompe e Mcclungia cymo. 


\section{Correlaçoes entre tamanhos populacionais (n-hat)}
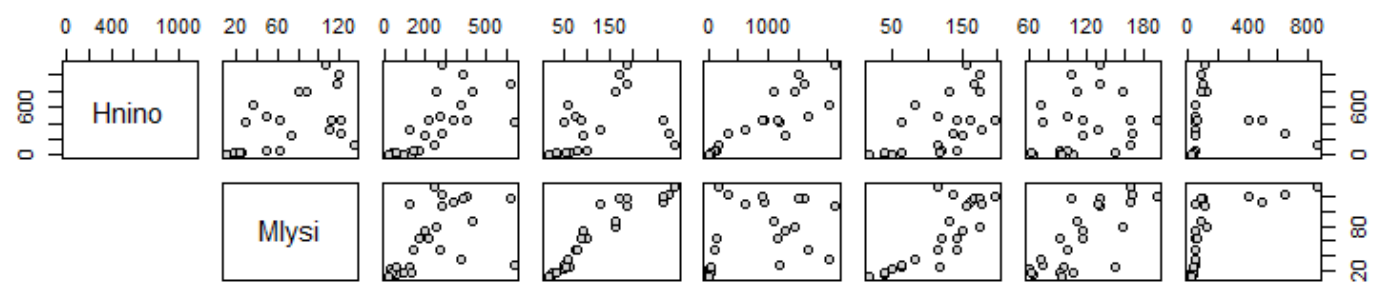

$$
\text { Mlysi }
$$
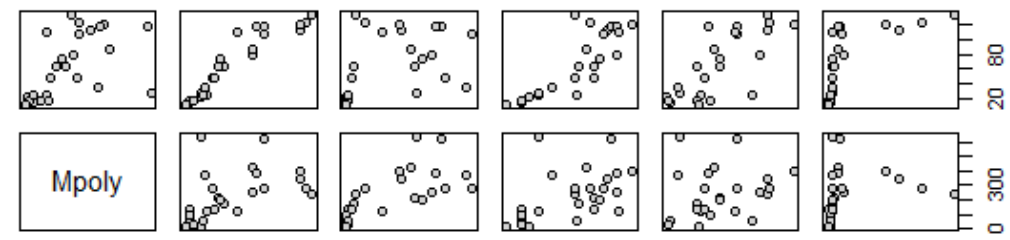

Mpoly
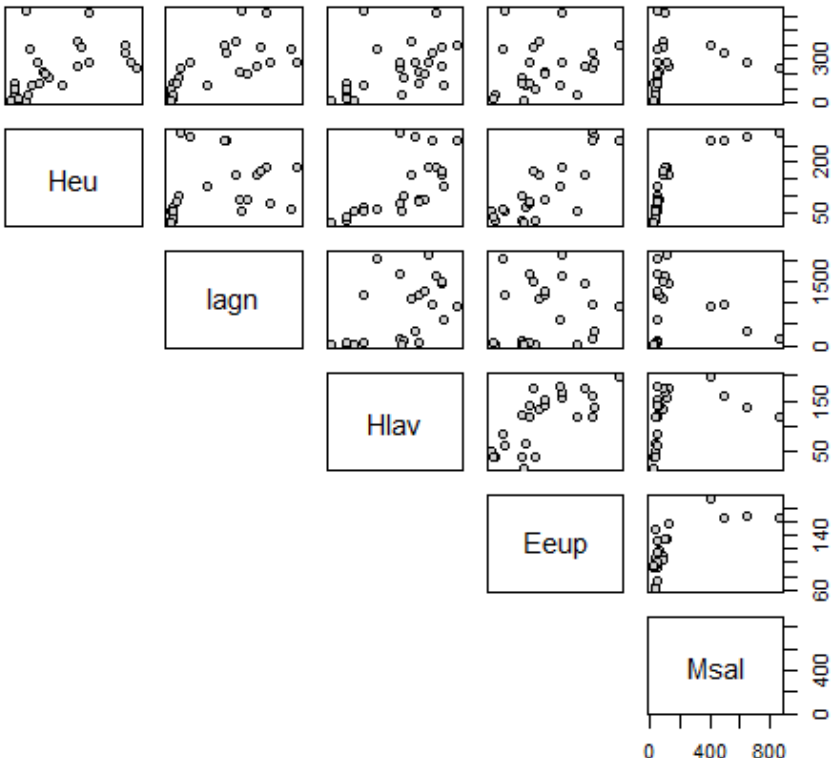

Figura 8. Correlações entre estimativas de tamanho populacional $(n-h a t)$ de oito espécies de borboletas da tribo Ithomiini (Nymphalidae, Dananinae) ao longo de 22 meses. De cima para baixo as espécies são: Hypothyris ninonia, Mechanitis lysimnia, Mechanitis polymnia, Hypothyris euclea, Ithomia agnosia, Hypoleria lavinia, Epityches eupompe e Mcclungia cymo.

Tabela 8. Resultados dos testes exatos utilizados para avaliar se parâmetros demográficos de espécies, anéis miméticos ou subtribos seriam mais correlacionados entre si do que o esperado por acaso.

\begin{tabular}{llcccc}
\hline Correlação entre & Parâmetro & r sim. médio & $\mathbf{r}$ sim. máximo & r obs. & p \\
\hline Espécies & Phi & $-0,0004$ & 0,1809 & 0,649 & $<0,0001$ \\
Espécies & pent & $-0,0005$ & 0,1972 & $0,2117<0,0001$ \\
Espécies & $\mathrm{n}$-hat & $-0,0002$ & 0,189 & 0,5369 & $<0,0001$ \\
Anéis miméticos (microanéis) & $\mathrm{n}$-hat & $-0,0010$ & 0,3847 & $0,4921<0,0001$ \\
Anéis miméticos (macroanéis) & $\mathrm{n}$-hat & 0,0021 & 0,5056 & 0,5847 & $<0,0001$ \\
Subtribos & $\mathrm{n}$-hat & 0,0001 & 0,3617 & $0,5391<0,0001$ \\
\hline
\end{tabular}

Parâmetros: Phi - sobrevivência aparente; $p$ - probabilidade de captura; pent - nascimentos aparentes. $r$ sim. médio: Média das correlações médias simuladas $(n=10000)$. $r$ sim. máximo: Valor máximo obtido nas correlações médias simuladas. $\mathbf{r}$ obs.: Correlação média observada nos dados empíricos. p: Probabilidade de obter a correlação média observada na ausência de correlação entre espécies, anéis miméticos ou subtribos. 


\section{Correlação demográfica entre anéis miméticos}

Os anéis miméticos de Ithomiini, agrupados pelo critério de microanéis ou pelo de macroanéis, tenderam a ter suas abundâncias ( $\mathrm{n}$-hat) mais correlacionadas entre si do que esperado por acaso (Tabela 8 e Figura 9). Considerando as espécies agrupadas por microanel, a correlação média entre as estimativas de $n$ - hat foi 0,49 e a probabilidade de se obter este valor sob a hipótese nula foi $p<0,0001$, visto que o valor máximo obtido nas simulações foi 0,38. Considerando as espécies agrupadas por macroanéis, a correlação média observada entre as estimativas de $\mathrm{n}$-hat foi 0,50 , e a probabilidade de se obter este valor sob a hipótese nula foi $\mathrm{p}$ $<0,0001$ (Tabela 8 e Figura 9).

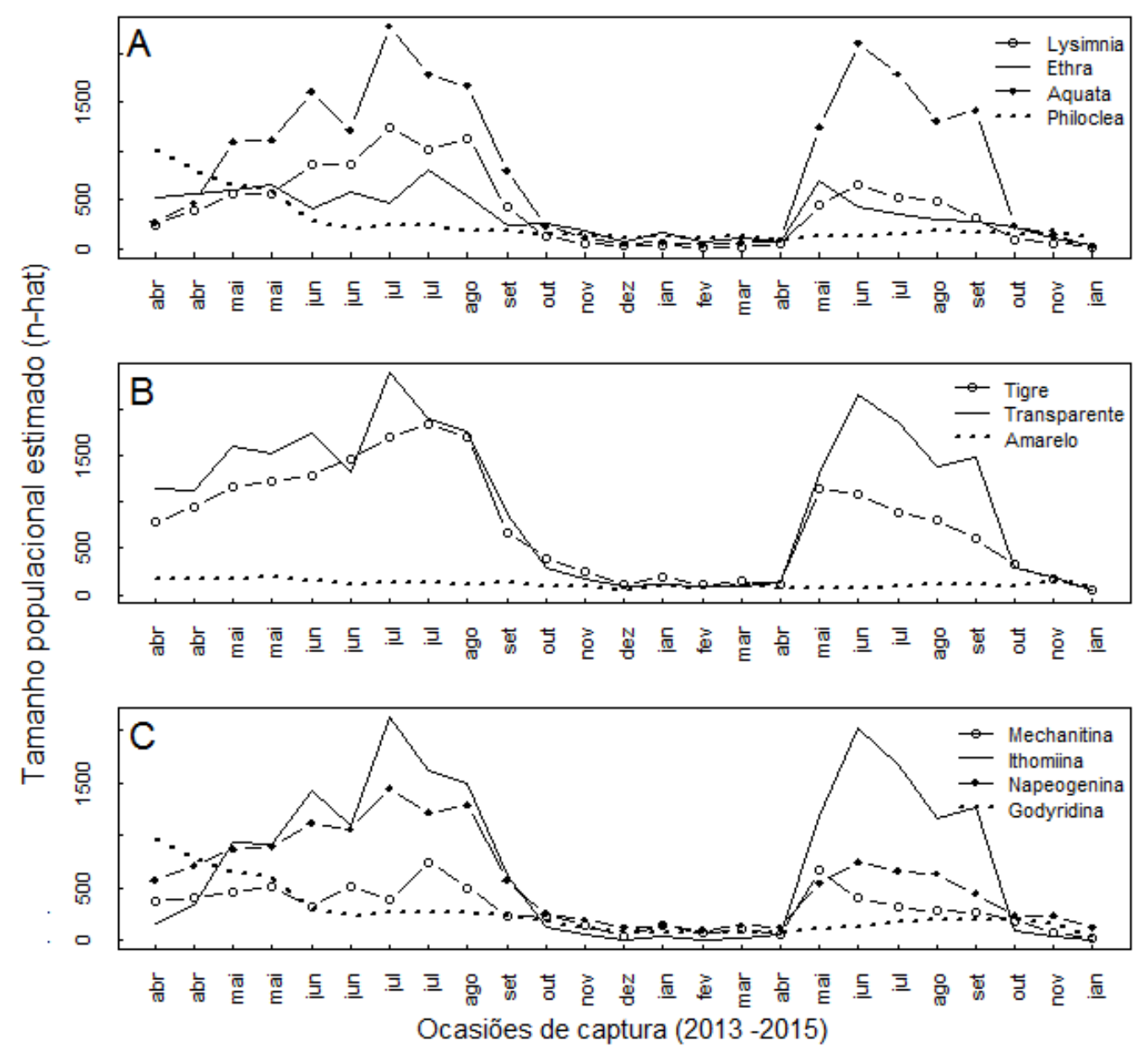

FIGURA 9. Estimativas de abundância $(n-h a t)$ de oito espécies de borboletas Ithomiini ao longo do tempo. A - Espécies agrupadas em microanéis miméticos segundo Willmott \& Mallet (2004); B- Espécies agrupadas em macroanéis miméticos segundo o critério apresentado nos métodos; C - espécies agrupadas por subtribos segundo taxonomia de Brower et al. (2014). Intervalos de confiança foram omitidos para melhor visualização. 


\section{Correlação demográfica entre subtribos}

As subtribos de Ithomiini tenderam a ter suas abundâncias mais correlacionadas entre si do que esperado por acaso. A correlação média entre as estimativas de cada subtribo foi 0,54 e a probabilidade de se obter este valor por acaso foi $p<0,0001$, visto que o valor máximo obtido nas simulações foi $r=0,35$ (Tabela 8 e Figura 9).

\section{DISCUSSÃO}

Apresentamos aqui o primeiro estudo comparativo de dinâmica populacional de borboletas miméticas baseado em estimativas demográficas que levam em conta variações na probabilidade de captura. Nossos dados referentes a oito espécies de borboletas da tribo Ithomiini não corroboram que espécies pertencentes ao mesmo anel mimético (hipótese 1) ou espécies mais próximas filogeneticamente (hipótese 2) tendem a apresentar dinâmicas populacionais mais correlacionadas entre si do que espécies agrupadas ao acaso. Por outro lado, nossos resultados corroboram a hipótese de correlação geral (hipótese 3), i.e., que os membros da tribo apresentam dinâmicas populacionais mais correlacionadas entre si do que seria esperado por acaso - independente do anel mimético ou da subtribo ao qual pertencem. Tais resultados não foram influenciados pelos critérios utilizados para definir anéis miméticos ou para medir proximidade filogenética.

Apesar de nenhum dos três parâmetros populacionais estimados terem sido mais correlacionados entre espécies co-miméticas ou entre espécies mais próximas filogeneticamente, as correlações entre cada tipo de parâmetro tiveram padrões ligeiramente diferentes. Enquanto os tamanhos populacionais $(n-h a t)$ e as sobrevivências aparentes (Phi) estimadas foram correlacionadas positivamente entre praticamente todas as espécies analisadas (em poucos casos correlações entre Phi foram iguais a zero), os nascimentos aparentes (pent) foram correlacionados tanto positiva quanto negativamente entre espécies. Essa heterogeneidade no sinal das correlações indica que, apesar dos tamanhos populacionais terem sido positivamente correlacionados, os processos demográficos que regularam estes tamanhos (i.e., entrada e saída de indivíduos) não necessariamente o foram. Em outras palavras, os intervalos de tempo em que houve maior entrada de indivíduos na população e, em menor escala, saída de indivíduos, não foram os mesmos para todas as espécies, apesar de seus tamanhos populacionais tenderem a ser sincronizados, independentemente de anel mimético ou clado. A origem dessa heterogeneidade nos processos demográficos é desconhecida, porém deve estar associada a diferenças na história de vida entre as espécies de Ithomiini (Vasconcellos-Neto 1980, Capítulo 1).

Duas das oito espécies analisadas, Mcclungia cymo salonina e Epityches eupompe parecem não formar agregações ("bolsões") durante a estação seca tal como as demais, especialmente a primeira (Vasconcellos-Neto 1980; Capítulo 1). As espécies que se agregam em bolsões transitam entre ambientes de mata e entorno de mata durante a estação chuvosa em busca de suas plantas hospedeiras (Solanaceae) e de parceiros (Vasconcellos-Neto 1980). Já M. cymo salonina, cuja planta hospedeira (Cestrum sp., Solanaceae) ocorre em ambientes sombreados e é abundante ao longo do ano todo, estaria associada apenas ao ambiente de interior da 
mata (Vasconcellos-Neto 1980). Por não formar agregações anuais, as variações no número de indivíduos de $M$. cymo salonina que estimamos devem ser mais indicativas de nascimentos e mortes do que de entrada e saída nos locais de captura (Vasconcellos-Neto 1980). Não temos evidências conclusivas sobre a realização de agregações sazonais por Epityches eupompe dada à incerteza na seleção dos modelos que descrevem sua dinâmica (Capítulo 1) e a ausência de outros estudos. Além de apresentar picos de abundância nos períodos de bolsão, E. eupompe também apresentou picos no verão-outono, época em que as espécies que se agregam se encontram dispersas. Curiosamente, $M$. cymo salonina e E. eupompe são as únicas representantes do anel mimético "philoclea" (Willmott \& Mallet 2004), porém parecem não compartilhar plantas hospedeiras (Drummond \& Brown 1987).

Os testes exatos demonstraram que os três parâmetros populacionais estimados tenderam a ser correlacionados entre todas as espécies, independente de anel mimético ou proximidade filogenética. A correlação média observada entre os tamanhos populacionais e as sobrevivências aparentes das espécies foram muito superiores do que o esperado por acaso. No entanto, a correlação média observada entre as estimativas de nascimentos aparentes de cada espécie foi mais próxima - porém ainda superior - ao valor máximo obtido nas simulações. Esses resultados também indicam que as estimativas de nascimentos aparentes foram mais heterogêneas entre espécies do que as estimativas dos demais parâmetros. Como consequência da correlação temporal geral observada entre espécies, as estimativas de tamanho populacional de cada anel mimético ou de cada subtribo também foram fortemente correlacionadas entre si. A forte correlação positiva que encontramos entre as dinâmicas populacionais das espécies, anéis miméticos e clados estudados (Tabela 8) indica que as relações miméticas ou o parentesco filogenético dentro da tribo não são fatores determinantes dessas dinâmicas. Esses resultados estão de acordo com um estudo com Ithomiini no Equador (Drummond 1976), porém destoam de outros estudos com Ithomiini realizados no Equador e no Espírito Santo, os quais encontraram co-ocorrência temporal entre espécies miméticas e divergência temporal entre anéis miméticos distintos (Brown Jr. \& Benson 1974, DeVries et al. 1999). No entanto, nosso estudo é o único que se baseou em estimativas de parâmetros populacionais que consideram probabilidades de captura variáveis e que comparou dinâmicas temporais com análises quantitativas.

Uma possível explicação para a sincronia demográfica encontrada no nosso estudo é que os requerimentos ecofisiológicos compartilhados pela tribo Ithomiini (Brown Jr. \& Benson 1974) resultariam em dinâmicas temporais semelhantes, moldadas pela pressão seletiva de fatores ambientais sazonais. De fato, em grande parte do Brasil extra-Amazônico a dinâmica sazonal dos Ithomiini é sincronizada com a mudança das estações seca e chuvosa (Vasconcellos-Neto 1980, Pinheiro et al. 2008, Capítulo 1), provavelmente devido à sua sensibilidade a altas temperaturas e à dessecação (Drummond 1976, Vasconcellos-Neto 1980, Pinheiro et al. 2008). Portanto, ao contrário das características morfológicas e comportamentais, que tendem a convergir entre co-miméticos e divergir entre anéis miméticos, supostamente devido aos benefícios do mimetismo Mülleriano (Elias et al. 2008), as dinâmicas populacionais das diferentes espécies e anéis miméticos de Ithomiini tenderam a ser uniformizadas por respostas comuns a pressões seletivas sazonais (Capítulo 1). 
Apesar de nossos resultados não corroborarem a hipótese de correlação demográfica entre comiméticos, não é possível refutar que, em outros cenários, relações miméticas poderiam influir nas dinâmicas populacionais. Uma previsão derivada da hipótese de correlação geral é que, dependendo dos fatores climáticos, as pressões seletivas sazonais que mantêm as dinâmicas temporais correlacionadas podem perder importância. É digno de nota que em regiões com chuvas abundantes e bem distribuídas ao longo do ano os Ithomiini não formam bolsões durante a estação seca (Drummond 1976, Vasconcellos-Neto 1980, Freitas 1996). Na ausência de pressões seletivas sazonais que induziriam convergência em toda a tribo, seleção dependente de micro-habitat para padrões de coloração (e.g., resultante de predação microhabitat específica) pode facilitar convergência entre espécies que voam no mesmo estrato, porém promover divergência entre anéis miméticos que ocorrem em microhabitats distintos (Beccaloni 1997b), resultando nas associações temporais entre co-miméticos e variação temporal nas abundâncias relativas dos diferentes anéis reportadas por Brown Jr. \& Benson (1974) e DeVries et al. (1999). De fato, o modelo matemático de Andrade et al. (Anexo I) sugere que até mesmo moderados níveis de predação poderiam induzir sincronização nas dinâmicas populacionais de co-miméticos. Portanto, prevemos que os fatores climáticos de uma região - notadamente a severidade da estação seca - devem influenciar o papel que relações miméticas podem ter sobre a dinâmica populacional de Ithomiini. Regiões com estiagens pronunciadas devem induzir sincronização em todas ou na maioria das espécies devido a sensibilidade à dessecação compartilhada pela tribo, sobrepondo-se a seleção para divergência entre anéis baseada em predação.

Destacamos que mesmo em ambientes com chuvas marcadamente sazonais, é possível que correlações demográficas entre co-miméticos e divergência temporal entre anéis distintos possam ocorrer em uma escala temporal maior, i.e., entre ciclos sazonais anuais. Nesse caso, esperaríamos encontrar diferentes anéis miméticos dominando numericamente a comunidade em anos diferentes, mesmo que a dinâmica populacional das espécies seja correlacionada ao longo de um ciclo anual. Esperamos, portanto, que estudos de longa duração, bem como estudos comparativos em regiões com regimes de chuva contrastantes, aumentem nosso entendimento sobre o papel do mimetismo e da filogenia nas dinâmicas populacionais de Ithomiini. Para tanto, recomendamos que futuros estudos comparativos de Ithomiini se baseiem em análises quantitativas e em estimativas populacionais que levem em conta probabilidades de captura variáveis.

\section{BIBLIOGRAFIA}

Accacio, G. de M. 1998. Borboletas em parques urbanos - estudos na cidade de São Paulo. Dissertação de Mestrado, Departamento de Zoologia, IB, Universidade de São Paulo.

Araújo, I. 2006. Estrutura e influência da sazonalidade na comunidade de borboletas da subfamília Ithomiinae (Lepidoptera: Nymphalidae) na Estação Científica Ferreira Penna, Melgaço, Pará. Dissertação de Mestrado, Museu Paraense Emílio Goeldi e Universidade Federal do Pará. 
Beccaloni, G. 1997a. Ecology, natural history and behaviour of the Ithomiinae Butterflies and their mimics in Ecuador (Lepidoptera: Nymphalidae: Ithomiinae). Tropical Lepidoptera, 8:130-124.

Beccaloni, G. 1997b. Vertical stratification of ithomiine butterfly (Nymphalidae: Ithomiinae) mimicry complexes: the relationship between adult flight height and larval host-plant height. Biological Journal of the Linnean Society, 62: 313-341.

Brower, A. V. Z., K. R. Willmott, K. L. Silva-Brandão, I. J. Garzón-Orduña, e A. V. L. Freitas. 2014. Phylogenetic relationships of ithomiine butterflies (Lepidoptera: Nymphalidae: Danainae) as implied by combined morphological and molecular data. Systematics and Biodiversity, 12:133-147.

Brown Jr., K. 1992. Borboletas da Serra do Japi: Diversidade, habitats, recursos alimentares e variação temporal. In L. P. C. Morellato (ed.) História Natural da Serra do Japi: ecologia e preservação de uma área florestal no Sudeste do Brasil. Editora Unicamp, Campinas, 142-186.

Brown Jr., K. S., e W. Benson. 1974. Adaptive polymorphism associated with multiple Müllerian mimicry in Heliconius numata (Lepid. Nymph.). Biotropica, 6: 205-228.

Brown, K. 1988. Mimicry, aposematism and crypsis in Neotropical Lepidoptera: the importance of dual signals. Bulletin de la Société Zoologique de France, 113: 83-101.

Burnham, K. P. e D. R. Anderson. 2002. Model Selection and Multimodel Inference. second edition. Springer, NewYork.

Cooch, E. G. e G. White. 2006. Program MARK: a gentle introduction. Disponível em http://www. phidot.org/software/mark/docs/book/.

DeVries, P. J., R. Lande e D. Murray. 1999. Associations of comimetic ithomiine butterflies on small spatial and temporal scales in a neotropical rainforest. Biological Journal of the Linnean Society, 67: 73-85.

Drummond, B. 1976. Comparative ecology and mimetic relationships of ithomiine butterflies in eastern Ecuador. Dissertação de Mestrado, University of Florida.

Drummond, B., and K. S. Brown. 1987. Ithomiinae (Lepidoptera: Nymphalidae): summary of known larval food plants. Annals of the Missouri Botanical Garden 74:341-358.

Elias, M., Z. Gompert, C. Jiggins e K. R. Willmott. 2008. Mutualistic interactions drive ecological niche convergence in a diverse butterfly community. PLoS Biology, 6: 2642-9.

Freitas, A. V. L. 1996. Population biology of Heterosais edessa (Nymphalidae) and its associated Atlantic forest Ithomiinae community. Journal Of The Lepidopterists' Society, 50:273289.

Goslee, S. C. e D. L. Urban. 2007. The ecodist package for dissimilarity-based analysis of ecological data. Journal of Statistical Software, 22:1-19. 
Gotelli, N. J. e G. R. Graves. 1996. Null models in ecology. Smithsonian Institution Press, Washington and London.

Hadeler, K. P., P. de Mottoni, and A. Tesei. 1982. Mimetic gain in Batesian and Müllerian Mimicry. Oecologia 53:84-92.

IAG. 2013. Boletim Climatológico Anual da Estação Meteorológica do IAG/USP. São Paulo.

IAG. 2015. Boletim Climatológico Trimestral da Estação Meteorológica do IAG/USP - Verão 2014/2015. São Paulo.

Joron, M. e J. L. B. Mallet. 1998. Diversity in mimicry: Paradox or paradigm? Trends in Ecology and Evolution, 13:461-466.

Kapan, D. 2001. Three-butterfly system provides a field test of Müllerian mimicry. Nature, 409:18-20.

Laake, J. L. 2013. RMark: An R Interface for Analysis of Capture-Recapture Data with MARK. Alaska Fish. Sci. Cent., NOAA, Natl. Mar. Fish. Serv, Seattle.

Lichstein, J. W. 2007. Multiple regression on distance matrices: A multivariate spatial analysis tool. Plant Ecology, 188:117-131.

MacDougall, A. e M. S. Dawkins. 1998. Predator discrimination error and the benefits of Müllerian mimicry. Animal Behaviour, 55:1281-1288.

Mallet, J. L. B. 1999. Causes and consequences of a lack of coevolution in Müllerian mimicry. Evolutionary Ecology, 13:777-806.

Mallet, J. L. B. e L. E. Gilbert. 1995. Why are there so many mimicry rings? Correlations between habitat, behaviour and mimicry in Heliconius butterflies. Biological Journal of the Linnean Society, 55:159-180.

Müller, F. 1879. Ituna and Thyridia: a remarkable case of mimicry in butterflies. Transactions of the Royal Entomological Society of London, 1879: xx-xxix.

Pasek, J. 2014. weights: Weighting and Weighted Statistics. R package version 0.80. Disponível em: http://CRAN.R-project.org/package=weights.

Pinheiro, C., Í. Medri e A. Salcedo. 2008. Why do the ithomiines (Lepidoptera, Nymphalidae) aggregate? Notes on a butterfly pocket in central Brazil. Revista Brasileira de Entomologia, 52:610-614.

Poole, R. 1970. Habitat preferences of some species of a Müllerian-mimicry complex in northern Venezuela, and their effects on evolution of mimic-wing pattern. Journal of the New York Entomological Society, 78:121-129.

R Core Team. 2013. R: A Language and environment for statistical computing. R Foundation for Statistical Computing, Vienna, Austria. 
Rowland, H. M., E. Ihalainen, L. Lindström, J. Mappes e M. P. Speed. 2007. Co-mimics have a mutualistic relationship despite unequal defences. Nature, 448:64-67.

Ruxton, G., T. Sherratt e M. Speed. 2004. Avoiding attack: the evolutionary ecology of crypsis, warning signals and mimicry. Oxford University Press, Oxford.

Schwarz, C. J. e A. N. Arnason. 1996. A general methodology for the analysis of capturerrecapture experiments in open populations. Biometrics, 52:860-873.

Srygley, R. B. 1999. Locomotor mimicry in Heliconius butterflies: contrast analyses of flight morphology and kinematics. Philosophical Transactions of the Royal Society B: Biological Sciences, 354:203-214.

Vasconcellos-Neto, J. 1980. Dinamica de populações de Ithomiinae (Lep., Nymphalidae) em Sumaré - SP. Dissertação de Mestrado, Universidade Estadual de Campinas.

Webb, C. O., D. D. Ackerly, M. A. McPeek e M. J. Donoghue. 2002. Phylogenies and Community Ecology. Annual Review of Ecology and Systematics, 33:475-505.

Williams, B. K., J. D. Nichols e M. J. Conroy. 2002. Analysis and Management of Animal Populations. (B. K. Williams, J. D. Nichols, and M. J. Conroy, Eds.). Academic Press, San Diego.

Willmott, K. R. e J. L. B. Mallet. 2004. Correlations between adult mimicry and larval host plants in ithomiine butterflies. Proceedings of the Royal Society B - Biological Sciences, 271:266-269.

Willmott, K. R., e A. V. L. Freitas. 2006. Higher level phylogeny of the Ithomiinae (Lepidoptera: Nymphalidae): classification, patterns of larval hostplant colonization and diversification. Cladistics 22:1-74. 


\title{
Capítulo 3 - MUDANÇAS TEMPORAIS NA COMPOSIÇÃO DE ASSEMBLEIAS DE AVES E BORBOLETAS TROPICAIS E SUBTROPICAIS SÃO CONDIZENTES COM EQUIVALÊNCIA DEMOGRÁFICA ENTRE ESPÉCIES?
}

\author{
TEMPORAL TURNOVER IN TROPICAL AND SUBTROPICAL BUTTERFLY AND BIRD ASSEMBLAGES: \\ THE ROLE OF DEMOGRAPHIC STOCHASTICITY
}

\begin{abstract}
RESUMO
Estudar a dinâmica de assembleias ao longo do tempo pode revelar processos ecológicos fundamentais, bem como descrever como pressões naturais e humanas afetam a biodiversidade. No entanto, pouco se sabe sobre como a abundância e identidade das espécies de assembleias animais na região neotropical - a mais diversa e ameaçada do planeta mudam ao longo do tempo, especialmente na ausência de perturbações. Pouco se sabe também sobre o papel relativo que mecanismos neutros e de nicho têm na regulação dessa dinâmica. Neste estudo descrevemos como a composição de espécies de assembleias de aves e borboletas de nove localidades tropicais e subtropicais na América do Sul e do Norte variou ao longo do tempo (anos a décadas), e se diferenças demográficas entre espécies (nicho) seriam importantes para explicar os padrões observados. Para tanto medimos a rotatividade na composição de espécies de cada assembleia nas escalas interanual e sazonal, e a comparamos com rotatividades simuladas por modelos que assumem equivalência demográfica. As assembleias de aves e borboletas tenderam a mudar ao longo dos anos, com taxas previstas por modelos que assumem equivalência entre espécies em metade dos casos. Sobreposta a essa rotatividade interanual, encontramos evidências de rotatividades sazonais, previsíveis, na composição de espécies da maioria das assembleias estudadas. Os modelos de equivalência previram as rotatividades interanuais das assembleias ricas em espécies raras situadas em localidades bem preservadas, porém tenderam a subestimar as rotatividades interanuais das assembleias de localidades que tiveram mudanças no uso do solo durante as amostragens. Ainda, os modelos de equivalência não foram capazes de gerar as rotatividades sazonais observadas. A premissa de equivalência demográfica entre espécies parece ser suficiente para modelar a rotatividade basal interanual de assembleias de áreas bem preservadas e ricas em espécies, porém parece ser limitada para explicar rotatividade sazonal bem como mudanças direcionais oriundas de perturbações. Nesses casos, considerar diferenças entre espécies parece ser fundamental. No entanto, modelos de equivalência podem ser oportunos para gerar previsões de rotatividades basais que sirvam de referência para monitoramentos de assembleias sujeitas a perturbações ambientais.
\end{abstract}

Palavras-chave: sazonalidade, rotatividade temporal, aves, borboletas Ithomiini, dinâmica de comunidades, processos estocásticos, mudanças no uso do solo. 


\begin{abstract}
Studying assemblies dynamics over time can reveal key ecological processes as well as describe how natural and human pressures affect biodiversity. However, little is known about how abundances and species identities of animal assemblages in the neotropical region - one of the most diverse and endangered of the planet - change over time, especially in the absence of human disturbances. Little is known about the relative role that neutral and niche mechanisms play in regulating this dynamics. In this study we describe how species composition of birds and butterflies aassemblages from nine tropical and subtropical locations in South and North America varied over time (years to decades), and whether demographic differences between species (niche) would be important for explain observed patterns. In order to do this, we measured temporal turnover in species composition of each assembly at the interannual and seasonal scales, and compared it with turnover rates simulated by models that assume demographic equivalence among species. The birds and butterflies assemblies tended to change over years, with rates predicted by equivalence models in half of the cases. Superimposed to this interannual turnover, we found evidence of seasonal, predictable turnover in species composition for most of the studied assemblies. Equivalence models predicted interannual basal turnover of assemblages rich in rare species located in well preserved locations, but underestimated interannual turnover of assemblies from localities that experienced land use chance during samplings. Also, equivalence models were not able to generate observed seasonal turnover. The assumption of demographic equivalence among species seems to be sufficient to model interannual basal turnover of assemblages from wellpreserved and species rich areas, but appears to be limited to explain seasonal turnover as well as directional changes due to disturbances. In these cases, considering species differences seems to be critical. However, equivalence models may be useful to generate predictions of basal turnovers that serve as reference for population and assemblage monitoring.
\end{abstract}

Key words: seasonality, temporal rotaturnovertion, birds, Ithomiini butterflies, community dynamics, stochastic processes, land use changes. 


\section{INTRODUÇÃO}

Apesar de ser amplamente reconhecido que as abundâncias e identidades das espécies de comunidades biológicas (doravante assembleias) variam tanto no espaço quanto no tempo (Darwin 1859, Preston 1960, MacArthur and Wilson 1967, Hubbell 2001), aspectos temporais têm recebido muito menos atenção do que os espaciais (Magurran 2011). Esta lacuna é especialmente evidente para assembleias animais da região neotropical - uma das regiões mais biodiversas do planeta - onde estudos de médio e longo-prazo são escassos. Estudar a dinâmica de assembleias de espécies ao longo do tempo pode revelar processos ecológicos fundamentais, bem como descrever como pressões naturais e humanas afetam a biodiversidade (Magurran and Dornelas 2010, Yen et al. 2016). Estudos de curto prazo, dependendo dos seus objetivos e enfoques, podem negligenciar fenômenos e processos perceptíveis apenas ao longo do tempo e gerar conclusões enviesadas (e.g. Grant and Grant 2014). Neste estudo descrevemos como a composição de espécies de assembleias de aves e borboletas de localidades tropicais e subtropicais na América do Sul e do Norte variou ao longo do tempo (anos a décadas), e se diferenças demográficas entre espécies seriam importantes para gerar os padrões observados.

Segundo Magurran (2011) a diversidade das assembleias pode mudar de duas formas ao longo do tempo: mudanças direcionais indicam alteração de um estado para outro e podem estar associadas à sucessão ecológica, perturbações ambientais e catástrofes naturais ou causadas pelo ser humano; mudanças não-direcionais (ou mudanças "basais") são resultado de extinções locais, (re)colonizações e alterações nas abundâncias das espécies residentes, e podem estar relacionadas a fenômenos naturais tal como competição, predação e dinâmicas demográficas estocásticas. Recentemente um terceiro tipo de mudança vem sendo reconhecido - mudanças sazonais - as quais representam mudanças cíclicas anuais geradas por grupos de espécies que têm picos de abundância em diferentes épocas do ano (Grøtan et al. 2012, Shimadzu et al. 2013, Yen et al. 2016). Apesar dos ambientes tropicais e suas comunidades biológicas serem historicamente considerados estáveis ao longo do tempo (MacArthur 1972, Connell 1978, Karr and Freemark 1983), variações sazonais na precipitação são comuns e adaptações a esta sazonalidade são bem documentadas na história de vida de plantas, insetos, mamíferos, lagartos e aves (Karr 1976 e referências inclusas; ver Capítulo 1). Porém, estudos focados em assembleias e que mediram taxas de rotatividade temporal na composição de espécies, com resolução para identificar padrões sazonais, ainda são raros na região neotropical (porém ver Grøtan et al. 2012, 2014).

Um intenso debate se desenvolveu nas últimas duas décadas a respeito do papel relativo que mecanismos de "nicho" (diferenças ecológicas determinísticas entre espécies) e "neutros" (nascimentos, mortes e imigração-emigração aleatórias) exercem na estruturação e dinâmica das comunidades (Nekola and Brown 2007). Segundo as teorias clássicas de nicho, a estrutura e dinâmica de uma assembleia resultariam de diferenças competitivas e de aptidão entre suas espécies, sendo as abundâncias relativas proporcionais à habilidade de cada espécie adquirir recursos (MacArthur 1957, Tokeshi 1999, Thibault et al. 2004, Magurran 2007). A teoria neutra (Hubbell 2001), por outro lado, postula que a estrutura e dinâmica de assembleias de espécies 
de um mesmo nível trófico seria resultado de deriva aleatória gerada sob um cenário de equivalência entre espécies, i.e., taxas demográficas equivalentes para todos os indivíduos da assembleia independente da espécie à qual pertencem (Bell 2000, Hubbell 2001). Sob essa perspectiva, portanto, a abundância relativa de cada espécie - o quão comum ou rara ela é seria resultado do acaso.

Apesar de grande parte dos biólogos não considerar a premissa de equivalência entre espécies realista ou suficiente para descrever como assembleias são formadas e organizadas, a teoria neutra teve sucesso em ajustar ou reproduzir alguns padrões ecológicos tal como a distribuição de abundância de espécies, relação espécies-área e padrões de beta-diversidade (Hubbell 2001, Volkov et al. 2003, Missa et al. 2016, porém ver Adler 2004, Dornelas et al. 2006). Proponentes dessa teoria interpretaram esses resultados como evidência de que estocasticidade demográfica seria mais importante do que diferenças entre espécies na estruturação de comunidades (Hubbell 2001, Adler et al. 2007). Entretanto, grande parte dos testes da teoria neutra têm se baseado no ajuste de previsões da teoria a padrões empíricos obtidos em estudos pontuais no tempo, especialmente distribuições de abundância de espécies (no entanto ver Clark and McLachlan 2003, Adler 2004, Wootton 2005, Ricklefs 2006). Um problema com essa abordagem é que dentre as dezenas de modelos propostos para descrever a estrutura das comunidades (incluindo aí a teoria neutra), poucos podem ser descartados pois seus ajustes aos dados empíricos são muito semelhantes entre si (McGill 2003, McGill et al. 2007, Nekola and Brown 2007). Por isso, considera-se que avaliar modelos ajustando curvas previstas a distribuições de abundância empíricas pontuais seria um teste fraco (McGill 2003). Ainda, análises das distribuições de abundância de espécies seriam pouco informativas para entender a importância relativa de mecanismos neutros e de nicho (Adler et al. 2007).

Um procedimento mais robusto para testar mecanismos de estruturação de comunidades consiste em avaliar padrões temporais ao invés de simples "fotografias" da comunidade (Adler 2004, Kalyuzhny et al. 2015), usando métricas de diversidade que, ao contrário das distribuições de abundância, levam em conta a identidade das espécies (Wootton 2005, McGill et al. 2007, Mac Nally 2007, Magurran 2008, Magurran and Henderson 2010). Por exemplo, quão frequentemente uma espécie rara ou ausente se torna comum e vice versa, i.e., qual a taxa de rotatividade (turnover) temporal na composição de espécies de uma comunidade? Modelos neutros e modelos baseados em nicho podem ter previsões contrastantes, e as vezes um mesmo modelo pode ter resultados contraditórios. Por exemplo, as taxas de rotatividade na composição de espécies previstas pela teoria neutra têm sido em alguns casos inferiores às taxas empíricas (Wootton 2005, Gilbert et al. 2006, Mac Nally 2007), porém em outros casos tem sido muito superiores (Clark and McLachlan 2003, McGill et al. 2005). Um estudo que analisou cem séries temporais de diferentes organismos ao redor do planeta encontrou que as mudanças na composição de espécies excederam sistematicamente as previsões de modelos neutros (Dornelas et al. 2014). No entanto, apesar da ampla e inédita representatividade global e taxonômica desse estudo, nele estão representadas apenas duas comunidades de animais tropicais (aves e gastrópodes terrestres) em uma única localidade na América Central. Portanto, ainda persiste uma importante lacuna no conhecimento sobre como assembleias de animais neotropicais mudam ao longo do tempo e quais mecanismos seriam responsáveis por essa dinâmica. 
Além de lançar luz sobre questões básicas sobre estruturação de comunidades, estudos ao longo do tempo também são fundamentais para abordar questões aplicadas. Um dos maiores desafios científicos da atualidade é quantificar e prever mudanças na biodiversidade atribuíveis a causas naturais e a causas humanas (Magurran 2011, Dornelas et al. 2012). Nesse sentido é muito pertinente quantificar taxas de mudança "basais" na composição das assembleias (Magurran 2016), i.e., mudanças que ocorrem nas abundâncias e na identidade das espécies de qualquer assembleia em virtude de processos naturais de variabilidade ambiental, extinções e (re)colonizações (Magurran and Dornelas 2010). Essas taxas basais de rotatividade (turnover) podem ser usadas como referência para avaliar perturbações humanas (Magurran 2008), de forma análoga a como taxas de extinção "de fundo", i.e., as que ocorreram ao longo da escala evolutiva antes dos impactos humanos, são usadas como referência para medir as taxas de extinção atuais (e.g. Lawton and May 1995). A ausência de dados sobre rotatividades basais de assembleias dificulta muito a tarefa de distinguir entre mudanças decorrentes de atividades humanas de mudanças que ocorreriam de qualquer forma (Magurran 2011).

Neste estudo descrevemos como a composição de espécies de assembleias de aves e borboletas tropicais e subtropicais em nove localidades no Brasil (Amazônia, Cerrado, Mata Atlântica) e nos EUA (Florida) variou ao longo do tempo. Avaliamos a rotatividade (turnover) na composição de espécies ao longo dos anos (tendência interanual) e, nas assembleias cuja frequência amostral teve resolução suficiente, também na escala intra-anual (sazonalidade). Verificamos se modelos que consideram equivalência demográfica entre espécies, premissa postulada pela teoria neutra de Hubbell (2001), foram capazes de prever os padrões de rotatividade dessas assembleias ao longo de intervalos de tempo de 2,5 a 46 anos. Essas informações são relevantes para identificar rotatividades basais de referência para o monitoramento de assembleias neotropicais e para avaliar o papel de diferenças entre espécies na estruturação de comunidades.

\section{MÉTODOS}

\section{Obtenção e descrição dos dados}

Neste estudo usamos dez séries temporais oriundas da amostragem de nove assembleias de aves ou borboletas tropicais e subtropicais em nove localidades no Brasil e nos EUA (Figura $1 \mathrm{e}$ Tabela 1). Quatro destes conjuntos de dados foram coletados pelo autor desta tese e os demais foram obtidos a através de colaborações ou de ferramentas de livre acesso. Oito das dez séries temporais representam amostragens de aves pela técnica de contagem por pontos (point counts - Gregory et al., 2004) e duas representam amostragens de borboletas da tribo Ithomiini (Nymphalidae, Danainae) pela técnica de captura-recaptura com redes entomológicas. Das dez séries duas foram obtidas no bioma Amazônico (estado de Rondônia), uma foi obtida na transição entre Amazônia e Cerrado (Mato Grosso), quatro no bioma Mata Atlântica (São Paulo) e três no bioma Floresta Temperada (EUA, estado da Flórida). As latitudes das localidades amostradas variaram entre $9^{\circ}$ e $24^{\circ}$ sul (séries no Brasil) e entre $26^{\circ}$ e $30^{\circ}$ norte (séries nos EUA). Das dez séries, seis foram obtidas em ambientes florestais (duas delas em contexto urbano) e quatro em ambientes costeiros em contexto urbano e/ou suburbano. A 
riqueza total registrada ao longo de cada série variou entre oito e 268 espécies (tabela 1). As séries variam quanto à duração total do estudo, frequência das amostragens e área amostrada, porém cada uma seguiu um protocolo amostral padronizado e consistente ao longo do tempo. A duração das séries temporais variou entre 2,5 a 46 anos e os intervalos entre as amostragens de cada série variaram entre 0,9 a 16,5 meses (tabela 1). As séries com amostragens distribuídas ao longo das estações do ano permitiram a análise de padrões sazonais (i.e., mudanças cíclicas associadas ao ano solar) enquanto que séries com amostragens concentradas em apenas uma estação do ano (três do total de dez) permitiram apenas a análise de tendências entre anos. A seguir descreveremos as séries temporais e seus respectivos procedimentos de coleta de dados.

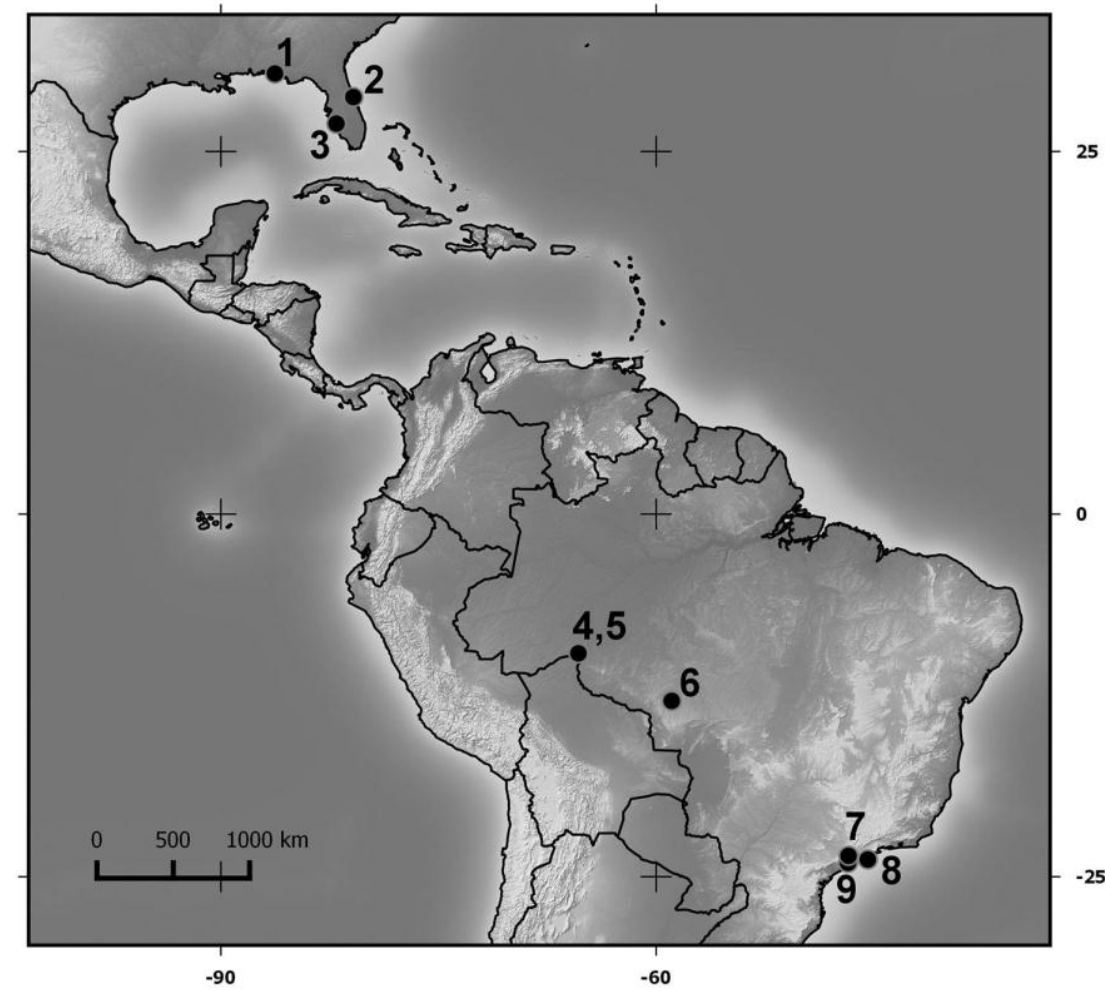

Figura 1. Localização das assembleias de aves e borboletas Ithomiini (Nymphalidae, Danainae) analisadas neste estudo. 1 - Fort Walnt Beach (FL), 2 - Scottsmoor (FL), 3 - Punta Gorda (FL), 4 - Jirau 10 (RO), 5 - Jirau 11 (RO), 6 - Juruena (MT), 7 - USP (SP), 8 - São Sebastião (SP), 9 - Curucutu (Parque Estadual da Serra no Mar - SP). Ver Tabela 1 para mais informações sobre cada assembleia. A escala de cinzas representa altitudes, onde as tonalidades mais claras representam altitudes mais elevadas. Figura elabora pelo Dr. Sérgio Marques de Souza. 


\section{Jirau 10 e Jirau 11}

Estas duas séries temporais consistem de amostragens de aves através da técnica de contagem por pontos em duas localidades às margens do Rio Madeira (município de Porto Velho, Rondônia), realizadas entre abril de 2010 e fevereiro de 2015 como parte do programa de monitoramento de avifauna da usina hidrelétrica de Jirau, dados gentilmente cedidos pelo Prof. Dr. Luis Fabio Silveira (Museu de Zoologia da Universidade de São Paulo). A diversidade de espécies de aves da região é surpreendente, tendo sido lá registradas pelo menos 645 espécies (Silveira, dados não-publicados). Parte dessa alta riqueza se deve ao fato de que o Rio Madeira separa duas áreas de endemismo distintas - Rondonia e Inambari (Cracraft 1985) de modo que diversas espécies ocorrem em apenas uma das margens do rio. De fato, estas duas séries temporais são as de maior riqueza neste estudo (239 e 268 spp.). Cada série foi obtida em um trajeto de $4 \mathrm{~km}$ de extensão localizado na margem esquerda (Jirau 11) e direita (Jirau 10) do Rio Madeira, sendo os dois trajetos separados por $10 \mathrm{~km}$ de distância (ver tabela 1 e figura 1). 0 trajeto Jirau 11 se encontra a pelo menos $4 \mathrm{~km}$ de qualquer borda com ambientes antrópicos. Partindo na direção noroeste é possível percorrer mais de $900 \mathrm{~km} \mathrm{sem}$ abandonar a floresta Amazônica ou cruzar estradas. O trajeto Jirau 10 se encontra a pelo menos $3 \mathrm{~km}$ de qualquer borda antrópica e na direção sudeste é possível percorrer $15 \mathrm{~km}$ da mata ininterrupta. Escolhemos estes dois trajetos dentre doze disponíveis devido à regularidade temporal de suas amostragens e devido a sua localização mais a montante da barragem da hidrelétrica, o que minimiza potenciais alterações na composição da comunidade relacionadas ao enchimento do lago da usina (ocorrido entre nov/2012 e abr/2013). Estes trajetos estão a mais de $80 \mathrm{~km}$ de distância da barragem de Jirau, e análises de séries históricas de imagens de satélite Landsat (disponíveis no software Google Earth) não revelam alterações no nível do rio no entorno imediato dos dois trajetos entre os períodos pré e pós-enchimento.

Em cada trajeto foram alocados 16 pontos de contagem regularmente separados por $500 \mathrm{~m}$ entre si, partindo em direção perpendicular ao rio para o interior da floresta, iniciando a $50 \mathrm{~m}$ de distância da margem. Como nem todos os pontos de cada trajeto foram amostrados em todas as campanhas, selecionamos para nossas análises os pontos que tiveram cobertura temporal completa, os quais corresponderam aos oito primeiros pontos (50 a $1800 \mathrm{~m}$ ) de cada trajeto. Os ambientes contemplados pelos pontos corresponderam a mata de terra firme, sendo que o primeiro ponto de cada trajeto $(50 \mathrm{~m})$ contemplou ambiente de mata de várzea. No trajeto Jirau 10 foram realizadas 15 campanhas (amostragens temporais) entre abril/2010 a dez/2014, separadas por um intervalo médio de 4,1 meses (desvio padrão $=2,8$ ), enquanto que no trajeto Jirau 11 foram realizadas 19 campanhas (de abril/2010 a fev/2015) com intervalo médio de 3,3 meses $(d p=1,22)$. Cada ponto foi amostrado duas vezes por campanha em dias diferentes, no período entre as $06 \mathrm{~h} 00$ e 09h00. Cada contagem durou 10 minutos e toda ave detectada visualmente ou por audição em um raio ilimitado ao redor do observador foi registrada, com o cuidado para não se contabilizar um mesmo indivíduo mais de uma vez em uma mesma contagem. Manifestações sonoras de aves que não foram identificadas de imediato foram registradas com gravadores e microfones direcionais e identificadas a posteriori. As amostragens foram realizadas por oito ornitólogos profissionais com experiência em avifauna amazônica. 
Tabela 1. Atributos das séries temporais analisadas neste estudo. Amb. - Ambiente. Duração - duração do estudo em anos. Freq. - frequência média das amostragens de cada série temporal; entre parênteses estão representados os desvio padrão. Riq. - número de espécies registradas ao longo de toda a série temporal. A - Área amostrada em cada estudo, em hectares.

\begin{tabular}{|c|c|c|c|c|c|c|c|c|c|}
\hline Série & Táxon & País & Estado & Bioma & Amb. & $\begin{array}{c}\text { Duração } \\
\text { (anos) }\end{array}$ & $\begin{array}{c}\text { Freq. } \\
\text { (meses) }\end{array}$ & Riq & A \\
\hline Jirau 10 & Aves & BRA & Rondônia & Amazônia & Florestal & 4,7 & $4,1(2,83)$ & $\begin{array}{c}23 \\
9\end{array}$ & 157,1 \\
\hline JIrau 11 & Aves & BRA & Rondônia & Amazônia & Florestal & 4,9 & $3,3(1,22)$ & $\begin{array}{c}26 \\
8\end{array}$ & 157,1 \\
\hline Juruena & Aves & BRA & $\begin{array}{l}\text { Mato } \\
\text { Grosso }\end{array}$ & $\begin{array}{l}\text { Cerrado/ } \\
\text { Amazônia }\end{array}$ & Florestal & 2,5 & $4,3(1,22)$ & 94 & 117,8 \\
\hline Curucutu & Aves & BRA & $\begin{array}{c}\text { São } \\
\text { Paulo }\end{array}$ & $\begin{array}{c}\text { Mata } \\
\text { Atlântica }\end{array}$ & Florestal & 4,4 & $3,1(0,91)$ & $\begin{array}{c}10 \\
9\end{array}$ & 3,9 \\
\hline $\begin{array}{l}\text { São } \\
\text { Sebastião }\end{array}$ & Aves & BRA & $\begin{array}{c}\text { São } \\
\text { Paulo }\end{array}$ & $\begin{array}{c}\text { Mata } \\
\text { Atlântica }\end{array}$ & $\begin{array}{l}\text { Costeiro } \\
\text { /urbano }\end{array}$ & 5,2 & $2,3(2,92)$ & $\begin{array}{c}11 \\
3\end{array}$ & 117,8 \\
\hline $\begin{array}{l}\text { BBS - Punta } \\
\text { Gorda }\end{array}$ & Aves & EUA & Florida & $\begin{array}{c}\text { Floresta } \\
\text { temperad } \\
\text { a }\end{array}$ & $\begin{array}{l}\text { Costeiro } \\
\text { /suburb. }\end{array}$ & 34 & $12,9(3,0)$ & 61 & 502,7 \\
\hline $\begin{array}{l}\text { BBS - Fort } \\
\text { Waltn } \\
\text { Beach }\end{array}$ & Aves & EUA & Florida & $\begin{array}{c}\text { Floresta } \\
\text { temperad } \\
\text { a }\end{array}$ & $\begin{array}{l}\text { Costeiro } \\
\text { /suburb. }\end{array}$ & 45 & $13,7(7,9)$ & 67 & 502,7 \\
\hline $\begin{array}{l}\text { BBS - } \\
\text { Scottsmoor }\end{array}$ & Aves & EUA & Florida & $\begin{array}{c}\text { Floresta } \\
\text { temperad } \\
\text { a }\end{array}$ & $\begin{array}{l}\text { Costeiro } \\
\text { /suburb. }\end{array}$ & 46 & $\begin{array}{c}16,5 \\
(17,8)\end{array}$ & 84 & 502,7 \\
\hline USP & $\begin{array}{l}\text { Borboletas } \\
\text { Ithomiini }\end{array}$ & BRA & $\begin{array}{l}\text { São } \\
\text { Paulo }\end{array}$ & $\begin{array}{c}\text { Mata } \\
\text { Atlântica }\end{array}$ & $\begin{array}{l}\text { Florestal } \\
\text { /urbano }\end{array}$ & 3 & $0,9(0,37)$ & 22 & 0,1 \\
\hline USP core & $\begin{array}{c}\text { Borboletas } \\
\text { Ithomiini }\end{array}$ & BRA & $\begin{array}{c}\text { São } \\
\text { Paulo }\end{array}$ & $\begin{array}{c}\text { Mata } \\
\text { Atlântica }\end{array}$ & $\begin{array}{l}\text { Florestal } \\
\text { /urbano }\end{array}$ & 2,9 & $0,9(0,37)$ & 8 & 0,1 \\
\hline
\end{tabular}

\section{Juruena}

Estes dados consistem de amostragens de aves através da técnica de contagem por pontos no alto curso do Rio Juruena (município de Campos de Júlio, Mato Grosso) realizadas entre setembro de 2007 e abril de 2010 (figura 1 e tabela 1) como parte dos programas de monitoramento da PCH (pequena central hidrelétrica) Rondon e PCH Telegráfica. $\mathrm{O}$ alto curso do Rio Juruena se localiza na Chapada dos Parecis, em uma área de transição entre os biomas Cerrado e Amazônia. A região é considerada uma IBA, sigla em inglês para "área importante para conservação de aves" (IBA MT03 - Alto Rio Juruena), por abrigar espécies endêmicas e ameaçadas do Cerrado (De Luca et al. 2009), como por exemplo o criticamente ameaçado tiêbicudo Conothraupis mesoleuca (Candia-Gallardo et al. 2010). Nesta região ocorrem exuberantes matas ciliares ao longo do Juruena, as quais pelo seu porte e pelas espécies de aves predominantes podem ser consideradas ambientes amazônicos. Os dados foram coletados em seis pontos de contagem, três em cada $\mathrm{PCH}$, alocados em ambientes de mata ciliar do Juruena. A largura da mata ciliar nos trechos de alocação dos pontos variou entre 300 e $900 \mathrm{~m}$, ocorrendo em seu entorno ambientes de cerradão e campina. Os seis pontos foram agrupados representando uma única localidade para que o número de pontos (e consequentemente a área amostrada) não fosse inferior ao mínimo obtido nos demais conjuntos de dados (cinco pontos). Os pontos de cada PCH distaram de 250 a $800 \mathrm{~m}$ entre si e a distância entre as $\mathrm{PCH}$ é de $5 \mathrm{~km}$. Foram realizadas oito campanhas de amostragem ao longo de 2,9 anos, com intervalo médio de 4,3 meses $(\mathrm{dp}=1,22)$. Entre maio e novembro de 2008 
durante o processo de construção de cada $\mathrm{PCH}$ foram suprimidos trechos de vegetação ribeirinha de ambas as margens do Juruena, afetando uma faixa de 50 a $200 \mathrm{~m}$ de largura e 2,5 a 3,5 km de extensão a montante das PCHs. Os pontos de amostragem foram alocados a jusante das $\mathrm{PCH}$, a pelo menos $500 \mathrm{~m}$ da linha de supressão da vegetação, por isso é possível que tenham ocorrido mudanças na comunidade de aves em função dessa perturbação. Cada ponto foi amostrado duas vezes por campanha, em dias consecutivos, entre as 06h00 e 09h00. Cada contagem durou 10 minutos, sendo registrada toda ave avistada ou ouvida em um raio ilimitado no entorno do observador. Vocalizações não identificadas de imediato foram registradas com gravador e microfone direcional e identificadas a posteriori. Todas as amostragens deste conjunto de dados foram realizadas pelo autor desta tese após 72 dias de familiarização com a avifauna local, distribuídos em três períodos (27, 30 e 15 dias) ao longo do ano.

\section{Curucutu}

Este conjunto de dados consiste de amostragens de aves através de contagens por ponto realizadas em um mata de baixada no interior do Parque Estadual da Serra do Mar (município de Itanhaém, São Paulo) entre maio de 2007 e dezembro de 2011 (Tabela 1). Estes dados foram gentilmente compartilhados pelo biólogo Fábio Schunck e fazem parte de sua tese de doutorado (em andamento) vinculada ao Departamento de Zoologia do Instituto de Biociências da Universidade de São Paulo. As florestas da baixada litorânea onde esta localidade está inserida abrigam uma das avifauna mais ricas da Mata Atlântica, com diversas espécies endêmicas e ameaçadas de extinção (Bencke et al. 2006). Esta área amostral se insere no maior bloco contínuo remanescente do bioma, sendo possível percorrer pelo menos $30 \mathrm{~km}$ de escarpas e platôs florestados ininterruptos, tanto para leste quanto para oeste da área amostral. Os dados foram coletados em cinco pontos de contagem alocados a cada $100 \mathrm{~m}$ de um trajeto que percorre ambiente de floresta ombrófila densa de terras baixas, a uma altitude média de $40 \mathrm{~m}$ acima do nível do mar. Foram realizadas 18 campanhas de amostragem com intervalo médio de 3,1 meses ( $d p=0,9$ ) entre si, sendo cada ponto amostrado duas vezes por campanha entre as $06 \mathrm{~h} 00$ e $09 \mathrm{~h} 00$ em dias consecutivos. Cada contagem durou 10 minutos, sendo contabilizados todos os indivíduos detectados por avistamento ou por audição até $50 \mathrm{~m}$ de distância do observador, com o cuidado de não se contar o mesmo indivíduo mais de uma vez em uma mesma contagem. Vocalizações não identificadas de imediato foram registradas com gravador e microfone direcional e identificadas posteriormente. Todas as amostragens deste conjunto de dados foram realizadas por um único observador (F. Schunck).

\section{São Sebastião}

Esta série temporal consiste de amostragens de aves através de contagem por pontos em ambientes costeiros no Canal de São Sebastião (município de São Sebastião, São Paulo), realizadas entre maio de 2011 e julho de 2016 como parte do programa de monitoramento da avifauna do entorno do Porto de São Sebastião (tabela 1), executado pela Fundação de Estudos e Pesquisas Aquáticas (FUNDESPA) e administrado pela Companhia das Docas de São Sebastião. A região apresenta diversos ambientes tal como floresta ombrófila densa, floresta secundária, costões rochosos, manguezal e planícies de maré, e abriga a mancha urbana da região central do município homônimo. Apesar da área amostral estar inserida em contexto urbano ou peri-urbano, não ocorreram alterações no uso do solo ou outras perturbações perceptíveis ao longo das amostragens. Sua avifauna apresenta mais de 130 espécies, com 
destaque para aves migratórias de diversas origens e modos de vida (Candia-Gallardo, dados não-publicados). As amostragens foram realizadas em seis pontos de contagem, separados por no mínimo $320 \mathrm{~m}$ entre si. Os pontos contemplaram ambientes de planície de maré, manguezal, costão rochoso e ambiente marinho. Quatro pontos foram alocados em terra e dois no Canal, entre 400 e $500 \mathrm{~m}$ da costa com acesso por embarcação. As amostragens foram realizadas ao longo de cinco anos com intervalo médio de 2,3 meses ( $d p=2,92$ ). Após o primeiro ano de estudo, no qual as amostragens foram mensais, houve uma interrupção de dezesseis meses na coleta de dados (entre maio/2012 e set/2013), sendo retomadas amostragens com frequência bimestral. Cada ponto foi amostrado de três a quatro vezes por campanha durante as quatro primeiras horas após o nascer do sol (período matutino) e durante as três últimas horas antes do pôr-do-sol (período vespertino), ao longo de três dias consecutivos. Cada ponto foi amostrado por campanha duas vezes no período matutino e uma ou duas no período vespertino, não sendo repetidas contagens em um mesmo ponto em um mesmo período e dia. Cada contagem durou 15 minutos, sendo contabilizada toda ave detectada por avistamento ou audição localizada a até $200 \mathrm{~m}$ do observador, tomando-se o cuidado de não contar um mesmo indivíduo duas ou mais vezes durante uma mesma contagem. Vocalizações não identificadas de imediato foram registradas com gravador $\mathrm{e}$ microfone direcional para identificação a posteriori. Todas as contagens desta série foram realizadas pelo autor da tese.

\section{Punta Gorda, Fort Waltn Beach e Scottsmoor - Breeding Bird Survey (BBS)}

Estas três séries temporais fazem parte do programa de monitoramento "Breeding Bird Survey" (BBS), um esforço cooperativo entre agências técnicas governamentais dos EUA, Canadá e México (Centro de Pesquisa de Vida Selvagem Patuxent (USGS), Serviço de Vida Selvagem do Canadá e Comissão Nacional Mexicana para o Conhecimento e Uso da Biodiversidade) para monitorar o status e as tendências das populações de aves da América do Norte (Sauer et al. 2013). Iniciado em 1966 e atualmente cobrindo grande parte daquele continente, o BBS é baseado no trabalho voluntário de milhares de "birders" que executam contagens por ponto anuais ao longo de rotas pré-estabelecidas, e tem sido fonte primária para a avaliação de mudanças populacionais e de possíveis impactos sobre a avifauna do continente (Sauer et al. 2013). Os dados do BBS são de acesso livre e disponibilizados na internet, sendo que aqui utilizamos a versão 2015.0 que engloba o período entre 1966 a 2015 (Pardieck et al. 2016). Os critérios que utilizamos para selecionar rotas para nosso estudo foram latitude (preferência por proximidade à região tropical), extensão temporal (a maior possível), regularidade das amostragens (a mais regular possível) e traçado por ambientes costeiros. Este último critério visou selecionar ambientes assemelhados aos da série temporal de São Sebastião, visto que os ambientes das demais séries que utilizamos neste estudo (floresta tropical) não ocorrem nos EUA continental nem no norte do México, onde há algumas rotas do BBS. Selecionamos três rotas no estado da Florida (Figura 1), localizadas na costa leste e norte do Golfo do México (Punta Gorda - BBS 25132 e Fort Waltn Beach - BBS 25002, respectivamente) e na costa Atlântica do estado (Scottsmoor BBS - 25025). A distância entre rotas varia entre 550 e 220 km (ver Figura 1).

A região biogeográfica das rotas selecionadas é a das "Planícies costeiras do Golfo e Atlânticas" e sua vegetação original corresponde a florestas e bosques temperados (Sayre et al. 2009). Os ambientes contemplados por cada rota foram bosques secundários, costa oceânica e de 
lagunas, manguezal, além de ambientes rurais e peri-urbanos. Mudanças significativas no uso do solo, tal como a expansão urbana e de condomínios suburbanos, ocorreram ao longo dos anos de amostragem dessas rotas, pelo menos entre 1984 e 2014, período no qual há séries temporais de imagens de satélite disponíveis na plataforma Google Earth. As amostragens de cada uma destas três rotas, assim como de todas as do BBS (ver detalhes em Sauer et al. 2013), foram feitas em 50 pontos de contagem ("stops") alocados a intervalos de $800 \mathrm{~m}$ ao longo de rodovias ou estradas. Cada rota foi amostrada uma vez por ano (exceto em alguns anos quando não houve amostragem, ver abaixo) durante a estação reprodutiva das aves da América do Norte (maio-junho) por um observador, geralmente um voluntário, apto a identificar aves por avistamento e audição. As amostragens se iniciaram 30 minutos antes do nascer-do-sol e em cada ponto o observador contabilizou todas as aves vistas ou ouvidas a até $400 \mathrm{~m}$ de distância. Para manter o número de pontos de amostragem das séries do BBS condizente com as demais séries deste estudo selecionamos para as análises apenas os dez primeiros pontos de cada rota, visto que os dados são disponibilizados em cinco conjuntos de 10 pontos e não por pontos individualmente. A série Punta Gorda foi amostrada durante 34 anos consecutivos (1980-2014) com exceção de dois anos (1983 e 1993), Fort Waltn durante 45 anos (1966-2011) exceto de 1981 a 84 e 1986, e Scottsmoor durante 46 anos (1968-2014), exceto 1974 a 76, 1978 a 85 e 1991 (Pardieck et al. 2016). Ao contrário das demais séries temporais que utilizamos neste estudo, a frequência das amostragens das rotas do BBS é anual (uma amostragem por rota por ano). Por isso, essas três séries do BBS não fornecem informações sobre padrões sazonais (i.e., variações dentro do ano), apenas tendências interanuais nas populações e comunidades de aves.

\section{USP e USP core}

Estas duas séries temporais consistem de amostragens de borboletas da tribo Ithomiini (Nymphalidae, Danainae) através de capturas com redes entomológicas, realizadas no campus da Universidade de São Paulo (na capital do estado de mesmo nome) entre abril/2013 e abril/2016, descritas em detalhe no Capítulo 1. Ambas as séries são oriundas do mesmo conjunto de dados, diferindo apenas no tipo de medida adotada para quantificar cada população (taxa de captura ou estimativa de tamanho populacional baseada em marcaçãorecaptura), na duração ("USP core" tem uma amostra temporal a menos) e no conjunto de espécies. Na série USP incluímos todas as espécies de Ithomiini registradas no estudo (22 espécies), enquanto que na USP core usamos apenas as oito espécies mais comuns ("core"), cujo número de capturas foi suficiente para o cálculo de estimativas populacionais (ver a sessão Análise de dados para mais detalhes). As borboletas Ithomiini são notáveis por suas defesas químicas (Brown 1984) e pelas relações de mimetismo entre as espécies da tribo e com outros grupos de Lepidoptera (Beccaloni 1997). O fato das espécies do grupo coexistirem e compartilharem microhabitats (Pinheiro et al. 2008), parte das plantas hospedeiras (Vasconcellos-Neto 1980) e fontes de néctar (Drummond 1976) os torna um grupo particularmente interessante para avaliar a premissa de equivalência entre espécies postulada pela teoria neutra.

Realizamos as amostragens em um fragmento de vegetação de aproximadamente cinco hectares inserido em uma matriz urbana, o Parque Esporte Para Todos (PEPT). Trata-se de um bosque dominado por eucalipto (Eucalyptus sp.) e pela palmeira-real (Archontophoenix cunninghamiana), espécies exóticas originárias da Austrália, e algumas espécies esparsas da 
flora nativa (para mais detalhes ver Capítulo 1). Amostramos as Ithomiini do PEPT ao longo de três anos (2,9 anos nos dados USP core) com intervalos aproximadamente mensais entre campanhas (média $=0,9$ meses, $d p=0,37$ ). Em cada campanha realizamos três ou quatro sessões de captura de 30 minutos de duração dentro de um intervalo de dois ou três dias consecutivos. Em um mesmo dia realizamos no máximo duas sessões de captura espaçadas por pelo menos quatro horas de intervalo, entre as $09 \mathrm{~h} 00$ e $16 \mathrm{~h} 00$. Em cada sessão de captura uma ou duas pessoas munidas de rede entomológica (puçá) percorreram um trajeto de $340 \mathrm{~m}$ de extensão com o formato do número oito, em sentidos opostos, capturando indivíduos detectados a até $3 \mathrm{~m}$ do trajeto e $2,5 \mathrm{~m}$ acima do nível do solo. Marcamos cada espécime individualmente com números sequenciais na face ventral da uma das asas anteriores ou posteriores (dependendo da espécie), com caneta permanente ponta ultrafina da marca "Sharpie". Após a marcação liberamos os indivíduos no local de captura. No Capítulo 1 (sessão métodos) constam mais detalhes sobre o procedimento de captura e marcação.

\section{Análise de dados}

Os procedimentos de análise de dados consistiram de cinco passos, repetidos para cada uma das 10 séries temporais aqui analisadas:

I. Obtenção de um índice ou estimativa de abundância para quantificar a população de cada espécie em cada campanha (amostra temporal) a partir dos dados de contagem ou captura-recaptura;

II. Cálculo de medidas de rotatividade (turnover) na composição de espécies ao longo do tempo;

III. Ajuste e seleção de modelos descritores dos padrões temporais de rotatividade empírica;

IV. Simulação de rotatividades temporais por modelo que assume equivalência demográfica entre espécies;

V. Comparação entre padrões de rotatividade empíricos e simulados.

A seguir descreveremos os procedimentos que adotamos em cada passo:

\section{Índices e estimativas de abundância}

Os dados de entrada das análises de cada série temporal consistiram de uma matriz com espécies nas linhas e campanhas (amostras temporais) nas colunas, preenchida com um índice ou estimativa de abundância para cada espécie em cada campanha. Para as séries baseadas em contagens por ponto (aves) usamos um índice escalonado pelo número de contagens (Mac Nally 2007):

$$
I_{x t}=\frac{\sum n_{x t}}{C_{t}} * 100
$$

Onde $I_{x t}$ representa a abundância escalonada da população da espécie $x$ na campanha $t$, $\sum n_{x t}$ representa a somatória do número de contatos da espécie $x$ obtidos em todas as contagens da campanha $t$, e $C_{t}$ representa o número total de contagens realizadas na campanha $t$. A multiplicação por uma centena serve para arredondar os menores valores para 
o número inteiro mais próximo (Mac Nally 2007). Formalmente este índice representa o número de contatos obtido a cada 100 contagens, e pode ser enquadrado na categoria dos métodos de índice, os quais consideram a probabilidade de detecção constante (Nichols et al. 2009).

Tratamos os dados provenientes de amostragens por captura-recaptura (borboletas Ithomiini) de duas formas distintas. Uma delas - taxa de captura - se baseou nos métodos de índice acima descritos resultando na série USP. A outra em estimativas de abundância corrigidas pela probabilidade de captura (Williams et al. 2002), resultando na série USP core. Obtivemos os índices (taxas de captura) das espécies registradas na série USP somando o número de indivíduos capturados por campanha e dividindo esse valor pelo esforço amostral de cada campanha multiplicado por 100 (Mac Nally, 2007):

$$
I_{x t}=\frac{\sum n_{x t}}{\sum\left(m_{t s_{i}} * c_{\left.t s_{i}\right)}\right.} * 100
$$

Onde $I_{x t}$ representa a taxa de captura da espécie $x$ na campanha $t ; \sum n_{x t}$ representa $\mathrm{o}$ número total de indivíduos da espécie $x$ capturados na campanha $t$ (excluindo recapturas dentro de uma mesma campanha); $m_{t s_{i}}$ representa a duração (em minutos) da sessão de captura $i$ da campanha $t ; c_{t s_{i}}$ representa o número de coletores que capturaram na sessão de captura $i$ da campanha $t . \sum\left(m_{t s_{i}} * c_{t s_{i}}\right)$ representa a somatória do esforço amostral empreendido em cada sessão de captura da campanha $t$, i.e., o esforço amostral total empreendido na campanha $t$. A taxa de captura $I_{x t}$ representa o número de indivíduos capturados por coletor a cada 100 minutos de esforço.

Obtivemos as estimativas de abundância baseadas em marcação-recaptura (série USP core) através do modelo Jolly-Seber formulação POPAN (doravante JS POPAN, Schwarz et al. 1993, Williams et al. 2002). O modelo JS POPAN utiliza estimativas de parâmetros demográficos (sobrevivência aparente, recrutamento aparente e tamanho da superpopulação) corrigidas por estimativas de parâmetros de captura (probabilidade de captura) para estimar abundância (Schwarz et al. 1993). Optamos pelo JS POPAN em detrimento de outros modelos de marcação-recaptura (e.g., modelo Robusto) pois seu conceito de superpopulação (i.e., um "reservatório" populacional que ao longo do tempo fornece indivíduos para a população estudada - Schwarz et al. 1993) tem afinidades com o conceito de meta-comunidade da teoria neutra de Hubbell (2001), sendo conveniente para basear simulações de equivalência demográfica descritas na próxima sessão. Realizamos os procedimentos de ajuste e seleção de modelos JS POPAN no programa Mark 8.0 (Cooch and White 2006) tendo como interface o pacote RMark (Laake 2016) do programa R versão 3.3.2 (R Core Team 2016). Os detalhes da obtenção dos valores de abundância estimada de cada espécie através de modelos JS POPAN estão descritos no Apêndice 1.

Nessa série de dados (USP core) desconsideramos a primeira e a última campanhas de amostragem pois para algumas espécies o modelo selecionado não pode, por definição, calcular de maneira confiável os parâmetros iniciais e finais. Trata-se do modelo "full" (o modelo com o maior número de parâmetros possível, sem covariáveis associadas, no qual todos os parâmetros são livres para variar no tempo), cujos parâmetros de recrutamento ou 
sobrevivência são confundidos com os parâmetros de captura na primeira e na última ocasião da série temporal (Cooch and White 2006). Consequentemente, a extensão total da série USP core foi de 2,9 anos (35 meses, tabela 1). Apenas oito das 22 espécies de Ithomiini capturadas tiveram número suficiente de capturas e recaptura para que estimativas de abundância pudessem ser estimadas. No entanto, estas oito espécies representaram mais de $95 \%$ do total de capturas e, ao contrário das demais, foram registradas em todas as campanhas. Segundo este último critério, as oito espécies poderiam ser consideradas espécies núcleo ("core", Magurran 2007) da assembleia de Ithomiini da área de estudo.

\section{Medidas de rotatividade temporal na composição de espécies}

Para descrever a rotatividade (turnover) temporal na composição de espécies de cada série medimos a similaridade entre cada par de campanhas em função do intervalo de tempo (meses ou anos) entre elas (Engen et al. 2011, Magurran 2011). Como medida de similaridade entre campanhas utilizamos a correlação de Spearman (Krebs 1999) sobre o logaritmo das medidas de abundância. A correlação entre duas amostras temporais representa a rotatividade na composição de espécies: valores de correlação próximos a 1 indicam que as espécies abundantes e as raras em uma campanha também o são na outra (baixa rotatividade); valores próximos de -1 indicam que espécies abundantes em uma campanha são raras na outra e vice-versa (alta rotatividade); valores próximos de zero indicam campanhas independentes em estrutura. Optamos por essa métrica de similaridade pois, ao contrário de medidas baseadas em distância (e.g., Bray-Curtis), ela pode distinguir mudanças em bloco na composição de espécies (e.g. no caso de sucessão ecológica ou rotatividade sazonal) de mudanças ao acaso (por exemplo deriva ecológica sensu Hubbell [2001]).

\section{Ajuste e seleção de modelos descritores de rotatividade temporal}

Analisamos a rotatividade temporal na composição de espécie em dois níveis: entre anos (tendência interanual) e dentro de um ano (sazonalidade). Estas duas dimensões temporais da rotatividade são complementares e podem ocorrer concomitantemente. Por exemplo, uma comunidade pode apresentar rotatividade sazonal porém nenhuma tendência interanual (na escala de tempo medida) e vice-versa. Para descrever padrões de rotatividade interanual na composição de espécies ajustamos modelos lineares às rotatividades de cada série e obtivemos o valor estimado do parâmetro inclinação (slope), seu erro-padrão e significância (i.e., a probabilidade da inclinação ser diferente de zero). Também calculamos o intervalo de confiança de $95 \%$ de cada estimativa de inclinação multiplicando seu erro-padrão por 1,962 e somando e subtraindo este valor da estimativa para obter o intervalo superior e inferior, respectivamente. Inclinações significativamente diferentes de zero indicam mudanças na composição de espécies (rotatividade) ao longo do tempo. Valores negativos de inclinação indicam que campanhas mais distantes no tempo têm composições de espécies mais distintas do que campanhas mais próximas; valores não distinguíveis de zero indicam uma composição de espécies estável ao longo do tempo; valores significativamente positivos indicam que campanhas mais distantes no tempo seriam mais semelhantes entre si do que campanhas mais próximas.

Para detectar eventuais padrões sazonais na rotatividade também ajustamos às séries funções polinomiais e funções baseadas em seno. Funções polinomiais são flexíveis a ponto de 
poderem modelar tendências lineares (o polinômio de $1^{\circ}$ grau corresponde ao modelo linear), parabólicas ( $2^{\circ} \mathrm{grau}$ ) ou cíclicas ( $>4^{\circ} \mathrm{grau}$ ). A forma das funções polinomiais ajustadas foi:

$$
\operatorname{Sim} f(x)=a_{n} x^{\mathrm{n}}+a_{\mathrm{n}-1} x^{\mathrm{n}-1}+\ldots+a_{2} x^{2}+a_{1} x+a_{0}
$$

Onde $\operatorname{Sim} f(x)$ representa a rotatividade no ranque de abundância de espécies entre pares de campanhas, " $n$ " representa o grau do polinômio, $x$ representa o intervalo de tempo (em anos) transcorrido entre campanhas, e $a$ representa os coeficientes (parâmetros) polinomiais, os quais foram estimados a partir do ajuste do modelo aos dados. Ajustamos funções de 0 até 16 o grau e avaliamos a plausibilidade de cada função frente aos dados através do Critério de Informação de Akaike corrigido para amostras pequenas AICc (Burnham and Anderson 2002). As funções baseadas em seno são adequadas para modelar oscilações periódicas (Gwinner 1986) e devem fornecer um bom ajuste caso a relação entre rotatividade e tempo tenha padrões sazonais marcantes. As duas funções ("seno3" e "seno4") que utilizamos para descrever a relação rotatividade-tempo sob um cenário de sazonalidade foram, respectivamente:

$$
\begin{gathered}
\operatorname{Sim} f(x)=a^{*} \operatorname{seno}\left(b^{*} x\right)+c \\
\operatorname{Sim} f(x)=a^{*} \operatorname{seno}\left(\left(b^{*} x\right)-c\right)+d
\end{gathered}
$$

Onde $\operatorname{Sim} f(x)$ representa a rotatividade no ranque de abundância de espécies entre pares de campanhas, $x$ representa o intervalo de tempo (em anos) transcorrido entre campanhas e $a$, $b, c$ e $d$ representam constantes estimadas a partir do ajuste da função aos dados. Estas constantes determinam a amplitude, o período e a posição horizontal da curva ajustada. Funções baseadas em seno que modelam fenômenos sazonais devem apresentar um período de aproximadamente um ano, o qual pode ser formalmente acessado pela fórmula $2 \pi / b$. Comparamos o ajuste das funções polinomiais (incluindo o modelo linear) e baseadas em seno, resultando em um total de 19 modelos candidatos, através de seus valores de AICc. Situações onde funções polinomiais com oscilações relativamente regulares ou funções baseadas em seno foram selecionadas - e cujas oscilações tenham duração em torno de um ano - indicam evidências de mudanças sazonais na composição de espécies. Apesar das séries cujas amostragens foram anuais (séries do BBS - Punta Gorda, Fort Waltn Beach e Scottsmoor) não permitirem que se avalie sazonalidade, também ajustamos modelos polinomiais/seno a essas séries a fim de detectar eventuais não-linearidades nos padrões de rotatividade interanual.

\section{Modelos de equivalência entre espécies}

Para verificar como seriam os padrões de rotatividade temporal na composição de espécies resultantes de cenários de equivalência demográfica nós criamos modelos para simular dinâmicas temporais de abundância das populações de cada assembleia. Esses modelos de equivalência serviram como modelos nulos para verificarmos se os padrões empíricos de rotatividade temporal seriam condizentes com cenários onde as espécies de cada assembléia são demograficamente equivalentes. Criamos modelos de dois tipos, um para as séries temporais baseadas em índices (aplicados a todas as séries menos a USP core) e um para a série baseada em estimativas de abundância oriundas de marcação-recaptura (série USP core). Concebemos este último para aproveitar os parâmetros demográficos estimados apenas por 
marcação-recaptura, os quais, ao contrário dos modelos de equivalência das séries baseadas em índices, permitiram quantificar e modelar sazonalidade nas probabilidades de entrada e permanência das populações, tornando o modelo mais realista sem abrir mão da condição de equivalência entre espécies. Não utilizamos o próprio modelo neutro de Hubbell (2001) como um modelo nulo para diferenças entre espécies por dois motivos. O primeiro é que observamos grandes oscilações temporais nas abundâncias, chegando até a 400 vezes de diferença (séries de borboletas Ithomiini USP e USP core). Esta situação viola a premissa de soma zero (i.e., número de indivíduos constante ao longo do tempo) do modelo neutro de Hubbell (2001). O segundo motivo é a dificuldade para se definirem os valores dos parâmetros do modelo neutro (taxa de especiação, probabilidade de migração e tamanho da metacomunidade), os quais são necessários para simular dinâmicas neutras para comparação com os dados empíricos. Portanto, nossas simulações podem ser consideradas como expectativas dos padrões temporais de rotatividade na composição de espécies esperados sob um cenário de equivalência demográfica entre espécies - e não simulações de dinâmica neutra tal como proposto por Hubbell (2001).

\section{Modelos de equivalência para séries baseadas em índices}

Construímos no programa R versão 3.3.2 (R Core Team 2016) um modelo para simular - a partir das séries temporais empíricas baseadas em índice (todas menos a série USP core) dinâmicas de populações e assembleias sob um cenário de equivalência demográfica entre espécies. $O$ modelo executa caminhadas aleatórias em tempo discreto, com cinco parâmetros estimados a partir dos dados empíricos. O modelo toma como ponto de partida as abundâncias iniciais observadas em cada série e simula as abundâncias ao longo das campanhas subsequentes, considerando que todas as espécies da assembleia têm as mesmas taxas de crescimento. A abundância de cada espécie em cada campanha é dada por:

Se $N_{t-1}>0$ :

$$
N_{t}=\left(N_{t-1} * \lambda_{s d}\right) *\{0 \mid 1\} P_{E}
$$

Se $N_{t-1}=0$ :

$$
N_{t}=\left(\bar{N} * \lambda_{s d}\right) *\{0 \mid 1\} P_{R}
$$

Onde $N_{t}$ representa a abundância (índice) da espécie $x$ na campanha $t ; N_{t-1}$ representa a abundância da espécie $x$ na campanha anterior; $\lambda_{s d}$ (lambda) representa a taxa de crescimento médio da população, cujo desvio-padrão é $s d ;\{0 \mid 1\} P_{E}$ representa um termo que a cada passo da simulação pode assumir o valor 0 ou $1 \mathrm{com}$ probabilidade $P_{E}$, a qual corresponde a probabilidade de "extinção" da espécie $x$, i.e., a probabilidade dela não estar presente ou não ser detectada em uma dada campanha; $\bar{N}$ representa a abundância média da espécie $x$ e $\{0 \mid 1\} P_{R}$ representa um termo que a cada passo da simulação pode assumir o valor 0 ou 1 com probabilidade $P_{R}$, a qual representa a probabilidade de "recolonização" da espécie $x$, i.e., a probabilidade dela ser registrada em uma campanha dado que ela não foi detectada na campanha anterior. Nos casos em que o valor de $N_{t}$ resultou em número negativo o 
valor foi automaticamente transformado em zero. A seguir descreveremos como obtivemos os valores de cada um dos cinco parâmetros do modelo: $\lambda_{s d}, s d, P_{E}, P_{R}$, e $\bar{N}$.

$\lambda_{\boldsymbol{s} \boldsymbol{d}}$ e $\boldsymbol{s} \boldsymbol{d}$ - Obtivemos a taxa de crescimento $\lambda_{s d}$ amostrando - em cada passo da simulação representada pela equação (6) - um valor de uma distribuição normal com média 1 e desviopadrão $s d$. Para simular um cenário de equivalência demográfica todas as espécies de uma dada série apresentaram os mesmos valores de $\lambda_{s d}$ e $s d$. Obtivemos o valor de $s d$ calculando o desvio padrão das taxas empíricas de crescimento da assembleia. As taxas de crescimento da assembleia descrevem se a abundância total empírica aumentou $(\lambda>1)$, diminuiu $(\lambda<1)$ ou se manteve constante $(\lambda=1)$ em relação à campanha anterior. A abundância total empírica de uma campanha corresponde à soma das abundâncias de todas as espécies registradas na campanha. A taxa de crescimento empírica da assembleia em cada campanha é dada por:

$$
\lambda_{t}=\frac{\sum I_{x_{i} t}}{\sum I_{x_{i} t-1}} \quad \text { para } t>1
$$

Onde $\lambda_{t}$ é a taxa empírica de crescimento da assembleia na campanha $t$ (excluindo a campanha 1 visto que por definição ela não possui taxa de crescimento); $\sum I_{x_{i} t}$ representa a abundância total da campanhat, i.e., a somatória das abundâncias (índices) de todas as espécies registradas na campanha $t ; \sum I_{x_{i} t-1}$ representa a abundância total da campanha anterior $(t-1)$. Calculadas as taxas de crescimento da assembleia em cada campanha, obtivemos $s d$ calculando o desvio-padrão destas taxas:

$$
s d=\sqrt{\frac{1}{C-1} \sum_{t=2}^{C}\left(\lambda_{t}-\bar{\lambda}\right)^{2}}
$$

Onde $s d$ representa o desvio-padrão da taxa de crescimento médio $\left(\lambda_{s d}\right)$ usada nas simulações (modelo nulo) de uma dada série temporal; $\lambda_{t}$ representa a taxa de crescimento empírica da assembleia na campanha $t ; \bar{\lambda}$ representa a média das taxas empíricas de crescimento da assembleia em cada campanha (excluindo a campanha 1 pois, por definição, ela não possui taxa de crescimento); $C$ representa o número total de campanhas da série de dados.

$\boldsymbol{P}_{\boldsymbol{E}}$ - Obtivemos as probabilidades de extinção $P_{E}$, i.e., a probabilidade de uma espécie não ser detectada ou estar ausente em uma campanha dado que foi detectada na campanha anterior, a partir da seguinte equação:

$$
P_{E x_{i}}=\frac{1}{\bar{C}_{N_{t} x_{i}>0}}
$$

Onde $P_{E x_{i}}$ representa a probabilidade de extinção da espécie $x_{i} ; \bar{C}_{N_{t} x_{i}>0}$ representa a média do número de campanhas seguidas onde a espécie $x_{i}$ teve abundância $>0$. Apesar de cada espécie da assembleia ter um valor de $P_{E}$, consideramos que ainda assim nosso modelo representa equivalência entre espécies visto que probabilidades de extinção variáveis podem ser entendidas como uma consequência da abundância da espécie - abundância que varia de forma estocástica no nosso modelo - e não necessariamente de características ecológicas. Nos 
dados empíricos encontramos uma forte relação positiva entre a abundância e a incidência das espécies: espécies abundantes tendem a ser registradas em maior número de campanhas do que espécies menos abundantes.

$\boldsymbol{P}_{\boldsymbol{R}}$ - Obtivemos as probabilidades de "recolonização" $P_{R}$, i.e., a probabilidade de uma espécie ser detectada em uma campanha dado que não foi detectada ou esteve ausente na campanha anterior, a partir da seguinte equação:

$$
P_{R x_{i}}=\frac{1}{\bar{C}_{N_{t} x_{i}=0}}
$$

Onde $P_{R x_{i}}$ representa a probabilidade de recolonização da espécie $x_{i} ; \bar{C}_{N_{t} x_{i}=0}$ representa a média do número de campanhas seguidas onde a espécie $x_{i}$ teve abundância zero. Apesar de cada espécie da assembleia também ter um valor de $P_{R}$ próprio, consideramos que ainda assim nosso modelo representa equivalência entre espécies pelos mesmos argumentos apresentados na definição do parâmetro $P_{E}$.

$\overline{\boldsymbol{N}}$ - Obtivemos a abundância média de cada espécie calculando a média dos seus valores de abundância empíricos considerando somente as campanhas onde a espécie foi registrada:

$$
\bar{N}_{x_{i}}=\frac{\sum_{t=1}^{C} N_{t}}{n_{N_{t}>0}}
$$

Onde $\bar{N}_{x_{i}}$ representa a abundância média da espécie $x_{i} ; \sum_{t=1}^{C} N_{t}$ representa a somatória das abundâncias da espécie $x_{i}$ registradas em cada campanha e $n_{N_{t}>0}$ representa o número de campanhas onde a abundância da espécie $x_{i}$ foi maior do que zero.

\section{Modelos de equivalência para série baseada em marcacão-recaptura}

Para simular equivalência demográfica a partir das estimativas de abundância baseadas em marcação-recaptura (série USP core - borboletas Ithomiini) utilizamos o módulo de simulações do programa Mark versão 8.0 (Cooch and White 2006). Optamos por esta abordagem pois ela nos permitiu, graças aos parâmetros demográficos de entrada e permanência estimados por marcação-recaptura, incluir nas simulações os ciclos sazonais de concentração e dispersão observados na assembleia de borboletas Ithomiini (ver Capítulo 1) mantendo a equivalência demográfica entre espécies. Por isso, ao contrário do modelo de equivalência desenvolvido para as séries baseadas em índice, este modelo incorpora sazonalidade nas probabilidades de entrada e permanência dos indivíduos.

As simulações do programa MARK se basearam no modelo JS POPAN, o mesmo tipo que usamos para estimar as abundâncias empíricas da série USP core. Assim como estimamos as abundâncias empíricas de cada espécie separadamente, também simulamos separadamente as dinâmicas de cada espécie e depois agrupamos os dados para obter cada assembleia simulada. As simulações reproduziram os dados empíricos em termos de número de ocasiões de captura e de intervalos de tempo entre elas. Para as simulações do programa MARK é necessário fornecer o true model, isto é, o modelo que gera os dados simulados (histórico de capturas) a partir de valores de parâmetros fornecidos pelo usuário (Phi, pent, $p$ e $N$ no caso do modelo POPAN, ver Apêndice 1 para detalhes), bem como o estimation model, o modelo 
que estima os parâmetros a partir dos dados simulados (Cooch and White 2006). Para simular equivalência demográfica entre espécies fornecemos as mesmas probabilidades de entrada (pent) e de saída (Phi) para o true model de todas as espécies, enquanto que o tamanho da superpopulação $N$ - i.e., o número total de indivíduos que ingressou na população ao longo do estudo - bem como as probabilidades captura $p$, variaram entre espécies (ver Apêndice 2 Tabela III). Com o tamanho da superpopulação $N$ variando entre espécies buscamos emular os diferentes tamanhos populacionais presentes na metacomunidade tal como postulado pela teoria neutra (Hubbell 2001). Para obter as probabilidades de entrada e saída únicas que utilizamos no true model das simulações agrupamos as oito espécies em um único conjunto de dados (modelo multi-espécies) e estimamos os valores de Phi e pent desse conjunto através do ajuste e seleção de 32 modelos JS POPAN candidatos (ver Apêndice 1, Tabela I). Os valores de entrada e permanência do modelo multi-espécies selecionado oscilaram sazonalmente (ver Apêndice 2 - Tabela III), reproduzindo o ciclo anual de abundâncias observado na assembleia de Ithomiini ao longo dos anos (ver Capítulo 1). Porém, como usamos os mesmos valores de Phi e pent para todas as espécies, adicionamos sazonalidade às simulações mantendo a equivalência demográfica entre espécies. A estrutura do true model e do estimation model das simulações reproduziu a estrutura do modelo multi-espécies selecionado para estimar os parâmetros $P$ hi e pent que usamos nas simulações. Nessa estrutura os parâmetros Phi, pent e $p$ variaram livremente ao longo do tempo, sem covariáveis associadas. Obtivemos os valores de $N$ e $p$ que parametrizaram o true model de cada espécie dos mesmos modelos que utilizamos para estimar a abundância empírica de cada espécie, tal como descrito no Apêndice 1.

\section{Comparação entre padrões de rotatividade empíricos e simulados}

A fim de verificar se os modelos que assumem equivalência demográfica entre espécies foram capazes de prever os padrões interanuais e/ou sazonais de rotatividade na composição de espécies nós comparamos as rotatividades empíricas com as simuladas. Para cada série temporal baseada em índices (i.e., todas com exceção da série USP core) rodamos 500 simulações de equivalência demográfica seguindo as equações (6) com os parâmetros obtidos segundo as equações (7) a (11). Para a série temporal baseada em marcação-recaptura (USP core) rodamos 100 simulações de equivalência demográfica, pois o poder computacional e o tempo exigidos pelo módulo de simulações do programa Mark 8.0 é muito superior ao do modelo de equivalência das equações (6). Para cada assembleia simulada, tanto as oriundas da equação (6) quanto as oriundas do programa Mark 8.0, calculamos a rotatividade na composição de espécies entre campanhas exatamente como fizemos para as séries temporais empíricas (ver as sessões anteriores "Medidas de rotatividade temporal na composição de espécies" e "Ajuste e seleção de modelos descritores de rotatividade temporal"). Obtivemos então a rotatividade interanual simulada de cada série ajustando modelos lineares a cada uma das 500 (ou 100) simulações e calculando a mediana da inclinação, do erro-padrão (SE) e da significância $(p)$ do conjunto de simulações. Então para cada série comparamos o valor de inclinação empírico com a mediana das inclinações obtida das simulações. Consideramos que as inclinações empíricas e simuladas diferiram se seus intervalos de confiança de $95 \%$ não se sobrepuseram. 
Para avaliar se os modelos de equivalência foram capazes de gerar rotatividades sazonais ajustamos a cada simulação de uma dada série, além do modelo linear, os mesmos modelos polinomiais e de seno que ajustamos aos dados empíricos. Avaliamos o ajuste dos 19 modelos candidatos a cada simulação a partir dos seus valores de AICc. Então verificamos qual dos 19 modelos candidatos teve com maior frequência o valor de AICc mais baixo nas 500 (ou 100) simulações de cada série, e ajustamos esse modelo (doravante "modelo simulado") a todas as simulações da série. Para descrever os resultados das simulações de cada série calculamos a média do ajuste do modelo simulado a cada uma das 500 (ou 100) simulações, bem como os valores máximos e mínimos de ajuste alcançados pelo modelo simulado. Então verificamos se o modelo selecionado para descrever as rotatividades simuladas foi o mesmo modelo selecionado para descrever as empíricas, e se os valores de rotatividade simulados e empíricos se sobrepuseram.

\section{RESULTADOS}

\section{Rotatividade interanual}

A inclinação (slope) do modelo linear ajustado às rotatividades observadas em cada série temporal foi significativamente diferente de zero em nove das dez séries (Figura $\mathbf{2}$ e Tabela 2), indicando que a composição de espécies dessas séries temporais se alterou ao longo dos anos. Essas nove séries tiveram tendências (inclinações) negativas (Figura 2), i.e., as campanhas mais distantes no tempo tenderam a ter composição de espécies mais diferentes entre si. As quatro séries que representam assembleias de aves em floresta tropicais (Jirau 10, Jirau 11, Juruena e Curucutu) e a série que representa abundância de borboletas estimadas por marcaçãorecaptura (USP core) apresentaram as maiores rotatividades (inclinações mais negativas), porém apresentaram também as maiores incertezas (i.e., intervalos de confiança mais amplos) no valor das suas respectivas inclinações (Figura 2). As demais séries, com exceção da série USP cuja inclinação não diferiu significativamente de zero, apresentaram rotatividades (inclinações negativas) em média oito vezes menores (inclinação média $=-0,004$ ) do que as cinco séries com as maiores rotatividades (inclinação média $=-0,035$, Figura 2). Os intervalos de confiança das três séries de aves em ambientes costeiros da Florida (Punta Gorda, Fort Walnt Beach e Scottsmoor) foram muito menores do que os intervalos de confiança das demais séries, a ponto de não serem observáveis na escala representada na Figura 2. 


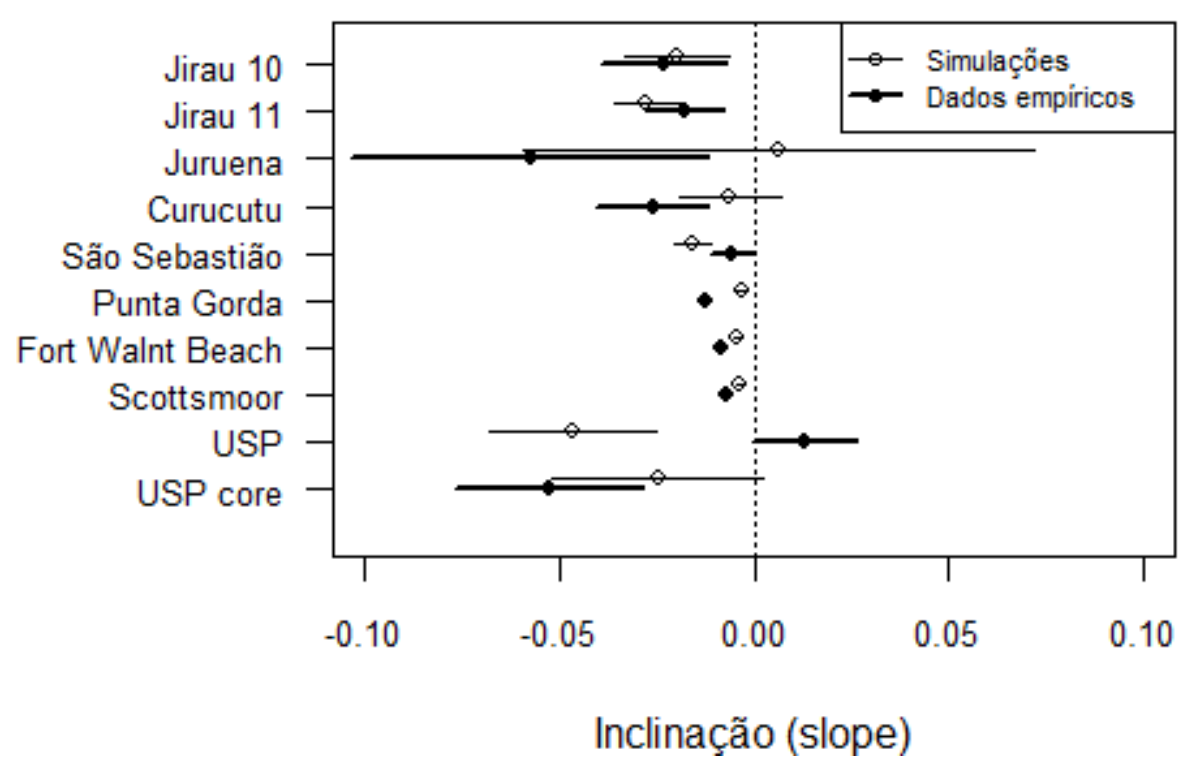

Figura 2. Inclinação (slope) do modelo linear ajustado a cada série temporal para descrever tendências (mudanças interanuais) na rotatividade da composição de espécies. Os pontos pretos representam os ajustes aos dados empíricos e os pontos brancos o ajuste médio aos dados simulados. As linhas horizontais representam o intervalo de confiança de $95 \%$ de cada estimativa. Notar que nas três séries mais inferiores os intervalos de confiança são pequenos a ponto de não serem visíveis na escala do gráfico.

As simulações de equivalência demográfica previram com relativa acurácia as riquezas e abundâncias totais observadas por campanha nos dados empíricos, bem como suas curvas de ranque-abundância, mostrando que as simulações foram capazes de capturar esses aspectos das assembleias (Apêndice 3: Figuras I a III). As simulações geraram inclinações negativas em sete das dez séries (Figura 2 e Tabela 2), indicando que sob um cenário de equivalência a composição de espécies dessas assembleias tenderia a se alterar com o passar do tempo. As simulações das outras três séries (Juruena, Curucutu e USP core) tiveram inclinações que não diferiram significativamente de zero (Figura 2 e Tabela 2). Os intervalos de confiança das inclinações simuladas e empíricas não se sobrepuseram em cinco das dez séries temporais, indicando que os modelos de equivalência não previram as rotatividades interanuais empíricas de metade das séries. Nessas cinco séries as inclinações empíricas foram mais negativas que as simuladas nas três séries de assembleias de aves da costa da Florida (Punta Gorda, Fort Walnt Beach e Scottsmoor) e mais próximas de zero nas séries São Sebastião (aves na costa de SP) e USP (borboletas Ithomiini em fragmento florestal urbano; Figura 2 e Tabela 2 ). 
Tabela 2. Valores de inclinação (slope) do modelo linear ajustado a cada série temporal empírica ("Dados empíricos") e às séries temporais simuladas pelos modelos de equivalência demográfica ("Simulações") para descrever tendências (mudanças interanuais) na rotatividade da composição de espécies. Também são apresentados os erros-padrão de cada estimativa de inclinação (SE), os limites inferiores (ICI) e superiores (ICS) do intervalo de confiança de $95 \%$ das estimativas de inclinação e a probabilidade de cada inclinação ser diferente de zero (p). Os valores de slope, SE e P das simulações representam medianas de 500 simulações (100 simulações na série USP core). Diff indica se cada inclinação empírica é significativamente distinta da inclinação simulada (i.e., se os intervalos de confiança de $95 \%$ dos dois tipos de estimativas se sobrepõem). Em caso positivo a coluna indica se a rotatividade empírica foi menor (i.e., mais próxima de zero) ou maior do que as rotatividades simuladas.

\begin{tabular}{|c|c|c|c|c|c|c|c|c|c|c|c|}
\hline \multirow{2}{*}{ Séries } & \multicolumn{5}{|c|}{ Dados empíricos } & \multicolumn{5}{|c|}{ Simulações } & \multirow{2}{*}{ Diff } \\
\hline & slope & SE & $\mathrm{ICI}$ & ICS & p & slope & SE & $\mathrm{ICI}$ & ICS & p & \\
\hline Jirau 10 & $-0,023$ & 0,0081 & $-0,0389$ & $-0,0072$ & 0,0053 & $-0,020$ & 0,0069 & $-0,034$ & $-0,0069$ & 0,0042 & Não \\
\hline Jirau 11 & $-0,018$ & 0,0051 & $-0,0281$ & $-0,0079$ & 0,0006 & $-0,027$ & 0,0044 & $-0,036$ & $-0,0187$ & $<0,0001$ & Não \\
\hline Juruena & $-0,057$ & 0,0233 & $-0,1032$ & $-0,0116$ & 0,0208 & 0,007 & 0,0337 & $-0,059$ & 0,0728 & 0,4851 & Não \\
\hline Curucutu & $-0,026$ & 0,0073 & $-0,0402$ & $-0,0116$ & 0,0005 & $-0,006$ & 0,0067 & $-0,019$ & 0,0075 & 0,2531 & Não \\
\hline $\begin{array}{l}\text { São } \\
\text { Sebastião }\end{array}$ & $-0,006$ & 0,0027 & $-0,0109$ & $-0,0004$ & 0,0348 & $-0,016$ & 0,0024 & $-0,021$ & $-0,0115$ & $<0,0001$ & $\begin{array}{c}\text { Sim } \\
\text { (menor) }\end{array}$ \\
\hline $\begin{array}{l}\text { Punta } \\
\text { Gorda }\end{array}$ & $-0,013$ & 0,0005 & $-0,0134$ & $-0,0116$ & $<0,0001$ & $-0,003$ & 0,0006 & $-0,005$ & $-0,0023$ & $<0,0001$ & $\underset{\text { (maior) }}{\text { Sim }}$ \\
\hline $\begin{array}{l}\text { Fort Walnt } \\
\text { Beach }\end{array}$ & $-0,008$ & 0,0003 & $-0,0087$ & $-0,0077$ & $<0,0001$ & $-0,004$ & 0,0003 & $-0,004$ & $-0,0031$ & $<0,0001$ & $\begin{array}{c}\text { Sim } \\
\text { (maior) }\end{array}$ \\
\hline Scottsmoor & $-0,007$ & 0,0004 & $-0,0076$ & $-0,0063$ & $<0,0001$ & $-0,004$ & 0,0004 & $-0,005$ & $-0,0029$ & $<0,0001$ & $\underset{\text { (maior) }}{\operatorname{Sim}}$ \\
\hline USP & 0,013 & 0,0068 & $-0,0003$ & 0,0263 & 0,0555 & $-0,046$ & 0,0108 & $-0,067$ & $-0,0245$ & $<0,0001$ & $\underset{\text { (menor) }}{\text { Sim }}$ \\
\hline USP core & $-0,053$ & 0,0121 & $-0,0063$ & $-0,0024$ & $<0,0001$ & $-0,025$ & 0,01383 & $-0,052$ & 0,0025 & 0,0574 & Não \\
\hline
\end{tabular}

\section{Rotatividade sazonal}

Quando comparado a funções (modelos) capazes de descrever sazonalidade o modelo linear foi plausível para descrever a rotatividade temporal na composição de espécies em apenas uma das sete séries empíricas disponíveis para avaliar sazonalidade (Tabela 3 e Figuras 3 e 4). Nessa série (Jirau 10), portanto, os dados não fornecem evidências de sazonalidade na composição de espécies (Figura 3A). Por outro lado, nas outras seis séries - com exceção da série Juruena - os modelos selecionados descrevem oscilações aproximadamente anuais condizentes com rotatividade sazonal na composição de espécies (Figuras 3 e 4). 0 modelo "seno4" foi o único selecionado (i.e., foi o único modelo com AICc $\leq 3$ ) para descrever as rotatividades das séries Jirau 11 e São Sebastião, cujos períodos tiveram a duração de 1,01 e 0,99 anos (12,08 e 11,96 meses), respectivamente (Figuras 3B e 4A). Porém, a amplitude da rotatividade da série São Sebastião (i.e., o quanto a similaridade na composição de espécies oscilou ao longo do tempo) foi quase o dobro (0,13 unidades de correlação de Spearman) da amplitude da série Jirau 11 (0,07; Figuras 3B e 4A). Nas séries Curucutu, USP e USP core houve incerteza na seleção de modelos, i.e., mais de um modelo teve $\mathrm{AlCc} \leq 3$, porém dentre eles ocorreram apenas modelos polinomiais com grau acima de sete (Curucutu), oito (USP) ou dez (USP core; Tabela 3). Os modelos de menor AICc e maior wAICc de cada uma destas três séries (Tabela 3) apresentaram oscilações não simétricas (porém com relativa regularidade), cujos 
picos foram separados por intervalos com duração aproximada de um ano (Figuras 3D, 4E e F). A amplitude dos modelos, porém, foi muito superior na série USP core $(1,01$ unidades de correlação de Spearman), intermediária na série Curucutu $(0,23)$ e mínima na série USP $(0,08$; Figuras 3D, 4E e F).

Na série Juruena o único modelo selecionado foi um polinômio de $16^{\circ}$ grau $(w \mathrm{AICc}=0,93)$ cuja forma irregular não é condizente com mudanças sazonais na composição de espécies (Tabela 3 e Figura 3C). A seleção deste modelo pode indicar um padrão de rotatividade aleatório e nãolinear, porém também poderia indicar "overfitting", visto que o tamanho amostral e extensão temporal desta série foram os menores do conjunto de dados que analisamos neste estudo. Nas três séries cuja amostragem anual não permite que se avalie sazonalidade (Punta Gorda, Fort Walnt Beach e Scottsmoor) o modelo linear foi plausível em apenas uma série (Punta Gorda; Tabela 3). No entanto, os modelos de menor AICc e maior wAICc dessas três séries apresentam não-linearidades muito menos acentuadas do que os modelos condizentes com rotatividade sazonal das demais séries, se aproximando ao modelo linear (Figura 4B a D).

As simulações de equivalência demográfica não reproduziram os padrões de rotatividade sazonal observados em cinco das sete séries que permitem avaliar sazonalidade (Figuras $3 \mathrm{e}$ 4A, E a F). Os modelos selecionados para descrever as simulações dessas sete séries (Apêndice 4 - Figura IV) diferiram dos modelos selecionados para descrever as respectivas séries empíricas (ver Tabela 3). As simulações da série USP core - as quais diferem das demais por terem sido geradas por um modelo que reproduziu as oscilações sazonais de abundância total observadas nos dados empíricos (ver Métodos) - foram as únicas que resultaram em um padrão sazonal (período de 0,98 anos; Figura 4F). No entanto, a amplitude do modelo simulado $(0,13$ unidades de correlação de Spearman) foi cerca de dez vezes menor do que a amplitude empírica $(1,01)$, não reproduzindo sua ampla rotatividade sazonal na composição de espécies (Figura 4F).

Os modelos selecionados para descrever as simulações das três séries cujas amostragens anuais não permitem avaliar sazonalidade (Punta Gorda, Fort Walnt Beach e Scottsmoor) foram praticamente os mesmos que os modelos selecionados para descrever os respectivos dados empíricos (Tabela 3 e Figura 4B a D). Apesar das rotatividades empíricas dessas séries terem sido maiores do que as rotatividades simuladas (Figuras 2 e 4B a D, Tabela 2), suas nãolinearidades poderiam ser explicadas por uma dinâmica demográfica estocástica com equivalência entre espécies. 
Tabela 3. Modelos selecionados pelo critério de seleção de Akaike ( $\triangle \mathrm{AICc} \leq 3$ ) para descrever a rotatividade temporal na composição de espécies em dez séries temporais de amostragem de assembleias de aves ou borboletas no Brasil e nos EUA. Os modelos candidatos (19 modelos) incluem o modelo linear e funções que podem descrever sazonalidade na composição de espécies (polinômios de até $16^{\circ}$ grau e funções baseadas em seno). Série temporal - conjunto de dados de acordo com a Tabela 1. Modelo - modelo ajustado aos dados: poli indica modelo polinomial (o número após o nome indica o grau do polinômio); linear designa o modelo linear; seno representa modelos baseados em seno com três (seno 3) ou quatro (seno 4) parâmetros. Npar - número de parâmetros de cada modelo. AICc critério de informação de Akaike corrigido para amostras pequenas; $\triangle \mathrm{AICc}$ - "Delta" AICc: valor de AICc do respectivo modelo subtraído do modelo de menor AICc; wAICc - peso de Akaike de cada modelo; Modelo simulado - Modelos que descrevem as rotatividades simuladas pelos modelos de equivalência.

\begin{tabular}{|c|c|c|c|c|c|c|}
\hline Série temporal & Modelo & Npar & AICc & $\triangle \mathrm{AICc}$ & wAICc & $\begin{array}{l}\text { Modelo } \\
\text { simulado }\end{array}$ \\
\hline \multirow[t]{2}{*}{ Jirau10 } & linear & 2 & $-217,7$ & 0 & 0,524 & linear \\
\hline & poli 2 & 3 & -216 & 1,74 & 0,22 & \\
\hline Jirau11 & seno 4 & 4 & $-399,5$ & 0 & 0,558 & poli 2 \\
\hline Juruena & poli 16 & 17 & $-73,7$ & 0 & 0,934 & poli 0 \\
\hline \multirow[t]{6}{*}{ Curucutu } & poli 13 & 14 & $-291,3$ & 0 & 0,253 & poli 0 \\
\hline & poli 15 & 16 & $-290,7$ & 0,61 & 0,186 & \\
\hline & poli 11 & 12 & $-289,5$ & 1,78 & 0,104 & \\
\hline & poli 14 & 15 & $-289,5$ & 1,79 & 0,103 & \\
\hline & poli 16 & 17 & $-288,9$ & 2,42 & 0,075 & \\
\hline & poli 7 & 8 & $-288,4$ & 2,88 & 0,06 & \\
\hline São Sebastião & seno 4 & 4 & $-1177,8$ & 0 & 0,878 & poli 4 \\
\hline \multirow[t]{3}{*}{ Punta Gorda } & poli 3 & 4 & $-1016,4$ & 0 & 0,434 & poli 3 \\
\hline & poli 4 & 5 & $-1015,3$ & 1,14 & 0,245 & \\
\hline & linear & 2 & -1014 & 2,47 & 0,126 & \\
\hline \multirow[t]{3}{*}{ Fort Waltn Beach } & poli 5 & 6 & $-1652,3$ & 0 & 0,461 & poli 5 \\
\hline & poli 6 & 7 & $-1650,5$ & 1,78 & 0,189 & \\
\hline & poli 4 & 5 & $-1649,7$ & 2,62 & 0,124 & \\
\hline \multirow[t]{4}{*}{ Scottsmoor } & poli 6 & 7 & $-969,7$ & 0 & 0,36 & poli 7 \\
\hline & poli 8 & 9 & $-968,8$ & 0,92 & 0,227 & \\
\hline & poli 7 & 8 & $-968,2$ & 1,46 & 0,174 & \\
\hline & poli 9 & 10 & -967 & 2,63 & 0,097 & \\
\hline \multirow[t]{4}{*}{ USP } & poli 10 & 11 & $-1162,2$ & 0 & 0,347 & poli 4 \\
\hline & poli 8 & 9 & $-1161,7$ & 0,54 & 0,265 & \\
\hline & poli 11 & 12 & $-1160,5$ & 1,7 & 0,148 & \\
\hline & poli 9 & 10 & -1160 & 2,15 & 0,118 & \\
\hline \multirow[t]{2}{*}{ USP core } & poli 10 & 11 & 668,1 & 0 & 0,502 & seno4 \\
\hline & poli 11 & 12 & 669,3 & 1,21 & 0,274 & \\
\hline
\end{tabular}




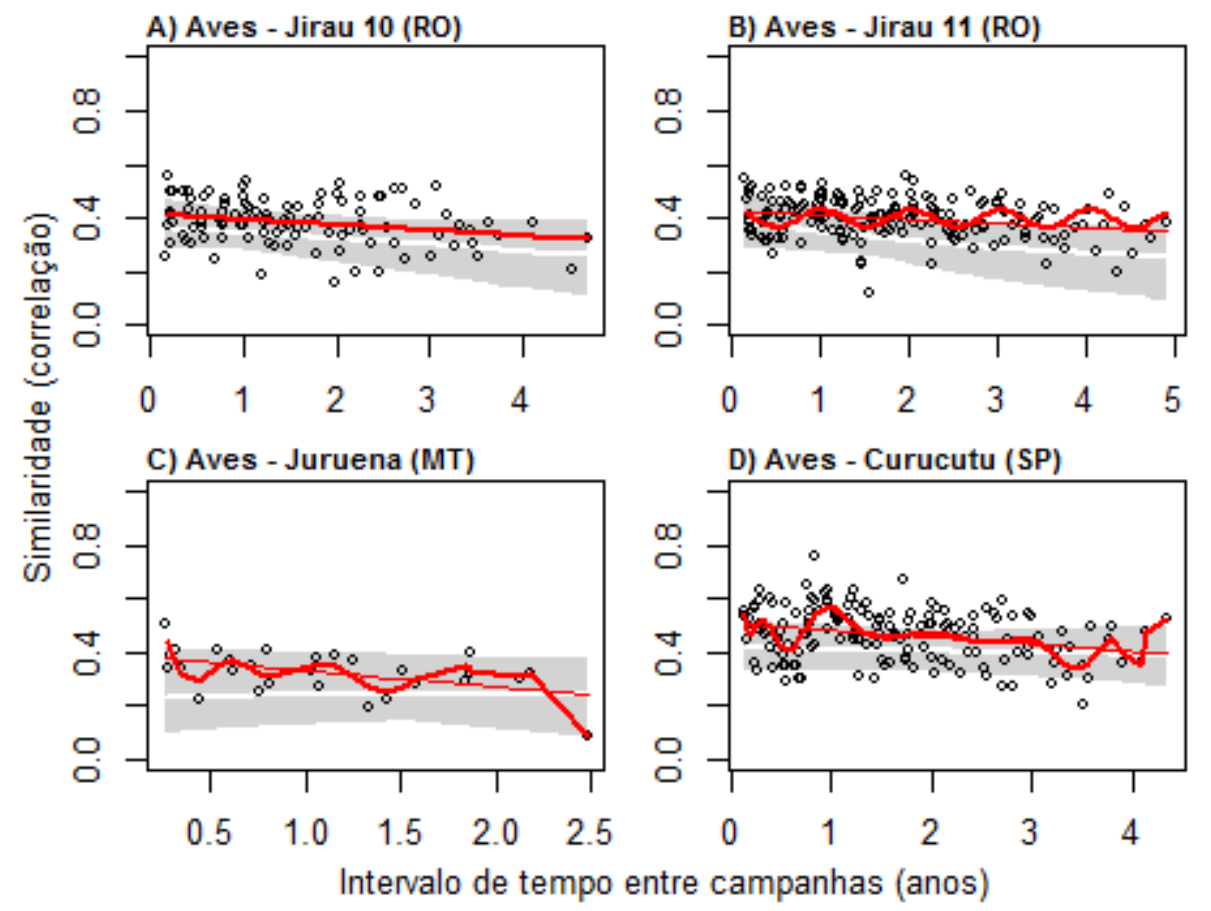

Figura 3. Rotatividade (turnover) na composição de espécies de aves florestais ao longo do tempo em quatro localidades no Brasil. As linhas vermelhas mais grossas representam os ajustes do melhor modelo dentre 19 modelos candidatos (modelos linear em A, modelo baseado em seno em $\mathbf{B}$ e modelos polinomiais em C e D, ver Tabela $\mathbf{3}$ ). As linhas vermelhas mais finas em B a D representam um ajuste linear aos dados. Os polígonos de coloração cinza representam as rotatividades na composição de espécies geradas pelo modelo de equivalência demográfica da equação (6) (500 simulações, ver Métodos) e as linhas brancas representam as previsões médias. 

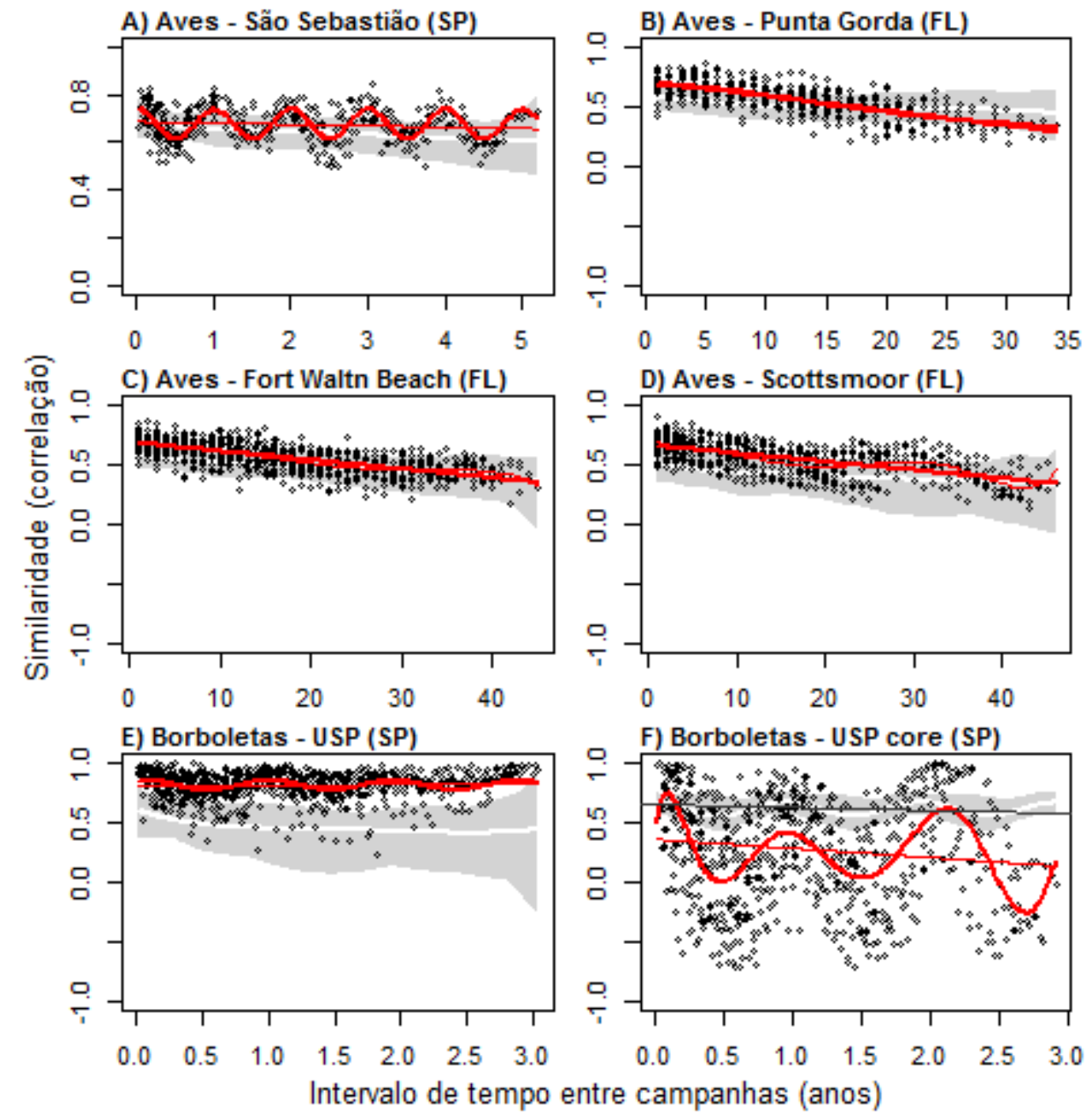

Figura 4. Rotatividade (turnover) na composição de espécies de aves costeiras ou borboletas Ithomiini (Nymphalidae, Danainae) ao longo do tempo em localidades no estado de São Paulo (A, E e F) e na Florida (EUA, B a D). As linhas vermelhas mais grossas representam os ajustes do melhor modelo dentre 19 modelos candidatos (modelos baseado em seno em A, e modelos polinomiais de $\mathbf{B}$ a $\mathbf{F}$, ver Tabela $\mathbf{3}$ ). As linhas vermelhas mais finas representam um ajuste linear aos dados. Os polígonos de coloração cinza representam as rotatividades na composição de espécies geradas pelo modelo de equivalência demográfica da equação (6) em A a E e pelo programa Mark 8.0 em F. As linhas brancas representam as previsões médias das simulações. 


\section{DISCUSSÃO}

Nossos resultados mostram que assembleias de aves e borboletas de nove localidades tropicais e subtropicais das Américas do Sul e do Norte tenderam a mudar sua composição de espécies ao longo dos anos, mesmo em localidades que não sofreram mudanças no uso do solo durante as amostragens. Além dessas rotatividades (turnover) interanuais, os resultados também mostram evidências de mudanças cíclicas, sazonais, na composição de espécies em cinco das sete assembleias que tiveram amostragens intra-anuais. Os modelos que assumem equivalência demográfica entre espécies previram taxas de rotatividade interanuais comparáveis às empíricas em metade dos casos, especialmente em assembleias cujas localidades não passaram por mudanças no uso do solo. Porém, esses modelos não previram as rotatividades sazonais observadas. Esses resultados, bem como os de estudos anteriores com aves e borboletas neotropicais (Brown and Benson 1974, Karr 1976, Karr and Freemark 1983, Grøtan et al. 2012, 2014), contradizem a visão clássica dos trópicos como regiões com comunidades animais estáveis. Implicam também que diferenças entre espécies podem ser importantes para entender a dinâmica sazonal de assembleias animais, bem como suas respostas a impactos ambientais. A seguir discutiremos nossos resultados e suas implicações teóricas e aplicadas.

\section{Rotatividade interanual}

Apesar da composição de espécies das assembleias de aves e borboletas ter se alterado significativamente ao longo dos anos, a taxa dessas mudanças (representada pela inclinação dos modelos lineares) variou até 10 vezes entre assembleias. Como as assembleias têm características variadas (e.g., número de espécies, tipo e grau de preservação do ambiente, extensão espaço-temporal das amostragens, ocorrência ou não de mudanças no uso do solo ao longo do estudo), é difícil identificar fatores responsáveis pela heterogeneidade nas taxas de rotatividade interanuais. No entanto, a composição das quatro assembleias de aves florestais das localidades da Amazônia (Jirau 10 e 11), Cerrado (Juruena) e Mata Atlântica (Curucutu) mudou em média quatro vezes mais rápido do que a composição das assembleias de aves em ambientes costeiros da Florida e do estado de São Paulo (São Sebastião). É possível que a maior riqueza e o predomínio de espécies raras nas assembleias de aves de floresta tropical (Karr 1971, Loiselle and Blake 1992, Thiollay 1994) - espécies estas cujos registros são mais sujeitos ao acaso - impliquem em maiores rotatividades na composição de espécies entre campanhas nesses ambientes.

As taxas de rotatividade interanual das quatro assembleias de aves de floresta tropical foram semelhantes entre si, a não ser pela série Juruena (MT) que teve uma rotatividade 2,5 vezes superior às demais, a maior taxa de rotatividade medida nesse estudo. Essa assembleia diferiu das outras pela ocorrência de uma perturbação durante as amostragens - desmatamento no entorno (> $500 \mathrm{~m}$ ) dos pontos de contagem - a qual pode ter causado mudanças repentinas na composição de espécies (e.g. Stouffer and Bierregaard Jr 1995, Stouffer et al. 2006). Por outro lado, as mudanças na composição das outras três assembleias de aves florestais, localizadas em Rondônia (Jirau 10 e 11) e na baixada da Serra do Mar (Curucutu), devem representar rotatividades basais (i.e., "naturais" sensu Magurran 2011), visto que não ocorreram alterações no uso do solo durante as amostragens dessas localidades. Apesar dos dados de 
aves de Rondônia (Jirau 10 e 11) serem oriundos do programa de monitoramento de fauna da usina hidrelétrica de Jirau, nós selecionamos os pontos localizados mais a montante de barragem ( $>80 \mathrm{~km}$ ), onde o nível do rio Madeira, de acordo séries temporais de imagens de satélite pré e pós-enchimento, não se elevou tal como ocorrido em trechos do rio mais próximos à barragem. Além disso, essas três localidades estão imersas em grandes blocos de floresta (ver Métodos) que poderiam atuar como tampões para eventuais perturbações locais (e.g. caça). A rotatividade basal média dessas três assembleias teve uma inclinação (slope do modelo linear) de $-0,022(\mathrm{dp}=0,004)$, mais que o dobro da rotatividade média na composição de espécies encontrada por Dornelas et al. (2014) em assembleias de diversos taxa distribuídas pelo globo $(-0,01)$. A rotatividade dessas três assembleias corresponde a uma queda de 0,22 pontos de correlação (em uma escala que vai de -1 a 1 ) na composição de espécies a cada dez anos. Essas estimativas de rotatividade basal podem ser usadas como referência para avaliação de alterações na avifauna dessas regiões em função de perturbações ambientais (Magurran 2016).

As assembleias de aves costeiras da Florida e de São Sebastião (SP) também tiveram taxas de rotatividade interanuais muito semelhantes entre si, cujo valor médio $(-0,008, d p=0,003)$ corresponde a uma queda de 0,08 pontos de correlação na composição de espécies a cada 10 anos, valor semelhante ao da rotatividade média encontrada por Dornelas et al. (2014) em seu estudo global $(-0,01)$. No entanto, dentre essas quatro assembleias de aves costeiras apenas a rotatividade interanual da assembleia de São Sebastião poderia ser considerada uma rotatividade basal. Apesar dessa localidade estar inserida em uma mancha urbana, não ocorreram mudanças no uso do solo nem tampouco perturbações perceptíveis durante seus cinco anos de amostragem. De fato, sua taxa de rotatividade interanual foi a menor de todo esse estudo $(-0,005)$, mostrando estabilidade (baixa rotatividade) na composição de espécies ao longo dos anos. Por outro lado, ocorreram mudanças significativas no uso do solo das três localidades da Flórida ao longo das três últimas décadas. Apesar de não existirem estudos específicos sobre mudanças no uso do solo dessas localidades, séries temporais de imagens de satélite disponíveis na plataforma Google Earth revelam expansão de áreas urbanas e condomínios suburbanos nessas localidades entre 1984 e 2014. De fato, o estado da Florida teve uma conversão de $13 \%$ de suas áreas naturais e semi-naturais para áreas urbanas e agricultura entre 1985 e 2003 (Kautz et al. 2007). Portanto, apesar das taxas de rotatividades semelhantes, os processos que regularam a estrutura e dinâmica das assembleias de aves costeiras da Florida e de São Sebastião podem ser distintos.

As duas séries temporais baseadas em amostragens de borboletas Ithomiini em um fragmento florestal urbano (USP e USP core) tiveram taxas de rotatividade interanual muito diferentes entre si (ver Figura 2). Parte dessa disparidade pode ser resultado do fato de que em uma das séries incluímos todas as 22 espécies da tribo (série USP, inclinação 0,013) e na outra apenas as oito espécies mais abundantes (USP core, inclinação -0,052). Com isso, as séries diferem na proporção de espécies ausentes por campanha, visto que em USP core todas as oito espécies estiveram presentes em todas as campanhas, enquanto que em USP - assim como em todas as demais séries de aves desse estudo - uma proporção considerável das espécies foi rara (i.e., foi registrada em apenas uma ou poucas campanhas). Uma maior proporção de ausências (zeros) em uma assembleia, proporcionada, por exemplo, por uma maior participação de espécies raras, resulta em correlações cujos pares de campanhas têm maior numero de ausências 
duplas, o que aumenta o valor das correlações e diminui sua amplitude, devido ao maior compartilhamento de valores (zeros). Assim, a diferença na taxa de rotatividade interanual entre as duas séries da assembleia de borboletas Ithomiini podem ser decorrentes, pelo menos em parte, da inclusão de zeros (espécies raras) nas correlações, bem como da atuação de processos ecológicos distintos sobre os diferentes grupos de espécies (abundantes vs. abundantes + raras).

\section{Rotatividade sazonal}

Os dados fornecem evidências de oscilações sazonais, previsíveis, na composição de espécies em cinco das sete séries temporais com resolução intra-anual, tanto em borboletas quanto em aves em ambientes florestais e costeiros. Rotatividades sazonais estão provavelmente relacionadas a variações sazonais nas condições climáticas e na disponibilidade de alimento (Heckman 1998, Grøtan et al. 2012, Yen et al. 2016), as quais podem atuar como pressões seletivas - mesmo nos trópicos - para a sincronização de histórias de vida das espécies com os ciclos ambientais anuais (Foster \& Kreitzman 2009). Assim, comportamentos sazonais (e.g., migração, diapausa) dos indivíduos de diferentes espécies deixariam uma assinatura sazonal em um nível de organização superior, i.e., na composição das assembleias, através da superimposição de ciclos anuais de ocorrência e abundância manifestados alternadamente por diferentes grupos de espécies (e.g., Shimadzu et al. 2013). As medidas de rotatividade que empregamos aqui não permitem situar as rotatividades no calendário, visto que utilizamos como medida temporal o intervalo de tempo entre campanhas - e não datas (ver Métodos). No entanto, as assembleias com rotatividade sazonal apresentaram relativa regularidade em relação aos solstícios de inverno e verão como revelado por plots de similaridade de cada campanha com o centróide da assembleia (i.e., com a assembleia formada pelas abundâncias médias de cada espécie ao longo do estudo - ver Figura I do Apêndice 5). Uma assinatura sazonal também poderia ser deixada por espécies sedentárias cuja detectabilidade apresente padrões sazonais devido a mudanças de comportamento (e.g., vocalização, agregação) entre os períodos reprodutivo e inter-reprodutivo.

As oscilações sazonais fortemente regulares na composição da assembleia de aves de São Sebastião - as quais contrastam com sua relativa estabilidade interanual - se devem a existência de grupos de espécies migratórias com cronogramas alternados, dos quais dois grupos são emblemáticos. De um lado os maçaricos e batuíras (aves pernaltas das famílias Scolopacidae e Chadriidae, respectivamente) "invernam" na área durante a primavera e verão, abandonando-a no outono em direção às altas latitudes da América do Norte, onde se reproduzem durante o verão boreal (Sick 1996); do outro lado, os trinta-réis (aves costeiras da família Sternidae) se reproduzem na costa de São Paulo no outono e inverno, abandonando a área na primavera e retornando apenas no outono seguinte (Campos et al. 2004). Assim, esses dois grupos de espécies se alternam regularmente na ocupação da área, coexistindo nela por apenas duas breves épocas do ano ao redor dos equinócios de primavera e de outono. Já as oscilações sazonais nas duas séries de borboletas Ithomiini estão relacionadas ao fenômeno sazonal conhecido como "bolsões" (Vasconcellos-Neto 1980, Pinheiro et al. 2008, ver Capítulo 1). Os bolsões consistem de picos anuais de agregações de borboletas Ithomiini em locais úmidos e sombreados da mata durante a estação seca, os quais se dissolvem com a chegada da estação chuvosa. Porém, algumas espécies dessas assembleias parecem não se agregar e 
apresentam picos na estação chuvosa (Vasconcellos-Neto 1980, ver Capítulo 1). Essa alternância previsível gera oscilações sazonais na composição de espécies. A diferença de amplitude na rotatividade sazonal das duas séries de borboletas Ithomiini pode estar relacionada à presença de zeros (ausências) em uma série (USP) porém não na outra (USP core).

As oscilações sazonais observadas na composição das assembleias de aves florestais em Rondônia (Jirau 11) e na Mata Atlântica (Curucutu) podem estar ligadas, pelo menos em parte, à ocorrência de espécies migratórias. A concepção clássica de que aves tropicais residentes, especialmente aves florestais, seriam sedentárias (i.e., não-migratórias) vêm sendo desafiada por estudos de campo (Loiselle \& Blake 1991, Levey 1994), pelo uso de tecnologias de rastreamento (Jahn et al. 2013, Cueto et al. 2015, Guaraldo et al. 2016) e por grandes bases de dados de ocorrência abastecidas por cidadãos (e.g., Wikiaves, E-bird; Lees \& Martin 2015). Estes estudos vêm revelando que algumas espécies neotropicais tradicionalmente tidas como sedentárias realizam movimentos migratórios anuais (e.g., Lees \& Martin 2015, Lees 2016). Assim, a mistura complexa de espécies migratórias e sedentárias em florestas tropicais pode gerar mudanças anuais na composição de espécies (Loiselle \& Blake 1992, Faaborg et al. 2010). As oscilações sazonais da assembleia de aves da Mata Atlântica (Curucutu) podem estar relacionadas, pelo menos em parte, a migrantes altitudinais, os quais passam o inverno nas áreas baixas e o verão nas áreas altas (Sick 1996, Faaborg et al. 2010), tal como a araponga (Procnias nudicollis) e o sabiá-una (Turdus flavipes). A rotatividade sazonal observada em uma das assembleias de aves de Rondônia (Jirau 11) poderia estar relacionada a espécies migratórias e também aos pulsos anuais de cheia e vazão do Rio Madeira, os quais devem oferecer oportunidades de uso sazonal para diversas espécies (e.g., Petermann 1997). Curiosamente, não encontramos evidências de rotatividade sazonal na outra assembleia de aves do Rondônia localizada na margem oposta do Rio Madeira (Jirau 10). É possível que a extensão de ambientes de floresta de várzea seja diferente entre essas duas assembleias.

\section{Premissa de equivalência demográfica}

Apesar dos modelos de equivalência demográfica terem previsto valores de riqueza e abundância próximos aos empíricos (Figuras I, II e III do Apêndice 3), eles subestimaram ou superestimaram as rotatividades interanuais na composição de espécies em metade das séries. Estudos anteriores mostraram que modelos neutros, os quais assumem equivalência demográfica entre espécies, subestimaram (Wootton 2005, Gilbert et al. 2006, Mac Nally 2007, Dornelas et al. 2014) ou superestimaram (Clark \& McLachlan 2003, McGill et al. 2005) rotatividades temporais empíricas. No estudo de Dornelas et al. (2014) a maioria das 100 assembleias de diversos taxa espalhadas pelo globo apresentou rotatividades superiores às previstas pelo modelo neutro, resultado atribuído pelos autores à ocorrência de impactos humanos nos últimos 40 anos. Esses impactos favoreceriam algumas espécies em detrimento de outras, violando a premissa de equivalência e causando mudanças na composição de espécies além da rotatividade basal (Gilbert et al. 2006). De fato, as quatro assembleias do nosso estudo cujas localidades passaram por mudanças no uso do solo ao longo das amostragens (Flórida e Juruena) tenderam a apresentar taxas de rotatividade interanual maiores do que as simuladas. Por outro lado, o modelo de equivalência foi capaz de simular as rotatividades interanuais das três assembleias de aves de floresta tropical que não sofreram 
impactos evidentes, indicando que processos demográficos estocásticos ("neutros") poderiam explicar a rotatividade basal desses ambientes ricos em espécies raras. Entretanto, as localidades das duas assembleias com rotatividades interanuais menores do que as simuladas (São Sebastião e USP, ambas em contexto urbano) também não passaram por mudanças no uso do solo. Porém, apresentaram uma estabilidade interanual na composição de espécies (baixa rotatividade basal) não compatível com a premissa de equivalência.

Os modelos de equivalência não foram capazes de prever as rotatividades sazonais observadas, reforçando a percepção de que diferenças entre espécies ou grupos de espécies são necessárias para gerar rotatividades sazonais (Shimadzu et al. 2013). A inclusão de uma sazonalidade "neutra", i.e., de taxas de entrada e saída da assembleia que variam sazonalmente, porém de forma igual para todas as espécies, não foi suficiente para gerar a sazonalidade empírica observada na série USP core. Apesar desse modelo de equivalência com sazonalidade estimada por captura-recaptura ter gerado uma discreta rotatividade sazonal (Figura 4), sua amplitude foi dez vezes menor do que a empírica. Infelizmente só pudemos simular sazonalidade "neutra" a partir de dados obtidos com técnicas de captura-marcaçãorecaptura (i.e., apenas para borboletas Ithomiini) visto que apenas essa técnica amostral permitiu a estimativa de taxas de entrada e saída total da assembleia.

A abordagem minimalista da teoria neutra promoveu consideráveis avanços ao explicar propriedades estáticas das assembleias (e.g., distribuição de abundâncias de espécies) com um modelo simples e genérico, porém é muito criticada por fazer previsões não realistas de padrões dinâmicos e por ser sensível a diferenças entre espécies (Kalyuzhny et al. 2015). Nossos resultados mostram que, pelo menos em alguns contextos, a premissa de equivalência assumida pela teoria neutra poderia ser suficiente para prever padrões de rotatividade basais interanuais, especialmente em assembleias com grande riqueza e com muitas espécies raras. No entanto, a premissa seria inválida para explicar rotatividades sazonais, uma característica fundamental de muitas assembleias (Grøtan et al. 2012, 2014, Shimadzu et al. 2013), além de mudanças na composição de espécies induzidas por perturbações humanas (Dornelas et al. 2014). Nesses casos entender diferenças entre espécies parece ser fundamental (Gilbert et al. 2006).

\section{Considerações Finais}

Nossos dados mostram que a composição de espécies de assembleias de aves e borboletas no Brasil e na Florida são altamente dinâmicas, seja na escala interanual e/ou sazonal. Esse resultado tem implicações teóricas e práticas importantes. As altas taxas de rotatividade interanual que encontramos nas assembleias de aves de localidades de floresta tropical bem preservada indicam que essas rotatividades basais têm que ser levadas em conta por estudos que visem detectar impactos de perturbações sobre as assembleias (Magurran 2016). As rotatividades sazonais que encontramos na maioria das assembleias estudadas, assim como a ampla ocorrência - mesmo dentre espécies tropicais - de estratégias de vida sincronizadas com a sazonalidade ambiental (Foster \& Kreitzman 2009) sugerem que é razoável supor que assembleias neotropicais com rotatividades sazonais sejam mais comuns do que se imagina. Por isso, estudos de monitoramento devem amostrar as diferentes estações do ano ou, como uma alternativa mais limitada, amostrar uma única época do ano tal como o Breeding Bird 
Survey (Sauer et al. 2013). A existência de sazonalidade na composição de espécies deve depender da presença de grupos de espécies com padrões sazonais distintos de ocorrência ou abundância (Shimadzu et al. 2013).

Visto que os modelos que assumem equivalência demográfica previram as rotatividades interanuais de assembleias ricas e com espécies raras situadas em localidades bem preservadas, processos estocásticos podem ser mais importantes do que diferenças entre espécies para determinar as taxas de rotatividade interanual basal desse tipo de assembleia. Portanto, a premissa de equivalência ecológica pode ser útil para modelar rotatividades interanuais basais de referência, pelo menos para assembleias mega-diversas. Porém, para entender e prever rotatividades sazonais, bem como mudanças direcionais causadas por perturbações, é necessário levar em conta que diferentes espécies e indivíduos podem reagir de forma distinta às alterações do ambiente (e.g., Gilbert et al., 2006), sejam elas naturais ou não. Nesse sentido a Ecologia de comunidades pode se beneficiar da interação com outras disciplinas tal como a biologia molecular, fisiologia, cronobiologia e ecologia comportamental (Halle \& Stenseth 2000, Gaston et al. 2009). Ainda estamos longe de um entendimento geral e até mesmo básico - dos padrões e processos relacionados à estrutura e dinâmica das assembleias animais no neotrópico. O primeiro passo para preencher essa lacuna é a disseminação de estudos sistemáticos de longo prazo, de preferência com resolução sazonal, que contemplem a diversidade espaço-temporal de táxons e ambientes da região neotropical uma das mais diversas, menos conhecidas e mais ameaçadas do planeta.

\section{BIBLIOGRAFIA}

Adler, P. B. 2004. Neutral models fail to reproduce observed species-area and species-time relationships in Kansas grasslands. Ecology 85:1265-1272.

Adler, P. B., J. HilleRisLambers, and J. Levine. 2007. A niche for neutrality. Ecology Letters 10:95-104.

Beccaloni, G. 1997. Ecology, natural history and behaviour of the Ithomiinae Butterflies and their mimics in Ecuador (Lepidoptera: Nymphalidae: Ithomiinae). Tropical Lepidoptera 8:130-124.

Bell, G. 2000. The distribution of abundance in neutral communities. The American Naturalist 155:606-617.

Bencke, G. A., G. N. Maurício, P. F. Develey, and J. M. Goerck. 2006. Áreas Importantes para a Conservação das Aves no Brasil. Parte I - Estados do Domínio da Mata Atlântica. Save Brasil, São Paulo.

Brown, K. S. 1984. Chemical ecology of dehydropyrrolizidine alkaloids in adult Ithomiinae (Lepidoptera: Nymphalidae). Revista Brasileira de Biologia 44:435-460.

Brown, K. S., and W. W. Benson. 1974. Adaptive polymorphism associated with multiple Müllerian mimicry in Heliconius numata (Lepid. Nymph.). Biotropica 6:205-228.

Burnham, K. P., and D. R. Anderson. 2002. Model Selection and Multimodel Inference. second edi. Springer, NewYork. 
Campos, F. P. D. P. D., P. D. J. F. Faria, and P. Martuscelli. 2004. Aves insulares marinhas, residentes e migratórias, do litoral do Estado de São Paulo. Pages 57-82in J. O. Branco, editor.Aves marinhas insulares brasileiras: bioecologia e conservação. Editora da UNIVALI, Itajaí.

Candia-Gallardo, C., L. F. Silveira, and A. A. Kuniy. 2010. A new population of the Cone-billed Tanager Conothraupis mesoleuca, with information on the biology, behaviour and type locality of the species. Bird Conservation International 20:149-160.

Clark, J. S., and J. McLachlan. 2003. Stability of forest biodiversity. Nature 423:635-638.

Connell, J. H. 1978. Diversity in tropical rain forests and coral reefs. Science 199:1302-1310.

Cooch, E. G., and G. White. 2006. Program MARK: a gentle introduction.

Cracraft, J. 1985. Historical biogeography and patterns of differentiation within the South American avifauna: areas of endemism. Ornithological Monographs 36:49-84.

Cueto, V., A. E. Jahn, D. T. Tuero, A. C. Guaraldo, J. H. Sarasola, S. P. Bravo, V. Gómez, J. I. Giraldo, D. Masson, M. MacPherson, and J. E. Jiménez. 2015. Las aves migratorias de América del Sul: Nuevas técnicas revelan información sobre su comportamiento. Ciencia Hoy 24:19-25.

Darwin, C. 1859. On the Origin of Species by Means of Natural Selection, or the Preservation of Favoured Races in the Struggle for Life. Page Darwin. John Murray, London, UK.

Dornelas, M., S. R. Connolly, and T. P. Hughes. 2006. Coral reef diversity refutes the neutral theory of biodiversity. Nature 440:80-82.

Dornelas, M., N. J. Gotelli, B. J. McGill, H. Shimadzu, F. Moyes, C. Sievers, and A. E. Magurran. 2014. Assemblage time series reveal biodiversity change but not systematic loss. Science 344:296-299.

Dornelas, M., A. E. Magurran, S. T. Buckland, A. Chao, R. L. Chazdon, R. K. Colwell, T. Curtis, K. J. Gaston, N. J. Gotelli, M. a Kosnik, B. J. McGill, J. L. McCune, H. Morlon, P. J. Mumby, L. Ovreås, A. Studeny, and M. Vellend. 2012. Quantifying temporal change in biodiversity: challenges and opportunities. Proceedings of the Royal Society B - Biological Sciences Biological Sciences 280:2-10.

Drummond, B. 1976. Comparative ecology and mimetic relationships of ithomiine butterflies in eastern Ecuador. Master Thesis, University of Florida.

Engen, S., V. Grøtan, and B. E. Sæther. 2011. Estimating similarity of communities: A parametric approach to spatio-temporal analysis of species diversity. Ecography 34:220231.

Faaborg, J., R. T. Holmes, A. D. Anders, K. L. Bildstein, K. M. Dugger, S. A. G. Jr, P. Heglund, K. A. Hobson, A. E. Jahn, D. H. Johnson, S. C. Latta, D. J. Levey, P. P. Marra, C. L. Merkord, E. Nol, S. I. Rothstein, T. W. Sherry, and N. Warnock. 2010. Recent advances in understanding migration systems of New World land birds. Ecological Monographs 80:348.

Foster, R. G., and L. Kreitzman. 2009. Seasons of life: The biological rhythms that enable living things to thrive and survive. Profile Books, London. 
Gaston, K. J., S. L. Chown, P. Calosi, J. Bernardo, D. T. Bilton, A. Clarke, S. Clusella-Trullas, C. K. Ghalambor, M. Konarzewski, L. S. Peck, W. P. Porter, H. O. Pörtner, E. L. Rezende, P. M. Schulte, J. I. Spicer, J. H. Stillman, J. S. Terblanche, and M. van Kleunen. 2009. Macrophysiology: A Conceptual Reunification. American Naturalist 174:595-612.

Gilbert, B., W. F. Laurance, E. G. Leigh, and H. E. M. Nascimento. 2006. Can neutral theory predict the responses of Amazonian tree communities to forest fragmentation? The American Naturalist 168:304-17.

Grant, P. R., and R. Grant. 2014. 40 Years of Evolution: Darwin's Finches on Daphne Major Island. Princeton University Press.

Gregory, R. D., D. W. Gibbons, and P. F. Donald. 2004. Bird census and survey techniques. Pages 17-56in W. J. Sutherland, I. Newton, and R. E. Green, editors.Bird Ecology and Conservation: A Handbook of Techniques. Oxford University Press, Oxford.

Grøtan, V., R. Lande, I. A. Chacon, and P. J. DeVries. 2014. Seasonal cycles of diversity and similarity in a Central American rainforest butterfly community. Ecography 37:509-516.

Grøtan, V., R. Lande, S. Engen, B. E. Sæther, and P. J. DeVries. 2012. Seasonal cycles of species diversity and similarity in a tropical butterfly community. Journal of Animal Ecology 81:714-723.

Guaraldo, A. C., J. F. Kelly, and M. Marini. 2016. Contrasting annual cycles of an intratropical migrant and a tropical resident bird. Journal of Ornithology 157:695-705.

Gwinner, E. 1986. Circannual Rhythms: Endogenous Annual Clocks in the Organization of Seasonal Processes. Springer-Verlag, Berlin.

Halle, S., and N. C. Stenseth. 2000. Chronoecology: New Light Through Old Windows - A Conclusion. Pages 275-284in S. Halle and N. C. Stenseth, editors.Activity Patterns in Small Mammals: An Ecological Approach. Springer.

Heckman, C. W. 1998. The seasonal succession of biotic communities in wetlands of the tropical wet-and-dry climatic zone: $\mathrm{V}$. Aquatic invertebrate communities in the pantanal of Mato Grosso, Brazil. International Review of Hydrobiology 83:31-63.

Hubbell, S. P. 2001. The Unified Neutral Theory of Biodiversity and Biogeography. Page Monographs in Population Biology. Princeton University Press.

IAG. 2013. Boletim Climatológico Anual da Estação Meteorológica do IAG/USP. São Paulo.

IAG. 2015. Boletim Climatológico Trimestral da Estação Meteorológica do IAG/USP - Verão 2014/2015. São Paulo.

Jahn, A. E., D. J. Levey, V. R. Cueto, J. P. Ledezma, D. T. Tuero, J. W. Fox, and D. Masson. 2013. Long-distance bird migration within South America revealed by light-level geolocators. The Auk 130:223-229.

Kalyuzhny, M., R. Kadmon, and N. M. Shnerb. 2015. A neutral theory with environmental stochasticity explains static and dynamic properties of ecological communities. Ecology Letters 18:572-580.

Karr, J. R. 1971. Structure of avian communities in selected Panama and Illinois habitats. Ecological Monographs 41:207-233. 
Karr, J. R. 1976. Seasonality, resource availability, and community diversity in tropical bird communities. American Naturalist 110:973-994.

Karr, J. R., and K. E. Freemark. 1983. Habitat selection and environmental gradients: dynamics in the "stable" tropics. Ecology 64:1481-1494.

Kautz, R., B. Stys, and R. Kawula. 2007. Florida vegetation 2003 and land use change between 1985-1989 and 2003. Florida Scientist 70:12-23.

Krebs, C. J. 1999. Ecological Methodology. The Benjamin/Cummings series in the life sciences. Addison-Wesley Euicational Publishers Inc.

Laake, J. L. 2016. RMark: An R Interface for Analysis of Capture-Recapture Data with MARK. Alaska Fish. Sci. Cent., NOAA, Natl. Mar. Fish. Serv, Seattle.

Lawton, J., and R. May. 1995. Extinction rates. Oxford University Press.

Lees, A. C. 2016. Evidence for longitudinal migration by a "sedentary" Brazilian flycatcher, the Ash-throated Casiornis. Journal of Field Ornithology 87:251-259.

Lees, A. C., and R. W. Martin. 2015. Exposing hidden endemism in a Neotropical forest raptor using citizen science. Ibis 157:103-114.

Levey, D. J. 1994. Why we should adopt a broader view of Neotropical migrants. The Auk 111:233-236.

Loiselle, B. A., and J. G. Blake. 1991. Temporal Variation in Birds and Fruits Along an Elevational Gradient in Costa Rica. Ecology 72:180-193.

Loiselle, B. A., and J. G. Blake. 1992. Population variation in tropical bird community: implications for conservation. BioScience 42:838-845.

De Luca, A. C., P. F. Develey, G. A. Bencke, and J. M. Goerck. 2009. Áreas Importantes para a Conservação das Aves no Brasil. Parte II - Amazônia, Cerrado e Pantanal. Page Forestry. Save Brasil, São Paulo.

MacArthur, R. H. 1957. On the relative abundance of bird species. Proceedings of the National Academy of Sciences (USA) 43:293-295.

MacArthur, R. H. 1972. Geographical Ecology. Harper and Row, New York, USA.

MacArthur, R. H., and E. O. Wilson. 1967. The theory of island biogeography. Page (R. H. MacArthur, Ed.) Monographs in Population Biology. Princeton University Press.

Magurran, A. E. 2007. Species abundance distributions over time. Ecology Letters 10:347-354.

Magurran, A. E. 2008. Diversity over time. Folia Geobotanica 43:319-327.

Magurran, A. E. 2011. Measuring species diversity in time (and space). Pages 89-94in A. E. Magurran and B. J. McGill, editors.Biological Dversity: Frontiers in Measurement and Assesment. Oxford University Press, USA, New York.

Magurran, A. E. 2016. How ecosystems change. Science 351:448-449.

Magurran, A. E., and M. Dornelas. 2010. Biological diversity in a changing world. Philosophical Transactions of the Royal Society of London. Series B, Biological sciences 365:3593-7. 
Magurran, A. E., and P. A. Henderson. 2010. Temporal turnover and the maintenance of diversity in ecological assemblages. Philosophical Transactions of the Royal Society of London. Series B 365:3611-20.

McGill, B. J. 2003. Strong and weak tests of macroecological theory. Oikos 102:679-685.

McGill, B. J., R. S. Etienne, J. S. Gray, D. Alonso, M. J. Anderson, H. K. Benecha, M. Dornelas, B. J. Enquist, J. L. Green, F. He, A. H. Hurlbert, A. E. Magurran, P. A. Marquet, B. A. Maurer, A. Ostling, C. U. Soykan, K. I. Ugland, and E. P. White. 2007. Species abundance distributions: moving beyond single prediction theories to integration within an ecological framework. Ecology Letters 10:995-1015.

McGill, B. J., E. A. Hadly, and B. A. Maurer. 2005. Community inertia of Quaternary small mammal assemblages in North America. Proceedings of the National Academy of Sciences 102:16701-16706.

Missa, O., C. Dytham, and H. Morlon. 2016. Understanding how biodiversity unfolds through time under neutral theory. Philosophical transactions of the Royal Society of London. Series B, Biological sciences 371:20150226.

Mac Nally, R. 2007. Use of the abundance spectrum and relative-abundance distributions to analyze assemblage change in massively altered landscapes. The American Naturalist 170:319-30.

Nekola, J. C., and J. H. Brown. 2007. The wealth of species: ecological communities, complex systems and the legacy of Frank Preston. Ecology Letters 10:188-96.

Nichols, J. D., L. Thomas, and P. B. Conn. 2009. Inferences About Landbird Abundance from Count Data: Recent Advances and Future Directions. Pages 201-235in D. Thomson, E. Cooch, and M. Conroy, editors.Modeling Demographic Processes in Marked Populations. Springer, New York.

Pardieck, K. L., D. J. J. Ziolkowski, M.-A. R. Hudson, and K. Campbell. 2016. North American Breeding Bird Survey Dataset 1966 - 2015, version 2015.0. Page U.S. Geological Survey, Patuxent Wildlife Research Center.

Petermann, P. 1997. The Birds. Pages 419-455in W. J. Junk, editor.The Central Amazon Floodplain: Ecology of a Pulsing System. Springer-Verlag, Berlin Heidelberg.

Pinheiro, C., Í. Medri, and A. Salcedo. 2008. Why do the ithomiines (Lepidoptera, Nymphalidae) aggregate? Notes on a butterfly pocket in central Brazil. Revista Brasileira de Entomologia 52:610-614.

Preston, F. W. 1960. Time and space and the variation of species. Ecology 41:612-627.

R Core Team. 2016. R: A Language and environment for statistical computing. R Foundation for Statistical Computing, Vienna, Austria.

Ricklefs, R. E. 2006. The unified neutral theory of biodiversity: do the numbers add up? Ecology 87:1424-1431.

Sauer, J. R., W. a. Link, J. E. Fallon, K. L. Pardieck, and D. J. Ziolkowski. 2013. The North American Breeding Bird Survey 1966-2011: Summary Analysis and Species Accounts. North American Fauna 79:1-32. 
Sayre, R., P. Comer, H. Warner, and J. Cress. 2009. A new map of standardized terrestrial ecosystems of the conterminous United States. Page US Geological Survey Professional Paper 1768. Renton.

Schwarz, C. J., and A. N. Arnason. 1996. A general methodology for the analysis of capturerrecapture experiments in open populations. Biometrics 52:860-873.

Schwarz, C. J., R. E. Bailey, J. R. Irvine, and F. C. Dalziel. 1993. Estimating salmon spawning escapement using capture-recapture methods. Canadian Journal of Fisheries and Aquatic Sciences 50:1181-1197.

Shimadzu, H., M. Dornelas, P. A. Henderson, and A. E. Magurran. 2013. Diversity is maintained by seasonal variation in species abundance. BMC Biology 11:98.

Sick, H. 1996. Ornitologia brasileira, uma introdução. Segunda ed. Editora Nova Fronteira, Rio de Janeiro.

Stouffer, P. C., R. O. Bierregaard, C. Strong, and T. E. Lovejoy. 2006. Long-Term Landscape Change and Bird Abundance in Amazonian Rainforest Fragments. Conservation Biology 20:1212-1223.

Stouffer, P. C., and R. Bierregaard Jr. 1995. Use of Amazonian forest fragments by understory insectivorous birds. Ecology 76:2429-2445.

Thibault, K. M., E. P. White, and S. K. M. Ernest. 2004. Temporal dynamics in the structure and composition of a desert rodent community. Ecology 85:2649-2655.

Thiollay, J. 1994. Structure, density and rarity in an Amazonian rainforst bird community. Journal of Tropical Ecology 10:449-481.

Tokeshi, M. 1999. Niche apportionment and relative abundances of coexisting species. Page Species Coexistence - Ecological and Evolutionary Perspectives. Blackwell Science, London.

Vasconcellos-Neto, J. 1980. Dinamica de populações de Ithomiinae (Lep., Nymphalidae) em Sumaré - SP. Universidade Estadual de Campinas.

Volkov, I., J. R. Banavar, S. P. Hubbell, and A. Maritan. 2003. Neutral theory and relative species abundance in ecology. Nature 424:1035-1037.

Williams, B. K., J. D. Nichols, and M. J. Conroy. 2002. Analysis and Management of Animal Populations. Page (B. K. Williams, J. D. Nichols, and M. J. Conroy, Eds.). Academic Press, San Diego.

Wootton, J. T. 2005. Field parameterization and experimental test of the neutral theory of biodiversity. Nature 433:309-12.

Yen, J. D. L., J. R. Thomson, J. M. Keith, D. M. Paganin, and R. Mac Nally. 2016. How do different aspects of biodiversity change through time? A case study on an Australian bird community. Ecography 39:1-9. 


\section{APÊNDICE 1}

\section{Estimativas De Abundância Baseadas Em Marcação-Recaptura}

O modelo JS POPAN é um modelo de população aberta, isto é, que assume a ocorrência de entradas (nascimentos e imigrações) e saídas (mortes e emigrações) de indivíduos entre as ocasiões de captura. Para adaptar nosso desenho amostral a este modelo agrupamos as três ou quatro sessões de captura de uma mesma campanha, resultando em um histórico de capturas com 38 ocasiões. O modelo JS POPAN estima diretamente quatro parâmetros:

Sobrevivência aparente - $\Phi(\boldsymbol{P h} \boldsymbol{i})$ : probabilidade de um indivíduo capturado campanha $i$ ser recapturado na campanha $i+1$;

Recrutamento aparente - pent: proporção do total de indivíduos que entraram na população, capturados ou não, que ingressaram entre campanha $i$ e a campanha $i+1$;

Tamanho da superpopulação - $\boldsymbol{N}$ : número total de indivíduos, capturados ou não, que entraram na população ao longo do estudo.

Parâmetros de captura - $\boldsymbol{p}$ : probabilidade de captura em cada ocasião primária.

A partir destes parâmetros este modelo estima de maneira derivada (iterativa) o número de indivíduos presente em cada ocasião de captura (Schwarz et al. 1993), isto é, a abundância estimada (adaptado de Cooch and White 2006):

$$
N_{t}=\left(N_{t-1} * \Phi_{t}^{i}\right)+\text { pent }_{t}
$$

Onde $N_{t}$ é a abundância (corrigida pela probabilidade de captura $p$, não mostrada na equação) na ocasião de captura $t, N_{t-1}$ representa a abundância na ocasião de captura anterior, $\Phi_{t}^{i}$ (Phi) representa a sobrevivência aparente entre as ocasiões de captura $t-1$ e $t$, cujo intervalo de tempo é $i$, e pent $t_{t}$ representa a probabilidade de indivíduos da superpolução $N$ (não mostrada na equação) entrarem na população no intervalo entre as ocasiões de captura $t-1$ e $t$.

Realizamos o ajuste dos modelos JS POPAN com o programa MARK versão 8.0 (Cooch and White 2006), usando como interface o pacote RMark versão 2.2.0 (Laake 2016) no programa $R$ versão 3.3.2 (R Core Team 2016). Obtivemos as abundâncias estimadas de cada espécie núcleo a partir do modelo ou do subconjunto de modelos mais plausíveis dentre um rol de 32 modelos JS POPAN candidatos (ver Tabela I), selecionados através do critério de seleção de Akaike corrigido para amostras pequenas (AICC - Burnham and Anderson 2002). Nos casos onde houve incerteza na seleção de modelos as estimativas de parâmetros foram ponderadas pelo peso de AICc (wAICc - Burnham and Anderson 2002) dos modelos que tiveram wAICc > 0,001 . O rol de modelos POPAN candidatos, os quais foram avaliados separadamente para cada espécie, diferiram quanto à possibilidade de variação temporal dos parâmetros e quanto à inclusão ou não de covariáveis (Tabela I). Montamos modelos em que os parâmetros Phi (sobrevivência aparente) e pent (recrutamento aparente) puderam: i) ser constantes ao longo do tempo, ii) variar entre cada ocasião ou iii) depender de covariáveis. Montamos modelos onde Phi e pent covariaram com i) chuva acumulada $(\mathrm{mm})$ entre cada campanha ou com ii) 
chuva mensal acumulada histórica (1933-2010). A chuva acumulada histórica é um proxy para representar o calendário, visto que seus valores se repetem no mesmo mês em anos diferentes (para mais informações sobre covariáveis que influenciam a dinâmica temporal da assembléia de Ithomiini ver Capítulo 1). Utilizamos dados de pluviosidade coletados por uma estação meteorológica localizada na mancha urbana de São Paulo, a $15 \mathrm{~km}$ da área de estudo (IAG 2013, 2015). Para levar em conta diferenças no esforço amostral entre ocasiões de captura, incluímos alguns modelos em que o parâmetro probabilidade de captura $(p)$ covariou com esforço amostral, definido como tempo (minutos) de captura multiplicado pelo número de coletores. Também incluímos modelos com $p$ constante ao longo do tempo e modelos em que $p$ pôde ser diferente em cada ocasião de captura (ver Tabela I). O parâmetro $N$ (superpopulação) representa o total de indivíduos que ingressou na população no período de estudo (incluindo os não detectados) e é representado por um valor único que, por definição, não varia no tempo. O parâmetro n-hat - a abundância de cada espécie núcleo em cada ocasião - não pôde ser diretamente associado a nenhuma covariável por não ser diretamente estimado pela função de verossimilhança, mas de forma derivada a partir dos demais parâmetros (Schwarz and Arnason 1996). No entanto, como deriva dos outros parâmetros, podemos dizer que nossos modelos possibilitam que $n$-hat seja afetado pelas covariáveis consideradas.

Tabela I. Trinta e dois modelos de captura-marcação-recaptura do tipo Jolly-Seber POPAN avaliados neste estudo para se obter estimativas de abundâncias de oito espécies de borboletas da tribo Ithomiini (Nymphalidae, Danainae). Npar se refere ao número total de parâmetros de cada modelo. São mostrados os tipos de parâmetro de cada modelo e entre parênteses suas covariáveis. Parâmetros: $\Phi$ (Phi): Sobrevivência aparente; $p$ : probabilidade de captura; pent: recrutamento aparente; $N$ : tamanho da superpopulação. Covariáveis entre parênteses: tempo = parâmetro pode variar livremente no tempo; esforço = esforço amostral; chuva_hist = chuva média mensal histórica (1933-2010), chuva = chuva acumulada $(\mathrm{mm})$ entre as ocasiões de captura; * indica que o parâmetro foi mantido constante ao longo do tempo. A abundância estimada em cada ocasião (n-hat) não é mostrada nos modelos pois é um parâmetro derivado não estimado diretamente pela função de verossimilhança.

\begin{tabular}{|c|c|c|}
\hline ID & Modelos JS POPAN & Npar \\
\hline 1 & $\Phi(*) p(*) \operatorname{pent}(*) N$ & 4 \\
\hline 2 & $\Phi$ (chuva_hist) $p\left({ }^{*}\right) \operatorname{pent}\left({ }^{*}\right) N$ & 5 \\
\hline 3 & $\Phi\left(\right.$ chuva) $p\left({ }^{*}\right) \operatorname{pent}\left({ }^{*}\right) N$ & 5 \\
\hline 4 & $\Phi\left({ }^{*}\right) p$ (esforço) pent $\left({ }^{*}\right) N$ & 5 \\
\hline 5 & $\Phi\left(\right.$ chuva_hist) $p\left({ }^{*}\right)$ pent(chuva_hist) $N$ & 6 \\
\hline 6 & $\Phi\left(\right.$ chuva_hist) $p\left({ }^{*}\right)$ pent (chuva) $N$ & 6 \\
\hline 7 & $\Phi$ (chuva_hist) $p$ (esforço) $\operatorname{pent}\left({ }^{*}\right) N$ & 6 \\
\hline 8 & $\Phi\left(\right.$ chuva) $p\left({ }^{*}\right)$ pent (chuva_hist) $N$ & 6 \\
\hline 9 & $\Phi\left({ }^{*}\right) p$ (esforço) pent(chuva_hist) $N$ & 6 \\
\hline 10 & $\Phi\left(\right.$ chuva) $p\left({ }^{*}\right)$ pent (chuva) $N$ & 6 \\
\hline 11 & $\Phi$ (chuva) $p$ (esforço) pent $\left(^{*}\right) N$ & 6 \\
\hline 12 & $\Phi\left({ }^{*}\right) p$ (esforço) pent(chuva) $N$ & 6 \\
\hline 13 & $\Phi$ (chuva_hist) $p$ (esforço) pent(chuva_hist) $N$ & 7 \\
\hline 14 & $\Phi$ (chuva_hist) $p$ (esforço) pent(chuva) $N$ & 7 \\
\hline
\end{tabular}




\begin{tabular}{|c|c|c|}
\hline ID & Modelos JS POPAN & Npar \\
\hline 15 & $\Phi$ (chuva) $p$ (esforço) pent(chuva_hist) $N$ & 7 \\
\hline 16 & $\Phi$ (chuva) $p$ (esforço) pent(chuva) $N$ & 7 \\
\hline 17 & $\Phi$ (chuva_hist) $p\left(^{*}\right)$ pent(tempo) $N$ & 40 \\
\hline 18 & $\Phi$ (chuva) $p\left(^{*}\right)$ pent $($ tempo) $N$ & 40 \\
\hline 19 & $\Phi\left({ }^{*}\right) p$ (tempo) pent $(*) N$ & 40 \\
\hline 20 & $\Phi$ (chuva_hist) $p$ (esforço) pent(tempo) $N$ & 41 \\
\hline 21 & $\Phi$ (chuva) $p$ (esforço) pent(tempo) $N$ & 41 \\
\hline 22 & $\Phi$ (chuva) $p$ (tempo) pent $(*) N$ & 41 \\
\hline 23 & $\Phi\left({ }^{*}\right) p$ (tempo) pent(chuva) $N$ & 41 \\
\hline 24 & $\Phi$ (chuva_hist) $p$ (tempo) pent $\left({ }^{*}\right) N$ & 41 \\
\hline 25 & $\Phi\left({ }^{*}\right) p$ (tempo) pent(chuva_hist) $N$ & 41 \\
\hline 26 & $\Phi$ (chuva) $p$ (tempo) pent(chuva) $N$ & 42 \\
\hline 27 & $\Phi$ (chuva_hist) $p$ (tempo) pent(chuva_hist) $N$ & 42 \\
\hline 28 & $\Phi$ (chuva) $p$ (tempo) pent(chuva_hist) $N$ & 42 \\
\hline 29 & $\Phi$ (chuva_hist) $p$ (tempo) pent(chuva) $N$ & 42 \\
\hline 30 & $\Phi$ (chuva_hist) $p$ (tempo) pent(tempo) $N$ & 76 \\
\hline 31 & $\Phi$ (chuva) $p$ (tempo) pent(tempo) $N$ & 76 \\
\hline 32 & $\Phi$ (tempo) $p$ (tempo) pent(tempo) $N$ & 108 \\
\hline
\end{tabular}

Os modelos selecionados que usamos para obter as estimativas ponderadas de abundância de cada espécie (i.e., modelos com wAICc $>0,001$ ) estão representados na tabela II. Os parâmetros populacionais de entrada (pent) e saída ( $P h i)$ - os quais representam os processos que afetam a abundância local - dos modelos mais plausíveis (i.e., modelos com $\Delta \mathrm{AICc} \leq 3$ ) incluíram como covariáveis as médias históricas de pluviosidade para a maioria das espécies e tempo para três espécies. 
Tabela II. Modelos selecionados (wAICc > 0,001) para a obtenção das estimativas ponderadas de parâmetros demográficas de cada espécie. Os parâmetros foram usados para gerar as simulações da série temporal de borboletas Ithomiini USP core. Npar se refere ao número total de parâmetros de cada modelo. $\triangle \mathrm{AICc}$ se refere ao delta AICc de cada modelo e wAICc ao seu peso de Akaike.

\begin{tabular}{|c|c|c|c|c|}
\hline Espécie & Modelos & Npar & $\triangle \mathrm{AICc}$ & wAICc \\
\hline Hypothyris ninonia & $\Phi($ tempo)p (tempo)pent(tempo) & 114 & 0 & 1 \\
\hline \multirow[t]{3}{*}{ Mechanitis polymnia } & $\Phi$ (chuva_hist) $p$ (tempo)pent(chuva_hist) & 45 & 0 & 0,964 \\
\hline & $\Phi$ (chuva_hist)p (esforço)pent(tempo) & 44 & 7,28 & 0,025 \\
\hline & $\Phi$ (chuva_hist) $p$ (tempo)pent(tempo) & 82 & 8,97 & 0,011 \\
\hline \multirow[t]{4}{*}{ Mechanitis Iysimnia } & $\Phi$ (chuva_hist) $p$ (tempo)pent(chuva_hist) & 45 & 0 & 0,76 \\
\hline & $\Phi$ (chuva_hist)p (esforço)pent(tempo) & 44 & 2,34 & 0,236 \\
\hline & $\Phi$ (chuva_hist)p (tempo)pent(chuva) & 45 & 11,57 & 0,002 \\
\hline & $\Phi$ (chuva_hist) $p$ (tempo)pent ${ }^{*}$ ) & 44 & 12,49 & 0,001 \\
\hline \multirow[t]{2}{*}{ Hypothyris euclea } & $\Phi($ tempo)p (tempo)pent(tempo) & 114 & 0 & 0,857 \\
\hline & $\Phi($ chuva_hist) $p$ (tempo)pent(tempo) & 82 & 3,6 & 0,142 \\
\hline Ithomia agnosia & $\Phi($ chuva_hist) $p$ (tempo)pent(tempo) & 82 & 0 & 1 \\
\hline \multirow[t]{2}{*}{ Hypoleria lavinia } & $\Phi$ (chuva_hist)p (esforço)pent(tempo) & 44 & 0 & 0,994 \\
\hline & $\Phi($ chuva)p (tempo)pent(chuva_hist) & 45 & 10,56 & 0,005 \\
\hline \multirow[t]{8}{*}{ Epityches eupompe } & $\Phi$ (chuva_hist) $p$ (tempo)pent(chuva_hist) & 45 & 0 & 0,424 \\
\hline & $\Phi($ chuva_hist) $p$ (tempo)pent(chuva) & 45 & 1,28 & 0,224 \\
\hline & $\Phi$ (chuva_hist) $p$ (esforço)pent(tempo) & 44 & 2,12 & 0,147 \\
\hline & $\Phi\left(\right.$ chuva_hist) $p\left(^{*}\right)$ pent(tempo) & 43 & 3,38 & 0,078 \\
\hline & $\Phi($ chuva $) p\left({ }^{*}\right)$ pent $($ tempo $)$ & 43 & 4,11 & 0,054 \\
\hline & $\Phi\left(\right.$ chuva_hist) $p$ (tempo)pent $\left(^{*}\right)$ & 44 & 4,14 & 0,053 \\
\hline & $\Phi($ chuva) $p$ (esforço)pent(tempo) & 44 & 6,43 & 0,017 \\
\hline & $\Phi($ chuva)p (tempo)pent(chuva) & 45 & 10,72 & 0,002 \\
\hline \multirow[t]{9}{*}{ Mcclungia cymo } & $\Phi$ (chuva_hist)p $\left({ }^{*}\right)$ pent(tempo) & 43 & 0 & 0,456 \\
\hline & $\Phi($ chuva $) p\left({ }^{*}\right) p e n t($ tempo $)$ & 43 & 0,93 & 0,286 \\
\hline & $\Phi$ (chuva_hist)p (esforço)pent(tempo) & 44 & 2,29 & 0,145 \\
\hline & $\Phi($ chuva)p (esforço)pent(tempo) & 44 & 3,37 & 0,085 \\
\hline & $\Phi$ (chuva_hist) $p$ (tempo)pent ${ }^{*}$ ) & 44 & 7,74 & 0,01 \\
\hline & $\Phi\left({ }^{*}\right) p$ (tempo)pent(chuva_hist) & 44 & 8,08 & 0,008 \\
\hline & $\Phi$ (chuva_hist)p (tempo)pent(chuva) & 45 & 9,06 & 0,005 \\
\hline & $\Phi($ chuva_hist) $p$ (tempo)pent(chuva_hist) & 45 & 9,85 & 0,003 \\
\hline & $\Phi\left(^{*}\right) p$ (tempo)pent $\left(^{*}\right)$ & 43 & 12,12 & 0,001 \\
\hline
\end{tabular}




\section{APÊNDICE 2}

Tabela III. Valores de parâmetros usados nas simulações de equivalência demográfica da série USP core (borboletas Ithomiini [Nymphalidade, Danainae] em um fragmento florestal na cidade de São Paulo ver Capítulo 1 para maiores detalhes) usando o modelo Jolly-Seber formulação POPAN no módulo de simulações do programa Mark 8.0 (Cooch and White 2006). São representados os valores fornecidos ao true model das 100 simulações de cada espécie (coluna). Os valores dos parâmetros Phi e pent são iguais para todas as espécies. Código das espécies: Hnino - Hypothyris ninonia; Mpoly - Mechanitis polymnia; Mlysi - Mechanitis lysimnia; Heu - HYpothyris euclea; Iagn - Ithomia agnosia; Hlavinia Hypoleria lavinia; Eeupompe - Epityches eupompe; Mcymo - Mcclungia cymo.

\begin{tabular}{lcccccccc}
\hline Param. & Hnino & Mpoly & Mlysi & Heu & lagn & Hlavinia & Eeupompe & Mcymo \\
\hline Phi 1 & 0,37 & 0,37 & 0,37 & 0,37 & 0,37 & 0,37 & 0,37 & 0,37 \\
Phi 2 & 0,41 & 0,41 & 0,41 & 0,41 & 0,41 & 0,41 & 0,41 & 0,41 \\
Phi 3 & 0,72 & 0,72 & 0,72 & 0,72 & 0,72 & 0,72 & 0,72 & 0,72 \\
Phi 4 & 0,62 & 0,62 & 0,62 & 0,62 & 0,62 & 0,62 & 0,62 & 0,62 \\
Phi 5 & 0,571 & 0,571 & 0,571 & 0,571 & 0,571 & 0,571 & 0,571 & 0,571 \\
Phi 6 & 0,69 & 0,69 & 0,69 & 0,69 & 0,69 & 0,69 & 0,69 & 0,69 \\
Phi 7 & 1 & 1 & 1 & 1 & 1 & 1 & 1 & 1 \\
Phi 8 & 0,39 & 0,39 & 0,39 & 0,39 & 0,39 & 0,39 & 0,39 & 0,39 \\
Phi 9 & 0,02 & 0,02 & 0,02 & 0,02 & 0,02 & 0,02 & 0,02 & 0,02 \\
Phi 10 & 0,02 & 0,02 & 0,02 & 0,02 & 0,02 & 0,02 & 0,02 & 0,02 \\
Phi 11 & 0,04 & 0,04 & 0,04 & 0,04 & 0,04 & 0,04 & 0,04 & 0,04 \\
Phi 12 & 0,18 & 0,18 & 0,18 & 0,18 & 0,18 & 0,18 & 0,18 & 0,18 \\
Phi 13 & 0,09 & 0,09 & 0,09 & 0,09 & 0,09 & 0,09 & 0,09 & 0,09 \\
Phi 14 & 0,167 & 0,167 & 0,167 & 0,167 & 0,167 & 0,167 & 0,167 & 0,167 \\
Phi 15 & 0,01 & 0,01 & 0,01 & 0,01 & 0,01 & 0,01 & 0,01 & 0,01 \\
Phi 16 & 0,21 & 0,21 & 0,21 & 0,21 & 0,21 & 0,21 & 0,21 & 0,21 \\
Phi 17 & 0,71 & 0,71 & 0,71 & 0,71 & 0,71 & 0,71 & 0,71 & 0,71 \\
Phi 18 & 0,69 & 0,69 & 0,69 & 0,69 & 0,69 & 0,69 & 0,69 & 0,69 \\
Phi 19 & 0,67 & 0,67 & 0,67 & 0,67 & 0,67 & 0,67 & 0,67 & 0,67 \\
Phi 20 & 0,52 & 0,52 & 0,52 & 0,52 & 0,52 & 0,52 & 0,52 & 0,52 \\
Phi 21 & 0,08 & 0,08 & 0,08 & 0,08 & 0,08 & 0,08 & 0,08 & 0,08 \\
Phi 22 & 0,04 & 0,04 & 0,04 & 0,04 & 0,04 & 0,04 & 0,04 & 0,04 \\
Phi 23 & 0 & 0 & 0 & 0 & 0 & 0 & 0 & 0 \\
Phi 24 & 0,08 & 0,08 & 0,08 & 0,08 & 0,08 & 0,08 & 0,08 & 0,08 \\
Phi 25 & 0,05 & 0,05 & 0,05 & 0,05 & 0,05 & 0,05 & 0,05 & 0,05 \\
Phi 26 & 0,09 & 0,09 & 0,09 & 0,09 & 0,09 & 0,09 & 0,09 & 0,09 \\
Phi 27 & 0,51 & 0,51 & 0,51 & 0,51 & 0,51 & 0,51 & 0,51 & 0,51 \\
Phi 28 & 0,67 & 0,67 & 0,67 & 0,67 & 0,67 & 0,67 & 0,67 & 0,67 \\
Phi 29 & 0,8 & 0,8 & 0,8 & 0,8 & 0,8 & 0,8 & 0,8 & 0,8 \\
Phi 30 & 0,52 & 0,52 & 0,52 & 0,52 & 0,52 & 0,52 & 0,52 & 0,52 \\
Phi 31 & 0,23 & 0,23 & 0,23 & 0,23 & 0,23 & 0,23 & 0,23 & 0,23 \\
Phi 32 & 0,17 & 0,17 & 0,17 & 0,17 & 0,17 & 0,17 & 0,17 & 0,17
\end{tabular}




\begin{tabular}{|c|c|c|c|c|c|c|c|c|}
\hline Param. & Hnino & Mpoly & Mlysi & Heu & lagn & Hlavinia & Eeupompe & Mcymo \\
\hline Phi 33 & 0 & 0 & 0 & 0 & 0 & 0 & 0 & 0 \\
\hline Phi 34 & 0,01 & 0,01 & 0,01 & 0,01 & 0,01 & 0,01 & 0,01 & 0,01 \\
\hline Phi 35 & 0,41 & 0,41 & 0,41 & 0,41 & 0,41 & 0,41 & 0,41 & 0,41 \\
\hline Phi 36 & 0,38 & 0,38 & 0,38 & 0,38 & 0,38 & 0,38 & 0,38 & 0,38 \\
\hline Phi 37 & 0,02 & 0,02 & 0,02 & 0,02 & 0,02 & 0,02 & 0,02 & 0,02 \\
\hline p 1 & 0,3 & 0,13 & 0,07 & 0,17 & 0,15 & 0,12 & 0,06 & 0,12 \\
\hline p 2 & 0,27 & 0,12 & 0,09 & 0,39 & 0,03 & 0,1 & 0,08 & 0,12 \\
\hline p 3 & 0,31 & 0,14 & 0,1 & 0,2 & 0,06 & 0,14 & 0,11 & 0,12 \\
\hline p 4 & 0,16 & 0,08 & 0,1 & 0,08 & 0,05 & 0,11 & 0,28 & 0,12 \\
\hline p 5 & 0,05 & 0,09 & 0,06 & 0,04 & 0,02 & 0,06 & 0,08 & 0,12 \\
\hline p 6 & 0,18 & 0,05 & 0,09 & 0,07 & 0,07 & 0,09 & 0,09 & 0,12 \\
\hline p 7 & 0,15 & 0,12 & 0,07 & 0,21 & 0,07 & 0,09 & 0,08 & 0,12 \\
\hline p 8 & 0,15 & 0,08 & 0,08 & 0,15 & 0,07 & 0,11 & 0,09 & 0,12 \\
\hline p 9 & 0,17 & 0,08 & 0,21 & 0,89 & 1 & 0,19 & 0,17 & 0,12 \\
\hline p 10 & 1 & 0,28 & 0,36 & 0,87 & 0,01 & 0,21 & 0,2 & 0,12 \\
\hline p 11 & 1 & 0,21 & 0,24 & 0,86 & 0,02 & 0,16 & 0,24 & 0,12 \\
\hline p 12 & 1 & 0,32 & 0,65 & 1 & 0,84 & 0,94 & 0,29 & 0,14 \\
\hline p 13 & 0,96 & 0,6 & 0,33 & 1 & 0,91 & 0,24 & 0,63 & 0,14 \\
\hline p 14 & 0,98 & 0,32 & 0,69 & 0,86 & 0,19 & 0,37 & 0,37 & 0,13 \\
\hline p 15 & 0,99 & 0,39 & 0,53 & 0,86 & 0,23 & 0,36 & 0,2 & 0,13 \\
\hline p 16 & 0,99 & 0,12 & 0,34 & 0,86 & 0,02 & 0,59 & 0,14 & 0,13 \\
\hline p 17 & 1 & 0,53 & 0,45 & 0,86 & 0,18 & 0,15 & 0,09 & 0,13 \\
\hline p 18 & 0,57 & 0,42 & 0,48 & 0,4 & 0,31 & 0,3 & 0,21 & 0,14 \\
\hline p 19 & 0,47 & 0,29 & 0,44 & 0,53 & 0,22 & 0,33 & 0,18 & 0,13 \\
\hline p 20 & 0,61 & 0,21 & 0,3 & 0,6 & 0,22 & 0,38 & 0,27 & 0,13 \\
\hline p 21 & 0,66 & 0,18 & 0,55 & 0,95 & 0,59 & 0,19 & 0,31 & 0,13 \\
\hline p 22 & 0,35 & 0,4 & 0,88 & 0,87 & 1 & 0,38 & 0,22 & 0,13 \\
\hline p 23 & 0,99 & 0,19 & 0,88 & 0,85 & 0,03 & 0,38 & 0,3 & 0,13 \\
\hline p 24 & 0,98 & 0,06 & 0,51 & 0,87 & 1 & 0,41 & 0,16 & 0,13 \\
\hline p 25 & 0,99 & 1 & 0,9 & 1 & 0,1 & 0,46 & 0,24 & 0,15 \\
\hline p 26 & 0,98 & 0,64 & 0,77 & 0,91 & 1 & 0,39 & 0,17 & 0,13 \\
\hline p 27 & 0,57 & 0,31 & 0,6 & 0,88 & 1 & 0,45 & 0,31 & 0,13 \\
\hline p 28 & 0,48 & 0,37 & 0,52 & 0,24 & 0,29 & 0,34 & 0,21 & 0,12 \\
\hline p 29 & 0,45 & 0,51 & 0,45 & 0,15 & 0,19 & 0,26 & 0,38 & 0,12 \\
\hline p 30 & 0,45 & 0,36 & 0,4 & 0,38 & 0,17 & 0,26 & 0,34 & 0,12 \\
\hline p 31 & 0,74 & 0,22 & 0,4 & 0,62 & 0,14 & 0,2 & 0,24 & 0,13 \\
\hline p 32 & 0,11 & 0,16 & 0,63 & 0,06 & 0,02 & 0,38 & 0,29 & 0,12 \\
\hline p 33 & 0,93 & 0,16 & 0,63 & 0,97 & 0,01 & 0,39 & 0,36 & 0,13 \\
\hline p 34 & 0,96 & 0,12 & 0,08 & 0,87 & 0,02 & 0,24 & 0,1 & 0,12 \\
\hline p 35 & 0,99 & 0,11 & 0,32 & 1 & 0,85 & 0,45 & 0,09 & 0,12 \\
\hline p 36 & 0,25 & 0,78 & 0,49 & 0,98 & 0,93 & 0,24 & 0,74 & 0,13 \\
\hline p 37 & 1 & 1 & 0,87 & 0,33 & 0,69 & 0,35 & 0,42 & 0,13 \\
\hline p 38 & 1 & 0,7 & 0,71 & 0,92 & 0,09 & 0,26 & 0,2 & 0,13 \\
\hline
\end{tabular}




\begin{tabular}{|c|c|c|c|c|c|c|c|c|}
\hline Param. & Hnino & Mpoly & Mlysi & Heu & lagn & Hlavinia & Eeupompe & Mcymo \\
\hline pent 1 & 0,023 & 0,023 & 0,023 & 0,023 & 0,023 & 0,023 & 0,023 & 0,023 \\
\hline pent 2 & 0,014 & 0,014 & 0,014 & 0,014 & 0,014 & 0,014 & 0,014 & 0,014 \\
\hline pent 3 & 0,113 & 0,113 & 0,113 & 0,113 & 0,113 & 0,113 & 0,113 & 0,113 \\
\hline pent 4 & 0,000 & 0,000 & 0,000 & 0,000 & 0,000 & 0,000 & 0,000 & 0,000 \\
\hline pent 5 & 0,009 & 0,009 & 0,009 & 0,009 & 0,009 & 0,009 & 0,009 & 0,009 \\
\hline pent 6 & 0,009 & 0,009 & 0,009 & 0,009 & 0,009 & 0,009 & 0,009 & 0,009 \\
\hline pent 7 & 0,024 & 0,024 & 0,024 & 0,024 & 0,024 & 0,024 & 0,024 & 0,024 \\
\hline pent 8 & 0,015 & 0,015 & 0,015 & 0,015 & 0,015 & 0,015 & 0,015 & 0,015 \\
\hline pent 9 & 0,003 & 0,003 & 0,003 & 0,003 & 0,003 & 0,003 & 0,003 & 0,003 \\
\hline pent 10 & 0,002 & 0,002 & 0,002 & 0,002 & 0,002 & 0,002 & 0,002 & 0,002 \\
\hline pent 11 & 0,003 & 0,003 & 0,003 & 0,003 & 0,003 & 0,003 & 0,003 & 0,003 \\
\hline pent 12 & 0,005 & 0,005 & 0,005 & 0,005 & 0,005 & 0,005 & 0,005 & 0,005 \\
\hline pent 13 & 0,009 & 0,009 & 0,009 & 0,009 & 0,009 & 0,009 & 0,009 & 0,009 \\
\hline pent 14 & 0,053 & 0,053 & 0,053 & 0,053 & 0,053 & 0,053 & 0,053 & 0,053 \\
\hline pent 15 & 0,004 & 0,004 & 0,004 & 0,004 & 0,004 & 0,004 & 0,004 & 0,004 \\
\hline pent 16 & 0,048 & 0,048 & 0,048 & 0,048 & 0,048 & 0,048 & 0,048 & 0,048 \\
\hline pent 17 & 0,056 & 0,056 & 0,056 & 0,056 & 0,056 & 0,056 & 0,056 & 0,056 \\
\hline pent 18 & 0,026 & 0,026 & 0,026 & 0,026 & 0,026 & 0,026 & 0,026 & 0,026 \\
\hline pent 19 & 0,003 & 0,003 & 0,003 & 0,003 & 0,003 & 0,003 & 0,003 & 0,003 \\
\hline pent 20 & 0,023 & 0,023 & 0,023 & 0,023 & 0,023 & 0,023 & 0,023 & 0,023 \\
\hline pent 21 & 0,014 & 0,014 & 0,014 & 0,014 & 0,014 & 0,014 & 0,014 & 0,014 \\
\hline pent 22 & 0,004 & 0,004 & 0,004 & 0,004 & 0,004 & 0,004 & 0,004 & 0,004 \\
\hline pent 23 & 0,003 & 0,003 & 0,003 & 0,003 & 0,003 & 0,003 & 0,003 & 0,003 \\
\hline pent 24 & 0,006 & 0,006 & 0,006 & 0,006 & 0,006 & 0,006 & 0,006 & 0,006 \\
\hline pent 25 & 0,004 & 0,004 & 0,004 & 0,004 & 0,004 & 0,004 & 0,004 & 0,004 \\
\hline pent 26 & 0,032 & 0,032 & 0,032 & 0,032 & 0,032 & 0,032 & 0,032 & 0,032 \\
\hline pent 27 & 0,093 & 0,093 & 0,093 & 0,093 & 0,093 & 0,093 & 0,093 & 0,093 \\
\hline pent 28 & 0,073 & 0,073 & 0,073 & 0,073 & 0,073 & 0,073 & 0,073 & 0,073 \\
\hline pent 29 & 0,019 & 0,019 & 0,019 & 0,019 & 0,019 & 0,019 & 0,019 & 0,019 \\
\hline pent 30 & 0,009 & 0,009 & 0,009 & 0,009 & 0,009 & 0,009 & 0,009 & 0,009 \\
\hline pent 31 & 0,170 & 0,170 & 0,170 & 0,170 & 0,170 & 0,170 & 0,170 & 0,170 \\
\hline pent 32 & 0,007 & 0,007 & 0,007 & 0,007 & 0,007 & 0,007 & 0,007 & 0,007 \\
\hline pent 33 & 0,001 & 0,001 & 0,001 & 0,001 & 0,001 & 0,001 & 0,001 & 0,001 \\
\hline pent 34 & 0,002 & 0,002 & 0,002 & 0,002 & 0,002 & 0,002 & 0,002 & 0,002 \\
\hline pent 35 & 0,046 & 0,046 & 0,046 & 0,046 & 0,046 & 0,046 & 0,046 & 0,046 \\
\hline pent 36 & 0,021 & 0,021 & 0,021 & 0,021 & 0,021 & 0,021 & 0,021 & 0,021 \\
\hline pent 37 & 0,006 & 0,006 & 0,006 & 0,006 & 0,006 & 0,006 & 0,006 & 0,006 \\
\hline $\mathbf{N}$ & 5358 & 3688 & 542 & 2073 & 23375 & 1099 & 1732 & 2166 \\
\hline
\end{tabular}




\section{APÊNDICE 3}
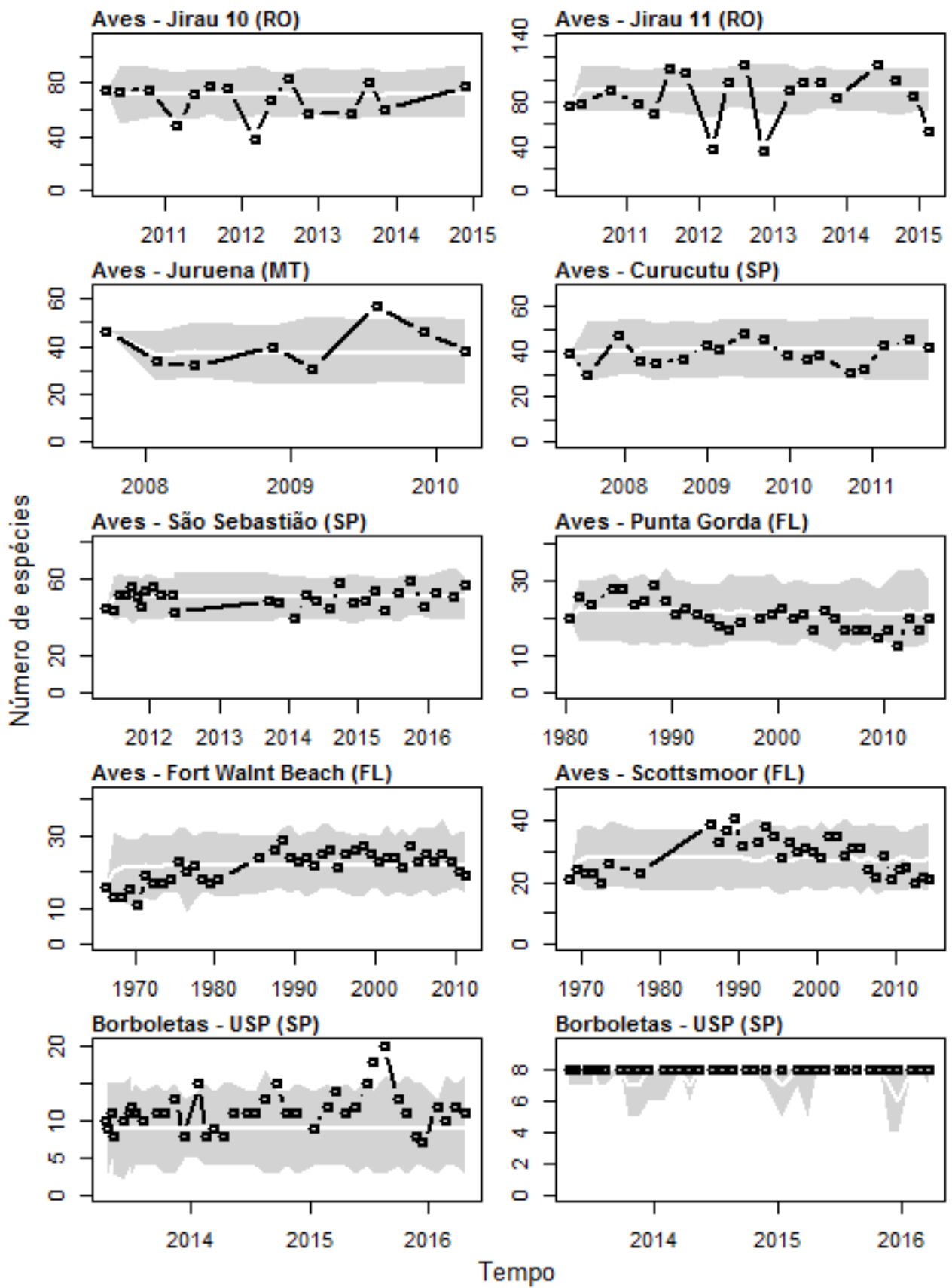

Figura I. Número de espécies registrado por campanha em cada série empírica (linhas pretas). Os polígonos cinza representam o número de espécies por campanha gerado nas simulações de equivalência demográfica. A linha branca representa o número médio de espécies gerado nas simulações. 

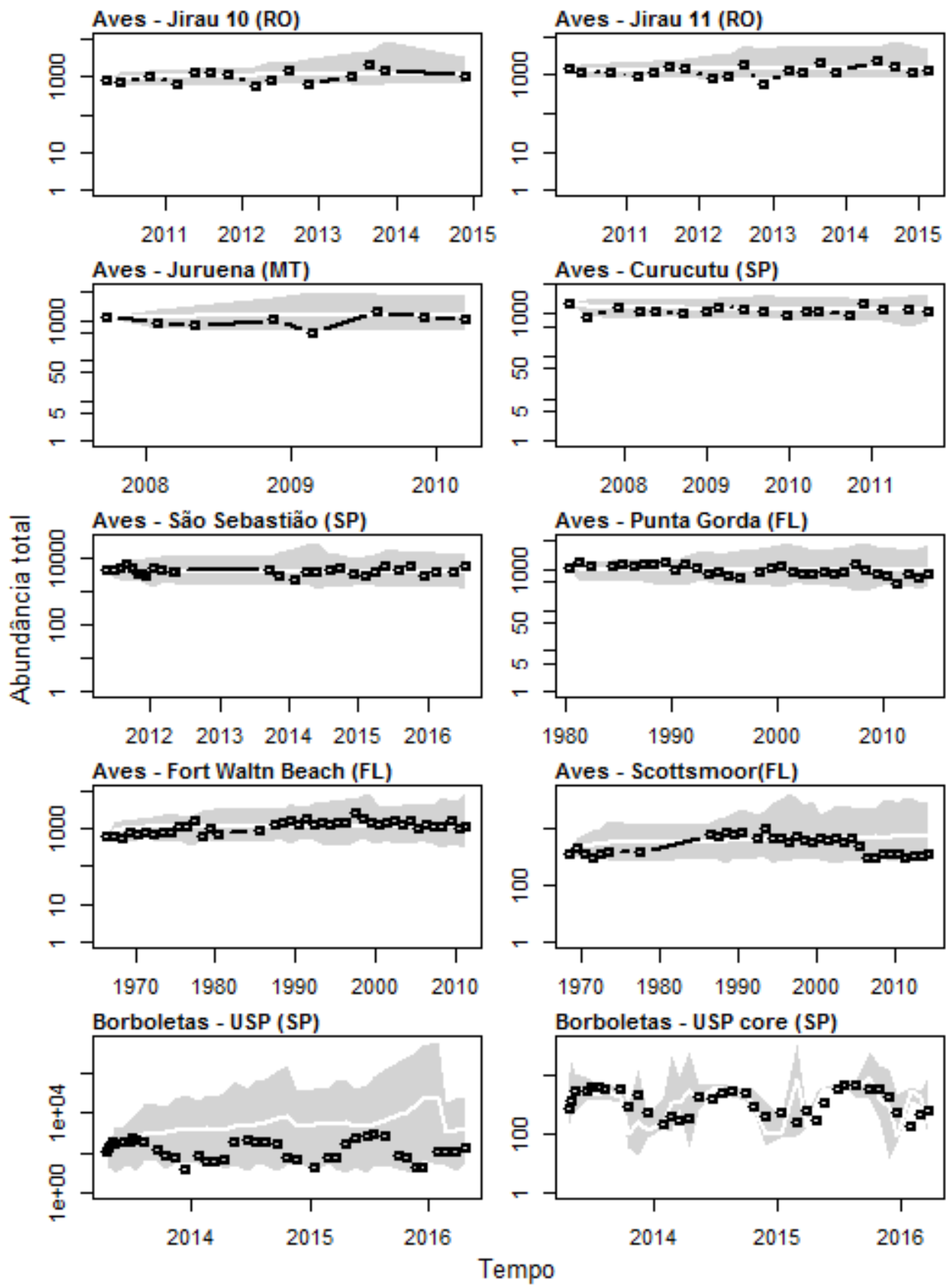

Figura II. Abundância total (todas as espécies somadas) registrada por campanha em cada série empírica (linhas pretas). Os polígonos cinzas representam as abundâncias totais geradas nas simulações de equivalência demográfica. A linha branca representa a abundância total média gerada nas simulações. 

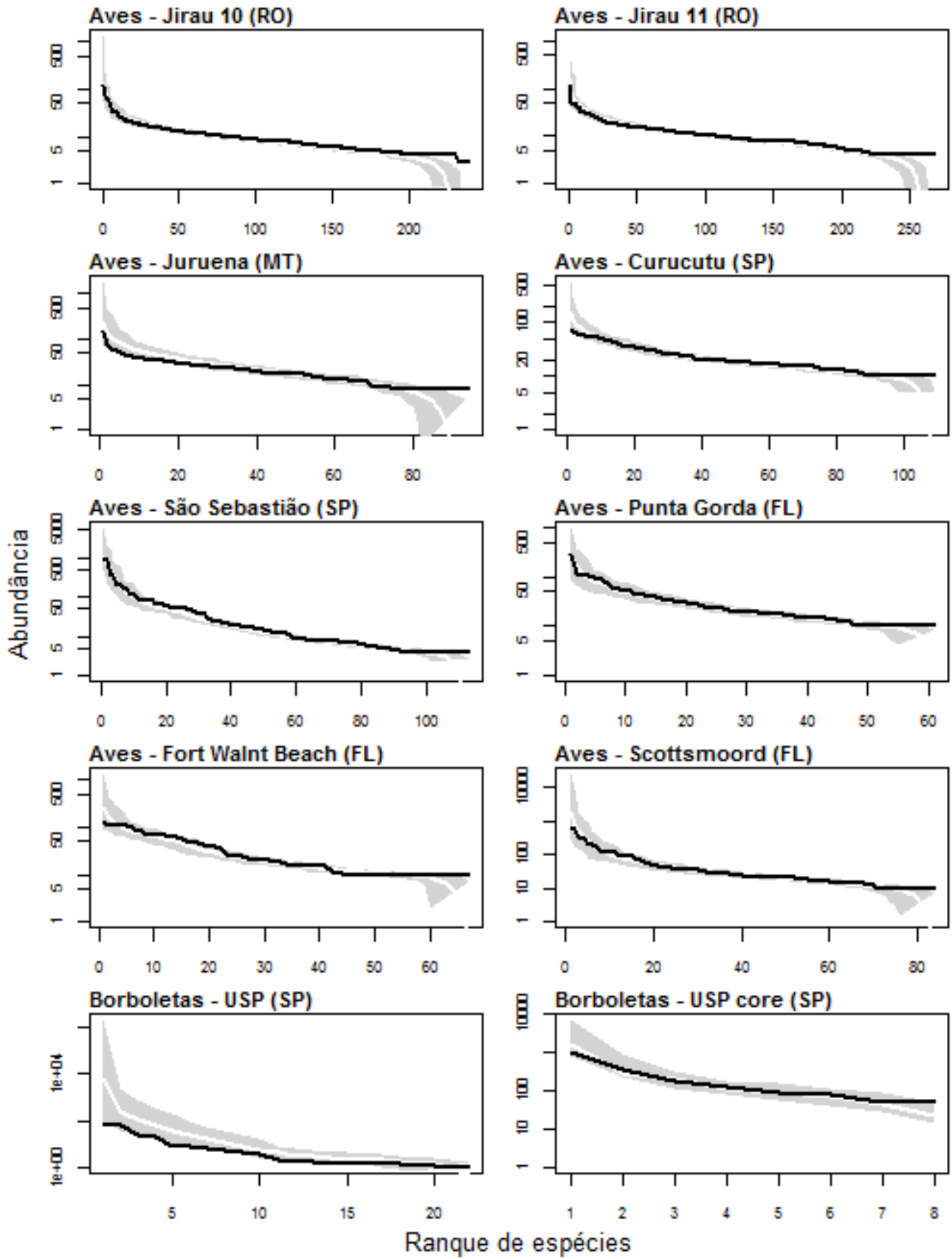

Figura III. Curvas de ranque-abundância das assembleias empíricas obtidas a partir da abundância média de cada espécie ao longo do estudo (linhas pretas). Os polígonos cinza representam as curvas de ranque-abundância geradas pelas simulações de equivalência demográfica. A linha branca representa a média das simulações. 


\section{APÊNDICE 4}

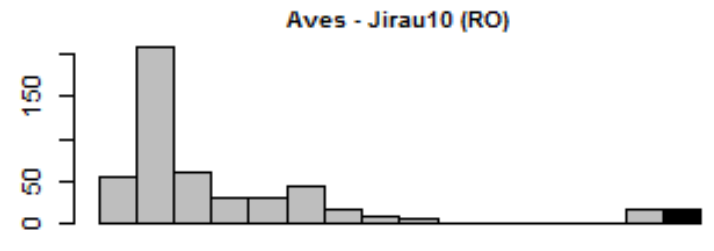

$\begin{array}{llllllllllllllll}0 & 1 & 2 & 3 & 4 & 5 & 6 & 7 & 8 & 9 & 10 & 11 & 13 & 14 & 17 & 18\end{array}$

Aves - Juruena (MT)
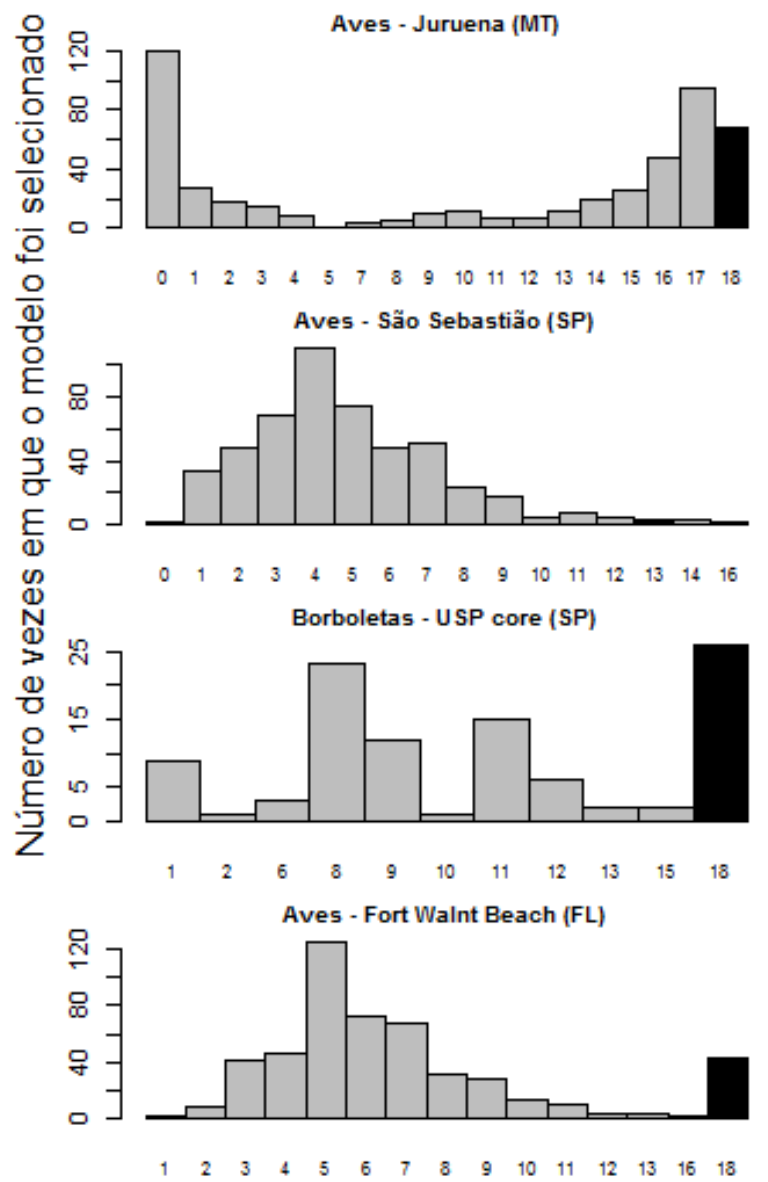
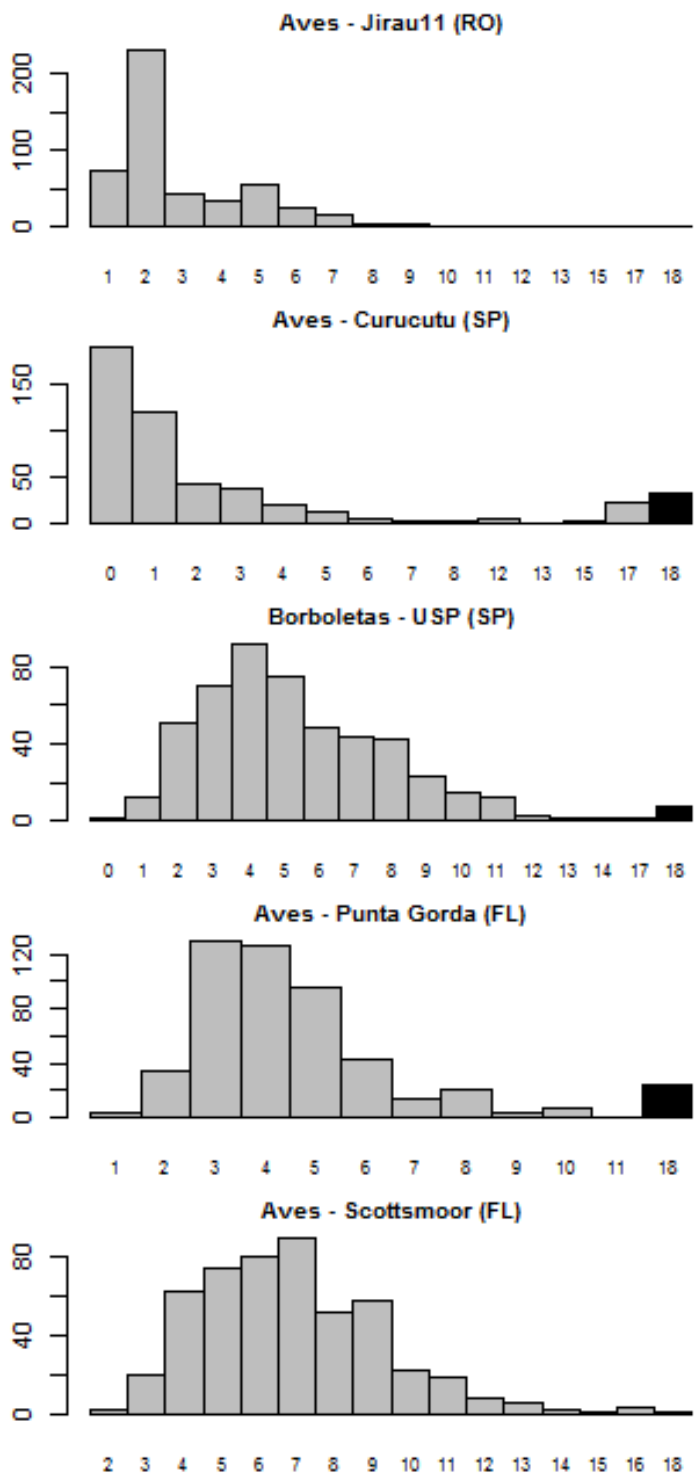

Grau do polinômio

Figura IV. Frequência de seleção de diferentes modelos polinomiais e modelos baseados em seno ajustados às simulações de equivalência demográfica (500 simulações) para descrever rotatividade temporal. Os números 0 a 16 no eixo x representam o grau do modelo polinomial (grau = 1 corresponde ao modelo linear e grau = zero corresponde a um modelo sem inclinação ["modelo nulo"]) enquanto que os números 17 e 18 (colunas em preto) representam modelos baseados em seno com três ou quatro parâmetros, respectivamente. 


\section{APÊNDICE 5}
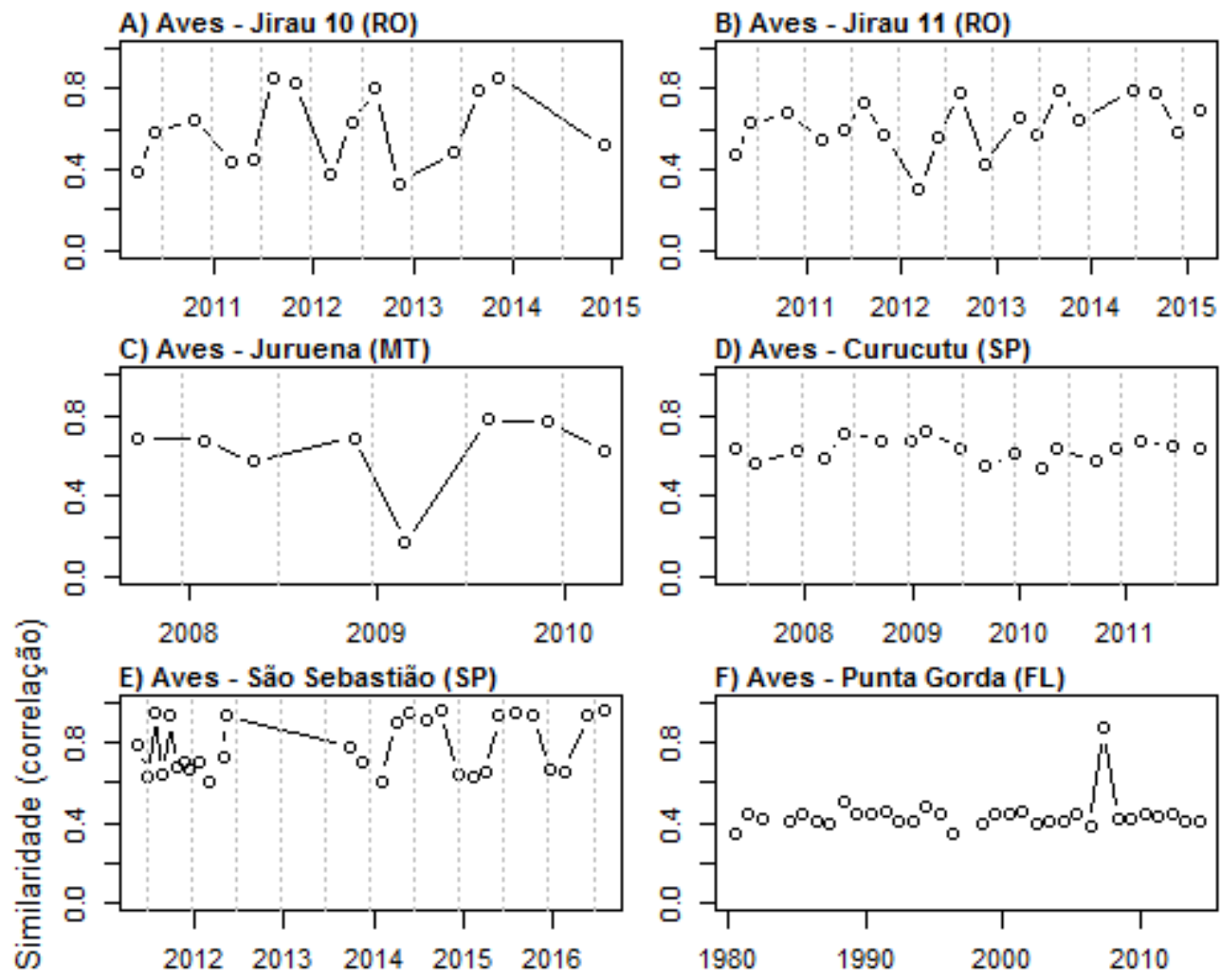

H) Aves - Scottsmoor (FL)
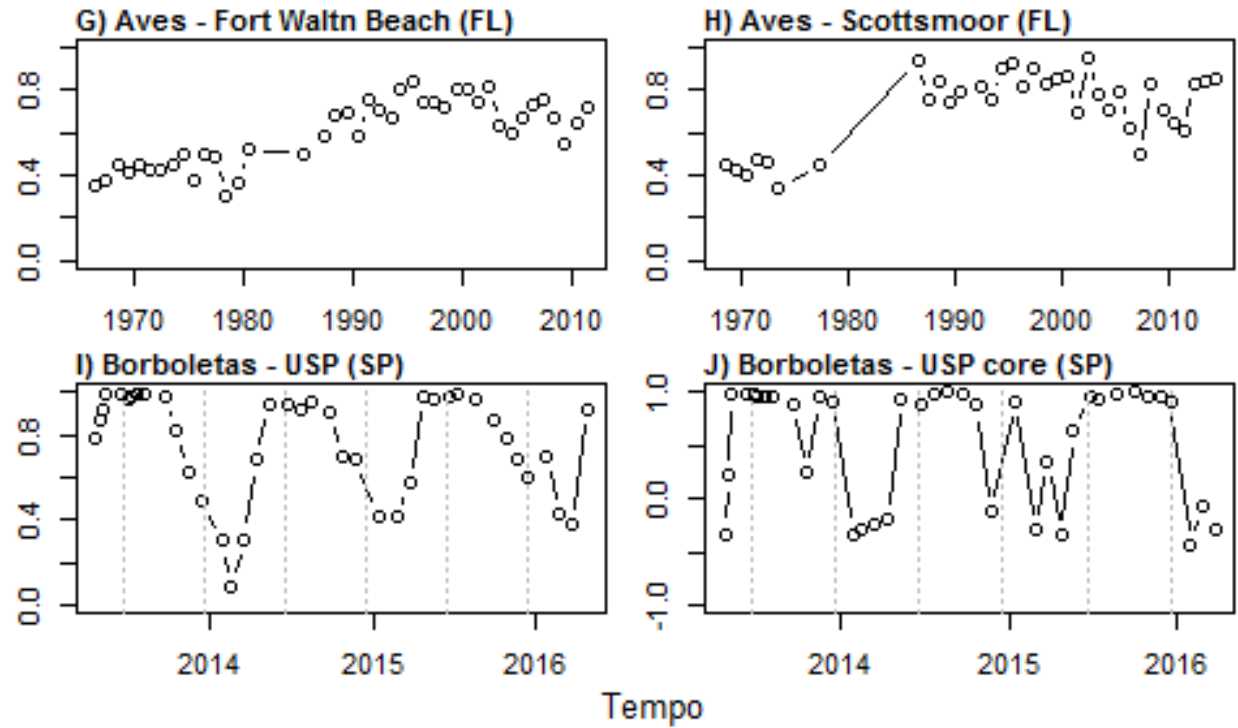

Figura I. Similaridade (correlação de Spearman) de cada campanha com o centróide (média) da assembleia (obtido calculando-se a abundância média de cada espécie) para seis conjuntos de dados de aves e borboletas Ithomiini no Brasil (RO,MT e SP) e nos EUA (Florida). A linhas pontilhadas verticais sinalizam os solstícios de inverno (meio do ano) e verão (final do ano). Em $\mathbf{F}$ a $\mathbf{H}$ não são mostrados os solstícios pois as amostragens foram anuais. 


\section{CONCLUSÕES GERAIS}

Nos estudos que integram esta tese descrevemos padrões de dinâmica temporal de populações e comunidades de borboletas e aves em florestas e ambientes costeiros no Brasil e na Flórida. Também avaliamos o papel que alguns processos poderiam ter na geração dessas dinâmicas: fatores ambientais, interações entre espécies e processos demográficos estocásticos. Apesar desses processos poderem atuar em conjunto, e de não termos avaliado eles simultaneamente ao longo dos capítulos, os estudos forneceram resultados relevantes para entendermos a dinâmica de populações e comunidades, resultados estes que têm implicações básicas e aplicadas. Realizaremos aqui uma concisa recapitulação dos principais achados de cada capítulo, além de uma integração entre suas conclusões e implicações.

No Capítulo 1 encontramos evidências de que as agregações sazonais de borboletas Ithomiini, um comportamento adaptativo à seca (Pinheiro et al. 2008), seriam respostas endógenas sincronizadas com o fotoperíodo, condizentes com síndrome de diapausa (Denlinger et al. 2001). Dada sua regularidade e relação com a atividade reprodutiva - atividade que parece cessar durante as agregações (Vasconcellos-Neto 1980) - esse comportamento poderia ser entendido como uma migração em escala local. Migração esta que, pela sua relação com o fotoperíodo, parece ter semelhanças com a migração de longa distância das borboletas monarca (Danaus plexuppus), as quais pertencem à tribo irmã de Ithomiini, Danaini (Brower et al. 2014). Como a migração das monarcas é um fenômeno bem estudado em termos comportamentais, fisiológicos e moleculares (Foster \& Kreitzman 2009), seu funcionamento e regulação pode ser um bom ponto de partida para entender o sistema sazonal das Ithomiini.

Também encontramos evidências no Capítulo 1 de que o comportamento de agregação das Ithomiini teria plasticidade limitada para lidar com imprevisibilidades no regime de chuvas. 0 fato das Ithomiini dissolverem regularmente as agregações com o aumento do fotoperíodo característico da primavera (época que normalmente coincide com o final da estiagem), mesmo com atrasos na chegada das chuvas, indica que poderiam ocorrer desajustes entre seus ritmos biológicos e os ciclos ambientais. Essa situação deve se tornar mais frequente com o aumento na duração da estação seca previsto para a região de estudo já na segunda metade deste século (Marengo et al. 2013). Como avaliamos respostas populacionais que não consideram variabilidade individual, não sabemos a magnitude dos impactos que um aumento da estação seca poderia promover sobre a persistência das populações de Ithomiini. No entanto, alterações no ciclo de chuvas foram consideradas determinantes na extinção local de populações de borboletas na Califórnia (McLaughlin et al. 2002). Apesar de não termos estudado o efeito de variáveis ambientais e suas flutuações sobre populações e comunidade de aves, já foram reportadas na literatura reduções no sucesso reprodutivo, na sobrevivência e no tamanho populacional de algumas espécies do hemisfério norte desse grupo em virtude do desacoplamento entre seus ritmos biológicos e ciclos ambientais em transformação (Helm et al. 2013). Pouco se sabe sobre os efeitos de variáveis ambientais nos ritmos biológicos de aves ou outros animais neotropicais (porém ver Hau et al., 2004, 1998; Heideman \& Bronson, 1994), porém a previsão de que novos regimes climáticos devem emergir no continente (Ordonez et al. 2016) é um alerta para a possibilidade de alterações na sua biodiversidade e ecossistemas. 
No Capítulo 2 verificamos que pares de espécies de borboletas Ithomiini co-miméticas (i.e., com morfologia convergente) não tendem a ter suas dinâmicas populacionais mais correlacionadas do que pares agrupados ao acaso. Verificamos também que as espécies analisadas tenderam a ter dinâmicas mais correlacionadas entre si, independente de anel mimético ou proximidade filogenética, do que seria esperado por acaso. Apesar de um modelo matemático prever sob algumas circunstâncias a ocorrência de sincronização entre pares de espécies miméticas Müllerianas em função de pressão de predação (ver Anexo 1), os resultados do Capítulo 2 e do Capítulo 1 sugerem que nessa assembleia as pressões seletivas exercidas por fatores ambientais parecem ser mais importantes do que interações entre as espécies para moldar a dinâmica das populações. No entanto, em regiões onde as condições climáticas são menos sazonais e mais favoráveis (i.e., chuvas bem distribuídas ao longo do ano), é possível que interações miméticas assumam um papel mais importante na dinâmica das populações. De fato, DeVries et al., (1999) encontrou associações temporais entre comiméticos e variação temporal nas abundâncias relativas dos diferentes anéis em uma localidade do Equador, cuja pluviosidade é alta e bem distribuída ao longo do ano. Infelizmente não pudemos avaliar o papel de interações entre espécies na dinâmica das assembleias de aves, visto que essas relações são muito pouco conhecidas, especialmente nas comunidades tropicais mega-diversas. Ainda, as técnicas de amostragem utilizadas não fornecem dados sobre interações. Não obstante, investigar o papel de interações na dinâmica de populações e assembleias de aves e outros organismos é tema de grande relevância.

No Capítulo 3 mostramos que a composição de espécies de assembleias de aves na Amazônia, Cerrado, Mata Atlântica e Flórida se alterou ao longo dos anos, mesmo em assembleias de áreas bem preservadas. Sobreposta a essa rotatividade (turnover) interanual também encontramos rotatividade sazonal, previsível, na composição de espécies de assembleias de aves da Amazônia e da Mata Atlântica e na assembleia de borboletas Ithomiini. Essas rotatividades sazonais são relacionadas às estratégias temporais de diferentes grupos de espécies (Shimadzu et al. 2013), expressas em ciclos alternados de migração, ocupação, abundância ou detectabilidade. As comparações entre dinâmicas empíricas e dinâmicas simuladas por modelo que assume equivalência demográfica entre espécies sugerem que a estocasticidade demográfica, o principal processo que estruturaria comunidades segundo a teoria neutra (Hubbell 2001), poderia explicar as taxas de rotatividade basal das assembleias de localidades bem preservadas e ricas em espécies - porém não explicaria rotatividades sazonais e nem preveria mudanças direcionais de composição associadas a perturbações. 0 motivo mais provável é que as espécies respondem de diferentes formas à sazonalidade do ambiente e à ocorrência de perturbações, sendo fundamental entender essas diferenças para entender a dinâmica sazonal das assembleias e suas respostas a perturbações. Não obstante, a premissa de equivalência demográfica poderia ser útil para modelar rotatividades basais interanuais de assembleias de localidades bem preservadas e ricas em espécies raras. A razão disso seria que nessas assembleias a composição de espécies na escala interanual estaria mais sujeita ao acaso devido à grande proporção de espécies com registros esporádicos (i.e., espécies raras).

A ampla ocorrência - mesmo dentre espécies tropicais - de estratégias de vida sincronizadas com a sazonalidade ambiental (Foster \& Kreitzman 2009), as rotatividades sazonais que encontramos na maioria das assembleias aqui estudadas e a carência de estudos temporais 
sugerem que é razoável supor que rotatividades sazonais sejam mais comuns do que se imagina em assembleias neotropicais. A sazonalidade na composição de espécies deve ser intensa em ambientes com mudanças anuais de grande amplitude, tal como o Pantanal (Heckman 1998) e florestas inundáveis na planície Amazônica (Petermann 1997), porém também pode ocorrer em ambientes mais estáveis como, por exemplo, nas florestas de baixada da Serra do Mar (ver Capítulo 3). Diferentes combinações de assembleias, causadas por sazonalidade ou por mudanças direcionais, podem implicar em diferentes funcionamentos (fluxos de energia e matéria) dos ecossistemas (Pandolfi \& Lovelock 2014), o que pode repercutir em seus serviços ecossistêmicos (Brauman \& Daily 2014). Como as mudanças climáticas e de uso do solo podem afetar os indivíduos de formas diferentes (Helm et al. 2013), é provável que esses processos criem novas combinações de assembleias e alterem as funções dos ecossistemas (Magurran 2016). Espécies migratórias, as quais parecem ter importante papel nas rotatividades sazonais na composição de espécies são particularmente sensíveis a mudanças climáticas (Møller et al. 2008) visto que dependem de antecipação e sincronização com condições ambientais em locais distintos, às vezes separados por milhares de quilômetros (Ian Newton 2008). No entanto, espécies residentes também podem enfrentar dificuldades se os padrões de precipitação e/ou temperatura variem de modo a dessincronizar os picos de disponibilidade de alimento e de atividade reprodutiva (Carey 2009).

Uma integração entre as abordagens da ecologia e da cronobiologia pode ser muito pertinente para atender ao grande desafio que é entender a dinâmica da biodiversidade e suas respostas às ações humanas (e.g., Halle \& Stenseth 2000). Processos de regulação estudados pela cronobiologia no nível do indivíduo podem moldar padrões em níveis de organização superiores - populações, comunidades e ecossistemas. Por outro lado, estudos de populações e comunidades de animais em vida livre, domínio tradicional da ecologia, podem revelar as consequências que processos de regulação fisiológicos e comportamentais podem ter sobre o fitness dos indivíduos e sobre a persistência de populações na natureza. A interação das perspectivas dessas duas disciplinas tem grande potencial para avançar nosso entendimento sobre questões básicas a respeito da estrutura e dinâmica da biodiversidade, tanto quanto para prever os impactos das rápidas mudanças ambientais do antropoceno. No entanto, a disponibilidade de dados de longo-prazo e de grande escala espacial, com alta resolução, é o fator único mais importante que limita o avanço do nosso entendimento sobre os padrões temporais da biodiversidade (Dornelas et al. 2012). Por isso, a disseminação de estudos de longo-prazo bem planejados, que possam ser usados para monitorar a biodiversidade e detector mudanças ao longo do tempo, são essenciais (Magurran et al. 2010).

A maioria dos estudos de biodiversidade realizados na região neotropical, se preocuparam apenas com a cobertura espacial e minimizaram a dimensão temporal, realizando amostragens extensas no espaço, porém pontuais no tempo. Estudos sobre padrões de biodiversidade podem ter resultados enviesados se tiverem uma amostragem temporal limitada, especialmente em regiões mega-diversas tal como a Amazônia (Stouffer et al. 2011). Por exemplo, Solar et al. (2015) reportaram grandes diferenças na composição de plantas, aves, besouros rola-bosta (Scarabaeidae), formigas e abelhas Euglossini entre 335 localidades distribuídas ao sul do Rio Amazonas, e concluíram que essa grande diversidade $\beta$ parece atenuar a perda de espécies em grandes escalas. No entanto, apesar da extensa escala espacial do estudo, sua amostragem pontual (as aves foram amostradas em apenas duas ocasiões 
totalizando 30 minutos/localidade) e a predominância de espécies raras que ocorre em ambientes mega-diversos tal como a Amazônia, sugerem que parte dessa grande diversidade $\beta$ possa ser oriunda de um artefato amostral. Amostragens continuadas poderiam revelar que as assembleias são mais parecidas do que revelado por suas amostragens pontuais, visto que medidas de diversidade podem ser bastante influenciadas pelo esforço amostral (Magurran 2011), especialmente em sistemas mega-diversos.

Investir em amostragens temporais em detrimento de espaciais não é uma situação ideal, mas frente ao atual estado de conhecimento sobre a dinâmica temporal dos sistemas tropicais, é uma estratégia que pode fornecer valiosos insights. Apesar de ser extremamente desejável incorporar espaço e tempo em uma única abordagem (White 2010, Wolkovich 2014), estudos que valorizam o tempo, mesmo em detrimento do espaço, têm fornecido valiosas informações (Grant \& Grant 2014, Capítulos 1, 2 e 3). Poucos estudos de longo prazo contribuíram desproporcionalmente para nosso conhecimento sobre como comunidades e populações naturais flutuam em número ou até mesmo como evoluem (Grant \& Grant 2014). Dois benefício obtidos de pesquisas de longo-prazo envolvem a percepção que se ganha do acúmulo gradual de dados ao longo dos anos e, em contraste, da ocorrência de eventos raros e imprevisíveis (Grant \& Grant 2014). O Capítulo 1, no qual tiramos proveito de eventos imprevisíveis (regime de chuvas atípicos), é um exemplo desses benefícios. Não conseguiríamos ter detectado os padrões que detectamos com um estudo pontual, nem conseguiríamos acessar em laboratório consequências da imprevisibilidade ambiental nos níveis de populações e assembleias. Na experiência de muitos biólogos de campo, quanto mais longo o estudo, maiores as chances de ocorrerem novas descobertas, especialmente em ambientes com grandes flutuações ambientais (Cody 1996, Grant \& Grant 2014). Estudos de longo-prazo devem ser realizados de forma permanente, pois, por definição, eles não apresentam um ponto de término lógico (Grant \& Grant 2014).

Devido às rápidas mudanças climáticas e no uso do solo, as comunidades parecem estar sofrendo mudanças massivas em suas composições de espécies, resultando na emergência global de comunidades com novas configurações (Dornelas et al. 2014, Pandolfi \& Lovelock 2014). Devemos incorporar o conceito de dinâmica na forma como concebemos a biodiversidade e aprender a distinguir entre mudanças naturais e mudanças que devemos evitar ou pelo menos mitigar (Magurran \& Dornelas 2010). Na condição de processos naturais, extinções e rotatividades basais são condições inevitáveis (e talvez necessárias) na estruturação e dinâmica da biodiversidade, porém são as extinções em massa causadas pela sobre-exploração dos recursos naturais (e.g., Lawton \& May 1995) que devem ser o foco de preocupação (Magurran \& Dornelas 2010).

Por fim, os resultados dos estudos aqui desenvolvidos, em conjunto com os conhecimentos gerados pela literatura prévia, podem ser sintetizados nas seguintes conclusões e recomendações:

- Padrões de rotatividade sazonal na composição de espécies podem ser mais comuns em comunidades neotropicais do que se imagina, mesmo em ambientes com sazonalidade moderada nas condições abióticas; 
- Diferenças entre espécies ("nicho") podem não ser relevantes para modelar rotatividades basais interanuais na composição de espécies de comunidades de locais preservados, especialmente comunidades mega-diversas e ricas em espécies raras - porém, diferenças entre espécies parecem ser indispensáveis para entendermos sazonalidade e respostas a perturbações;

- As estratégias temporais dos organismos neotropicais, as quais parecem ser a base dos padrões sazonais observados nas comunidades, podem ser largamente determinadas por ritmos ("relógios") endógenos. Estudos sobre os efeitos de mudanças climáticas e do uso do solo sobre os ritmos e estratégias temporais dos organismos, bem como da sua variação individual, são essenciais;

- Para avaliar os efeitos de perturbações sobre comunidades é necessário o uso de medidas que considerem a identidade das espécies (tal como as medidas de similaridade utilizadas no Capítulo 3), visto que medidas de diversidade que não o fazem, tal como riqueza e distribuições de abundâncias de espécies, parecem se manter relativamente constantes ao longo do tempo mesmo frente a alterações ambientais (Thibault et al. 2004, Mac Nally 2007, Magurran \& Dornelas 2010, Dornelas et al. 2014);

- A disseminação de estudos de populações e comunidades de longo-prazo, sistemáticos, contínuos e com resolução para detectar padrões sazonais, é essencial;

- A interação das perspectivas, bases teóricas e abordagens das diferentes disciplinas, tal como a biologia molecular, fisiologia, cronobiologia e ecologia pode avançar nosso entendimento sobre os processos que moldam a dinâmica da biodiversidade e sobre as consequências das perturbações humanas sobre os ecossistemas. 


\section{Bibliografia}

Brauman, K. A., and G. C. Daily. 2014. Ecosystem Services. Pages 1148-1154in S. A. Elias, editor.Reference Module in Earth Systems and Environmental Sciences. Oxford University Press, Oxford.

Brower, A. V. Z., K. R. Willmott, K. L. Silva-Brandão, I. J. Garzón-Orduña, and A. V. L. Freitas. 2014. Phylogenetic relationships of ithomiine butterflies (Lepidoptera: Nymphalidae: Danainae) as implied by combined morphological and molecular data. Systematics and Biodiversity 12:133-147.

Carey, C. 2009. The impacts of climate change on the annual cycles of birds. Philosophical transactions of the Royal Society of London. Series B, Biological sciences 364:3321-3330.

Cody, M. L. 1996. Introduction to Long-Term Community Ecological Studies. Pages 1-15in M. L. Cody and J. Smalwood, editors.Long-Term Studies of Vertebrate Communities. Academic Press, San Diego.

Denlinger, D. L., J. M. Giebultowicz, and D. S. Saunders. 2001. Insect Timing: Circadian Rhythmicity to Seasonality. Page (D. L. Denlinger, J. M. Giebultowicz, and D. S. Saunders, Eds.). Elsevier, Amsterdam.

DeVries, P. J., R. Lande, and D. Murray. 1999. Associations of comimetic ithomiine butterflies on small spatial and temporal scales in a neotropical rainforest. Biological Journal of the Linnean Society 67:73-85.

Dornelas, M., N. J. Gotelli, B. J. McGill, H. Shimadzu, F. Moyes, C. Sievers, and A. E. Magurran. 2014. Assemblage time series reveal biodiversity change but not systematic loss. Science 344:296-299.

Dornelas, M., A. E. Magurran, S. T. Buckland, A. Chao, R. L. Chazdon, R. K. Colwell, T. Curtis, K. J. Gaston, N. J. Gotelli, M. a Kosnik, B. J. McGill, J. L. McCune, H. Morlon, P. J. Mumby, L. Ovreås, A. Studeny, and M. Vellend. 2012. Quantifying temporal change in biodiversity: challenges and opportunities. Proceedings of the Royal Society B - Biological Sciences Biological Sciences 280:2-10.

Foster, R. G., and L. Kreitzman. 2009. Seasons of life: The biological rhythms that enable living things to thrive and survive. Page Seasons of Life: The Biological Rhythms that Enable Living Things to Thrive and Survive. Profile Books, London.

Grant, P. R., and R. Grant. 2014. 40 Years of Evolution: Darwin's Finches on Daphne Major Island. Princeton University Press.

Halle, S., and N. C. Stenseth. 2000. Chronoecology: New Light Through Old Windows - A Conclusion. Pages 275-284in S. Halle and N. C. Stenseth, editors.Activity Patterns in Small Mammals: An Ecological Approach. Springer.

Hau, M., M. Wikelski, H. Gwinner, and E. Gwinner. 2004. Timing of reproduction in a Darwin's finch: temporal opportunism under spatial constraints. Oikos 106:489-500.

Hau, M., M. Wikelski, and J. C. Wingfield. 1998. A neotropical forest bird can measure the slight changes in tropical photoperiod. Proceedings of The Royal Society B.

Heckman, C. W. 1998. The seasonal succession of biotic communities in wetlands of the tropical wet-and-dry climatic zone: $\mathrm{V}$. Aquatic invertebrate communities in the pantanal 
of Mato Grosso, Brazil. International Review of Hydrobiology 83:31-63.

Heideman, P. D., and F. H. Bronson. 1994. An endogenous circannual rhythm of reproduction in a tropical bat, Anoura geoffroyi, is not entrained by photoperiod. Biology of Reproduction 50:607-614.

Helm, B., R. Ben-Shlomo, M. J. Sheriff, R. a Hut, R. Foster, B. M. Barnes, and D. Dominoni. 2013. Annual rhythms that underlie phenology: biological time-keeping meets environmental change. Proceedings of the Royal Society B.Biological sciences 280:20130016.

Hubbell, S. P. 2001. The Unified Neutral Theory of Biodiversity and Biogeography. Page Monographs in Population Biology. Princeton University Press.

Ian Newton. 2008. The Migration Ecology of Birds. Elsevier, Oxford.

Lawton, J. H., and R. M. May. 1995. Extinction Rates. Oxford University Press.

Magurran, A. E. 2011. Measuring species diversity in time (and space). Pages 89-94in A. E. Magurran and B. J. McGill, editors.Biological Dversity: Frontiers in Measurement and Assesment. Oxford University Press, USA, New York.

Magurran, A. E. 2016. How ecosystems change. Science 351:448-449.

Magurran, A. E., S. R. Baillie, S. T. Buckland, J. M. Dick, D. a Elston, E. M. Scott, R. I. Smith, P. J. Somerfield, and A. D. Watt. 2010. Long-term datasets in biodiversity research and monitoring: assessing change in ecological communities through time. Trends in Ecology \& Evolution 25:574-82.

Magurran, A. E., and M. Dornelas. 2010. Biological diversity in a changing world. Philosophical Transactions of the Royal Society of London. Series B, Biological sciences 365:3593-7.

Marengo, J. A., M. C. Valverde, and G. O. Obregon. 2013. Observed and projected changes in rainfall extremes in the Metropolitan Area of São Paulo. Climate Research 57:61-72.

McLaughlin, J. F., J. J. Hellmann, C. L. Boggs, and P. R. Ehrlich. 2002. Climate change hastens population extinctions. Proceedings of the National Academy of Sciences of the United States of America 99:6070-6074.

Møller, A. P., D. Rubolini, and E. Lehikoinen. 2008. Populations of migratory bird species that did not show a phenological response to climate change are declining. Proceedings of the National Academy of Sciences of the United States of America 105:16195-16200.

Mac Nally, R. 2007. Use of the abundance spectrum and relative-abundance distributions to analyze assemblage change in massively altered landscapes. The American Naturalist 170:319-30.

Ordonez, A., J. W. Williams, and J. Svenning. 2016. Mapping climatic mechanism likely to favour the emergence of novel communities. Nature Climate Change Letters; 0:1-8.

Pandolfi, J. M., and C. E. Lovelock. 2014. Novelty Trumps Loss in Global Biodiversity. Science 344:266-267.

Petermann, P. 1997. The Birds. Pages 419-455in W. J. Junk, editor.The Central Amazon Floodplain: Ecology of a Pulsing System. Springer-Verlag, Berlin Heidelberg.

Pinheiro, C., Í. Medri, and A. Salcedo. 2008. Why do the ithomiines (Lepidoptera, Nymphalidae) 
aggregate? Notes on a butterfly pocket in central Brazil. Revista Brasileira de Entomologia 52:610-614.

Shimadzu, H., M. Dornelas, P. A. Henderson, and A. E. Magurran. 2013. Diversity is maintained by seasonal variation in species abundance. BMC Biology 11:98.

Solar, R. R. de C., J. Barlow, J. Ferreira, E. Berenguer, A. C. Lees, J. R. Thomson, J. Louzada, M. Maués, N. G. Moura, V. H. F. Oliveira, J. C. M. Chaul, J. H. Schoereder, I. C. G. Vieira, R. Mac Nally, and T. A. Gardner. 2015. How pervasive is biotic homogenization in humanmodified tropical forest landscapes? Ecology Letters 18:1108-1118.

Stouffer, P. C., E. I. Johnson, R. O. Bierregaard, and T. E. Lovejoy. 2011. Understory bird communities in Amazonian rainforest fragments: species turnover through 25 years postisolation in recovering landscapes. PloS One 6:e20543.

Thibault, K. M., E. P. White, and S. K. M. Ernest. 2004. Temporal dynamics in the structure and composition of a desert rodent community. Ecology 85:2649-2655.

Vasconcellos-Neto, J. 1980. Dinamica de populações de Ithomiinae (Lep., Nymphalidae) em Sumaré - SP. Dissertação de Mestrado, Universidade Estadual de Campinas. 


\section{ANEXO}

Anexo 1 - Modelo para avaliar sincronização de dinâmica populacional entre pares de miméticos Müllerianos

Renato Andrade, Renato Mendes Coutinho, Carlos Candia-Gallardo e Paulo Inácio Prado 


\title{
Modelo para avaliar sincronização de dinâmica populacional entre pares de miméticos Müllerianos
}

\author{
Renato Andrade Renato Mendes Coutinho \\ Carlos Candia-Gallardo Paulo Inácio Prado
}

17 de março de 2017

\section{Introdução}

O benefício obtido por espécies miméticas Müllerianas provem da redução do custo por espécie para treinar predadores para que evitem atacar indivíduos que apresentem o padrão visual compartilhado pelo anel mimético [1]. Esse benefício será tanto maior para uma certa espécie quanto maior a abundância - e portanto a quantidade de ataques pelo predador - das outras espécies [2]. Por conta disso, parece razoável que espécies que se deslocam sazonalmente (doravante migração) entre áreas com e sem predadores tendam a sincronizar suas épocas de deslocamento: caso contrário, a espécie que retorna mais cedo à área com predadores não se beneficia do mimetismo, já que sofre todos os ataques de predadores naïve (não-condicionados), pagando o custo que poderia ser dividido com as demais espécies do anel mimético.

No entanto, é provável que haja outros fatores que determinem a época de migração de cada espécie. Em particular, condições climáticas e a fenologia de plantas hospedeiras podem afetar fortemente a capacidade reprodutiva das populações. Dessa forma, qualquer tentativa de explicar a sincronização, ou não, de populações miméticas deve levar em conta essa classe de fatores. Em particular, eles podem atuar favorecendo ou opondo a sincronização.

Aqui, desenvolvemos e analisamos um modelo para duas espécies miméticas Müllerianas que migram entre duas áreas, sendo uma com predadores (doravante "mata"), e a outra um refúgio sem predadores, o "bolsão". Modelamos a evolução ao longo do tempo da distribuição de épocas migratórias de cada população, buscando compreender em que situações a sincronização é favorecida. 


\section{Formulação do modelo}

Primeiramente, precisamos de uma formulação consistente da dinâmica populacional de um par mimético que leve em conta o mecanismo de manutenção do mimetismo. Adotamos como base o modelo de Hadeler (1982) [3], que descreve duas populações sujeitas a um mesmo predador, que podem ser mais ou menos similares, e podem ser aposemáticas ou não, de modo que o modelo cobre todo o espectro de mimetismo Mülleriano a Batesiano. Assumimos que as duas espécies são perfeitamente similares (na notação de [3], $\alpha=1$ ) e aposemáticas (ou seja, $h_{i}=0$ ). A seguir, introduzimos dois locais entre os quais os indivíduos migram sazonalmente: a mata (populações de índice $M$ ) e o bolsão (índice $B$ ). Assumimos que predação, reprodução e competição intra-específica (que acarreta uma capacidade de suporte) ocorrem apenas na mata.

Para estudar a evolução da época de migração, descrevemos cada população $u_{i}$ como uma distribuição de características, $u_{i}(\phi)$, em que cada valor de $\phi$ corresponde a uma época de migração ao longo do ano. Como a época do ano é uma característica "periódica" (o dia 1 é o mesmo que o 366), as populações são tratadas mais naturalmente como distribuições circulares. A variável $\phi$ pertence ao intervalo $[0,2 \pi)$ e denota, após converter a escala para o intervalo $[0,365)$, o dia do ano em que ocorre a migração da mata para o bolsão - por simplicidade, assumimos que a migração de volta acontece exatamente 6 meses depois.

As equações diferenciais que descrevem a dinâmica das população são:

$$
\begin{aligned}
\frac{\partial u_{i M}(\phi, t)}{\partial t} & =r_{i}(t) u_{i M}\left(1-\frac{\int u_{i M}\left(\phi^{\prime}\right) d \phi^{\prime}}{K_{i}}\right)-\rho v_{0} \hat{u}_{i M} \\
& -m_{i M}(t, \phi) u_{i M}+m_{i B}(t, \phi) u_{i B} \\
\frac{\partial u_{i B}(\phi, t)}{\partial t} & =-\mu_{i} u_{i B}+m_{i M}(t, \phi) u_{i M}-m_{i B}(t, \phi) u_{i B} \\
\frac{d v_{0}}{d t} & =-c v_{0} \frac{u_{T}}{u_{0}+u_{T}}+c_{3}(t)\left(v-v_{0}\right),
\end{aligned}
$$

onde

$$
\begin{aligned}
\hat{u}_{i M} & \equiv \frac{u_{i M}}{u_{0}+u_{T}} \\
u_{T} & \equiv \int\left(u_{1 M}\left(\phi^{\prime}\right)+u_{2 M}\left(\phi^{\prime}\right)\right) d \phi^{\prime} \\
v & =v_{0}+v_{3},
\end{aligned}
$$

em que $v_{0}$ é a quantidade de predadores naïve e $v_{3}$ a de predadores treinados para evitar ambas as espécies, de acordo com a notação de Hadeler (1982) [3]. 
Assumindo a população total de predadores constante, obtemos a equação acima.

As funções $m_{i X}(t)$, com $t$ medido em dias, são modeladas por uma distribuição Gaussiana circular (também conhecida como distribuição de von Mises), definida por:

$$
\mathcal{G}(x \mid \mu, \kappa)=\frac{e^{\kappa \cos (x-\mu)}}{2 \pi I_{0}(\kappa)},
$$

onde os parâmetros $\mu$ e $1 / \kappa$ são análogos à média e à variância, respectivamente, da distribuição Gaussiana tradicional. Desse modo, as taxas de migração são escritas como:

$$
m_{i M}(t, \phi)=m_{i B}\left(t-\frac{365}{2}, \phi\right)=M \mathcal{G}\left(t \mid \frac{365}{2 \pi} \phi, \frac{1}{\sigma_{M}^{2}}\right)
$$
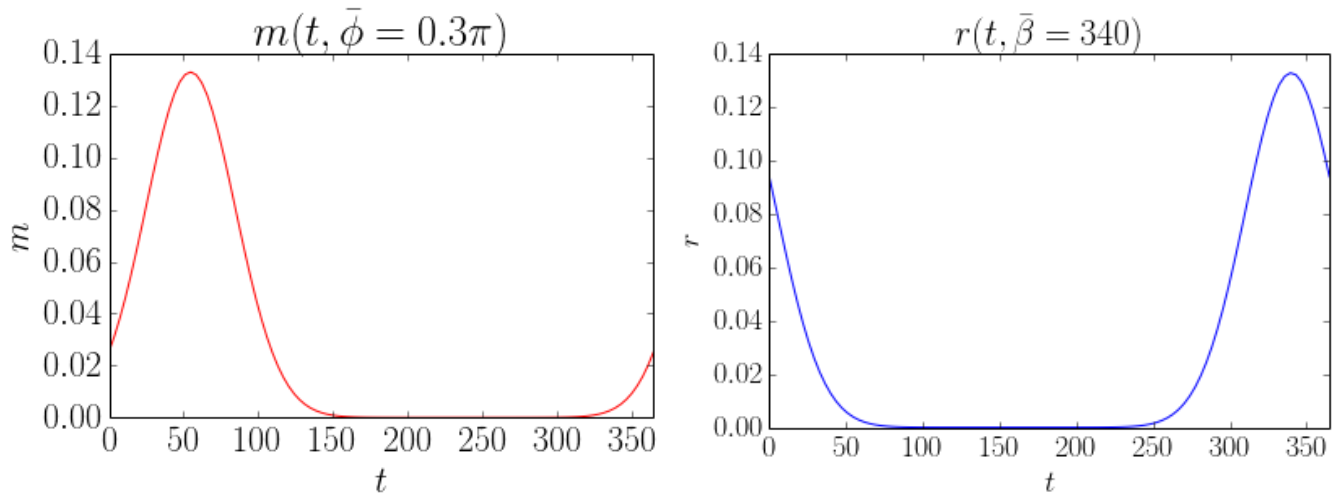

Figura 1: Exemplo de $m(t, \bar{\phi})$, com $M=10, \sigma_{M}=30$ e $\phi=0.3 \pi$ (esquerda); e de $r_{\bar{\beta}}(t)$, com $\bar{r}=10, \sigma_{r}=30$ e $\beta=340$ (direita).

Um exemplo de função $m(t)$ é mostrado na figura 1 (esquerda). De forma análoga, as taxas de crescimento intrínseco $r_{i}$ apresentam uma época favorável ao longo do ano, dependente da identidade da espécie mas não da época de migração do indivíduo, e são descritas pela função:

$$
r_{i}(t)=\bar{r} \mathcal{G}\left(t \mid \beta_{i}, \frac{1}{\sigma_{r}^{2}}\right)
$$

um exemplo da qual pode ser vista na figura 2 , à direita.

A taxa de recrutamento de predadores naïve, também sazonal, é modelada por uma função quadrada, que é constante (igual a $C_{3}$ ) no intervalo entre $\phi_{c}$ 
e $\phi_{c}+L$ em cada ano, e zero no restante do tempo. Essa função é descrita pela fórmula:

$$
c_{3}(t)=C_{3} Q\left(t, \phi_{c}, L\right)= \begin{cases}C_{3} & , \text { se } \phi_{c}<t \bmod 365<\phi_{c}+L \\ 0 & , \text { caso contrário. }\end{cases}
$$

Os valores dos parâmetros utilizados no modelo estão representados na Tabela 1. Os valores foram escolhidos sempre que possível com base em observações empíricas reportadas na literatura ou obtidas no estudo de borboletas Ithomiini que serviu de base aos capítulos 1 e 2. Na ausência de informações nos baseamos na percepção de especialistas (G. Accacio e A. Freitas). Em alguns casos os valores dos parâmetros foram definidos iterativamente para que as populações não colapsassem em intervalos de tempo curtos. Os parâmetros que tiveram menor base empírica, devido à ausência de informações disponíveis, foram os relacionados aos predadores.

Tabela 1: Valores dos parâmetros usados no modelo

\begin{tabular}{c|l|} 
Parâmetro & Descrição \\
\hline$M$ & Integral da taxa de migração máxima \\
$\sigma_{M}$ & SD da distribuição da taxa de migração \\
$\bar{r}$ & Integral da taxa de reprodução máxima (na mata) \\
$G$ & Número de gerações por ano na mata \\
$\sigma_{r}$ & SD da distribuição da taxa de reprodução \\
$\beta_{1}$ & dia da máxima taxa de crescimento na mata (sp. 1) \\
$\beta_{2}$ & dia da máxima taxa de crescimento na mata (sp. 2) \\
$K_{1}$ & capacidade de suporte na mata (sp. 1) \\
$K_{2}$ & capacidade de suporte na mata (sp. 2) \\
$\mu_{1}$ & taxa de mortalidade no bolsão (sp. 1) \\
$\mu_{2}$ & taxa de mortalidade no bolsão (sp. 2) \\
$v$ & população (constante) de predadores \\
$c$ & probabilidade por ataque de aprendizagem do predador \\
$C 3$ & taxa de recrutamento de predadores naïve \\
$\phi_{C}$ & dia de início do recrutamento de predadores naïve \\
$L$ & duração do período de recrutamento de predadores naïve
\end{tabular}

Valor estimado $20 \mathrm{dia}^{-1}$ 10 dias $G \log \left(\frac{60}{2}\right) \mathrm{dia}^{-1}$ 2 gerações 90 dias 20 350

50 borboletas 50 borboletas $1 / 180 \mathrm{dia}^{-1}$ $1 / 180 \mathrm{dia}^{-1}$ 7

$0.3 \mathrm{dia}^{-1}$ 240 150 dias

\section{Resultados e Discussão}

A época de migração das duas espécies é determinada pelas suas respectivas épocas reprodutivas ótimas (única diferença entre espécies no início 
das simulações) e pela época do aparecimento da nova geração de predadores. A influência exercida pelos predadores nas dinâmicas das espécies vai se tornando mais importante que as épocas reprodutivas à medida que a intensidade da predação (rho) aumenta. Mesma na ausência da outra espécie co-mimética a predação induz o pico de migração de ambas as espécies para uma mesma época (Figura 3). Quando na presença uma da outra, a predação também induz os picos de migração para a mesma época, porém maior intensidade de predação é necessária para que seja obtido o mesmo resultado (figura 3). Este efeito se deve a proteção que uma espécie exerce sobre a outra. Na presença uma da outra as populações persistem sob maiores taxas de predação do que persistiriam se estivessem sós (figura 3).

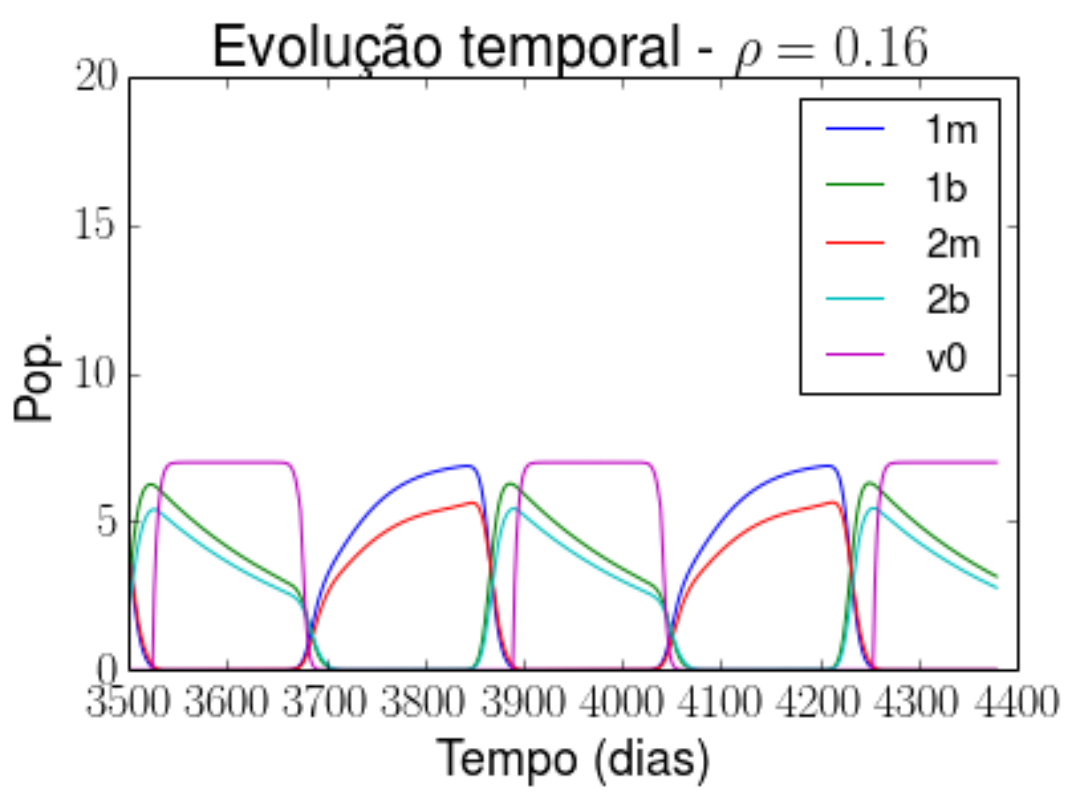

Figura 2: Evolução temporal para $\rho=0.16$. As populações das espécies $1 \mathrm{e}$ 2 são exibidas em termos de suas médias.

Os resultados mostram que a predação influi na dinâmica das populações alterando o timing de suas migrações, induzindo-as para uma mesma época do ano. Este efeito é mais acentuado a medida que as taxas de predação são mais intensas. Portanto, espera-se que emerja sincronia entre pares de miméticos a partir de níveis moderados a altos de predação. Em níveis baixos de predação a proteção que cada espécie confere a outra faz com elas alterem menos seu timing de migração em função da predação.Em concordância com as previsões de modelos clássicos de mimetismo Mülleriano, as populações são capazes de persistir sob maiores níveis de predação quando co-existem do que quando estão sós. 

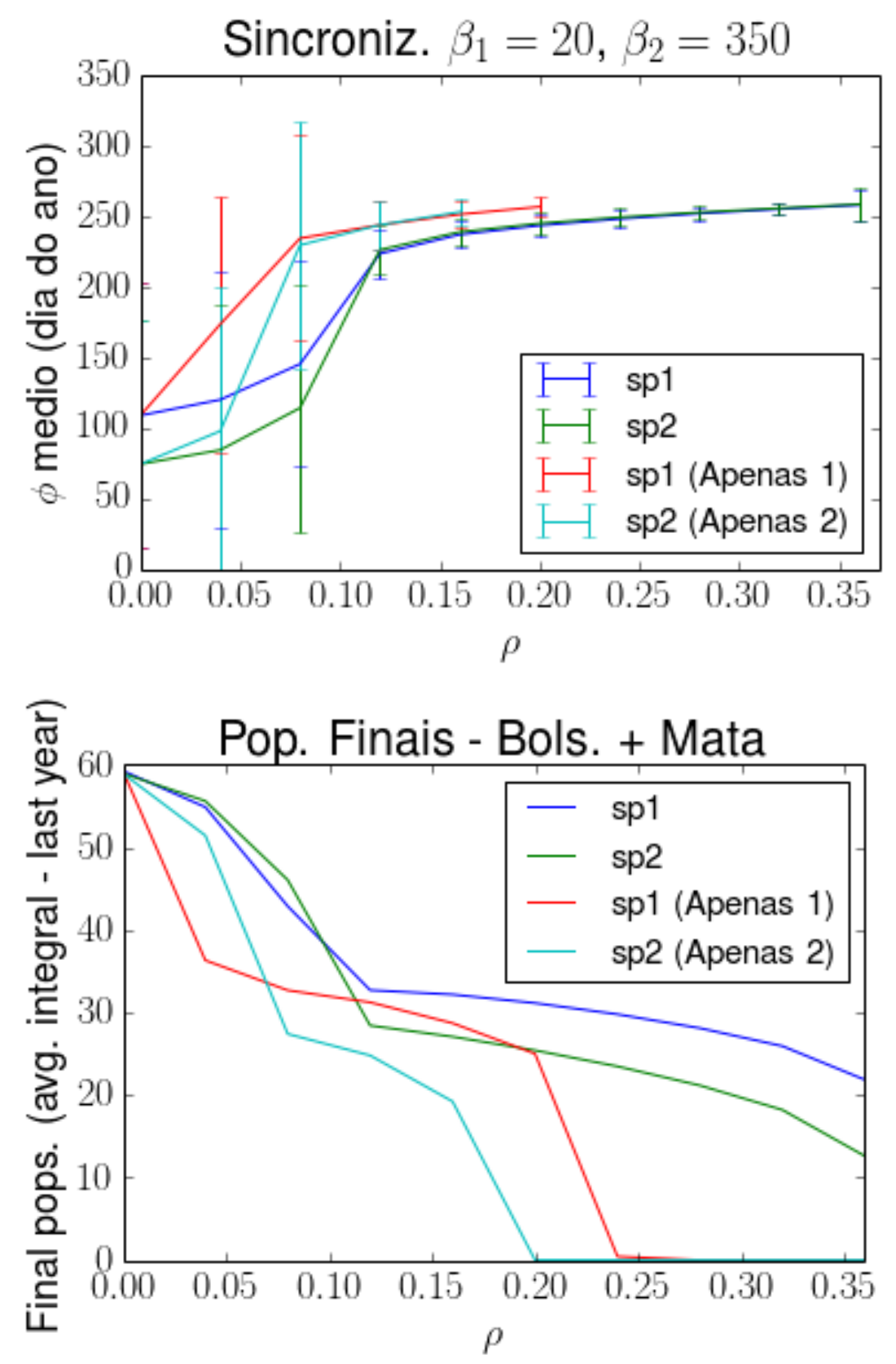

Figura 3: Painel superior: Época média (dia do ano) de migração de cada população em função da taxa de predação (eixo x) e da presença ou não de espécie co-mimética. Painel inferior: Tamanho das populações ao final das simulações em função da taxa de predação (eixo x) na presença ou não de espécie co-mimética. 


\section{Referências}

[1] F. Müller, "Ituna and Thyridia: a remarkable case of mimicry in butterflies," Transactions of the Royal Entomological Society of London, vol. 1879, pp. xx-xxix, 1879.

[2] G. Ruxton, T. N. Sherratt, and M. Speed, Avoiding attack: the evolutionary ecology of crypsis, warning signals and mimicry. Oxford: Oxford University Press, 2004.

[3] K. Hadeler and P. T. de Mottoni, "Mimetic gain in batesian and müllerian mimicry a," Oecologia, vol. 53, p. 84, 1982. 